UCRL-ID-128735 Pt. 2

\title{
Hydrothermal Alteration of Cementitious Materials Part II: Second and Third Batch of Samples
}

\author{
K.B.L. Myers \\ A. Meike
}

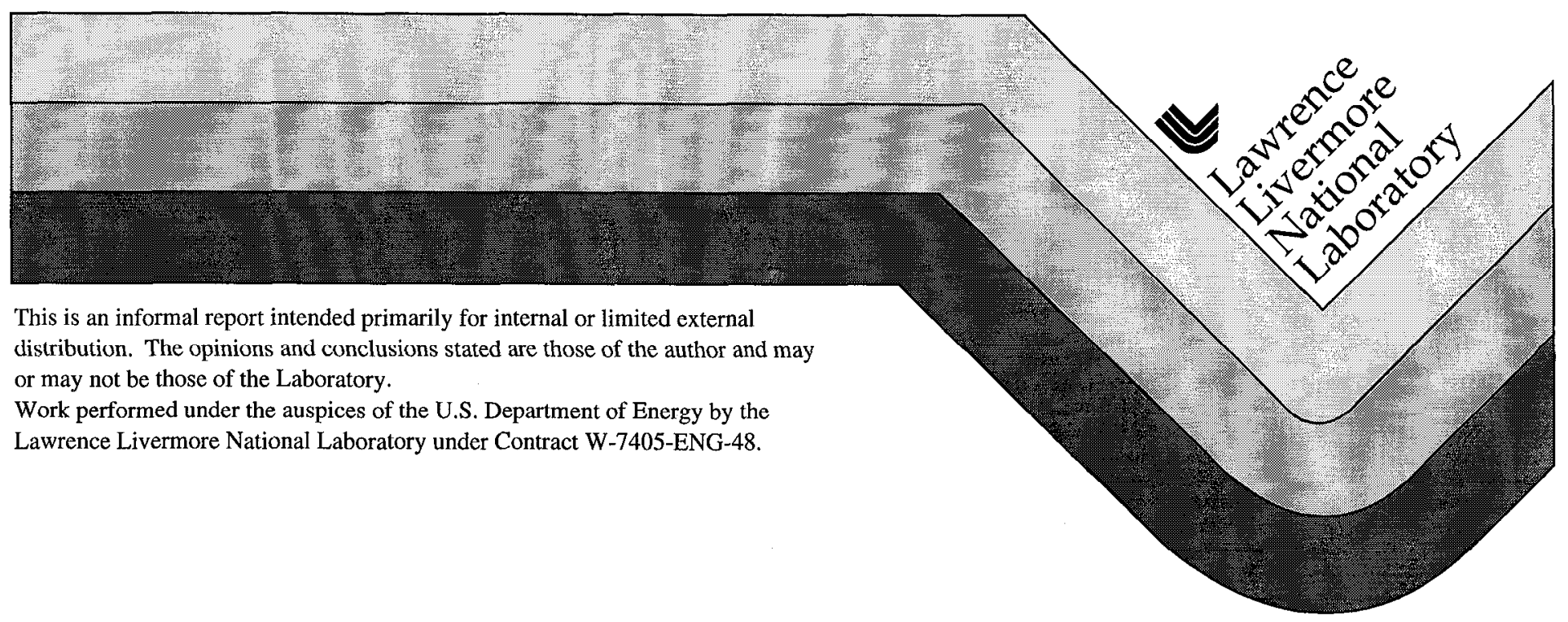




\section{DISCLAIMER}

This document was prepared as an account of work sponsored by an agency of the United States Government. Neither the United States Government nor the University of California nor any of their employees, makes any warranty, express or implied, or assumes any legal liability or responsibility for the accuracy, completeness, or usefulness of any information, apparatus, product, or process disclosed, or represents that its use would not infringe privately owned rights. Reference herein to any specific commercial product, process, or service by trade name, trademark, manufacturer, or otherwise, does not necessarily constitute or imply its endorsement, recommendation, or favoring by the United States Government or the University of California. The views and opinions of authors expressed herein do not necessarily state or reflect those of the United States Government or the University of California and shall not be used for advertising or product endorsement purposes.

This report has been reproduced directly from the best available copy.

Available to DOE and DOE contractors from the

Office of Scientific and Technical Information

P.O. Box 62, Oak Ridge, TN 37831

Prices available from (423) 576-8401

Available to the public from the

National Technical Information Service

U.S. Department of Commerce

5285 Port Royal Rd.,

Springfield, VA 22161 
UCRL-ID-128735

\section{Hydrothermal Alteration of Cementitious Materials Part II: Second and Third Batch of Samples}

K. B. L. Myers and A. Meike

Publication date: October 25, 1997 


\section{ACKNOWLEDGMENTS}

We would like to thank E. Lindsey and J. Ferreira for SEM/EDS support, R. Pletcher for sample preparation, $M$. Spragge for experimental support, C. Aracne and D. Delgiudice for $x$-ray diffraction spectra acquisition, and D. Freeman and R. Sanchez for mechanical testing. We would also like to thank N. Butler-Briant, T. Duewer, and K. King for aqueous chemistry analyses, S. Fletcher and T. Carey for artwork, and R. Kirvel for editing.

This work is performed under the auspices of the U.S. Department of Energy by Lawrence Livermore National Laboratory under Contract W-7405-ENG-48, and is supported by the Yucca Mountain Site Characterization Project, LLNL. This report was prepared, and the supporting laboratory investigations were conducted, in accordance with the LLNL Statement of Work for fiscal 1997 (LLNL-LV.SS.CIN.10/96.023). The data in this report are non-QA and acquired in compliance with the Quality Assurance Requirements Document for the Yucca Mountain Site Characterization Project (QARD) (reference DOE-RW-0333) for non-QA data. A second set of experiments is planned which will produce Q data in compliance with all QARD requirements.

\section{DISCLAIMER}

'This document was prepared as an account of work sponsored by an agency of the United States Government. Neither the United States Government nor the University of California nor any of their employees, makes any warranty, express or implied, or assumes any legal liability or responsibility for the accuracy, completeness, or usefulness of any information, apparatus, product, or process disclosed, or represents that its use would not infringe privately owned rights. Reference herein to any specific commercial product, process, or service by trade name, trademark, manufacturer, or otherwise, does not necessarily constitute or imply its endorsement, recommendation, or favoring by the United States Government or the University of California. The views and opinions of authors expressed herein do not necessarily state or reflect those of the United States Government or the University of California, and shall not be used for advertising or product endorsement purposes.

This report has been reproduced directly from the best available copy.

Available to DOE and DOE contractors from the Office of Scientific and Technical Information

P.O. Box 62, Oak Ridge, TN 37831

Prices available from (615) 576-8401, FTS 626-8401

Available to the public from the National Technical Information Service

U.S. Department of Commerce

5285 Port Royal Rd., Springfield, VA 22161 


\section{Contents}

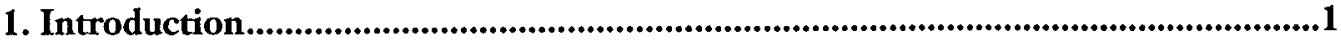

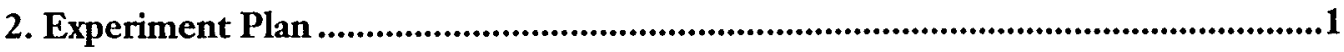

2.1 Sample Composition .............................................................................................

2.2 Sample Preparation................................................................................................

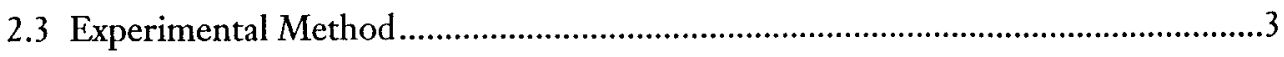

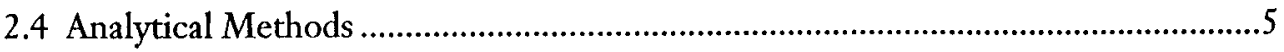

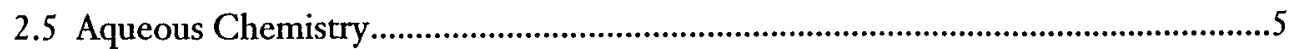

2.5.1 IM NaHCO${ }_{3}$ Solution ............................................................................6

2.5.2 $1 \mathrm{M} \mathrm{NaCl}$ Solution .......................................................................................6

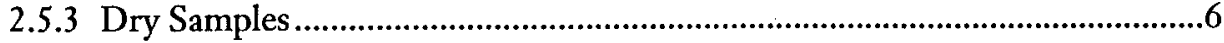

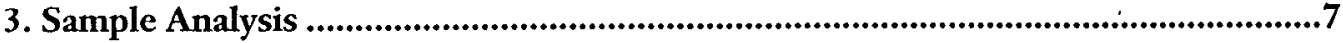

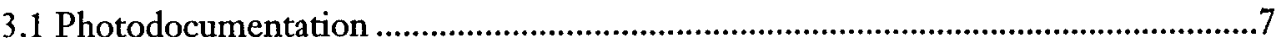

3.1.1 Treated Samples, Dry ......................................................................................

3.1.2 Treated Samples, $1 \mathrm{M} \mathrm{NaHCO}_{3}$ Solution ……............................................

3.1.3 Treated Samples, $1 \mathrm{M} \mathrm{NaCl}$ Solution...............................................................

3.1.4 Untreated Samples.............................................................................................9

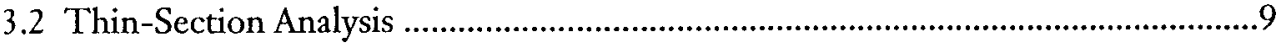

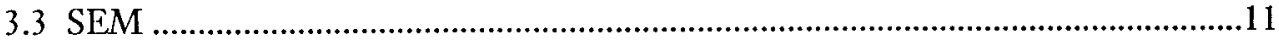

3.3.1 Treated Samples, Dry ..................................................................................12

3.3.2 Treated Samples, $1 \mathrm{M} \mathrm{NaHCO}_{3}$ Solution ..................................................14

3.3.3 Treated Samples, $1 \mathrm{M} \mathrm{NaCl}$ Solution............................................................15

3.3.4 Untreated Samples...........................................................................................16

3.4 Glancing-Angle X-Ray Diffraction .......................................................................

3.4.1 Treated Samples, $1 \mathrm{M} \mathrm{NaCl}$ Solution...............................................................17

3.4.2 Treated Samples, $1 \mathrm{M} \mathrm{NaHCO}_{3}$ Solution ....................................................17

3.4.3 Treated Samples, Dry ...........................................................................................17

3.4.4 Untreated Samples..............................................................................................17

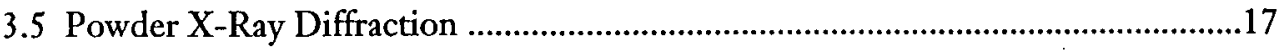

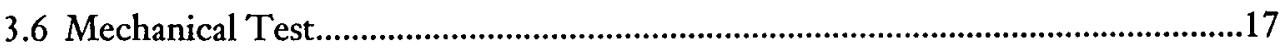

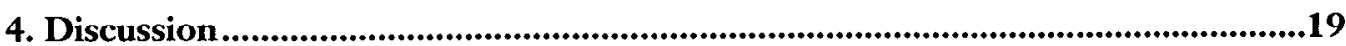

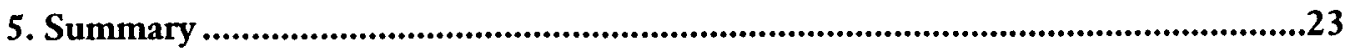

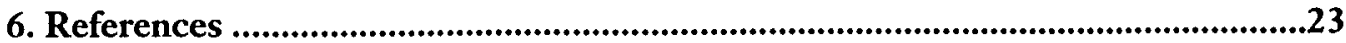

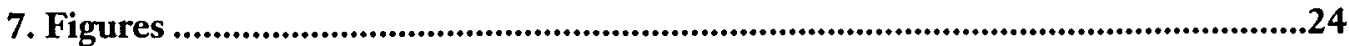

Appendix A. SEM Sample Point Description Logs...................................................A-1

Appendix B. Thin-Section Description Sheets ............................................................B-1 
Figure 1. Cross-sectional diagram of pressure vessel assembly ...........................24

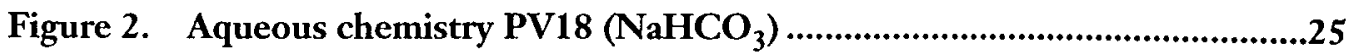

Figure 3. Maximum value $\mathrm{NaHCO}_{3}$ solution.......................................................25

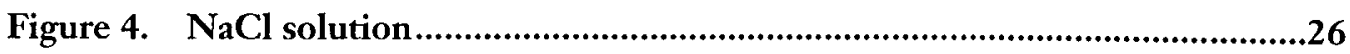

Figure 5. Maximum value $\mathrm{NaCl}$ solution.........................................................26

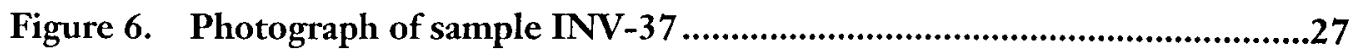

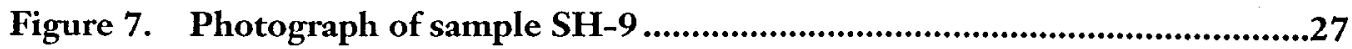

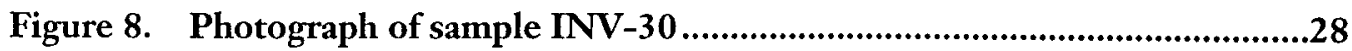

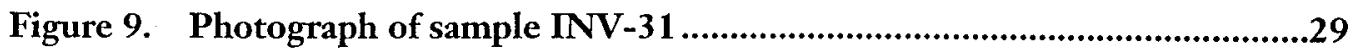

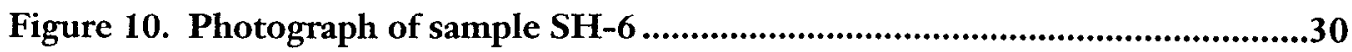

Figure 11. Photograph of sample INV-23a, side 1 ............................................32

Figure 12. Photograph of sample INV-23a, side 2 ..............................................33

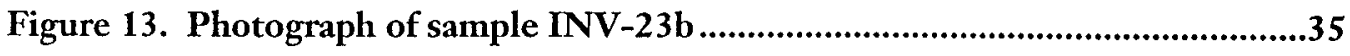

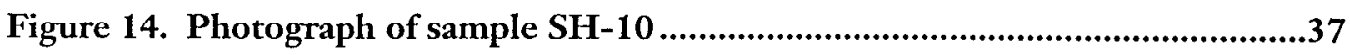

Figure 15. Photograph of sample INV-28, side 1 .....................................................39

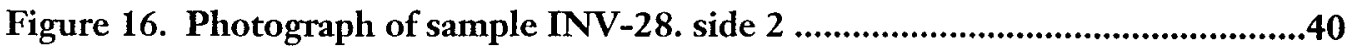

Figure 17. Photograph of sample INV-29 .............................................................41

Figure 18. Photograph of sample SH-3 ….............................................................42

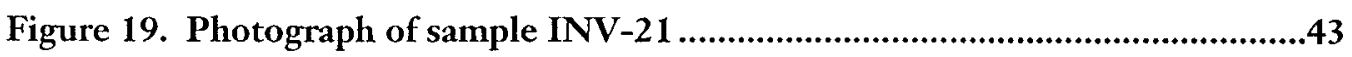

Figure 20. Photograph of sample INV-36 ............................................................45

Figure 21. Photograph of sample SH-13 ..........................................................4

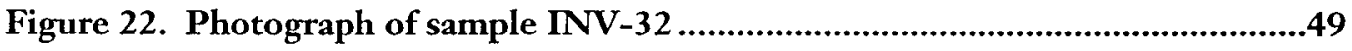

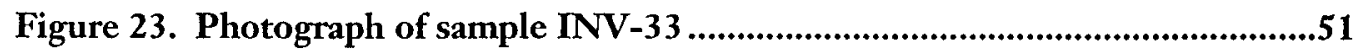

Figure 24. Photograph of sample SH-4 …..................................................................52

Figure 25. SEM photomicrograph and EDS of INV-37 .........................................53

Figure 26. Detail SEM photomicrograph and EDS of INV-37 ................................54

Figure 27. Detail SEM photomicrograph and EDS of INV-37 ..........................55

Figure 28. Detail SEM photomicrograph and EDS of INV-37 ...............................56

Figure 29. Detail SEM photomicrograph and EDS of INV-37 ............................57

Figure 30. SEM photomicrograph and EDS of INV-38 …....................................58

Figure 31. Detail SEM photomicrograph and EDS of INV-38 ..............................59

Figure 32. Detail SEM photomicrograph and EDS of INV-38 ............................60

Figure 33. Detail SEM photomicrograph and EDS of INV-38 ..............................61

Figure 34. Detail SEM photomicrograph and EDS of INV-38 .............................62 


\section{Figures}

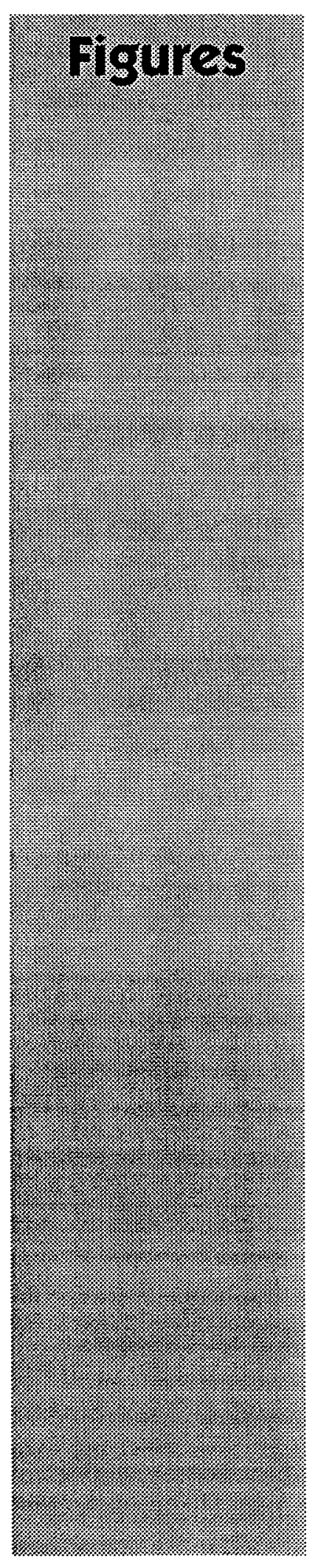

Figure 35. SEM photomicrograph and EDS of SH-9 .64

Figure 36. Detail SEM photomicrograph and EDS of SH-9 ...................................65

Figure 37. Detail SEM photomicrograph and EDS of SH-9 ..................................66

Figure 38. Detail SEM photomicrograph and EDS of SH-9 ...............................67

Figure 39. Detail EDS of SH-9 ...............................................................................68

Figure 40. Detail SEM photomicrograph and EDS of SH-9 ...............................69

Figure 41. Detail SEM photomicrograph and EDS of SH-9 ....................................70

Figure 42. Detail SEM photomicrograph and EDS of SH-9 ................................71

Figure 43. Detail SEM photomicrograph and EDS of SH-9 ................................72

Figure 44. Detail SEM photomicrograph and EDS of SH-9 .....................................73

Figure 45. Detail SEM photomicrograph and EDS of SH-9 .....................................74

Figure 46. Detail SEM photomicrograph and EDS of SH-9 ...................................75

Figure 47. Detail SEM photomicrograph and EDS of SH-9 ...................................76

Figure 48. Detail SEM photomicrograph and EDS of SH-9 ..................................77

Figure 49. Detail SEM photomicrograph and EDS of SH-9 ....................................78

Figure 50. Detail SEM photomicrograph and EDS of SH-9 ....................................79

Figure 51. SEM photomicrograph and EDS of INV-23a, side 1 ..............................80

Figure 52. Detail SEM photomicrograph and EDS of INV-23a, side 1 ...................81

Figure 53. Detail SEM photomicrograph and EDS of INV-23a, side 1 ...................83

Figure 54. Detail SEM photomicrograph and EDS of INV-23a, side 1 ..................84

Figure 55. Detail SEM photomicrograph and EDS of INV-23a, side 1 ...................85

Figure 56. SEM photomicrograph and EDS of INV-23a, side 2 .............................86

Figure 57. Dctail SEM photomicrograph and EDS of INV-23a, side 2 ...................87

Figure 58. Detail SEM photomicrograph and EDS of INV-23a, side 2 ....................88

Figure 59. Detail SEM photomicrograph and EDS of INV-23a, side 2 ...................89

Figure 60. Detail SEM photomicrograph and EDS of INV-23a, side 2 ..................90

Figure 61. SEM photomicrograph and EDS of INV-23b .....................................92

Figure 62. Detail SEM photomicrograph and EDS of INV-23b ............................93

Figure 63. SEM photomicrograph of INV-23b.................................................94

Figure 64. Detail SEM photomicrograph and EDS of INV-23b .............................95

Figure 65. Detail SEM photomicrograph and EDS of INV-23b .............................96

Figure 66. SEM photomicrograph and EDS of SH-10 ...........................................97

Figure 67. Detail SEM photomicrograph and EDS of SH-10 .................................98

Figure 68. Detail SEM photomicrograph and EDS of SH-10 .................................99 


\section{Figures}

Figure 69. Detail SEM photomicrograph and EDS of SH-10 100

Figure 70. Detail SEM photomicrograph and EDS of SH-10 .................................101

Figure 71. Detail SEM photomicrograph and EDS of SH-10 ................................102

Figure 72. Detail SEM photomicrograph and EDS of SH-10 ..........................103

Figure 73. Detail SEM photomicrograph and EDS of SH-10 ...............................104

Figure 74. Detail SEM photomicrograph and EDS of SH-10 ...............................105

Figure 75. SEM photomicrograph and EDS of INV-21 .......................................106

Figure 76. Detail SEM photomicrograph and EDS of INV-21 .............................107

Figure 77. Detail SEM photomicrograph and EDS of INV-21 .............................108

Figure 78. SEM photomicrograph and EDS of INV-36 .....................................109

Figure 79. Detail SEM photomicrograph and EDS of INV-36 ............................110

Figure 80. Detail SEM photomicrograph and EDS of INV-36 ............................112

Figure 81. Detail SEM photomicrograph and EDS of INV-36 ...............................113

Figure 82. SEM photomicrograph and EDS of SH-13 ..........................................114

Figure 83. Detail SEM photomicrograph and EDS of SH-13 ...............................115

Figure 84. Detail SEM photomicrograph and EDS of SH-13 ..............................116

Figure 85. Detail SEM photomicrograph and EDS of SH-13 ..............................118

Figure 86. Detail SEM photomicrograph and EDS of SH-13 ..............................120

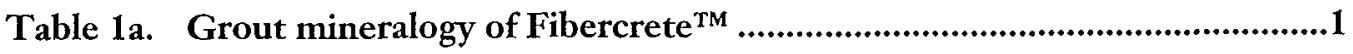

Table 1b. Fibercrete ${ }^{\mathrm{TM}}$ grout composition .................................................................2

Table 1c. Fibercrete ${ }^{\mathrm{TM}}$ steel fiber composition............................................................2

Table 2a. Cement composition of approved ESF invert concrete mixes...................2

Table 2b. Aggregate physical characteristics from ASTM C33) .............................2

Table 2c. Cement composition of ESF composition concrete...................................2

Table 3a. Sample placement and pressure vessel labels ............................................4

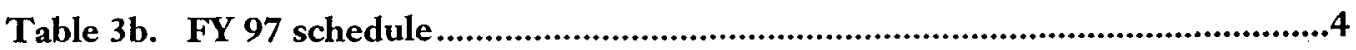

Table 4. Status of analyses as of September 10, 1997 ...........................................

Table 5. Summary of color photo observations ..........................................................8

Table 6. Estimated modal percentages of phases observed in Batch 1 samples under petrologic microscope..........................................................................11

Table 7. Batch 1 concrete experiments: Thin-section observations.....................12

Table 8. Summary of phases identified by glancing-angle XRD .....................18-21

Table 9. Mechanical tests comparing Batch 1 and Batch $2 \ldots \ldots \ldots \ldots \ldots \ldots \ldots \ldots . . . . . . . . . .17$ 


\section{Introduction}

\section{$\mathbf{T}$} his and a previous report (Part I, Meike et al., 1997) describe experiments designed to provide data for a quick engineering assessment of the microstructural, mineralogical, and (to a lesser extent) mechanical changes in hydrothermally altered concrete and changes in associated water chemistry. Data were acquired from these experiments to help understand the material transformations and processes that may occur as a result of a hydrothermal cycle at a proposed nuclear waste repository, which may be located at Yucca Mountain, Nevada. The concrete samples that were used in the experiments are intended to support a design decision regarding the use of precast concrete liners for mechanical support in repository emplacement drifts. In such a location, the concrete will be subjected to elevated temperatures of at least $150^{\circ}$ to $200^{\circ} \mathrm{C}$, and perhaps even greater temperature if backfill is used.

At the time that these experiments were planned (mid1996), discussions with Yucca Mountain Project repository design staff suggested that a likely potential candidate material would be similar, if not identical, to the composition of the inverts presently being emplaced in the Exploratory Studies Facility (ESF). However, the use of other precast formulations as well as cast-in-place formulations had not yet been ruled out. Since that discussion, a panel of experts (Sassani, 1996) suggested some options that could affect the composition chosen for an emplacement drift liner. The panel unanimously supported precast segments, high silica formulations (e.g., addition of silica fume), and $\mathrm{C}_{2} \mathrm{~S}$ (concrete nomenclature) formulations to minimize the impact of the grout on $\mathrm{pH}$ ( $\mathrm{pH}$ values of 12-14 can be achieved by water in contact with young concrete) and to reduce the amount of water introduced to the repository. A report by Tang (1997) describes the resultant formulation, which uses Type $V$ grout. Type II grout still appears to be under consideration because of economic considerations (G. Theirs, personal communication). Given that precured and aged invert material is readily available-and it is not clear which, if any, of the suggestions of the expert panel will be pursued-we used ESF invert material and Fibercrete $^{\mathrm{TM}}$ in this experiment.
Three batches of samples were treated over successively longer durations. Each of the batches was subjected to a range of analytical techniques. Because some analytical methods are destructive, we necessarily conducted our analyses sequentially, saving the most destructive techniques for the last analyses. Therefore, the time required for analytical work cannot be condensed. As a result, the period of time required to analyze one batch of samples overlapped significantly onto the analysis periods of the others.

This interim report is the second of three reports that discuss the progress of these experiments. The first report described the available analytical results for the first batch of samples. This second report concludes the analytical results from the first batch, and describes available results from the second and third batches.

\section{Experiment Plan}

\subsection{SAMPLE COMPOSITION}

We obtained general information pertaining to the composition of Fibercrete ${ }^{\mathrm{TM}}$ and the ESF invert concrete from the Tracers, Fluids, and Materials Databasc and the respective manufacturers and materials sources. Yucca Mountain Site Charactcrization Project engineers provided the composition of Fibercrete ${ }^{\mathrm{TM}}$ as listed in Tables 1a through 1c (Meike and Spragge, 1995).

Table 1a. Grout mineralogy of fibercrete ${ }^{\mathrm{TM}}$.

\begin{tabular}{llc}
\hline $\begin{array}{c}\text { Grout } \\
\text { mineralogy }\end{array}$ & Formula & $\begin{array}{c}\text { Composition } \\
\text { (wt\%) }\end{array}$ \\
\hline Tricalcium silicate & $(\mathrm{CaO})_{3} \mathrm{SiO}_{2}$ & 61 \\
Dicalcium silicate & $(\mathrm{CaO})_{2} \mathrm{SiO}_{2}$ & 15 \\
Tricalcium aluminate & $(\mathrm{CaO})_{3} \mathrm{Al}_{2} \mathrm{O}_{3}$ & 6 \\
Tetracalcium aluminoferrite & $(\mathrm{CaO})_{4} \mathrm{Al}_{2} \mathrm{O}_{3} \mathrm{Fe}_{2} \mathrm{O}_{3}$ & 9 \\
\hline Total & & 91 \\
\hline
\end{tabular}


Table 1b. Fibercrete ${ }^{T M}$ grout composition.

\begin{tabular}{lc}
\hline Oxide & Composition (wt\%) \\
\hline $\mathrm{SiO}_{2}$ & 21.4 \\
$\mathrm{Al}_{2} \mathrm{O}_{3}$ & 4.3 \\
$\mathrm{Fe}_{2} \mathrm{O}_{3}$ & 2.9 \\
$\mathrm{CaO}$ & 64.9 \\
$\mathrm{MgO}$ & 1.7 \\
$\mathrm{SO}_{3}$ & 2.7 \\
$\mathrm{Na}_{2} \mathrm{O}$ & 0.53 \\
Loss on ignition & 0.87 \\
Insoluble residue & 0.2 \\
\hline Total & 99.5 \\
\hline
\end{tabular}

Table 1c. Fibercrete ${ }^{\text {TM }}$ steel fiber composition.

\begin{tabular}{lc}
\hline Element & Composition (wt\%) \\
\hline $\mathrm{Fe}$ & 99.8 \\
$\mathrm{C}$ & 0.018 \\
$\mathrm{Mn}$ & 0.075 \\
$\mathrm{P}$ & 0.040 \\
$\mathrm{~S}$ & 0.050 \\
\hline Total & 99.983 \\
\hline
\end{tabular}

Table 2a shows information supplied to us regarding the composition of approved concrete mixes for the invert. Multiple suppliers have been named for some of the materials in these mixes. We understand that each mix was assessed and approved on the basis of standard construction criteria before the inverts were fabricated. We have not yet been able to verify which of these suppliers actually contributed materials to the inverts that have been emplaced in the ESF. The specifications and information furnished by suppliers to date for the coarse aggregate (Table $2 \mathrm{~b}$ ) are primarily related to physical characteristics. Although chemical information (e.g., total carbonate content) related to known degradation mechanisms [i.e., delayed ettringite formation (DEF) and alkali silica reaction (ASR)] were furnished by one supplier, we are awaiting
Table 2a. Cement composition of approved ESF invert concrete mixes.

$\begin{array}{lc}\text { Maximum aggregate size } & 0.5 \text { in. } \\ \text { Cement (lb/cy) } & 635-752 \\ \text { Water (Ib/cy) } & 209-286 \\ \text { W/C ratio } & 0.37-0.47 \\ \text { Coarse aggregate (Ib/cy) } & 1516-1544 \\ \text { Fine aggregate (lb/cy) } & 1414-1569 \\ \text { Air entraining admixture (AEA) (oz/cy) } & 100-125 \\ \text { Water reducing agent (WRA) } & \\ \text { Master Builders "polyheed" (Oz/cy) }\end{array}$

Table 2b. Aggregate physical characteristics (from ASTM C33).

$\begin{array}{lc}\text { Size Number } & 7 \\ \begin{array}{l}\text { Nominal size (sieves with square } \\ \text { openings) }\end{array} & 0.5 \text { in. to No. } 4 \\ (12.5 \text { to } 4.755 \mathrm{~mm})\end{array}$

Amounts finer than each laboratory sieve (square openings)

$$
\begin{aligned}
& 0.75 \mathrm{in.}(19.0 \mathrm{~mm}) \\
& 0.5 \mathrm{in} .(12.5 \mathrm{~mm}) \\
& 0.375 \mathrm{in.}(9.5 \mathrm{~mm}) \\
& \text { No. } 4(4.755 \mathrm{~mm}) \\
& \text { No. } 8(2.36 \mathrm{~mm})
\end{aligned}
$$$$
100 w t \%
$$$$
90 \text { to } 100 w t \%
$$$$
40 \text { to } 70 w t \%
$$$$
0 \text { to } 15 \text { wt\% }
$$

0 to $5 w t \%$

Table 2c. Cement composition of ESF invert concrete.

\begin{tabular}{lc}
\hline Oxide & Composition (wt\%) \\
\hline $\mathrm{SiO}_{2}$ & 22.4 \\
$\mathrm{CaO}$ (total) & 65.07 \\
(free lime) & $(1.7)$ \\
$\mathrm{SO}_{3}$ & 2.7 \\
\hline Total & $\mathbf{9 0 . 1 7}$ \\
Remainder (undefined composition) & $\mathbf{9 . 8 3}$ \\
\hline
\end{tabular}


verification that this aggregate was used. The mineralogical variation of the aggregate through time is evident from letter BABFCC000-01717-6300-03480-VD-13-0, which describes mineralogical variation in aggregate from the WMK Buffalo plant. Physical characteristics of the aggregate have been specified on drawing BABFCC00001717-2100-41099-03 note \#10 as ASTM C33 size 7

(Table 2b). The grout is specified as ASTM type II cement, for which the data (accounting for $90.7 \mathrm{wt} \%$ of the total) are listed in Table $2 \mathrm{c}$. The data that we have received to date from the manufacturers for the fine aggregate (sand) suggest that some of this aggregate is composed primarily of carbonate materials and exhibited expansion characteristics beyond that acceptable for the alkali/silica reaction in an aggregate. Results of the more appropriate alkali/carbonate test are not available at this time.

More useful to our present purpose is the specific mineralogical data obtained from thin-section analysis of the first batch of samples, described below and in Appendix B.

\subsection{SAMPle Preparation}

A large concrete core $(\sim 200 \mathrm{~mm}$ diameter) obtained from the ESF invert was cut into approximately $13-\mathrm{mm}$ slabs of circular cross section using a large rock saw with a diamond-impregnated saw blade cooled with house water. This large slab was then cut at $90^{\circ}$ to the first cut into widths of approximately $25 \mathrm{~mm}$. Holes approximately $4 \mathrm{~mm}$ were cored through the center of the resultant rectangular prisms of invert parallel to the long axis. Finally, these prisms were slabbed normal to the hole using an Isomet low-speed saw, resulting in $3-\mathrm{mm} \times$ 13-mm $\times 25-\mathrm{mm}$ coupons. Thus, the 13-mm dimension of each coupon is parallel to the axis of the concrete core, which corresponds to vertical orientation in the ESF. Each side of each coupon was ground using silicon carbide grinding powder (400 grit) to remove most optically visible saw marks, rinsed with deionized water water, air dried for 24 hours, and then weighed.

Shotcretc (Fibercrete ${ }^{\mathrm{TM}}$ ) samples were prepared similarly from a block of invert obtained from the North Portal. These coupons measured approximately $2 \mathrm{~mm} \times 13 \mathrm{~mm} \times$ $25 \mathrm{~mm}$ with a through hole approximately $4 \mathrm{~mm}$ in diameter centered on the $13-\mathrm{mm} \times 25-\mathrm{mm}$ plane. In these samples, "up" and "down" can be easily ascertained because the texture due to the settling of the fine aggregate before the cure is clear in each coupon.

\subsection{Experimental MEtHOD}

Figure 1 illustrates the pressure vessel assembly in cross section. Each of six relatively large-capacity $(125-\mathrm{ml})$ pressure vessels (4749 general purpose pressure vessel, Parr Instrument Company) contains a Teflon liner and a Teflon platform, standing approximately $6.4 \mathrm{~cm}$ in height and fitted with platinum spikes, which allow us to conduct water and vapor phase studies in a single vessel. As shown in Table 3, careful scheduling of the available equipment provided six sample treatments for the invert and three for the shotcrete. Each treatment consisted of total cycle lengths of 6 weeks, and 4 and 9 months before the end of FY 97.

The Teflon liners and stands were cleaned with nitric acid according to the following procedure. First, $80 \mathrm{ml}$ of a $1 \%$ nitric acid solution $\left(10 \mathrm{ml}\right.$ of $70 \% \mathrm{HNO}_{3}+$ $1 \mathrm{~L}$ MilliQ distilled $\mathrm{H}_{2} \mathrm{O}$ ) was placed into each liner. The liners were inserted into pressure vessels, and assemblies were baked at $120^{\circ} \mathrm{C}$ overnight. When the vessels cooled, liners were rinsed with MilliQ distilled water. Subsequently, $80 \mathrm{ml}$ of MilliQ distilled water was placed in each liner. Vessels were reassembled and baked at $200^{\circ} \mathrm{C}$ overnight. When cooled, the $\mathrm{pH}$ of the aqueous solution was measured. Liners were rinsed, filled, and reheated until $\mathrm{pH}$ readings stabilized.

Three samples were inserted into each pressure vessel: two (one Fibercrete and one invert) rested between the platinum pins of the teflon stand, and one (invert) rested on the floor of the pressure vessel (refer to Figure 1, in which two samples are shown). The experimental runs are numbered consecutively $(\mathrm{CN}-1$ through $\mathrm{CN}-3)$ with respect to the the time the experiment was initiated. Each run represents experiments in three pressure vessels exposed to identical thermal conditions. One vessel was heated in the absence of an aqueous fluid. The other two vessels contained roughly $60 \mathrm{ml}$ of aqueous solution that was formulated so as to vary the concentration of $\mathrm{CO}_{3}$ at elevated temperature. The first batch of samples represented runs $\mathrm{CN}-1$ and $\mathrm{CN}-2$, the shortest and longest durations, respectively. $\mathrm{CN}-3$ was initiated after $\mathrm{CN}-1$ was removed from the pressure vessels. To prepare the vessels, the samples were loaded, then if fluid was required, $60 \mathrm{ml}$ was poured along the inner edge of the liner to submerge the lower sample without contacting the upper samples. All liners were sealed, and pressure vessels were assembled according to the manufacturer's instructions. Assemblies were handled with care to prevent wetting of the upper 
Table 3a. Sample placement and pressure vessel labels.

\begin{tabular}{|c|c|c|c|c|}
\hline & $\begin{array}{c}\text { Lower invert } \\
(\mathrm{gm})\end{array}$ & $\begin{array}{c}\text { Upper invert } \\
(\mathrm{gm})\end{array}$ & $\begin{array}{c}\text { Upper Shotcrete } \\
\text { (gm) }\end{array}$ & $\begin{array}{l}\text { PV number/ } \\
\text { liner number }\end{array}$ \\
\hline \multicolumn{5}{|l|}{$\mathrm{CN}-1$} \\
\hline Condition & aqueous phase & vapor phase & vapor phase & \\
\hline Dry & - & $\begin{array}{l}\text { INV-25 (1.37) } \\
\text { INV-24 (1.31) }\end{array}$ & $\mathrm{SH}-1(1.48)$ & $13 / 13$ \\
\hline 1 molar $\mathrm{NaHCO}_{3}(60 \mathrm{ml})$ & INV-26 (1.35) & INV-27 (1.41) & $\mathrm{SH}-2(1.47)$ & $18 / 18$ \\
\hline 1 molar $\mathrm{NaCl}(60 \mathrm{ml})$ & INV-17 (2.207) & INV-18 (2.2923) & $\mathrm{SH}-5(1.33)$ & $7 / 7$ \\
\hline \multicolumn{5}{|l|}{$\overline{\mathrm{CN}-2}$} \\
\hline Condition & aqueous phase & vapor phase & vapor phase & \\
\hline $\begin{array}{l}\text { "Dry" (+90 wet } \\
\text { thermal treatment) }\end{array}$ & INV-31 (1.51) & INV-30 (1.56) & SH-6 (1.45) & blank/blank \\
\hline 1 molar NaHCO3 $(60 \mathrm{ml})$ & INV-28(1.48) & INV-29 (1.45) & $\mathrm{SH}-3(1.21)$ & $24 / 23$ \\
\hline 1 molar $\mathrm{NaCl}(60 \mathrm{ml})$ & INV-32 (1.38) & INV-33 (1.35) & $\mathrm{SH}-4(1.35)$ & $14 / 14$ \\
\hline $\mathrm{H}_{2} \mathrm{O}$ control $(60 \mathrm{ml})$ & - & - & - & $12 / 12$ \\
\hline \multicolumn{5}{|l|}{$\overline{C N-3}$} \\
\hline Condition & aqueous phase & vapor phase & vapor phase & \\
\hline Dry & - & $\begin{array}{l}\text { INV-38 }(1.9772) \\
\text { INV-37 }(2.1172)\end{array}$ & $\mathrm{SH} .9(1.48)$ & $13 / 13$ \\
\hline 1 molar $\mathrm{NaHCO}_{3}(60 \mathrm{ml})$ & INV-23a $(2.4714)$ & INV-23b (2.4714) & $\mathrm{SH}-10(1.55)$ & $18 / 18$ \\
\hline 1 molar $\mathrm{NaCl}(60 \mathrm{ml})$ & INV-21 (2.2815) & INV-36 (1.38) & $\mathrm{SH}-13(1.15)$ & $7 / 7$ \\
\hline $\mathrm{H}_{2} \mathrm{O}$ control $(60 \mathrm{ml})$ & - & - & - & $12 / 12$ \\
\hline
\end{tabular}

Table 36. FY97 schedule

\begin{tabular}{lllllllllll}
\hline Oct Nov Dec Jan June July Aug & Sept \\
\hline
\end{tabular}

CN-1

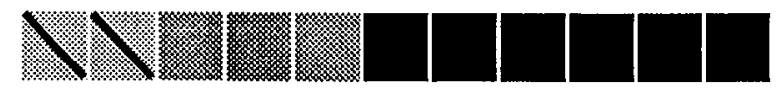

CN-2

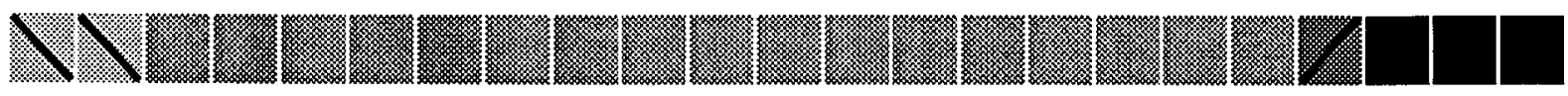

CN-3

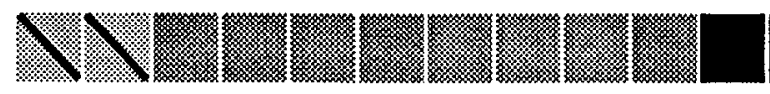

$100^{\circ} \mathrm{C}$ wet thermal treatment

$90^{\circ} \mathrm{C}$ wet thermal treatment

$200^{\circ} \mathrm{C}$ wet thermal treatment

analysis 
samples from splashing liquid. To minimize and perhaps eliminate the need to cool the pressure vessels during a run, $60 \mathrm{ml}$ of MilliQ water was added to an otherwise empty liner (the fluid level control). This pressure vessel was used to monitor water loss from evaporation or leakage of the assembly. Although the Teflon liners of the pressure vessels are permeable, we measured no significant loss of water over the duration of the experiments.

All vessels were preheated in a convection oven to $100^{\circ} \mathrm{C}$ for 14 days and then moved to a convection oven heated to $200^{\circ} \mathrm{C}$. After 33 days, which was the shortest run (CN-1), one pressure vessel representing each of the three chemical treatments [ 1 molar $(1 \mathrm{M}) \mathrm{NaHCO}_{3}, 1 \mathrm{M} \mathrm{NaCl}$, and dry] and the control vessel were removed from the oven and allowed to cool at room temperature. The samples were not rinsed (due to the fragile nature of some of the minerals that were formed during the experiment) and were allowed to air dry. For this reason, aqueous-phase evaporite deposits are expected on the samples in addition to the hydrothermal alteration products. These pressure vessels were unloaded and then cleaned and reloaded as described above to initiate $\mathrm{CN}-3$, the medium duration run. The vessels were preheated for 14 days at $100^{\circ} \mathrm{C}$ and then moved to a convection oven heated to $200^{\circ} \mathrm{C}$ for 20 weeks.

The final batch of samples ( $\mathrm{CN}-2)$ was removed from $200^{\circ} \mathrm{C}$ treatment after 41 weeks. The vessels were cooled and checked for moisture loss, which was insignificant in any of the pressure vessels. These samples received an additional treatment in which $60 \mathrm{ml}$ of deionized water was added to the "dry" pressure vessel. The vessels were then reheated to $90^{\circ} \mathrm{C}$ for an additional two weeks. The batch numbers (Batch 1-Batch 3), unlike the run numbers (e.g., CN-1), are labeled in the order of increasing experimental duration; Batch 1 represents the shortest duration (47 days) and Batch 3 represents the longest (43 weeks).

Samples were removed from the containers and allowed to air dry. Special care was taken to avoid knocking secondary phases from the surface of the samples. The samples were stored, between analyses in evacuated chambers containing Drierite $^{\mathrm{TM}}$. As is clear from the analysis below, dehydrated splash droplets are easily differentiated from secondary precipitates. The splash droplets served at times to preserve underlying secondary precipitates. Both the samples and the aqueous fluids either have been or are to be analyzed as described subsequently.

\subsection{ANalytical Methods}

Inductively coupled plasma mass spectrometry (ICP-MS) and ion chromotography (IC) analyses were conducted on the aqueous solutions. IC analyses are given as ionic species, whereas ICP-MS analyses are not speciated. It is important to note that the aqueous chemistry elements are selected previous to the analysis. Therefore pertinent information to the interpretation of these experiments are not only concentrations, but elements analyzed and detection limits. Samples were photographed using a camera attached to a reflected light microscope. The camera was a Sony CCD-iris DXC-107a with Sony camera adapter model CAM-d7. The camera was connected to a Nikon optical light microscope OLM 218109, Nikon Transformer model UN, and Sony color video printer UP-3000. Glancing-angle $x$-ray diffraction, which provides analysis of the first few microns of sample, was used to characterize the surface of the treated specimens. Scanning electron microscopy (SEM) was conducted with a Hitachi S-800 FESEM with Tracor Northern Energy Dispersive Spectral analysis (EDS). Mechanical tests have been conducted on the second batch of samples in uniaxial compression at a cross-head advance rate of $0.002 \mathrm{in} . / \mathrm{min}$.

\subsection{Aqueous Chemistry}

During the course of the experiments, the chemistry of the aqucous solution in contact with the concrete coupon in the bottom of the pressure vessel was expected to evolve. We have analyzed the chemistry of each batch at the end of the treatment as well as the original solution. These results can be interpreted as the evolution of the solutions in contact with the ESF concrete over time. In the future, we will compare the aqueous and the mineralogical results from these experiments with chemical modeling simulations (EQ3/6 and Geochemists Workbench) to assess whether our thermodynamic and kinetic data (Clodic and Meike, 1997) are adequate for the purpose of the Yucca Mountain Project.

The chemistry of the original aqueous solutions, described above, was expected to be modified by the sample coupon (invert material) that was inserted in the solution underneath the platform. The samples exposed to the vapor phase on top of the platform (see Figure 1) were not expected to affect the solution chemistry. We expect the aqueous interaction to be between the solution and the 
invert sample only because-although some splashing may have caused droplets of the solution to form and evaporate on the vapor phase samples (upper invert samples, Table 3a) - the analyzed aqueous solution in each case was only in direct, long-term contact with the sample at the bottom of the vessel (lower invert sample, Table 3a). Each solution was analyzed with ICP-MS and IC. As of the date of this report, the analysis of Batch 3 has not been completed. The $\mathrm{pH}$ of each solution was also measured. The $\mathrm{pH}$ of Batch 1 solutions was not measured immediately after opening the pressure vessels; therefore, those values may not be as accurate. The true $\mathrm{pH}$ of these solutions could have been more alkaline before it was allowed to interact with $\mathrm{CO}_{2}$ in the atmosphere. The results are plotted in Figures 2 through 5.

\subsection{1 $1 \mathrm{M} \mathrm{NaHCO}_{3}$ Solution}

Figure 2 and Figure 3 illustrate aspects of the general evolution of the aqueous chemistry of a $1 \mathrm{M} \mathrm{NaHCO}_{3}$ solution in contact with ESF invert concrete. It is important to note that, although we interpret the data as an evolutionary sequence, from the original $1 \mathrm{M} \mathrm{NaHCO}_{3}$ solution (labeled "original solution" in Figure 2 and Figure 3) through six weeks (Batch 1) to four months (Batch 2), each analysis represents the interaction between a different although somewhat equivalent concrete sample and the solution. As a consequence, some chemical variation may occur due to sample heterogeneity. Figure 2 illustrates the chemical constituents that were present in detectable concentrations, and thus the standard solution chemistry. Figure 3 includes all of the chemical species that were analyzed but not detected, plotted at their detection limit.

It is clear that the $\mathrm{pH}$ of the $\mathrm{NaHCO}_{3}$ solution increases with time to a value of 9.15 . Not included on this plot is the $\mathrm{pH}$ measurement from Batch 3, which increases slightly to a $\mathrm{pH}$ value of 9.50 . Thus, it appears that the solution had achieved a steady state with respect to the concrete sample at the conditions of the experiment within six weeks (the duration of $\mathrm{CN}-1$, which represents Batch 1). It is not clear whether the slightly increased $\mathrm{pH}$ at the end of Batch 3 represents sample heterogeneity or a renewed increase in $\mathrm{pH}$; either possibility could be due to an excess of portlandite. In the former case, it could be due to a greater mass of portlandite in the Batch 3 sample. In the latter case, it could be related to the ratio of reaction surface area to fluid volume and the time required for the portlandite within the sample to increase its influence.

\subsection{2 $1 \mathrm{M} \mathrm{NaCl}$ Solution}

Figures 4 and 5 illustrate aspects of the general evolution of the aqueous chemistry of a $1 \mathrm{M} \mathrm{NaCl}$ solution in contact with ESF invert concrete. It is important to note that, although we interpret the data as an evolutionary sequence, from the original $1 \mathrm{M}-\mathrm{NaCl}$ solution (labeled "original solution" in Figure 4 and Figure 5) through one month (Batch 1) to four months (Batch 2), each analysis represents the interaction between a different although somewhat equivalent concrete sample and the solution. As a consequence, some chemical variation may occur due to sample heterogeneity.Figure 4 illustrates the chemical constituents that were present in detectable concentrations. Similarly to Figure 3, Figure 5 includes the remainder of the chemical species, primarily those that were analyzed but not detected, plotted at their detection limit.

It is clear that the $\mathrm{pH}$ of the $\mathrm{NaCl}$ solution increases with time to a value of near 11.5. Not included on this plot is the $\mathrm{pH}$ measurement from Batch 3, which was also 11.48, suggesting that the solution achieved a steady state with the concrete sample, at the conditions of the experiment, within four months (the duration of $\mathrm{CN}-3$, which represents Batch 2). The relation between $\mathrm{pH}$ change and time is not completely clear, due to the uncertainty in the Batch $1 \mathrm{pH}$ value (6.35), which was measured two months after the samples had been removed from the pressure vessel. It is probable, however, by comparison with the $\mathrm{NaHCO}_{3}$ results, that the solution achieved equilibrium with the sample within one month. We suspect that the Batch 1 aqueous solution originally had a $\mathrm{pH}$ of near 11.5 , but it was not at equilibrium with atmospheric $\mathrm{CO}_{2}$. We suspect that, over time, it equilibrated with atmospheric $\mathrm{CO}_{2}$ (becoming carbonate species in solution), and the $\mathrm{pH}$ of the solution was consequently reduced. This interpretation is consistent with the $\mathrm{NaHCO}_{3}$ solution results in which the $\mathrm{pH}$ appears to have reach a steady state by the end of Batch 1 . The $\mathrm{pH}$ of the Batch 1 $\mathrm{NaHCO}_{3}$ solution was apparently not affected by the one month delay between removal from the vessel and $\mathrm{pH}$ measurement, because of significant buffering by the high concentration of $\mathrm{HCO}_{3}^{-}$.

\subsubsection{Dry Samples}

The aqueous chemistry is not relevant to the "dry" samples from Batch 1 or Batch 2. However, water was added before the last two weeks of thermal treatment at $90^{\circ} \mathrm{C}$ of Batch 3 . 
In the discussions the various analyses below, these "dry" treatment coupons are usually included in the discussions of the "vapor treatment" samples. The two week water sample was collected from Batch 3 after the experiment. The analytical results have not been completed. However, the $\mathrm{pH}$ was measured at a value of 11.84 . This gives additional credence to the supposition that the $\mathrm{pH}$ of the $\mathrm{NaCl}$ solution also increased quickly.

\section{Sample Analysis}

\subsection{Photodocumentation}

Table 4 shows the current status of sample analyses. Batch 1 and the untreated samples were not photographed; however, most of Batch 2 and all of Batch 3 were photographed, and the photos are described in the sections below. Black and white photos do not have scale bars; sample dimensions are approximately $13 \times 25 \mathrm{~mm}$. Table 5 is a summary of the features observed in the color photographs.

Table 4. Status of analyses as of September 10, 1997.

\begin{tabular}{lcccc}
\hline $\begin{array}{c}\text { Analytical } \\
\text { method }\end{array}$ & $\begin{array}{c}\text { Untreated } \\
\text { samples }\end{array}$ & $\begin{array}{c}\text { Batch } 1 \\
\text { samples }\end{array}$ & $\begin{array}{c}\text { Batch } 2 \\
\text { samples }\end{array}$ & $\begin{array}{c}\text { Batch } 3 \\
\text { samples }\end{array}$ \\
\hline $\begin{array}{l}\text { Color } \\
\text { photodocumentation }\end{array}$ & NA & NA & II & II \\
Thin-section analysis & II & II & III & III \\
SEM & I & I & II & III \\
Glancing-angle XRD & I & I & II & II \\
Powder XRD & I & I & III & III \\
Mechanical test & I, I & I, II & II & III \\
\hline
\end{tabular}

$N A=$ no analysis performed.

I = Analysis documented in Melke (1997),

$\|=$ Analysis documented in this report.

III = Analysis to be documented in a future, final report.

\subsubsection{Treated Samples, Dry}

\section{Batch 1}

No photos were taken of Batch 1 samples.

Batch 2

Invert. Sample INV-37. Figure 6 is a black and white photograph of this sample. At this scale, little evidence of secondary phases is observed on the surface of the sample.

Invert. Sample INV-38. No photos were taken.

Shotcrete. Sample SH-9. Figure 7 is a black and white photograph of this sample. At this scale, little evidence of secondary phases is observed on the surface of the sample. A thin, white crust is visible around the central hole.

\section{Batch 3}

Invert. Sample INV-30. A typical view of the sample (Figure 8) shows white rims surrounding small aggregate grains, but not the large grains (in the photo the large grains are gray). Also illustrated is a higher-magnification view of a white rim around a small aggregate grain. The grout is white.

Invert. Sample INV-31. The sample (Figure 9) appears to have very few white rims around grains. A typical view of the sample shows some aggregate with thin white rims, and some without. Tiny crystals are also observed on aggregate. The tiny crystals were not observed on grout, but were observed on other aggregate grains.

Shotcrete. Sample SH-6. Photographs of this sample appear in Figure 10. White rims occur on many aggregatc grains, both large and small. Other notable features shown in the photos are brown mica grains, a white phase near the central hole, and three stainless steel fibers with a black/red phasc that occurs on the surface of the fibers.

\subsubsection{Treated Samples, $1 \mathrm{M} \mathrm{NaHCO}_{3}$ Solution}

\section{Batch 1 \\ No photos were taken of Batch 1 samples.}

\section{Batch 2}

Invert. Aqueous treatment. Sample INV-23a. Figures 11 and 12 are photographs of this sample. Both sides of this sample were photographed because they were quite different. Side 1 (Figure 11) is nearly covered with a 
Table 5. Summary of color photo observations. "

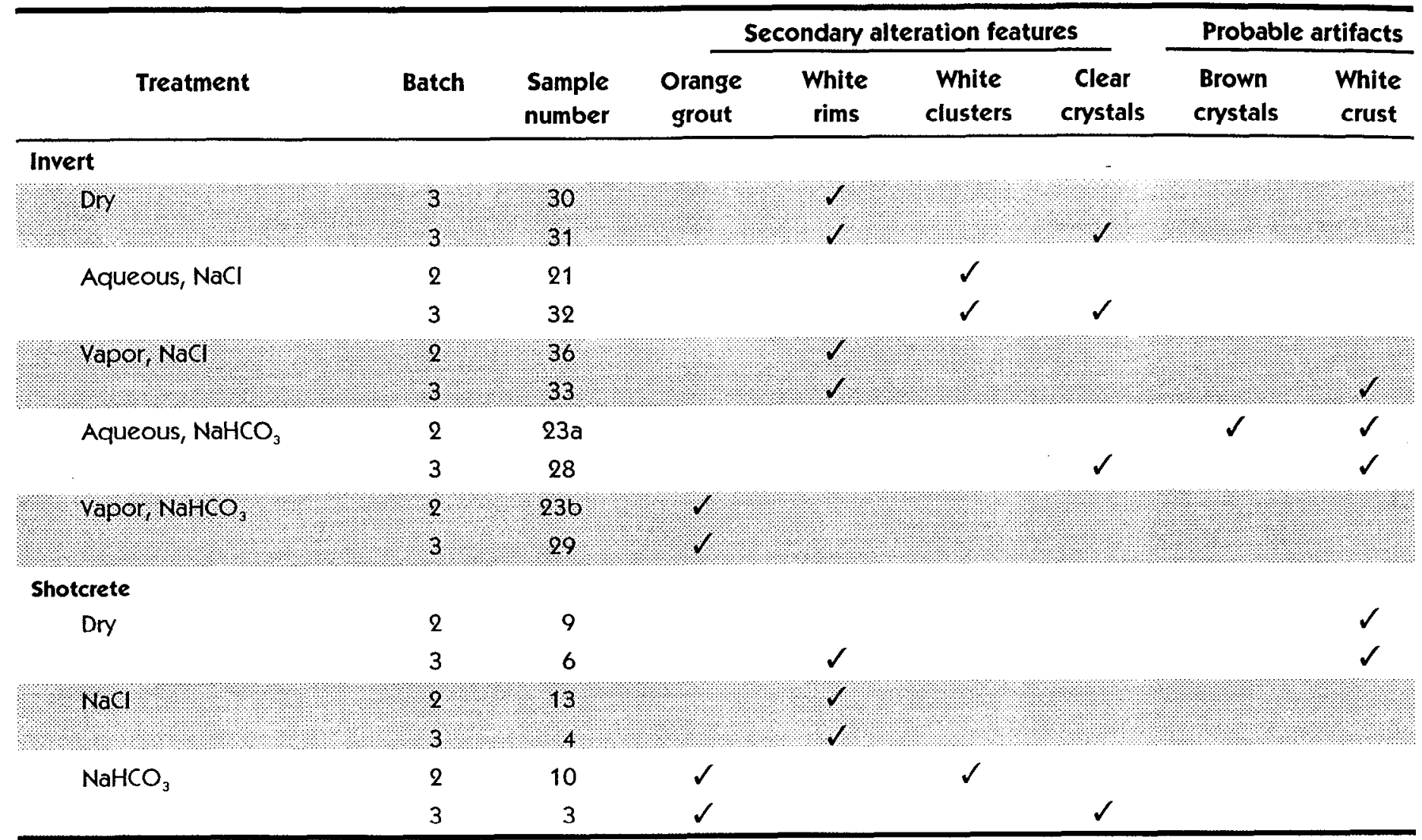

a Photographs of untreated samples, Batch 1 samples, and some Batch 2 samples were not obtained.

white crust. At least two patterns emerge on the white crust over a large, gray aggregate grain. One resembles a radiating web, and the other, mud cracks. These are probably the vestiges of evaporated solution.

Unlike side 1, side 2 (Figure 12) only shows crust around the central hole. Two odd, brown crystals are shown on aggregate grains. Also documented are a white, fanshaped phase that occurs around the central hole on both aggregate and grout and a white, granular phase that occurs near the edge of the sample on both aggregate and grout. The grout has a sugary appearance in this sample.

\section{Invert. Vapor treatment. Sample INV-23b.}

Photographs of this sample are shown in Figure 13. In the black and white photo, the sample does not appear to have white rims or other white crystals on it. At higher magnification, faint, flat white rims come into view and appear sugary, not spindly. A white granular phase is shown at the bottom of a pit in grout.
Shotcrete. Vapor treatment. Sample SH-10. The sample (Figure 14) bears little evidence of secondary phases at this scale. Many pits are visible in the grout. A steel fiber is visible in association with black and orange areas that appear to be alteration of the fiber. Also visible are two white crystals attached to the central hole, and an aggregate grain with a yellow colored phase within it.

\section{Batch 3}

Invert. Aqueous treatment. Sample INV-28. Both sides of this sample were photographed (Figure 15 and Figure 16) because they were quite different. Side 1 (Figure 15) has no white crust, and side 2 (Figure 16) is nearly covered with a white crust (probably droplets of the aqueous solution). No white rims are evident around the aggregate grains of side 1; however, euhedral crystals are fairly evenly distributed on both aggregate and grout. Side 2 is nearly covered with a white crust. The white crust partially coats both aggregate and grout. Euhedral crystals also occur on this side of the sample; however, they are not as abundant. 
Invert. Vapor treatment. Sample INV-29. This sample (Figure 17) has orange colored grout and few, if any, white rims on grains. One grain shown in a photo may have a white rim, but not of the thickness and development of rims seen in other samples.

Shotcrete. Vapor treatment. sample SH-3. This sample (Figure 18) has orange colored grout and widespread, tiny euhedral crystals that commonly occur on aggregate and sparsely occur on grout.

\subsubsection{Treated Samples, $1 \mathrm{M} \mathrm{NaCl}$ Solution}

\section{Batch 1}

No photos were taken of Batch 1 samples.

\section{Batch 2}

Invert. Aqueous treatment. Sample INV-21. Notable features in this sample (Figure 19) include clusters of white radiating crystals that commonly occur on aggregate. At least five of these clusters were observed on the sample. Also photographed were two pits in grout, filled with a white phase that has a sugary texture. There were several such pits on this sample. The small aggregate grains in this photo do not appear to have reaction rims.

Invert. Vapor treatment. Sample INV-36. In the black and white photo (Figure 20), white rims of secondary phase can be observed around the smaller aggregate grains and within the large grains. A large pit is visible. Color photos reveal a white fibrous mat of crystals attached to an aggregate grain on the edge of the sample, as well as white rims around smaller aggregate grains and within a large aggregate grain. Other features are aggregate grains with no white rims, white rims that appear to be in grout (note the fine, white spindles on the inside one of the white rims), and a fibrous mat of crystals near the central hole in the sample. The crystals also radiate into the hole, but they are out of focus in the photo.

Shotcrete. Vapor treatment. Sample SH-13.

Photographs of this sample are shown in Figure 21. Eighty to ninety percent of all the grains have visible white rims. Some of the features photographed include tiny white crystals that radiate from the edge of the sample, needleshaped crystals radiating from a mound of other crystals, a white rim with inward-radiating spines, and two brown mica grains (probably biotite) with no reaction rims.

\section{Batcb 3}

Invert. Aqueous treatment. Sample INV-32. The sample (Figure 22) appears to have few obvious secondary reaction features at this scale. One photograph documents a white, radiating crystal cluster on an aggregate grain. Four crystal clusters occur on the sample, all on aggregate. The photo also illustrates the typical texture of the grains and grout in this sample. Another notable feature is tiny cubic crystals that occur on two types of aggregate as well as grout.

Invert. Vapor treatment. Sample INV-33. The photos (Figure 23) show that white rims occur around some aggregate grains, and a white crust sparsely coats some of the sample. An unusual raised white rim was observed within an aggregate grain. Only one raised rim occurs on each side of the sample. Also shown are two morphologies of the white crust-forming phases that sparsely coat the sample. The examples in the photo are shown on aggregate. Although sparse, some small grains within the noncoated areas have white rims.

Shotcrete. Vapor treatment. Sample SH-4. This sample (Figure 24) contains numerous grains with white rims. The photos show a crack in the corner of the sample containing a fiber that appears to have oxidized. Also shown are highmagnification views of the white rims around many of the grains in the sample.

\subsubsection{Untreated Samples}

No photos were taken of untreated samples.

\subsection{ThIN-SeCtion ANALYSIS}

A thin section is an approximately $30-\mu \mathrm{m}$-thick slice of sample mounted on a glass slide. Many opaque materials, when sliced thinly enough, allow light to pass through. We have identified aggregate minerals from thin sections, on the basis of their optical properties, using a petrographic microscope. This standard method of geological analysis takes advantage of certain optical properties that can be observed in polarized light, one of which is known as birefringence. The advantage of this method over our other surface-analysis techniques is that we can document the extent to which changes occur within the sample or even permeate the sample. 
The fractured Batch 1 samples were rebuilt and embedded in epoxy before mounting on petrographic slides, cutting with a diamond saw, and polishing with a series of microgrits. Appendix B contains the detailed results of thin-section analysis, and Tables 6 and 7 summarize those results. Modal percentages of aggregate mineralogy were estimated visually and should be treated as approximate values.

This section summarizes general observations made during thin-section analysis. Sections that follow provide individual sample descriptions, grouped by treatment type. The invert and shotcrete samples can be distinguished by their aggregate size and mineralogy, and only somewhat by the percentage of grout in the sample.

Both shotcrete and invert have bimodal distributions of aggregate size. In the invert case, the two sizes arc explicitly defined. In the case of the shotcrete, one size fraction (fine aggregate) is defined. The biomodal distribution is an implicit characteristic of the original fine aggregate. The scale of that size distribution is quite different for the invert aggregate than for the shotcrete. Although coarse and fine size groupings were determined on a sample-by-sample basis (a 3-mm grain might be grouped with the fine aggregate in one sample, and with the coarse aggregate in another sample) invert coarse aggregate is approximately 12 to $3 \mathrm{~mm}$, and fine aggregate is 4 to $0.05 \mathrm{~mm}$, whereas shotcrete coarse aggregate is 2.25 to $0.5 \mathrm{~mm}$, and fine aggregate is 0.2 to $0.05 \mathrm{~mm}$. Estimates of grain size are included in Appendix B.

Aggregate mineralogy varies greatly between invert and shotcrete samples, but is less variable within those groupings. Table 6 is a summary of aggregate mineralogy. The invert aggregate consists mostly of carbonate minerals, whereas shotcrete aggregate consists mostly of silicate minerals, such as quartz and feldspar. The invert aggregate consists of 80 to $100 \%$ carbonate, 5 to $20 \%$ $\mathrm{SiO}_{2}$ phases (quartz, quartz-bearing lithic fragments, and chert), and $1 \%$ or less of hematite and other opaque phases (Table 6 and Appendix B). Shotcrete aggregate has a more diverse mineralogy and consists of 80 to $90 \%$ silicate minerals ( $\mathrm{SiO}_{2}$ phases and feldspar), 5 to $15 \%$ carbonate, 3 to $18 \%$ lithic fragments and biotite, and 1 to $10 \%$ accessory phases (Table 6 and Appendix B).

The percentage of grout visible in a thin section can be affected by several factors. Invert samples can appear to have less grout if several, large aggregate grains dominate the thin section. Similarly, shotcrete samples can appear to have less grout if aggregate grains dominate the thin section (shotcrete can be stratified due to the way it is applied to the tunnel wall). The grout fraction estimated for each sample should be viewed in light of the abovementioned factors. Invert samples showed 20 to $50 \%$ grout, and shotcrete samples exhibited 48 to $55 \%$ grout (Appendix B).

In the discussion that follows, unique features of each thin section are described. These features are derived from Appendix B and summarized in Table 7. A brief description of the features is given here. Birefringent rims on grains are typically thin, less than one-one hundredth of a millimeter. We were unable to determine the identity of these phases that make up the birefringent rins by light optical methods. Buff-colored grout has the optical propertics of normal grout and only differs in color. Clouded brown grout differs from normal grout in that it is nearly opaque. Blotchy grout consists of irregularly alternating patches of bright, birefringent grout, and brown cloudy grout.

Both vapor and aqueous invert samples exposed to the $1 \mathrm{M} \mathrm{NaCl}$ solution exhibit birefringent rims on some quartz. and carbonate grains, clouded brown grout, and blotchy grout. The vapor shotcrete sample exhibited birefringent rims around some quartz, feldspar, and carbonate grains, and clouded brown grout.

All $\mathrm{NaHCO}_{3}$-treated samples exhibit buff-colored grout. Invert samples exposed to both vapor and aqueous treatments exhibited birefringent rims on some quartz and carbonate grains, clouded brown grout, and blotchy grout. The vapor shotcrete sample exhibited birefringent rims around some quartz and feldspar grains.

Both invert samples thermally treated under "dry" conditions showed birefringent rims on some quartz and carbonate grains. Only one of the invert samples, INV-24, showed clouded brown grout. The shotcrete sample showed birefringent rims on quartz and feldspar grains, and brown cloudy grout.

In comparison to the treated samples, the untreated invert sample showed birefringent rims on quartz and carbonate grains, and clouded, brown grout. The untreated shotcrete sample showed birefringent rims on quartz and feldspar grains. 
Table 6. Estimated modal percentages of phases observed in Batch 1 samples under petrologic microscope.

\begin{tabular}{|c|c|c|c|c|c|c|c|c|c|c|c|c|c|c|c|c|c|c|c|c|}
\hline & \multicolumn{12}{|c|}{ Invert sample numbers } & \multicolumn{8}{|c|}{ Shotcrete sample numbers } \\
\hline & c & $f$ & c & $f$ & $\frac{25^{b}}{f}$ & c & $f$ & c & $\mathbf{f}$ & $\frac{26^{b}}{f}$ & c & $\mathbf{f}$ & c & $f$ & c & $f$ & c & $\mathbf{f}$ & c & $t$ \\
\hline $\mathrm{SiO}_{2}$ phases $^{c}$ & & 10 & & 10 & 5 & & 20 & & 10 & 15 & & 15 & 40 & 50 & 45 & 72 & 35 & 50 & 50 & 50 \\
\hline Feldspar & & & & & & & & & & & & & 40 & 20 & 35 & 10 & 50 & 25 & 21 & 40 \\
\hline Lithics & & & & & & & & & & & & & 6 & & 2 & 5 & 2 & & 17 & \\
\hline Biotite & & & & & & & & & & & & & 3 & 10 & 1 & & 5 & 8 & 1 & 5 \\
\hline Opaques' & & & & & & & & & 1 & 1 & & 1 & & 1 & & 1 & & 2 & & 1 \\
\hline Pyroxene & & & & & & & & & & & & & & 1 & & 1 & & 2 & & 2 \\
\hline Epidote & & & & & & & & & & & & & & & & & & & & 1 \\
\hline Zircon & & & & & & & & & & & & & & 1 & & & & 1 & & \\
\hline Muscovite & & & & & & & & & & & & & & & & & & 2 & & \\
\hline Chlorite & & & & & & & & & & & & & 1 & 1 & & & & 2 & & \\
\hline Clinozoisite & & & & & & & & & & & & & & 1 & & & & & & \\
\hline $\begin{array}{r}\text { Numbers } \\
c=c \\
f=f i\end{array}$ & $\begin{array}{l}\text { ese } \\
\text { se-s } \\
\text { srain }\end{array}$ & $\begin{array}{l}\text { the e } \\
\text { ined f } \\
\text { d frac }\end{array}$ & $\begin{array}{l}\text { mate } \\
\text { ction } \\
\text { n of }\end{array}$ & nod & serce & of ec & ch phe & obs & ed in & & ise o & ine as & & f the & $\mathrm{mpl}$ & & & & & \\
\hline These sam & les did & ot $\mathrm{Cc}$ & tain c & arse a & ggrega & & & & & & & & & & & & & & & \\
\hline $\mathrm{SiO}_{2}$ phas & inclue & quar & , cher & quar & zite an & quart & sanc & one lit & $=$ fras & nents. & & & & & & & & & & \\
\hline
\end{tabular}

\subsection{SEM}

Scanning Electron Microscopy (SEM) was conducted using a Hitachi S-800 FESEM with Tracor Northern Energy Dispersive Spectral analysis (EDS). Appendix A contains analysis point sketch maps that allow the reader to spatially relate the SEM analysis points discussed in the text below to figure numbers, and to relate features observed at light microscope magnifications to features observed at SEM scales. The SEM photomicrographs are presented in Figures 25-86.The samples were coated to eliminate charging. Palladium was chosen so as not to interfere with the chemical analysis. The Pd signature is visible in the chemical spectra (e.g., Figure 57 and Figure 58) of some of the more thickly coated samples.
To obtain quantitative information from the EDS it is essential to use well characterized standards. The ratio of signal intensities is not directly proportional to the ratio of concentrations of the related elements in the chemical profile of a single mineral. That ratio (often referred to as the $\mathrm{K}$ ratio) varies, proportional to the atomic number, and must be determined for a particular machine and particular settings using the well characterized and chemically appropriate standards. However, these $\mathrm{K}$ ratios are only accurate in the case of a flat sample; because of the relief inherent in our samples, we question the benefit of a completely quantitative approach at this point in our investigation. In contrast, this study uses the chemical information from the EDS in a qualitative manner in order to distinguish trends that should be pursued in further studies, and in particular, for this study as potential support to our solutions to XRD spectra. For our interpretations we only assume that for a given instrument and sctting (i.e., an undetermined but singular set of $\mathrm{K}$ ratios) we can, 
Table 7. Batch 1 concrete experiments: Thin-section observations.

\begin{tabular}{|c|c|c|c|c|c|c|}
\hline $\begin{array}{l}\text { Sample number } \\
\text { and treatment }\end{array}$ & Qtz * & Fsp " & Carb " & $\begin{array}{l}\text { Buff-colored } \\
\text { cement }\end{array}$ & $\begin{array}{l}\text { Clouded, brown } \\
\text { cement }\end{array}$ & $\begin{array}{c}\text { Blotchy cement } \\
\text { (brown/birefringent) }\end{array}$ \\
\hline INV-20, untreated & $\checkmark$ & & $\checkmark$ & & $\checkmark$ & \\
\hline $\mathrm{SH} \cdot 12$, untreated & 18 & s. & & & s. & \\
\hline $\mathrm{SH}-1, \mathrm{dry}$ & $\checkmark$ & $\checkmark$ & & & $\checkmark$ & \\
\hline $\mathrm{INV}-24, \mathrm{dr}$ : & $\checkmark$ & ? & $\checkmark$ & & $\checkmark$ & 8 \\
\hline INV-25, dry & $\checkmark$ & & $\mathcal{S}$ & & & \\
\hline $\mathrm{SH} 2 \mathrm{2} \mathrm{NaH} / \mathrm{CO}, \mathrm{r}, \mathrm{vapor}$ & s. & 8. & & s. & / & \\
\hline INV-26 $\mathrm{NaHCO}_{3}$, liquid & $\checkmark$ & & $\checkmark$ & $\checkmark$ & $\checkmark$ & $\checkmark$ \\
\hline INV 27 NaHCCO, vapor & t. & & r. & s. & s. & v. \\
\hline SH-5 NaCl, vapor & $\checkmark$ & $\checkmark$ & $\checkmark$ & & $\checkmark$ & \\
\hline MV 17 NaCl, llagid & s. & & r. & & \% & r. \\
\hline INV-18 NaCl, vapor & $\checkmark$ & & $\checkmark$ & & $\checkmark$ & $\checkmark$ \\
\hline
\end{tabular}

- Birefringent rims were observed on some of these grains. Qtz = quartz; Fsp = potassium feldspar and plagioclase feldspar; $\mathrm{Carb}=$ carbonate minerals and lithic fragments, such as limestone. Birefringent rims were more common on $\mathrm{SH}-2$ than on $\mathrm{SH}-1$ and were more common on SH-5 than on SH-2. Note: invert samples do not contain feldspar aggregate grains.

by comparing the chemical signature of one mineral to that of another, obtain a qualitative understanding of the relative concentrations of the associated elements in the two minerals.

We expect to resolve carbon and oxygen because the lower detection limit of the EDS system is below atomic number 14. Even though the uncertainty of the EDS signal as a function of the angle of the sample surface increases with decreasing atomic number, and thus the carbon and oxygen signals are even more uncertain than those of elements with higher atomic number in these samples, we pay particular attention to these elements as significant evidence of the formation of secondary carbonate and hydrate phases. The relative ratios of intensities are therefore interpreted qualitatively as representative of relatively higher or lower concentrations of particular elements from sample to sample. In particular, quantities of carbon and oxygen are discussed as evidence in support of the presence of a particular hydrate or carbonate phase also detected by other techniques such as XRD.

\subsubsection{Treated Samples, Dry}

\section{Batch 1}

SEM analysis of the Batch 1 dry-treated samples is documented in Meike et al. (1997), Figures 53 through 63.

\section{Batch 2}

Invert. In general, the surface alteration of INV-37 (PV-13-37) appears as localized rings of $\mathrm{Ca}$-Si-hydrate crystallites. Figure 25a is an SEM photomicrograph of an aggregate grain, showing reaction phases around the rim. EDS suggests that the grain is carbonate (Figure 25b). The reaction phases are illustrated at higher magnification in Figures 26a, 27a, and 28a. One of the ring-forming phases is needle-shaped (Figure 26a), and one is bladed (Figure 27a). The two phases have similar EDS signatures (Figure $26 \mathrm{~b}$ and Figure $27 \mathrm{~b}$ ), potentially differentiated by the abundance of $\mathrm{Ca}$.

At least two other possible alteration phases can be identified in the grout and on grain surfaces. Figure 29a is an SEM photomicrograph of stubby crystals that formed outside of the grain, in the grout, to the left of the phase in Figure 27a. EDS indicates the presence of $\mathrm{Ca}$ with minor 
amounts of $\mathrm{Si}$ and $\mathrm{O}$, which is similar to the EDS signature of unaltered grout (Figure 27c). Also occurring on the sample is a thin, stringy reaction phase (Figure 28a) that occurs on the surface of the grain, inboard of the needle-like and bladed crystals shown in Figures 26a and 27a. EDS indicates nearly equal amounts of $\mathrm{Si}$ and $\mathrm{Ca}$, with minor amounts of $\mathrm{O}, \mathrm{K}, \mathrm{C}$, and $\mathrm{Al}$, which is fairly distinct from the phases that rim the grain.

The surface alteration of INV-38 (PV-13-38) is similar to that of INV-37 in that the majority of the reaction phases occur at grain boundaries and form rings of alteration around the grain. The alteration phases that rim aggregate grains are similar in morphology and composition to those that rim grains in sample INV-37. Photomicrographs shown in Figures 30 through 34 illustrate the three morphologies of the grain-rimming phases: needle shaped, tabular, and fibrous. The aggregate grains in Figure 30 and Figure 32 are quartz or some other silica-bearing phase (Figure $30 \mathrm{~b}$ and Figure $32 \mathrm{~b}$ ). The ratios of $\mathrm{Si}, \mathrm{Ca}$, and $\mathrm{K}$ are fairly similar in the grout outside the two aggregate grains (Figure 30c and Figure 32c). The reaction phases rimming the grains include needle-shaped, tabular, and fibrous, all with a calcium silicate composition. The tabular phases (Figure 31a and Figure 32a) rimming the grains have a similar $\mathrm{Ca}: \mathrm{Si}$ ratio (Figure $31 \mathrm{c}$ and Figure 32d). Figure 33 and Figure 34 illustrate more examples of the needle-shaped and fibrous morphologies, with EDS of the material on either side of the reaction phases.

Shotcrete. The surface alteration on sample SH-9 (PV-13-9) is similar to that in the other dry treated samples. Several Ca-Si phases occur as alteration rims on grain boundaries, and several occur on grout. This sample also has a steel fiber that shows no reaction phases or alteration (Figure 35) and a carbonate phase that occurs in and around the drilled-out hole in the center of the sample (Figure 36). Feldspar grains were found both with reaction phases (Figure 37) and without (Figure 38 and Figure 39).

Approximately six $\mathrm{Ca}-\mathrm{Si}$ alteration phases occur on aggregate or at the aggregate/grout boundary. Figure 40a is an SEM photomicrograph of a tiny tabular phase (see center of photo). EDS of the area (Figure 40b) indicates that the tabular phase has precipitated on a quartz or other $\mathrm{SiO}_{2}$-bearing aggregate grain. The aggregate grain likely makes up the majority of the $x$-ray volume. Figure $40 \mathrm{c}$ is an SEM photomicrograph of the tabular phase at higher magnification. EDS of the tabular phase (Fig 40d) indicates the presence of $\mathrm{Si}, \mathrm{O}$, and $\mathrm{Al}$, with minor amounts of $\mathrm{Ca}$. The underlying grain likely contributes most of the signal in this spectrum. Figures $41 c, 42 c$, and 43a show Ca-Si phases with a fine, stringy morphology. The phase was most commonly found in the center of an aggregate grain with a reaction rim and is similar to a phase seen on Batch 1 sample SH-1, areas 2 and 7 . This phase occurs on a variety of substrates, such as feldspar and quartz or other $\mathrm{SiO}_{2}$ phases.

Figures 44 through 47 illustrate four more $\mathrm{Ca}-\mathrm{Si}$ phases that occur at grain boundaries. Figure 44a is an SEM photomicrograph of an aggregate grain with a white, stringy reaction phase and band of black glassy material. EDS of the aggregate grain indicates that it is quartz or some other $\mathrm{SiO}_{2}$ phase. At higher magnification (Figure 45c), the white, stringy reaction phase shown in Figure 44a appears threadlike. EDS of the glassy phase (Figure 45b), possibly the result of an alkali/silica reaction (see, e.g., Taylor, 1990) between the $\mathrm{SiO}_{2}$ phase and the grout, indicates the presence of $\mathrm{Si}$ and $\mathrm{O}$, with minor amounts of $\mathrm{Ca}, \mathrm{K}, \mathrm{Al}$, and $\mathrm{Na}$. Figure 46 is an aggregate grain with at least two different phases occurring at the grain boundary. Figure 46a illustrates a tabular phase, and Figure $46 \mathrm{c}$ shows a spindleshaped phase. The two phases have distinctly different $\mathrm{Ca}: \mathrm{Si}$ ratios (Figure 46b and Figure 46d). Figure 42a illustrates a tabular reaction phase found on a plagioclase grain boundary (same grain as in Figure 37). The morphology differs from the tabular phase in Figure 46; the phase illustrated in Figure 42 has pointed, serrated tips. EDS (Figure 42b) indicates the presence of $\mathrm{Si}, \mathrm{Ca}, \mathrm{O}, \mathrm{Al}$, and $\mathrm{K}$, with possible minor amounts of $\mathrm{Na}$ and $\mathrm{Fe}$.

Figure 47a is an SEM photomicrograph of a fcathery, radiating reaction phase, with a less-developed example in the upper left corner. The phase is shown at higher magnification in Figure 47b. The radiating feathers were transparent at higher magnification and could be as thin as 6 to 10 atom layers. An EDS of the more developed phase (Figure 47c), measured from the center of the phase, indicates the presence of $\mathrm{Si}, \mathrm{Ca}$, and $\mathrm{O}$, with minor amounts of $\mathrm{Al}$. Figure $47 \mathrm{~d}$ is a photomicrograph of the less-developed example.

Two Ca-Si phases occur on grout, in the absence of a grain boundary. Figure 48a is a photomicrograph of acicular crystals that occur in a pit in grout (the pit is shown in Figure 49a). EDS of the acicular crystals (Figure 48b) indicates the presence of $\mathrm{Si}, \mathrm{O}, \mathrm{Al}$, and $\mathrm{Ca}$, with minor amounts of $\mathrm{K}$ and $\mathrm{Na}$. Figure 50a is an SEM photomicrograph of a thin veneer of a bladed secondary phase. The 
crystals do not appear to be on a grain boundary, and were observed elsewhere on the sample. EDS (Figure 50b) indicates the presence of $\mathrm{Si}, \mathrm{Ca}$, and $\mathrm{O}$, with minor amounts of $\mathrm{Al}$ and $\mathrm{K}$. A significant portion of the spectrum may have been contributed by the underlying material because the veneer of crystals is thin and sparse.

\subsubsection{Treated Samples, $1 \mathrm{M} \mathrm{NaHCO}_{3}$ Solution}

\section{Batch 1}

SEM analysis of the Batch $1 \mathrm{NaHCO}_{3}$-treated samples is documented in Meike et al. (1997), Figures 30 through 52.

\section{Batch 2}

Invert. Aqueous treatment. The sides of sample INV23A (PV-18-23a) wcrc sufficiently different that we surveyed both sides and discuss them separately as side 1 and side 2. No Ca-Si crystallites occur on the sample's surface.

Side 1 had an abundance of white crust coating most of the surface, on which at least four morphological textures can be abserved (Figure 51a). One of these phases (Figure 51b) resembles fibrous clumps. EDS of the fibrous phase (Figure 51c) suggests the presence of $\mathrm{Si}, \mathrm{Cl}, \mathrm{Na}$, and $\mathrm{O}$. A second phase that occurs in the white crust is a globuleshape (Figure 52a), and EDS (Figure 52b) suggests the presence of $\mathrm{Si}, \mathrm{O}, \mathrm{Na}, \mathrm{Al}$, and $\mathrm{Cl}$. A third phase (Figure 52c) is typical of the smoother areas of the white crust, and EDS (Fig 52d) suggests the presence of $\mathrm{Si}, \mathrm{Cl}, \mathrm{Na}$, and $\mathrm{O}$. Figure 53a is an SEM photomicrograph of a rhombohedron poking through the white crust. EDS of the rhombohedron (Figure 53b) suggests the presence of $\mathrm{Ca}, \mathrm{Si}, \mathrm{O}, \mathrm{Cl}$, and $\mathrm{Na}$. Figures 54a and 54b illustrate two acicular phases that occur in the crust. EDS of the phase shown in Figure 54b suggests the presence of $\mathrm{O}, \mathrm{Na}$, and $\mathrm{Si}$. Figure 55a is an SEM photomicrograph of a needleshaped phase that has a square cross-sectional shape. EDS (Figure 55b) of the needle-shaped phase, where it occurs on an aggregate grain, suggests the presence of $\mathrm{O}, \mathrm{Na}$, and $\mathrm{Si}$. EDS (Figure 55c) of an area adjacent to the needleshaped phase suggests the presence of $\mathrm{O}, \mathrm{Na}$, and $\mathrm{Si}$.

On side 2, white crust is only evident around the drilledout central hole of sample INV-23A (PV-18-23a). The remainder of the surface is fairly homogeneous. In a typical view of the surface (Figure 56a), trapezohedral and rhombohedron phases, as well as a third smaller phase, are observed in the ground mass. EDS of the trapezohedral crystals (Figure 56b) suggests the presence of $\mathrm{Si}, \mathrm{O}, \mathrm{Al}$, and $\mathrm{Na}$, and could be analcime. EDS of the rhombohedral crystals (Figure 56c) suggests a calcite composition. EDS of the tiny crystals in the ground mass (not shown) also suggests a calcite composition.

Five Na-bearing phases are also present on this sample. Figure 57a is an SEM photomicrograph of a fine, radiating crystalline phase. EDS of the phase (Figure 57b) suggests the presence of $\mathrm{O}, \mathrm{Na}$, and $\mathrm{Cl}$. Figure 58a is an SEM photomicrograph of a radiating phase. EDS of the radiating phase (Figure 58b) suggests the presence of $O$ and $\mathrm{Na}$. At lower magnification (Figure 58c), the radiating phase is observed in mats between the abundant trapezohedrons. Figure 59a is an SEM photomicrograph of a lath-shaped phase at low magnification. Figure 59b shows the lath-shaped phase at higher magnification and reveals a mound of spike-shaped crystals. EDS of this phase (Figure 59c) suggests the presence of $\mathrm{O}$ and $\mathrm{Na}$. Figure $60 \mathrm{a}$ is an SEM photomicrograph of a $2-$ to $3-\mathrm{mm}$ plate on the sample that contains lath-shaped crystals and trapezohedrons. The plate sits higher than the surrounding surface. EDS of a clear area of the plate (Figure 60b) suggests the presence of $\mathrm{Si}, \mathrm{O}, \mathrm{Na}$, and $\mathrm{Cl}$. Figure $60 \mathrm{c}$ shows trapezohedrons within a web of feathery crystals. EDS of the feathery web-like (Figure 60d) crystals suggests $\mathrm{O}, \mathrm{Na}$, and $\mathrm{Cl}$.

Invert. Vapor treatment. In general, the surface alteration of INV-23b (PV-18-23b) appears as patches of euhedral carbonate rhombs on grout and, less commonly, crystal clusters on grout. Photomicrographs and EDS of grout in this sample from two areas yielded consistent results (Figures 61-63). The euhedral carbonate rhombs are shown in Figure 64. A lower-magnification photomicrograph in Figure 62b illustrates the patches of rhombs. The crystal clusters occur in a pit in the grout and are shown in Figure 65. Because this phase is in a pit, all of the $\mathrm{x}$ rays generated by the beam may not reach the detector (the pit walls may block some of the $\mathrm{x}$-rays' path to the detector).

Shotcrete. Vapor treatment. The surface alteration of $\mathrm{SH}-10$ (PV-18-10) varies widely. At least two $\mathrm{Ca}-\mathrm{Si}$ bearing phases, three carbonate phases, one $\mathrm{Si}-\mathrm{O}$, two $\mathrm{Na}-\mathrm{O}$ phases, and three others occur sparsely on the sample. A steel fiber is present in this sample. Figure 66a illustrates the steel fiber. At higher magnification (Figure $66 \mathrm{~b}$ ), a coating of platy crystals is observed covering the steel fiber. The EDS of the fiber surface (Figure 66c) shows a high Fe peak, as well as $\mathrm{Si}, \mathrm{O}$, and $\mathrm{K}$, possibly 
contributed by the platy phase. The crystals are similar in morphology (but not composition) to Batch 1, sample SH1 , area 4 . The three round crystal clusters near the center of the Figure 66a were some of several found near the steel fiber. Other examples are shown in greater detail in Figure 67a. The clusters in Figure 67a occur on the fiber and have EDS spectra similar to those of the platy phase. Not all of the clusters occur on the fiber. Three carbonate phases occur on the rim of the steel fiber, each with a slightly different morphology (Figure 67c and Figure 68). Figure 68 illustrates grains with the rounded appearance common to dissolution features.

Another carbonate phase is shown in Figure 69a. It appears as tiny, euhedral rhombs on grout and is fairly widespread on the sample. The two $\mathrm{Na}-\mathrm{O}$ phases have very different morphologies. One is a honeycomb-like mineral (Figure 70a) that occurs on an unknown substrate adjacent to the metal fiber. At higher magnification, this phase is similar to Batch 1, sample SH-2, area 1. EDS (Figure 70b) suggests the presence of $\mathrm{O}, \mathrm{Na}, \mathrm{Ca}, \mathrm{K}, \mathrm{Cl}, \mathrm{Si}, \mathrm{Al}$, and $\mathrm{C}$. This composition is similar to Batch 1 , sample $\mathrm{SH}-2$, area 1 , which contains $\mathrm{Na}, \mathrm{O}, \mathrm{C}, \mathrm{S}, \mathrm{Cl}, \mathrm{Si}$, and $\mathrm{Ca}$. The other $\mathrm{Na}-\mathrm{O}$ phase, shown in Figure 71a and Figure 71b, occurs in a band along a grain boundary. EDS of this phase (Figure 71c) is slightly different and indicates the presence of $\mathrm{O}, \mathrm{Na}, \mathrm{C}$, and $\mathrm{Si}$, with possible $\mathrm{Al}$.

Figure 72 illustrates tiny, euhedral crystals that occur on grout. EDS (Figure 72c) suggests that the crystals could be quartz or some other $\mathrm{Si}-\mathrm{O}$ phase. The two $\mathrm{Ca}-\mathrm{Si}$ phases are shown in Figure 73 and Figure 74. They have a fairly similar morphology, and both occur on grout. EDS (Figure 73c and Figure 74b) indicates that one could have a higher $\mathrm{Ca}-\mathrm{Si}$ ratio than the other.

\subsubsection{Treated Samples, $1 \mathrm{M} \mathrm{NaCl}$ Solution}

\section{Batch 1}

SEM analysis of the Batch $1 \mathrm{NaCl}$-treated samples is documented in Meike et al. (1997), Figures 1 through 29.

\section{Batch 2}

Invert. Aqueous treatment. Surface alteration of sample INV-21 (PV-7-21) is homogeneous. Figure 75a illustrates the three phases that are common throughout the sample. One is a faceted, euhedral phase that occurs more densely on aggregate and has a carbonate composition (Figure 75b). Crystals of a smaller rhombohedral phase that occurs on the aggregate grain, and a platy phase that occurs on grout, are also observed. Higher magnification of the rhombohedral and platy phases is shown in Figure 76. Figure 76a demonstrates the small, platy phase that occurs on grout. Note the serrated edges on the plates. This phase occurs in random orientations and sometimes is clustered into rosettes. EDS of the platy phase (Figure $76 \mathrm{~b}$ ) indicates the presence of $\mathrm{Cl}, \mathrm{Ca}, \mathrm{Si}, \mathrm{Na}$, and $\mathrm{O}$. The smaller, rhombohedral phase appears on aggregate grains (Figure 76c) and has an EDS (Figure 76d) that indicates the presence of $\mathrm{Ca}$, $\mathrm{Si}, \mathrm{O}$, and $\mathrm{C}$. The $\mathrm{Ca}: \mathrm{Si}$ ratio of the platy phase and the rhombohedral phase differ. In addition, $\mathrm{Cl}$ is indicated in association with the platy phase and not with the rhombohedral phase. Also present on this sample are several clusters of crystals with long, thin, radiating spines (Figure 77a). At higher magnification, cubic crystals are visible in the center of the cluster. EDS of the cluster center (Figure $77 \mathrm{~b})$ suggests the presence of $\mathrm{Ca}, \mathrm{Si}$, and $\mathrm{O}$.

Invert. Vapor treatment. Raised Ca-Si crystallite reaction rims characterize the surface alteration of sample INV-36 (PV-7-36). In Figure 78a, rims within and around an aggregate grain can be observed. A large aggregate grain is visible in the upper portion of the photomicrograph. The grain has two, faint rings of secondary phases within it, and a ring on the grain edge. Grout is present in the lower portion of the photomicrograph. The small aggregate grain imbedded in the grout is surrounded by a thick ring of secondary phase. EDS of the ring around the small aggregate grain (Figure $78 \mathrm{~b}$ ) suggests the presence of $\mathrm{Si}, \mathrm{Ca}, \mathrm{O}, \mathrm{K}$, and $\mathrm{Cl}$. EDS of the small grain center (not shown) suggests that it is quartz or another phase of $\mathrm{SiO}_{2}$ composition. The ring is illustrated at higher magnification in Figure 78c. EDS of one of the two faint rings within the large aggregate grain (Figure 78d) suggests the presence of $\mathrm{Si}, \mathrm{Ca}, \mathrm{O}, \mathrm{K}$, and $\mathrm{Cl}$. EDS of several grains elsewhere on the sample with thick reaction rims suggests that it is quartz or another phase of $\mathrm{SiO}_{2}$ composition. Several calcite grains were observed with no reaction rims. EDS analyses for these results are not shown.

Other examples of $\mathrm{Ca}-\mathrm{Si}$ crystallite grain boundary phases are shown in Figure 79c and Figure 80. Figure 79c illustrates platy crystals with serrated edges. EDS (Figure 79d) suggests the presence of $\mathrm{Ca}, \mathrm{Si}, \mathrm{O}$, and $\mathrm{K}$ EDS of the aggregate grain center (not shown) indicates a calcite composition. Figure 80a shows another platy phase with serrated edges. Outboard of that (with respect to the grain) is a mat of long, thin, straight crystals. EDS of the platy 
crystals (Figure 80b) suggests the presence of $\mathrm{Si}, \mathrm{Ca}, \mathrm{O}, \mathrm{K}$, and $\mathrm{Cl}$, and substantially different $\mathrm{Ca}: \mathrm{Si}$ ratio from that of the other platy phase.

Other alteration products on sample INV-36 include two phases that occur on aggregate. Figure 79a is an SEM photomicrograph of tiny crystal clusters with radiating spines. EDS (Figure 79b) suggests the presence of $\mathrm{Si}, \mathrm{Ca}$, and $\mathrm{O}$. Figure 81 a shows a mat of thin, curly, fibrous crystals that coat the interior of the aggregate grain. EDS of the mat of crystals (Figure 81b) suggests the presence of $\mathrm{Si}, \mathrm{K}, \mathrm{Ca}, \mathrm{Cl}$, and $\mathrm{O}$. We were unable to determine how thick the mat is or what the underlying grain is. Several of these thick mats occur on grain centers throughout the sample.

Shotcrete. Vapor treatment. Sample SH-13 (PV-7-13) is nearly coated with surfacc alteration composed of up to eight types of $\mathrm{Ca}-\mathrm{Si}$ crystallites. Several morphologies of crystals are visible on the surface of the sample at relatively low magnification (Figure 82a), including ribbon-shaped, tabular, needle-shaped, and fibrous. A ribbon-shaped phase (Figure 82b) occurs on grout or very fine aggregate. EDS of the ribbon-shaped phase (Figure 82c) suggests the presence of $\mathrm{Si}, \mathrm{Ca}, \mathrm{O}, \mathrm{Cl}$, and $\mathrm{Al}$. Tabular crystals with serrated tips (Figure 83a) appear as part of a larger cluster, not part of a distinctive ring around a grain. EDS

(Figure 83b) suggests the presence of $\mathrm{Si}, \mathrm{Ca}, \mathrm{Al}, \mathrm{Cl}, \mathrm{K}$, and $\mathrm{O}$, with a different $\mathrm{Ca}: \mathrm{Si}$ ratio than that in the ribbonshaped phase. Also within that same cluster is a mat of thin, straight, long crystals (Figure 83c). EDS of that phase (Figure 83d) suggests the presence of $\mathrm{Si}, \mathrm{Ca}, \mathrm{K}, \mathrm{Cl}$, and $\mathrm{O}$.

Figures $84 \mathrm{a}$ and $85 \mathrm{a}$ illustrate phases that occur on the interior of aggregate grains. Figure 84 a is an SEM photomicrograph of a fibrous mass of crystals that cover the interior of an aggregate grain. EDS (Figure 84b) suggests the presence of $\mathrm{Si}, \mathrm{Al}, \mathrm{Ca}, \mathrm{O}, \mathrm{K}$, and $\mathrm{Cl}$. Jagged, tabular crystals (Figure 85a) occur on the surface of an aggregate grain. EDS of the tabular phase (Figure 85b) suggests the presence of $\mathrm{Si}, \mathrm{Ca}, \mathrm{K}, \mathrm{Cl}$, and $\mathrm{O}$. EDS of the aggregate grain (not shown) indicates a quartz composition.

Needle-shaped crystals (Figure 84c) form a thick ring around an aggregate grain. This phase also forms mounds, with no aggregate grain visible (the grain could be small and obscured by the thick ring). EDS of the needle-shaped crystals (Figure 84d) suggests the presence of $\mathrm{Si}, \mathrm{Ca}, \mathrm{O}, \mathrm{Cl}$, and $\mathrm{K}$. Figure $85 \mathrm{c}$ is an SEM photomicrograph of tiny rhombs on the surface of an aggregate grain rimmed by a thick, needle-shaped phase. EDS of the needle shaped phase (Figure 85d) suggests the presence of $\mathrm{Ca}, \mathrm{Si}$, and $\mathrm{O}$. It is possible that the rhombs are calcite on a quartz (or other $\mathrm{SiO}_{2}$ phase) aggregate grain, and that the thick phase on the rim absorbs the $\mathrm{C}$ and $\mathrm{O} x$-rays. Figure 86a is an SEM photomicrograph of a rosette cluster of platy crystals. EDS (Figure 86b) suggests the presence of $\mathrm{Si}$, $\mathrm{Ca}, \mathrm{O}$, and $\mathrm{K}$. We were unable to determine if this phase occurs on grout or aggregate. Approximately six of these clusters are scattered locally, in contact with the thick rims of needle-shaped crystals.

\subsubsection{Untreated Samples}

SEM analysis of untreated Fibercrete ${ }^{\mathrm{TM}}$, sample SH- 8 , is documented in Meike et al. (1997), Figures 64 through 68. SEM analysis of untreated invert, INV-20, is also documented in Meike et al. (1997), Figures 69 through 73.

\subsection{Glancing-Angle X-Ray DIFFRACTION}

Glancing-angle $x$-ray diffraction (XRD) emphasizes the surface mineralogy, but does not distinguish between primary and secondary phases. Thin-section, SEM, and untreated sample data clarify the distinction between aggregate and secondary phases.

The results of glancing-angle XRD analysis are summarized in Table 8 (pages 18-21). In this table, aggregate is not distinguished from secondary phases. However, phases found in the aggregate are located at the top of the table, and possible secondary phases are found toward the middle of the table (including $\mathrm{Ca}$-Si-hydrate phases). Phases associated with evaporated water droplets are found on the bottom of the table. Comparison of these data with thin-section results and the spectra from untreated samples allows us to distinguish between aggregate and secondary phases. Evidence of increasing intensity of a phase with treatment time and correlation with SEM photographs also support our interpretations. Calcite and quartz are present as aggregate in most of the samples. Dolomite occurs in the invert samples. Taramite is also associated with the aggregate. 


\subsubsection{Treated Samples, $1 \mathrm{M} \mathrm{NaCl}$ Solution}

Glancing-angle spectra of Batch 1 samples are documented in Meike et al. (1997). Salient features of these samples seem to be the occurrence of scawtite and killalite in the invert aqueous treatment and the shotcrete vapor treatment. Scawtite and killalite are Ca-Si-carbonate phases. Tobermorite may be present in the $\mathrm{NaCl}$ vapor treatment of both shotcrete and invert.

\subsubsection{Treated Samples, $1 \mathrm{M} \mathrm{NaHCO}$ Solution}

Glancing-angle spectra of Batch 1 samples are documented in Meike et al. (1997). Analcime occurs as a secondary phase in the aqueous $\mathrm{NaHCO}_{3}$ treatment of the invert.

\subsubsection{Treated Samples, Dry}

Glancing-angle spectra of Batch 1 samples are documented in Meike et al. (1997). Very little can be distinguished using glancing-angle XRD techniques on this sample. Given the paucity of secondary phases observed using SEM, this is no surprise. There is some suggestion of the occurrence of tobermorite in the shotcrete, dry treatment sample.

\subsubsection{Untreated Samples}

Glancing-angle XRD analysis of untreated samples is documented in Meike et al. (1997).

\subsection{Powder X-Ray Diffraction}

Powder $\mathbf{x}$-ray diffraction analysis of untreated samples is documented in Meike et al. (1997).

\subsection{Mechanical Tests}

Mechanical tests have been conducted in compression, and the results are shown in Table 9. When mechanically testing heterogeneous samples, it is common practice to choose a sample size large enough that the scale renders the sample essentially homogeneous. However, because the treatment may not have permeated a larger sample, our sample size was necessarily small to allow the desired chemical effects to permeate the sample in the allotted period of time. As a result of this choice of smaller sample size, the samples cannot be viewed as essentially homogeneous for the purpose of this experiment. The data, especially for the most heterogeneous invert samples, are expected to exhibit a fair amount of scatter. Given the apparent increases in strength suggested by these data, experiments on ASI'M standard samples would be recommended, if time permits (at least two to three years could be required to achieve the equivalent fully permeated chemical effects in an ASTM standard size sample).

Table 9. Mechanical tests comparing Batch 1 and Batch 2. Failure load is in pounds of force.

\begin{tabular}{llrr}
\hline & & \multicolumn{2}{c}{ Failure load } \\
\cline { 3 - 4 } Treatment & & Batch 1 & Batch 2 \\
\hline Untreated & Invert & 234 & \\
& Shotcrete & 80 & \\
Dry & INV, vapor & 90 & 258 \\
& INV, vapor & 65 & 248 \\
\multirow{2}{*}{ NaHCO 3} & INV, aqueous & 87 & 390 \\
& SH, vapor & 75 & 137 \\
& INV, vapor & 174 & 709 \\
& SH, vapor & 258 & 446 \\
\cline { 2 - 2 } & INV, aqueous & 137 & 264 \\
& INV, vapor & 129 & 145 \\
& SH, vapor & 78 & a
\end{tabular}

a Broken during handling. 
Table 8. Summary of phases identified by glancing-angle XRD.

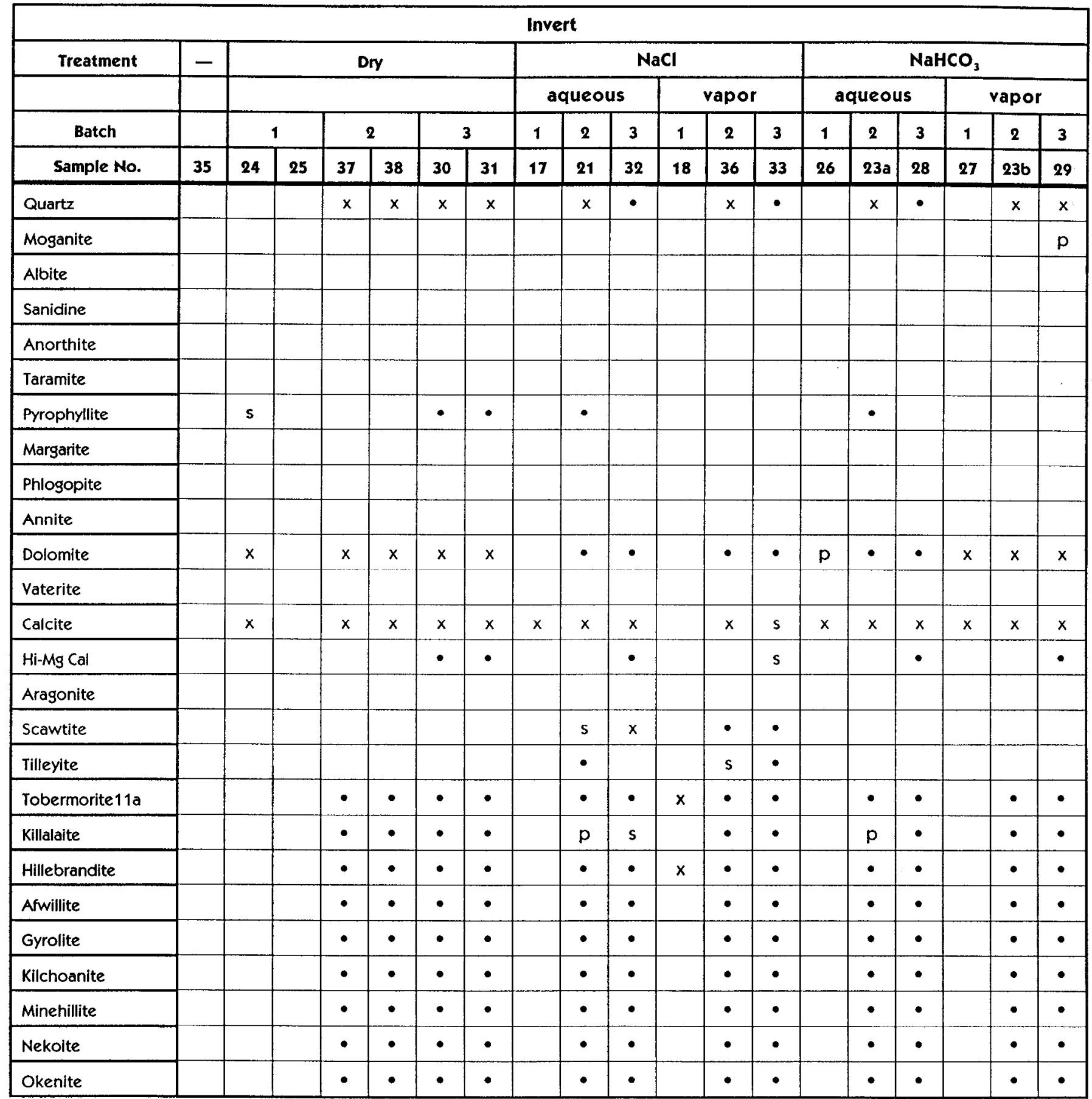

- indicates an untreated sample. Untreated samples analyzed by the powder method. All other samples analyzed by the glancing angle method.

- indicates that the phase is not detected in the sample, according to the glancing-angle technique. 
Table 8. Summary of phases (continued).

\begin{tabular}{|c|c|c|c|c|c|c|c|c|c|c|}
\hline \multicolumn{11}{|c|}{ Shotcrete } \\
\hline Treatment & - & \multicolumn{3}{|c|}{ Dry } & \multicolumn{3}{|c|}{$\mathrm{NaCl}$} & \multicolumn{3}{|c|}{$\mathrm{NaHCO}_{3}$} \\
\hline & & & & & \multicolumn{3}{|c|}{ vapor } & \multicolumn{3}{|c|}{ vapor } \\
\hline Batch & & 1 & 2 & 3 & 1 & 2 & 3 & 1 & 2 & 3 \\
\hline Sample No. & 11 & 1 & 9 & 6 & 5 & 13 & 4 & 2 & 10 & 3 \\
\hline Quartz & & & $\mathbf{s}$ & $x$ & & $p$ & $p$ & $x$ & $x$ & $x$ \\
\hline Moganite & & & & & & & & & & \\
\hline Albite & & & s & s & & - & & & $\mathbf{s}$ & $x$ \\
\hline Sanidine & & & $\mathbf{s}$ & s & & & & & $\bullet$ & \\
\hline Anorthite & & & $s$ & s & & - & & & $\bullet$ & $\mathbf{s}$ \\
\hline Taramite & & & $p$ & & & & & & & \\
\hline Pyrophyllite & & & & & $p$ & $\mathbf{s}$ & $\bullet$ & & & \\
\hline Margarite & & & $p$ & & $p$ & & - & & & \\
\hline Phlogopite & & & $\mathrm{p}$ & & & $p$ & $\bullet$ & & & \\
\hline Annite & & & $p$ & & & & & & & \\
\hline Dolomite & & & - & & & - & & & & - \\
\hline Vaterite & & & - & & & - & & & $\bullet$ & \\
\hline Calcite & & $x$ & - & $x$ & & - & & $x$ & $x$ & $x$ \\
\hline $\mathrm{Hi}-\mathrm{Mg} \mathrm{Cal}$ & & & $x$ & - & & $x$ & - & & & - \\
\hline Aragonite & & & & & & & & & s & - \\
\hline Scawtite & & & & & & s & $\bullet$ & & $p$ & $\bullet$ \\
\hline Tilleyite & & & & & & & & & & \\
\hline Tobermorite11a & & & - & $p$ & $x$ & $\mathbf{s}$ & $\mathbf{s}$ & & $\bullet$ & $\bullet$ \\
\hline Killalaite & & & $\bullet$ & $\bullet$ & & $p$ & $\mathbf{s}$ & & - & $\bullet$ \\
\hline Hillebrandite & & & - & $\bullet$ & & $\bullet$ & $\mathbf{s}$ & & $\bullet$ & $\bullet$ \\
\hline Afwillite & & & $\bullet$ & $\bullet$ & & $\bullet$ & $\bullet$ & & $\bullet$ & $\bullet$ \\
\hline Gyrolite & & & $\bullet$ & $\bullet$ & & $\bullet$ & $\bullet$ & & $\bullet$ & $\bullet$ \\
\hline Kilchoanite & & & - & $\bullet$ & & $\bullet$ & - & & $\bullet$ & $\bullet$ \\
\hline Minehillite & & & $\bullet$ & $\bullet$ & & - & $\bullet$ & & $\bullet$ & $\bullet$ \\
\hline Nekoite & & & $\bullet$ & $\bullet$ & & $\bullet$ & $\bullet$ & & $\bullet$ & $\bullet$ \\
\hline Okenite & & & $\bullet$ & - & & - & $\bullet$ & & $\bullet$ & $\bullet$ \\
\hline
\end{tabular}

Blank spaces indicate work in progress, i.e., that the phase has not been reviewed.

$x=$ definite; $s=$ strong possibility; $p=$ possibly.

\section{Discussion}

\section{Aqueous Cbemistry}

The chemistry of the aqueous solution is expected to evolve during the course of the experiments. The chemistry of aqueous solutions collected at the end of each experiment was analyzed with inductively coupled plasma mass spectrometry (ICP-MS) and ion chromatography (IC). Because ICPMS measures the total elemental concentration, the data in Figures 2-5 are given as uncharged species (e.g., $\mathrm{Ca}, \mathrm{Na}$ ). The data from IC is species specific (e.g., $\mathrm{F}^{-}$, $\left.\mathrm{PO}_{4}{ }^{2-}, \mathrm{SO}_{4}{ }^{2-}\right)$ and listed as such. These data are plotted as representative of the chemical evolution of each experiment in Figures 2-5. We note that the $\mathrm{pH}$ of the $\mathrm{NaHCO}_{3}$ solution increased with time, and stabilized at 9.5 after six weeks. The $\mathrm{Na}$ concentration of the original solution is great enough to have obscured any small changes in this element due to reaction with the sample. $\mathrm{Ca}, \mathrm{Si}$ and $\mathrm{SO}_{4}{ }^{2}$ concentrations are seen to increase and then reach steady state, and thus may have reached saturation with respect to certain minerals early in the experiment. The concentrations of $\mathrm{NO}_{3}{ }^{-}$and $\mathrm{PO}_{4}{ }^{2-}$ appear to increase but remain at relatively low values.

The $\mathrm{pH}$ of the $\mathrm{NaCl}$ solution increased with timc, approaching 11.5 within four months. Both $\mathrm{Na}$ and $\mathrm{Cl}^{-}$concentrations in the original solution are great enough to have obscured any small changes in these elements due to reaction with the sample. Similarly to the $\mathrm{NaHCO}_{3}$ solution, $\mathrm{Ca}$ and $\mathrm{SO}_{4}=$ concentrations increase and then reach steady state, and thus may have reached saturation with respect to some minerals. In contrast, the $\mathrm{Si}$ concentration of the $\mathrm{NaCl}$ solution remains low and even decreases. The $\mathrm{F}^{-}, \mathrm{NO}_{3}{ }^{-}$and $\mathrm{PO}_{4}{ }^{2-}$ concentrations appear to continue to increase. This could reflect the difference in $\mathrm{pH}$ of the two solutions, or the predominant negative species in each case $\left(\mathrm{Cl}^{-}\right.$ vs. $\left.\mathrm{HCO}_{3}{ }^{-}\right)$and will be verified with chemical 
Table 8. Summary of phases identified by glancing-angle XRD (continued).

\begin{tabular}{|c|c|c|c|c|c|c|c|c|c|c|c|c|c|c|c|c|c|c|c|}
\hline \multicolumn{20}{|c|}{ Invert } \\
\hline Treatment & - & \multicolumn{6}{|c|}{ Dry } & \multicolumn{6}{|c|}{$\mathrm{NaCl}$} & \multicolumn{6}{|c|}{$\mathrm{NaHCO}_{3}$} \\
\hline & & & & & & & & \multicolumn{3}{|c|}{ aqueous } & \multicolumn{3}{|c|}{ vapor } & \multicolumn{3}{|c|}{ aqueous } & \multicolumn{3}{|c|}{ vapor } \\
\hline Batch & & \multicolumn{2}{|c|}{1} & \multicolumn{2}{|c|}{2} & \multicolumn{2}{|c|}{3} & 1 & 2 & 3 & 1 & 2 & 3 & 1 & 2 & 3 & 1 & 2 & 3 \\
\hline Sample No. & 35 & 24 & 25 & 37 & 38 & 30 & 31 & 17 & 21 & 32 & 18 & 36 & 33 & 26 & $23 a$ & 28 & 27 & 236 & 29 \\
\hline Reyerite & & & & - & $\bullet$ & - & $\bullet$ & & $\bullet$ & - & & $\bullet$ & - & & $\bullet$ & $\bullet$ & & - & $\bullet$ \\
\hline Rustumite & & & & $\bullet$ & $\bullet$ & $\bullet$ & $\bullet$ & & - & $\bullet$ & & $\bullet$ & $\bullet$ & & $\bullet$ & • & & - & - \\
\hline Suolunite & & & & $\bullet$ & $\bullet$ & $\bullet$ & $\bullet$ & & - & $\bullet$ & & $\bullet$ & - & & • & - & & - & $\bullet$ \\
\hline Wairakite & & & & $\bullet$ & $\bullet$ & $\bullet$ & $\bullet$ & & $\bullet$ & • & & $\bullet$ & $\bullet$ & & $\bullet$ & • & & • & - \\
\hline Wollastonite & & & & $\bullet$ & $\bullet$ & $\bullet$ & $\bullet$ & & - & $\bullet$ & & $\bullet$ & • & & $\bullet$ & - & & - & $\bullet$ \\
\hline Xonotlite & & & & 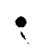 & - & - & $\bullet$ & & $\bullet$ & $\bullet$ & & $\bullet$ & $\bullet$ & & - & - & & $\bullet$ & $\bullet$ \\
\hline Gismondine & & & & & & $p$ & - & & $\bullet$ & & & & & & - & & & & $p$ \\
\hline Foshagite & & & & & & & & & & & & & & & & & & & \\
\hline Pectolite & & & & $\bullet$ & $\bullet$ & $\bullet$ & $\bullet$ & & • & - & $x$ & - & s & & $\bullet$ & • & & $\bullet$ & $\bullet$ \\
\hline Plombierite & & & & & & & & & $\bullet$ & & $p$ & & - & & & & & & \\
\hline Riversideite & & & & & & & & & - & & $p$ & & $p$ & & & & & & \\
\hline Na-Al-Si hydrate & & & & & & & & & & & & & & $p$ & & & & & \\
\hline Henritermierite & & & & & & & & & & & & & & & & & & & \\
\hline Analcime & & & & - & - & - & - & & - & $\bullet$ & & - & - & $x$ & $x$ & $x$ & & - & - \\
\hline Magadiite & & & & & & & & & & & & & & & & & & & \\
\hline Ferdisilicate & & & & & & & & & & & & & & & & & & & \\
\hline Goethite & & & & & & & & & & & & & & & & & & & \\
\hline Szomolnkite & & & & & & & & & & & & & & & & & & & \\
\hline Gupeiite & & & & & & & & & & & & & & & & & & & \\
\hline Halite & & & & & & & & $x$ & $x$ & $x$ & & - & $x$ & & $p$ & $\bullet$ & & & - \\
\hline Arcanite & & & & & & & & & & & & & & $p$ & & $\bullet$ & & & $\bullet$ \\
\hline Langbeinite & & $p$ & & & & $\bullet$ & $\bullet$ & & & & & & & $p$ & & $\bullet$ & & & $\bullet$ \\
\hline
\end{tabular}

-indicates an untreated sample. Untreated samples analyzed by the powder method. All other samples analyzed by the glancing angle method. - indicates that the phase is not detected in the sample, according to the slancing-angle technique. 
Table 8. Summary of phases (continued).

\begin{tabular}{|c|c|c|c|c|c|c|c|c|c|c|}
\hline \multicolumn{11}{|c|}{ Shotcrete } \\
\hline Treatment & 一 & \multicolumn{3}{|c|}{ Dry } & \multicolumn{3}{|c|}{$\mathrm{NaCl}$} & \multicolumn{3}{|c|}{$\mathrm{NaHCO}_{3}$} \\
\hline & & & & & \multicolumn{3}{|c|}{ vapor } & \multicolumn{3}{|c|}{ vapor } \\
\hline Batch & & 1 & 2 & 3 & 1 & 2 & 3 & 1 & 2 & 3 \\
\hline Sample No. & 11 & 1 & 9 & 6 & $\mathbf{5}$ & 13 & 4 & 2 & 10 & 3 \\
\hline Reyerite & & & $\bullet$ & - & & - & $\bullet$ & & - & $\bullet$ \\
\hline Rustumite & & & - & $\bullet$ & & - & $\bullet$ & & - & - \\
\hline Suolunite & & & - & $\bullet$ & & - & $\bullet$ & & $\bullet$ & $\bullet$ \\
\hline Wairakite & & & $\bullet$ & $\bullet$ & & - & - & & $\bullet$ & - \\
\hline Wollastonite & & & $\bullet$ & $\bullet$ & & $\bullet$ & $x$ & & $\bullet$ & $\bullet$ \\
\hline Xonotlite & & & - & $\bullet$ & & $\bullet$ & $\bullet$ & & $\bullet$ & - \\
\hline Gismondine & & & & & & $\mathbf{p}$ & $\bullet$ & & - & $\bullet$ \\
\hline Foshagite & & & $p$ & & & & & & & \\
\hline Pectolite & & & $\bullet$ & $\bullet$ & & - & $\bullet$ & & $\bullet$ & $\bullet$ \\
\hline Plombierite & & & & & & & & $p$ & $\bullet$ & $\bullet$ \\
\hline Riversideite & & & - & & & - & & & $\bullet$ & \\
\hline \multicolumn{11}{|l|}{ Na-AlShydrate } \\
\hline Henritermierite & & & & $p$ & & & & & & \\
\hline Analcime & & & - & $\bullet$ & & $\bullet$ & $\bullet$ & & - & - \\
\hline Magadiite & & & & & & & & $p$ & & $\bullet$ \\
\hline Ferdisilicate & & $\mathbf{s}$ & & & & & & & $\bullet$ & \\
\hline Goethite & & & & & & & & $p$ & - & $\bullet$ \\
\hline Szomolnkite & & & & & & & & $p$ & & - \\
\hline Gupelite & & & & & & & $p$ & & & \\
\hline Halite & & & & $x$ & $p$ & $\bullet$ & $p$ & & & \\
\hline \multicolumn{11}{|l|}{ Arcanite } \\
\hline Langbeinite & & & & & & & & & & \\
\hline
\end{tabular}

Blank spaces indicate work in progress, i.e., that the phase has not been reviewed. $x=$ definite; $s=$ strong possibility; $p=$ possibly. simulation exercises. Aqueous chemistry was not relevant to the "dry" samples from Batch 1 or Batch 2. However, distilled water added for the last two weeks of Batch 3 evolved to a $\mathrm{pH}$ of 11.84 .

The concentration of $\mathrm{Mg}$ in all solutions measured remains low. Data from the SUPCRT database for EQ3/6 geochemical code (see, e.g., Wolery, 1992a, b; Wolery and Daveler, 1992) indicate that at the vapor pressure of $\mathrm{H}_{2} \mathrm{O}$ at $200^{\circ} \mathrm{C}$ the solubility product $(\log \mathrm{K})$ of dolomite is -2.7744 and of calcite is -0.5838 . These values indicate that at the standard conditions measured, although both minerals have a low solubility, calcite is more soluble than dolomite. The low concentrations of $\mathrm{Mg}$ probably reflect a lower solubility of dolomite aggregate with respect to calcite. Factors such as ionic strength, the partial pressure of $\mathrm{CO}_{2}\left(\mathrm{PCO}_{2}\right)$, and $\mathrm{pH}$ play a role in the evolution of the solution chemistries and thus lend complexity to the interpretation of these experiments. These factors will be pursued through chemical simulations.

\section{Thin Section Analysis}

Birefringent rims occur on both untreated and treatcd samples, and on invert and shotcrete samples. Therefore, it cannot be assumed that any of the treatments or concrete types caused the rims to form. Similarly, clouded brown grout is observed on both treated and untreated shotcrete and invert samples. Buff-colored grout is unique to the $\mathrm{NaHCO}_{3}$ treatment. This grout occurs in all three sample batches, although less is observed in the Batch 3 aqueous sample. Sample INV-23b (Batch 2, $\mathrm{NaHCO}_{3}$ vapor) showed blotchy grout in SEM images magnified 1000 times. The two types of grout that comprise the blotchiness are an ordinary looking grout, and one coated with calcite rhombs. It is conceivable that the blotchiness observed in this Batch 2 sample may have some relation to the analogous Batch 1 sample that had blotchy grout when observed in thin section. We interpreted the ordinary looking grout to be analogous to the brown, cloudy patches, and the calcite coated areas to be analogous to the birefringent patches. Although calcite is a highly birefringent mineral, that birefringence is not observed unless the mineral is suitably thick, that is, unless the 
mineralization penetrates deeper than the surface. The analogous Batch 1 sample showed rhombs of calcite composition on the surface, although not as well developed or euhedral as those observed in the Batch 2 sample (Batch 1 report, Figure 38a). Aggregate mineralogy varies between invert and shotcrete samples, but is less variable within each sample type. Invert aggregate consists of $80-100 \%$ carbonate, $5-20 \%$ silicate minerals (quartz, quartz-bearing lithic fragments, and chert), and $1 \%$ or less of hematite and other opaque phases. Shotcrete aggregate mineralogy consists of $80-90 \%$ silicate minerals $\left(\mathrm{SiO}_{2}\right.$ phases and feldspar), $5-15 \%$ carbonate, $3-18 \%$ lithic fragments and biotite, and 1-10\% accessory phases.

\section{SEM}

Evaporited deposits can be easily distinguished from experimental secondary mineralization. In addition, the vapor and aqueous treatments are distinct. The most striking difference between the vapor-treated and aqueous-treated samples is in the diversity of secondary phases in the vaportreated samples. Clearly, the localized nature of vapor-phase reactions is responsible for the large number of phases in the vapor-treated samples. The formation of secondary precipitates in the aqueous samples is controlled by the chemistry of the solution, as can be seen in the predominance of analcime in the aqueous $\mathrm{NaHCO}_{3}$ treated samples.

It is clear from thin-section and SEM evidence that secondary calcite is precipitated in many of these samples. Determining the relative amount of secondary calcite formation is not straightforward due to the presence of carbonates in the original sample and will require further work. We know that some of the crystalline $\mathrm{Ca}$-Si-hydrate phases are unstable in the presence of $\mathrm{CO}_{2}$ or $\mathrm{HCO}_{3}^{-}$, and calcite or $\mathrm{Ca}-\mathrm{Si}$ carbonate hydrates form at their expense. Thus, both the $\mathrm{NaHCO}_{3}$ treatment and the presence of carbonate minerals in the original aggregate affected the character of the secondary mineralization.

Secondary analcime and calcite are observed in the $\mathrm{NaHCO}_{3}$ aqueous treated samples. Secondary calcite, a $\mathrm{Ca}-\mathrm{Si}$ phase, and a $\mathrm{SiO}_{2}$ phase are observed in $\mathrm{NaHCO}_{3}$ vapor treated samples. The secondary mineralization in $\mathrm{NaCl}$ aqueous treated samples includes at least two $\mathrm{Ca}-\mathrm{Si}$ phases and at least two carbonate phases. Vapor treated samples contain at least four Ca-Si secondary phase morphologies and one carbonate phase. Dry samples show at least three morphologies of localized $\mathrm{Ca}$-Si-hydrate rings around aggregate grains and a secondary carbonate phase.
Given the apparent contribution of dissolved carbonates from the aggregate to secondary mineralization, and the presence of dolomite as a major component of the concrete (invert) aggregate, one might expect to observe $\mathrm{Mg}$ in the secondary phases. However, $\mathrm{Mg}$ is notably absent from the secondary phases observed in these studies. The concentration of $\mathrm{Mg}$ increases quite slowly in solution over time, which suggests that the aqueous solution did not reach saturation with respect to $\mathrm{Mg}$ bearing phases during the experiment. Combined with the preceding discussion, this result suggests that if carbonate from the aggregate contributed to the formation of secondary calcite during the experiment, it was primarily due to the dissolution of the calcite aggregate. Similarly, we expect the rise and apparent plateau in the concentration of $\mathrm{SO}_{4}{ }^{2-}$ to be accompanied by the precipitation of sulfate mineral phases. However, sulfate phases were not observed. We expect to learn more about this in future experiments and through modeling.

\section{Glancing Angle X-Ray Diffraction.}

Analcime and possibly killalaite and halite occur as secondary phases in the aqueous $\mathrm{NaHCO}_{3}$ treated samples. Scawtite and aragonite are possible secondary phases on the vapor treated samples. Secondary phases possibly occurring in the $\mathrm{NaCl}$ aqueous treated samples include scawtite, halite, and killalaite. Secondary phases possibly occurring in the vapor treated samples include scawtite, tilleyite, tobermorite, killalaite, hillebrandite, gismondine, pectolite, plombierite, riversideite, and halite. Few secondary phases can be distinguished on dry treated samples. Tobermorite, ferdisilicate, and halite may occur.

\section{Mechanical Test}

Mechanical test results exhibit variability, and interpretation is deferred until the magnitude of the error has been firmly established. Our future direction will be to document the third batch and establish possible trends. If, for the moment, we discount the heterogeneity of samples (i.e., the experimental error that is yet to be established), Table 9 suggests that the force required to cause a brittle fracture in the samples may be increasing, especially in those samples subjected to $\mathrm{NaHCO}_{3}$ treatment. This is at least consistent with industry practice, in which precast concrete is carbonated for increased strength (Rubin et al, 1997). It is important to note that all treatments may involve more than atmospheric $\mathrm{CO}_{2}$ because of the presence of large amounts of limestone in the aggregate. In addition, these experiments were conducted at a pressure above atmospheric. 


\section{Summary}

The results of analyses of the second and third batches of hydrothermally treated samples demonstrate that the trends in alteration are continuing. In as little as a month's time at $200^{\circ} \mathrm{C}$, alteration occurs, and in some cases the alteration is extensive. By four months, thin-section analysis shows that secondary mineralization on some of the treatments is pervasive. These preliminary observations seem to show:

- Evidence for further investigation into an apparent increase in mechanical strength with treatment time.

- Possible correlation between the apparent increased strength and secondary calcite formation.

- Formation of secondary carbonates, calcium silicates and calcium silicate carbonates.

- The precipitation of some of the secondary phases that are formed cannot presently be modeled because data does not presently exist in the database.

- Evaporated salt deposits from droplets of experimental fluid were observed and retained in order to preserve delicate underlying secondary mineral structures.

Although the data in this report will require further interpretation, we feel that it would be better to defer detailed interpretation until after the results of longer-duration treatments have been analyzed and the trends are verified.

\section{References}

Clodic, L. and A. Meike (1997). Thermodynamics of Calcium Silicate Hydrates. Livermore, CA: Lawrence Livermore National Laboratory. Deliverable No. SPLG1EM4.

Meike, A., M. Spragge, and C. Aracne-Ruddle (1997). Hydrothermal Alteration of Cementitious Materials: First Batch of Samples. Livermore, CA: Lawrence Livermore National Laboratory. YMSCO Deliverable No. SPLGBM4.

Rubin, J. B., Carey, J. W., and C. M. V. Taylor (1997). Enbancement of Cemented Waste Forms by Supercritical $\mathrm{CO}_{2}$ Carbonation of Standard Portland Cements. LA-UR-97-1859.

Sassani, D. (1996). Status/Summary Report for Fiscal Year 1996 Activities within the Performance Assessment Overview Study on the Consequences of Cementitious Materials. Las Vegas, Nevada: Yucca Mountain Project M\&O.

Tang, D. (1997). Emplacement Drift Ground Support. YMP Document BCAA00000-01717-0200-00003 Rev. 00B, May 23, 1997.

Taylor, H. F. W. (1990). Cement Cbemistry. London: Academic Press.

Wolery, T. J. (1992a). EQ3NR, A Computer Program For Geochemical Aqueous Speciation-Solubility Calculations: Theoretical Manual, User's Guide, and Related Documentation. (UCRL-MA-1 10662) Livermore, CA: Lawrence Livermore National Laboratory. (Version 7.0)

Wolery, T. J. (1992b). EQ3/6, A Software Package for Geochemical Modeling of Aqueous Systems: Package Overview and Installation Guide. (UCRL-MA-110662) Livermore, CA: Lawrence Livermore National Laboratory. (part 1)

Wolery, T. J., and S. A. Daveler (1992). EQ6, A Computer Program for Reaction Path Modeling of Aqueous Geochemical Systems: Theoretical Manual, User's Guide, and Related Documentation (Version 7.0). (UCRL-MA-1 10662) Livermore, CA: Lawrence Livermore National Laboratory. (part 4) 


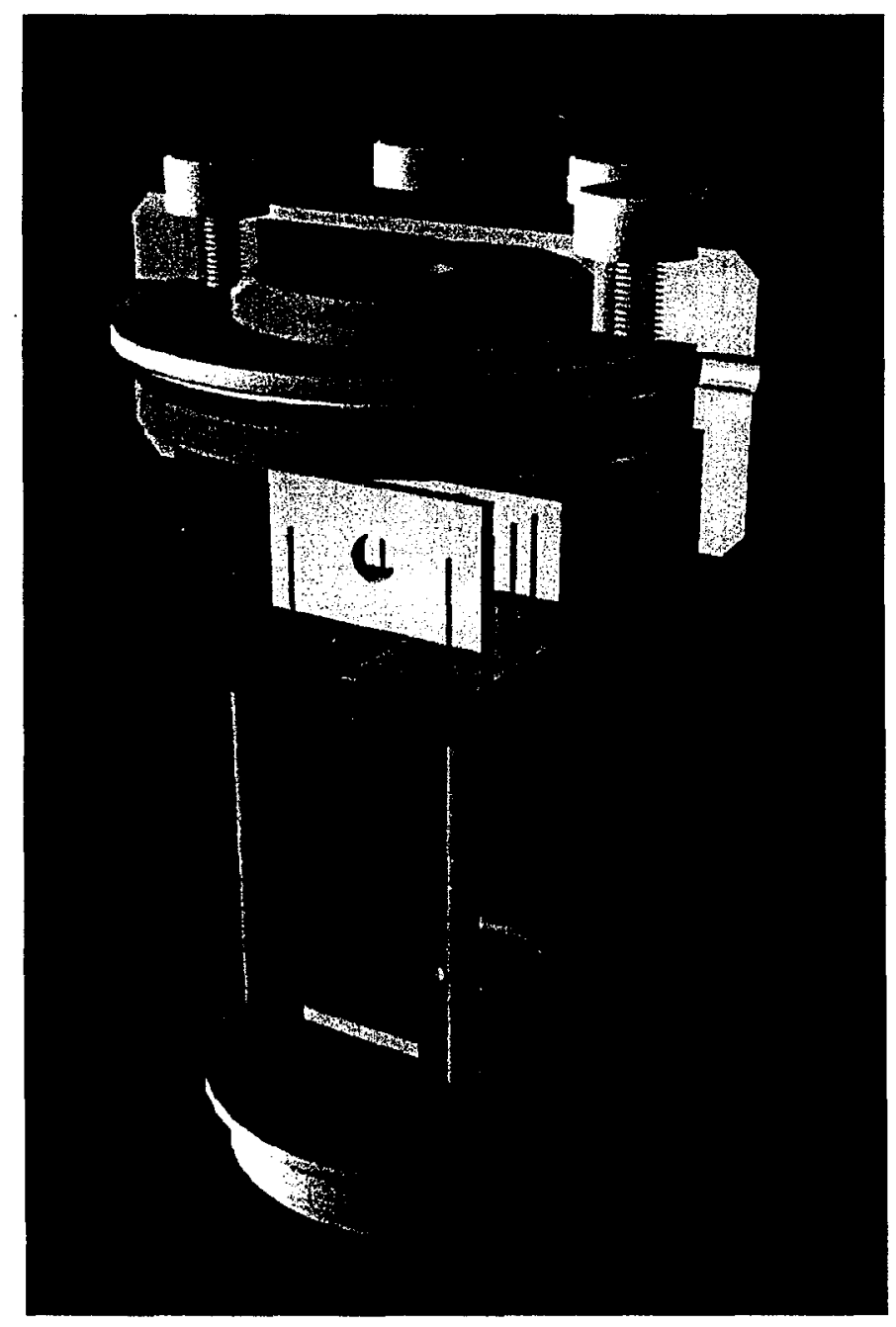

Figure 1. Cross-sectional diagram of pressure vessel assembly illustrates sample placement. 


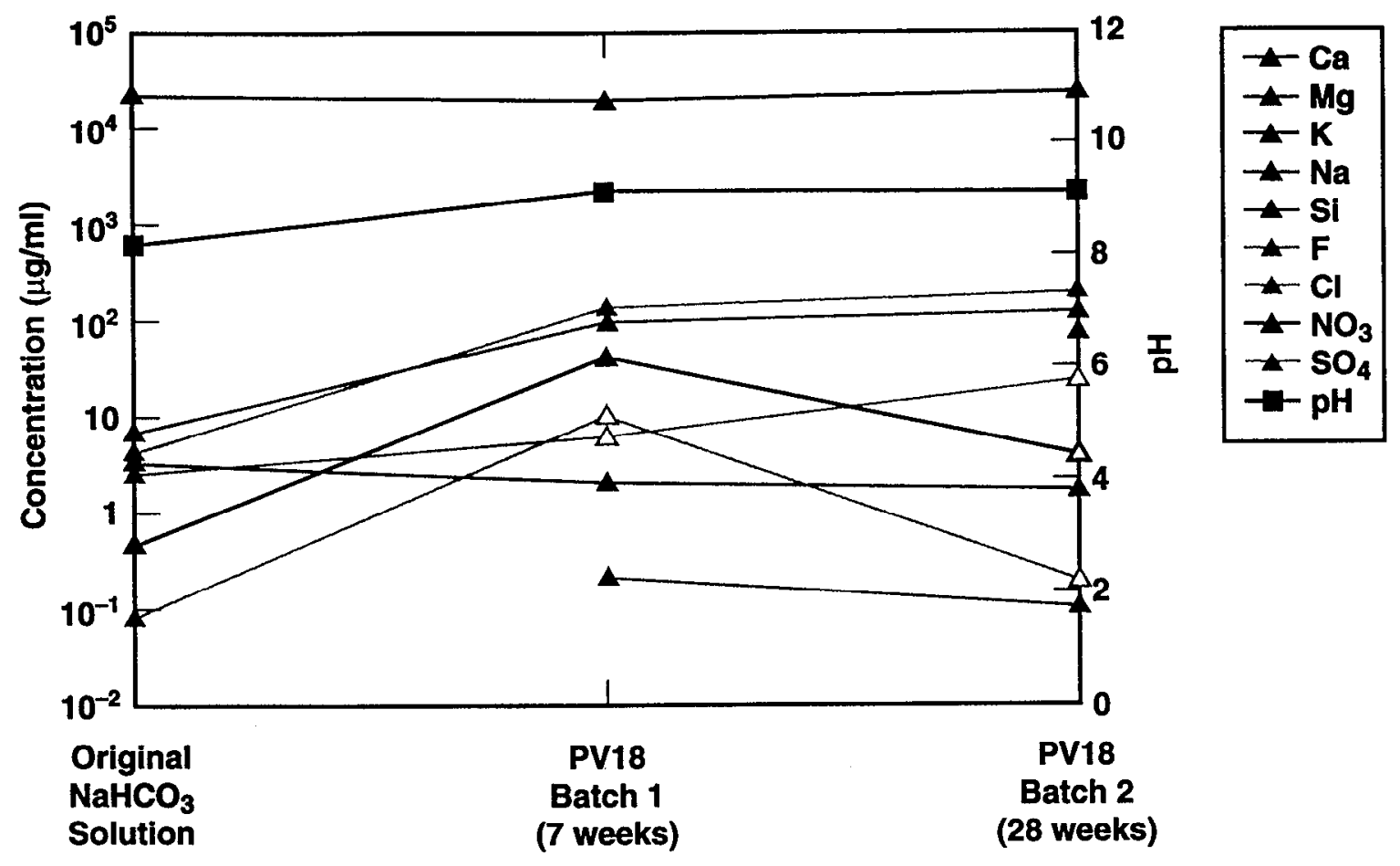

Figure 2. Chemistry of selected chemical species for the hydrothermal reaction concrete with $\mathrm{NaHCO}_{3}$ solution. Data from the various batches are plotted with the analysis of the original solution to represent an evolutionary sequence. Open symbols indicate maximum possible concentrations of species that were not detected (i.e., detection limits).

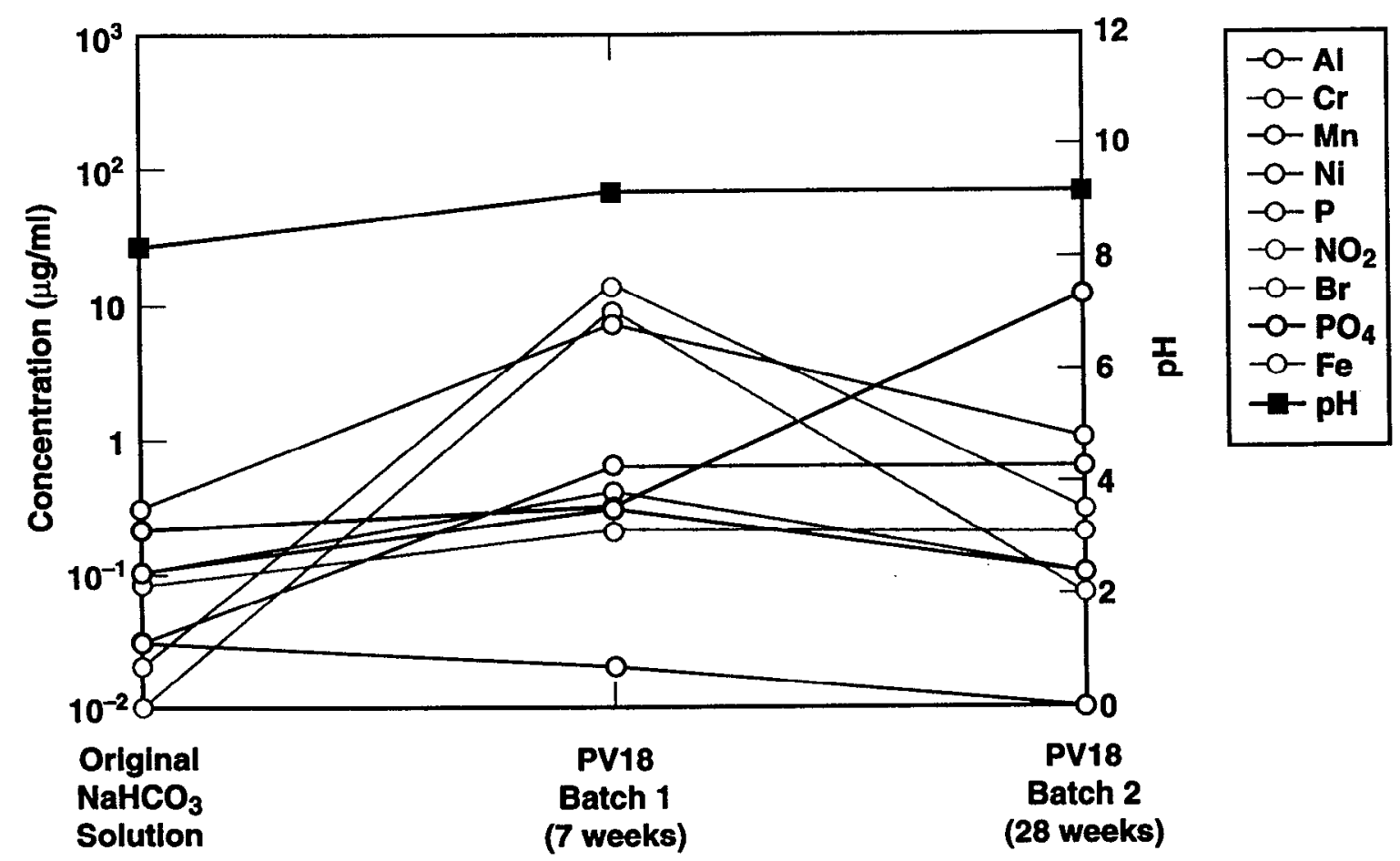

Figure 3. Maximum concentrations of undetected species (i.e., detection limits). All species that were analyzed in the $\mathrm{NaHCO}_{3}$ solution are included in either Figure 2 or Figure 3. (Note the magnification of scale in Figure 3.) 


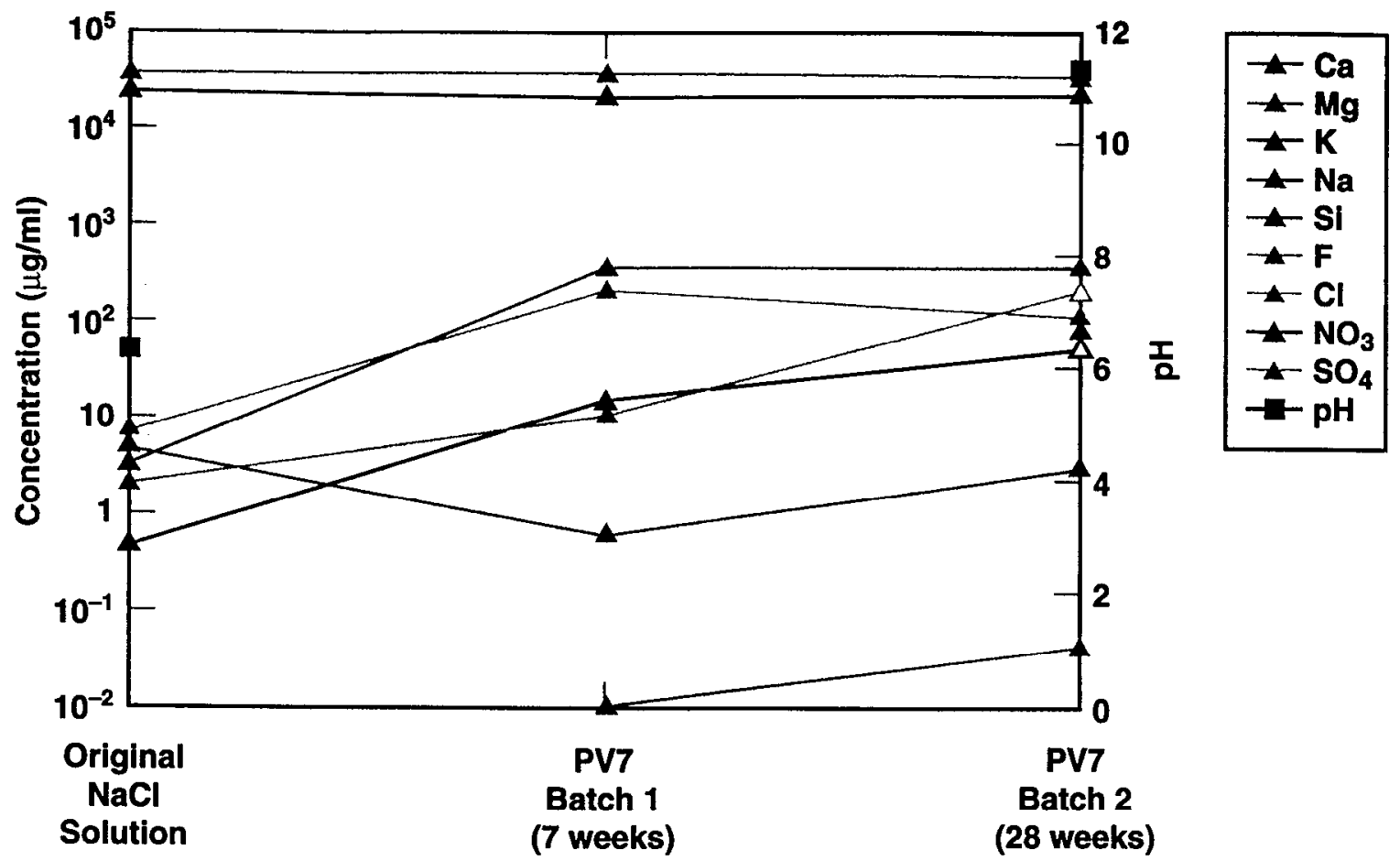

Figure 4. Chemistry of selected chemical species for the hydrothermal reaction concrete with $\mathrm{NaCl}$ solution. Data from the various batches are plotted with the analysis of the original solution to represent an evolutionary sequence. Open symbols indicate maximum possible concentrations of species that were not detected (i.e., detection limits).

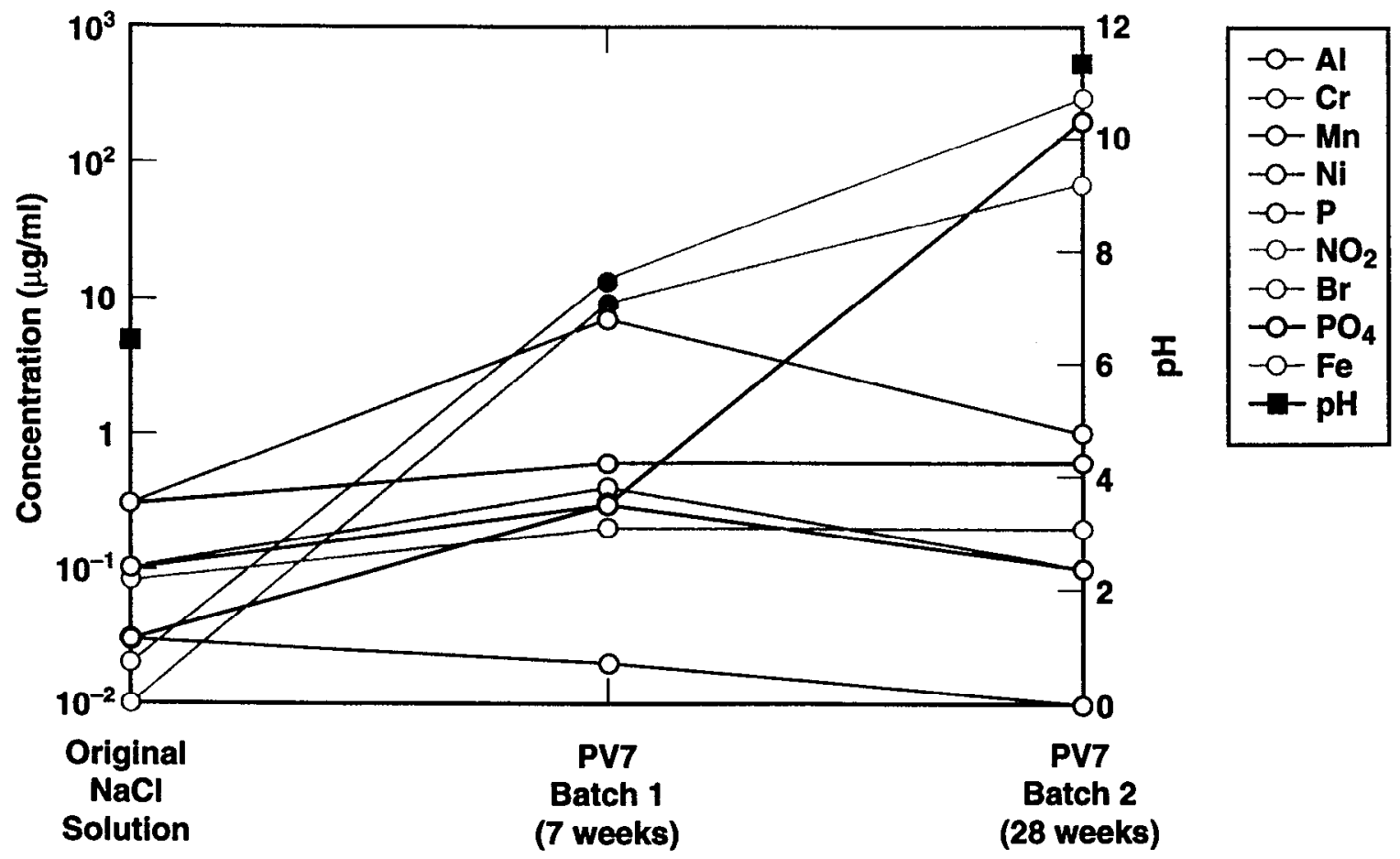

Figure 5. Concentrations of remaining chemical species. Filled symbols identify actual measurements, and open symbols identify maximum concentrations of undetected species (i.e., detection limits). All species that were analyzed in the $\mathrm{NaCl}$ solution are included in either Figure 4 or Figure 5. (Note the magnification of scale in Figure 5.) 


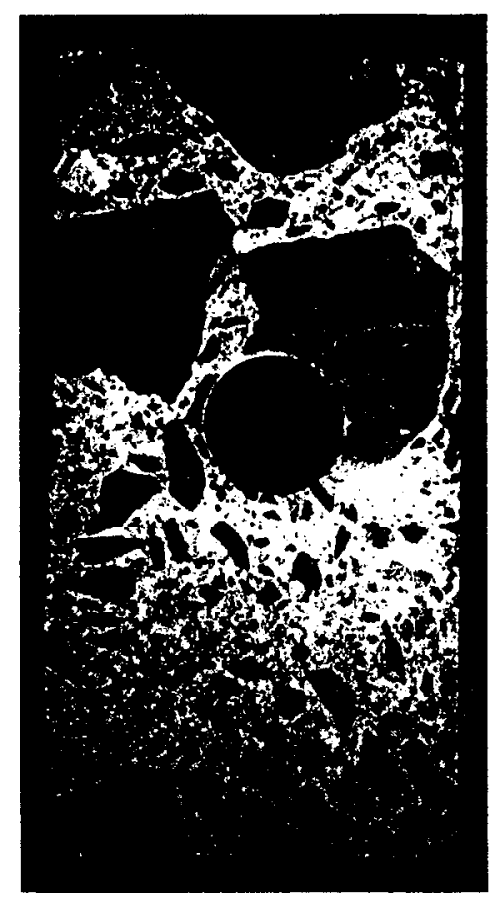

Figure 6. Photograph of sample INV-37. Dimensions are approximately 14 by $25 \mathrm{~mm}$, and $2 \mathrm{~mm}$ thick. The surface of the sample appears to be relatively unreacted.

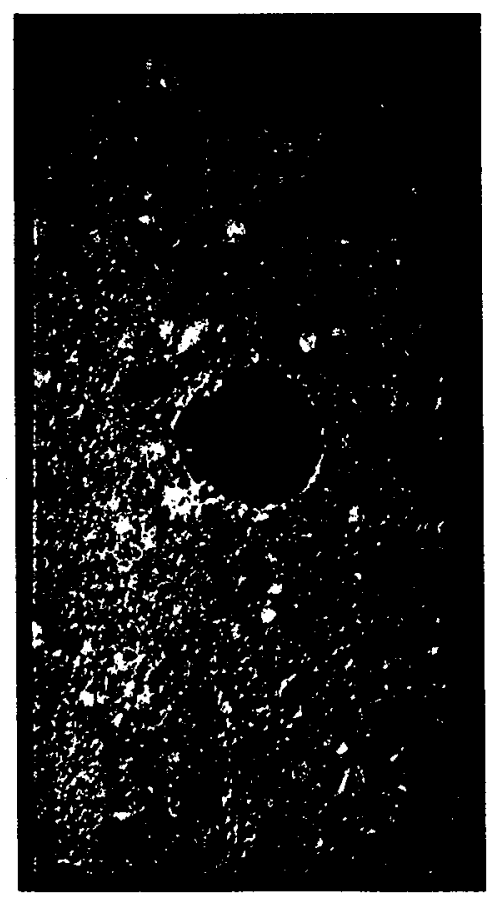

Figure 7. Photograph of sample SH-9. Dimensions are approximately 14 by $25 \mathrm{~mm}$, and $2 \mathrm{~mm}$ thick. The sample appears to be relatively unreacted. A thin, white crust is visible around the central hole. 
(a)

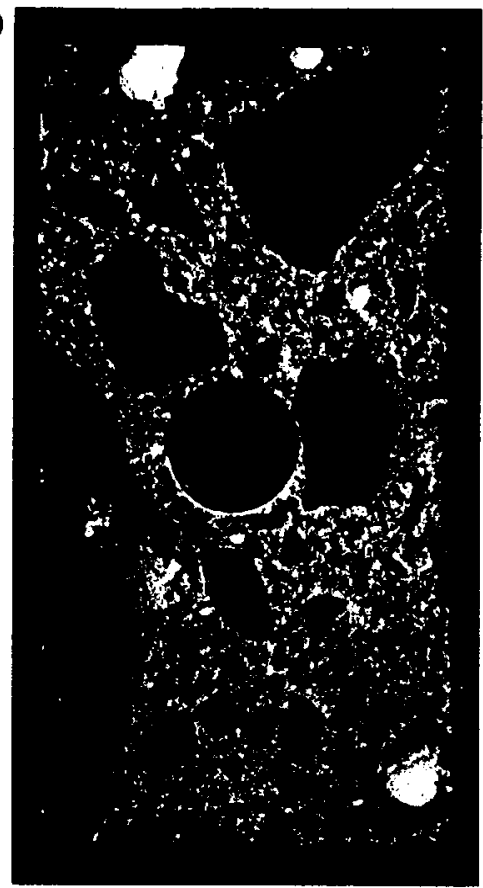

(b)

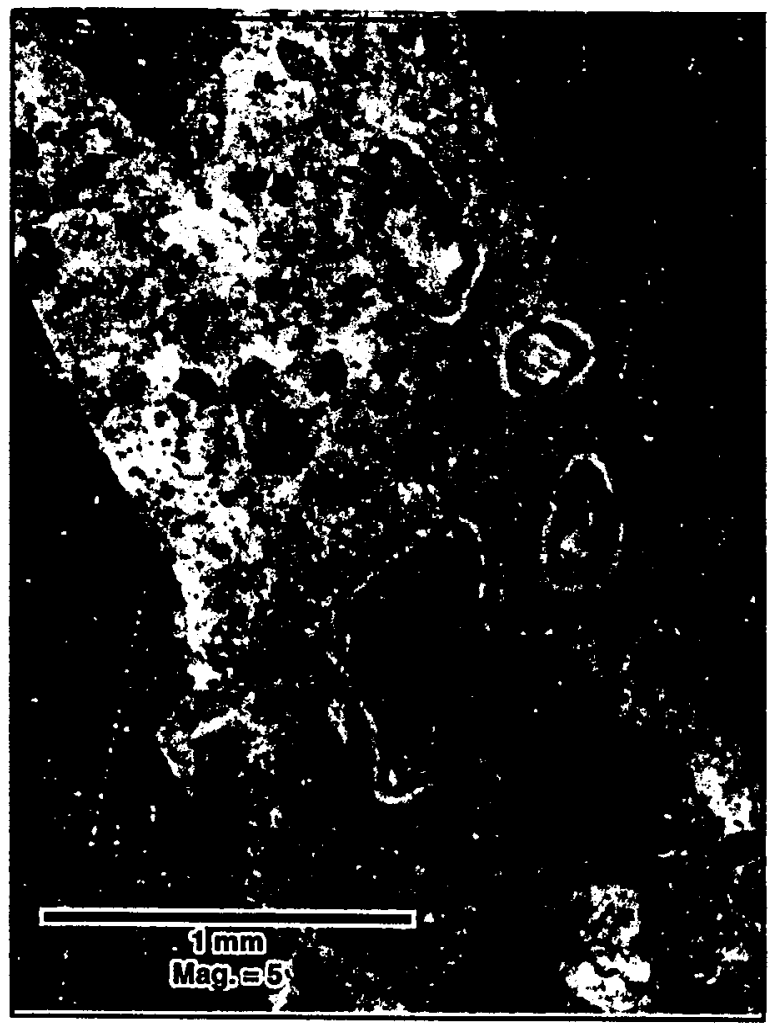

(c)

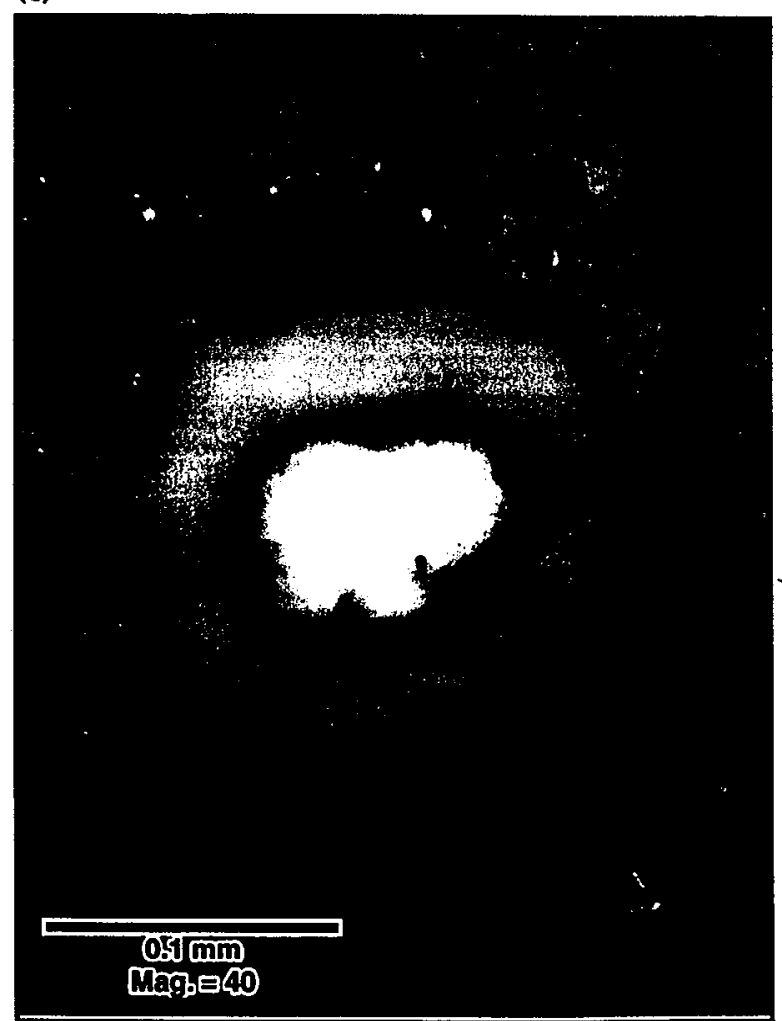

Figure 8. Photographs of sample INV-30. (a) Whole specimen. (b) A typical view of the sample, with white rims on small aggregate grains, but not on large grains (in this photo the large grains are gray). (c) A highermagnification view of a white rim around a small aggregate grain. The grout is white. 


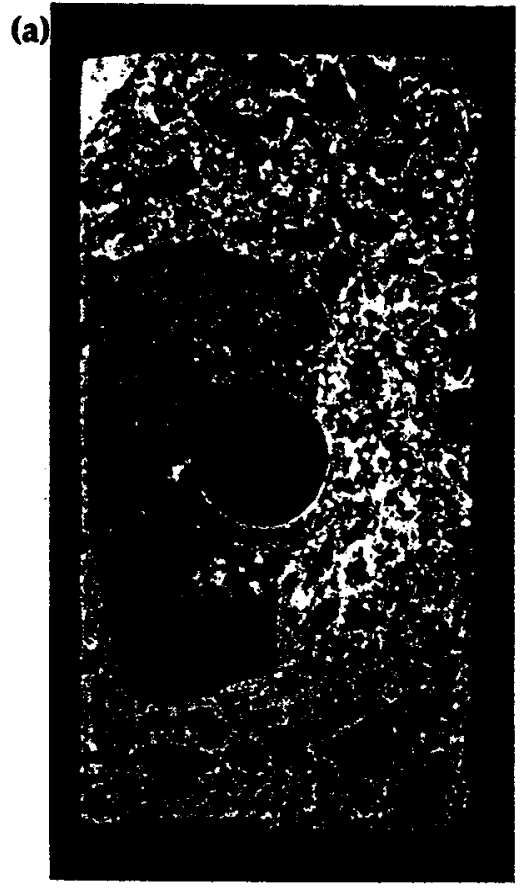

(c)

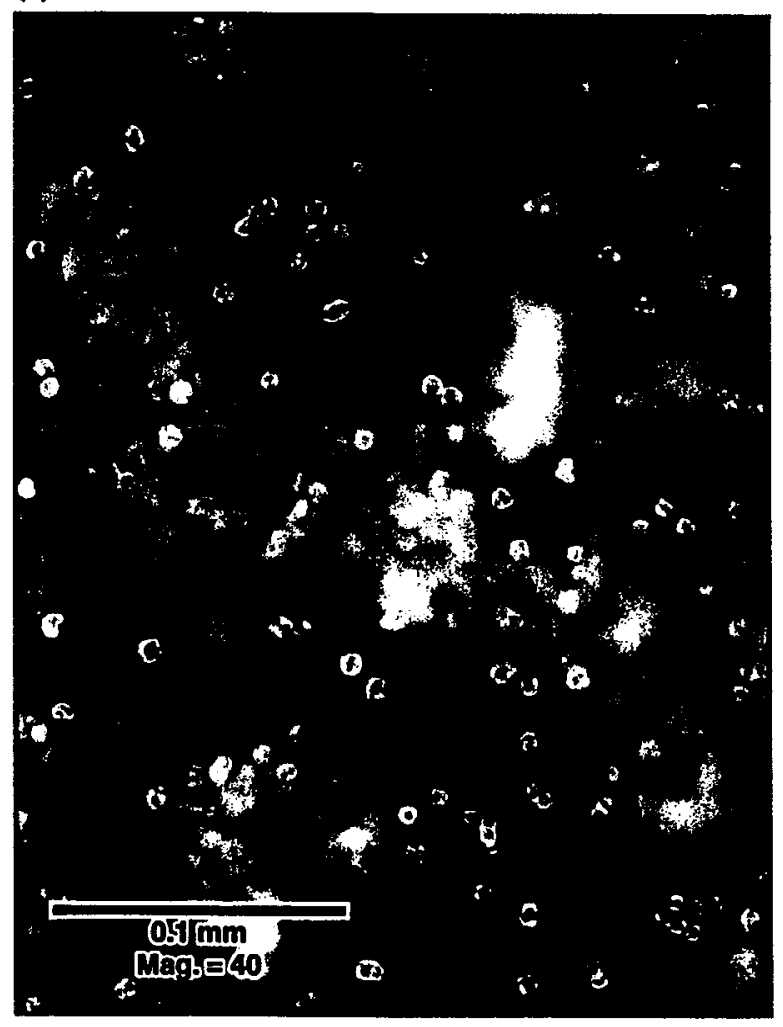

(b)

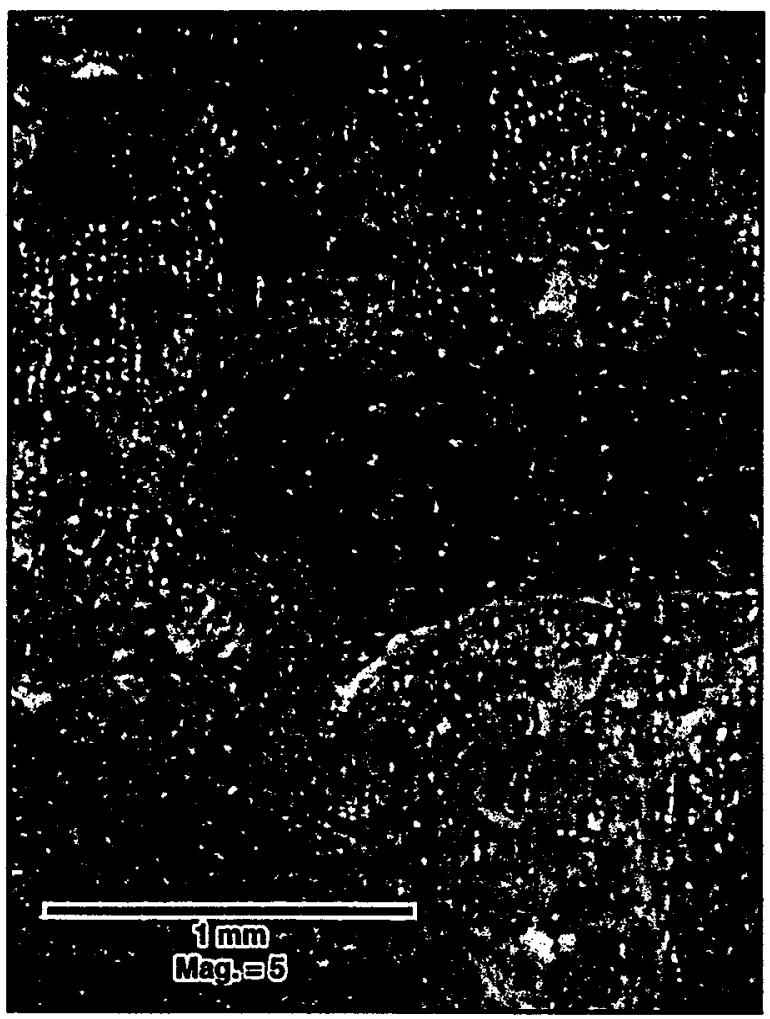

(d)

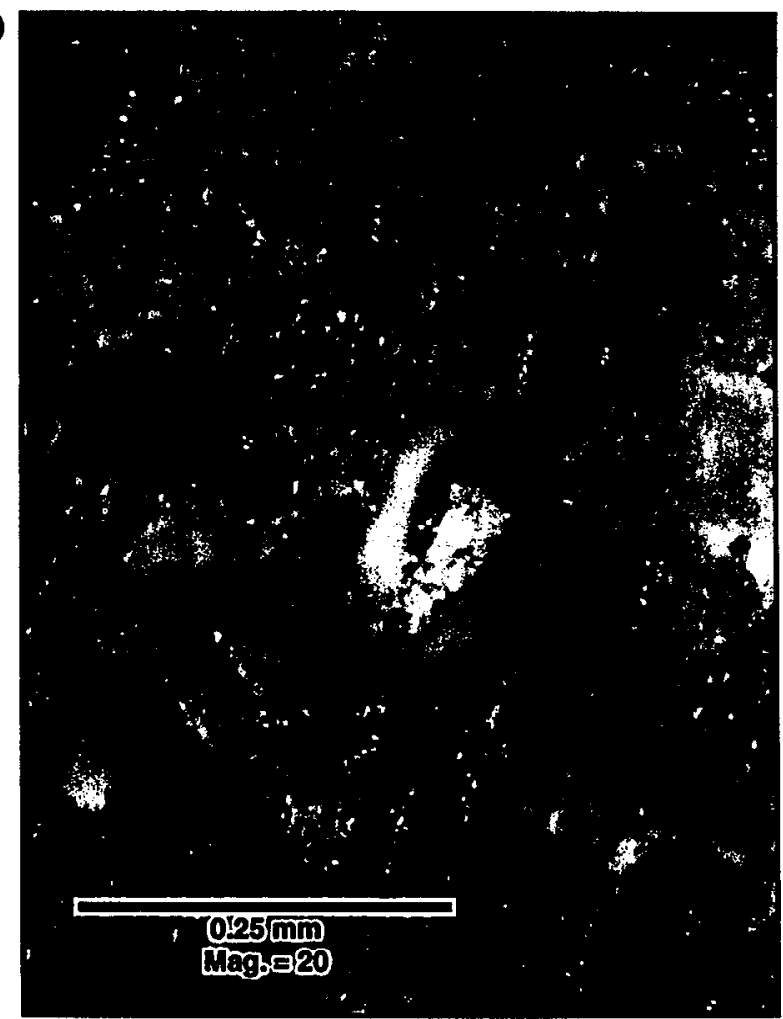

Figure 9. Photograph of sample INV-31. (a) The sample appears to have very few white rims around grains. (b) Typical view of the sample showing some aggregate with thin, white rims, and some without. (c) Tiny crystals on the dark gray aggregate grain in the center of (b). The white specs on the gray aggregate in (b) appear as white blotches in this photo. The tiny crystals were not observed on grout, but were seen on other aggregate. (d) Typical white rims around small aggregate grains. 
(a)

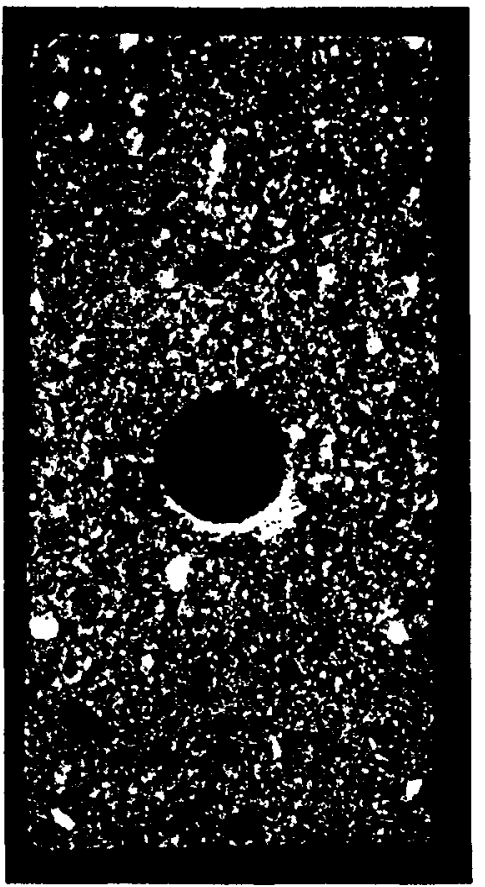

(c)

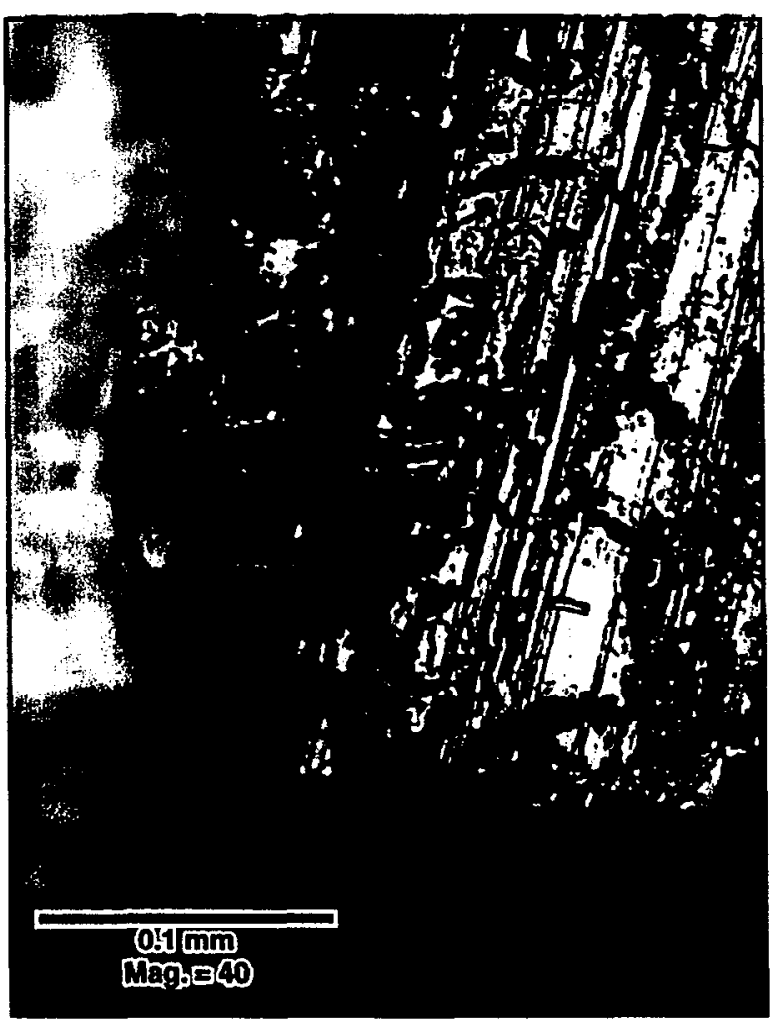

(b)

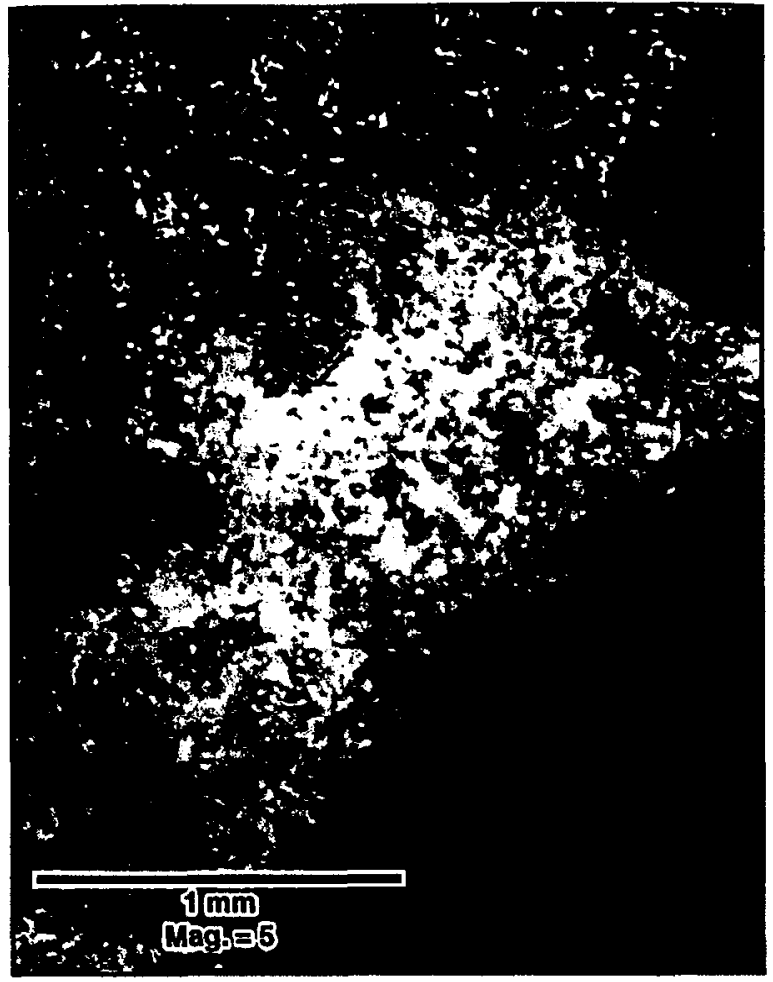

(d)

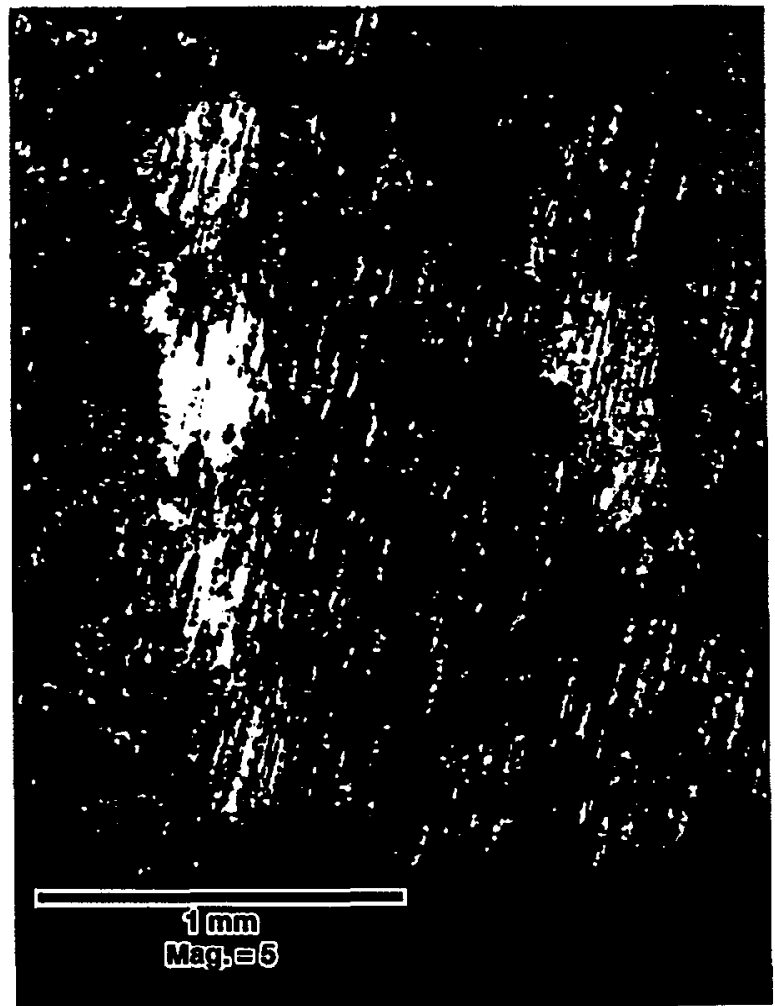

Figure 10. Photographs of sample SH-6. (a) White rims occur on many aggregate grains. (b) A white phase near the central hole. (c) A high-magnification view of a black/red colored phase on the surface of a stainless steel fiber. (d) Two stainless steel fibers. Note the black/red phase visible on both fibers. 
Part ll: Second ano Thad Butch of Sumples

(e)

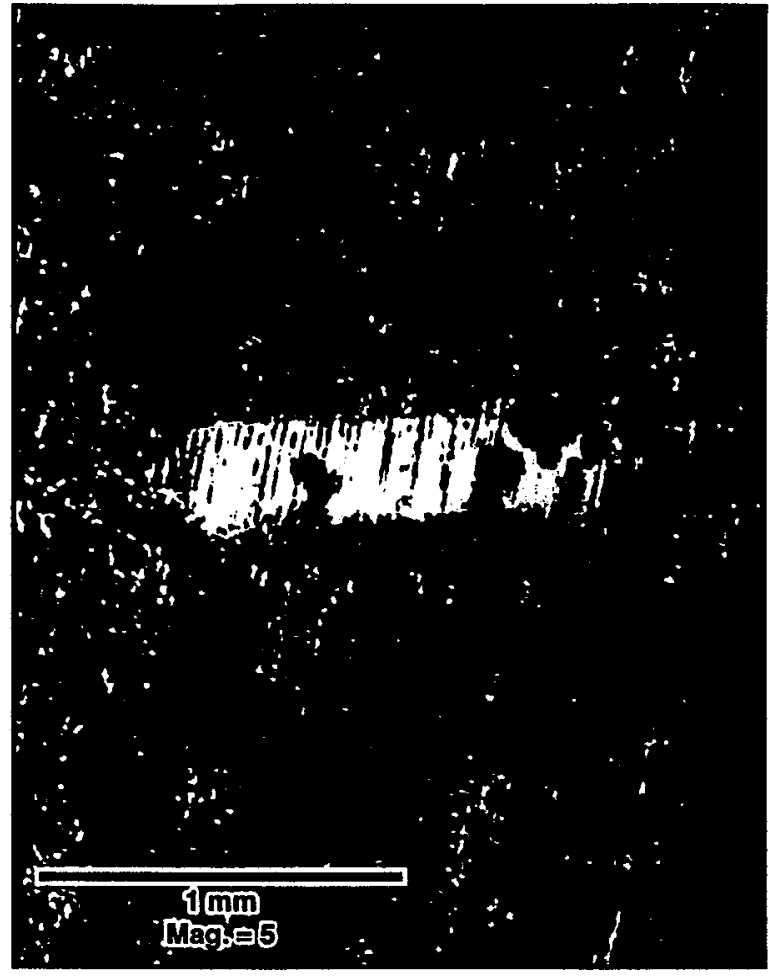

(f)

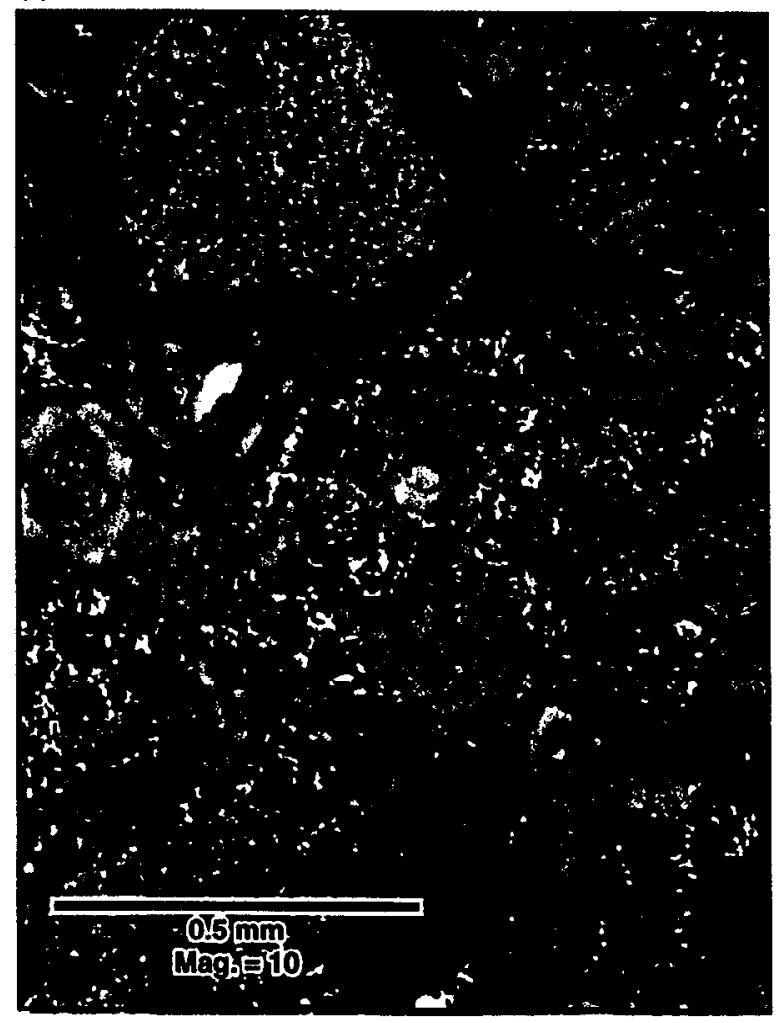

(g)

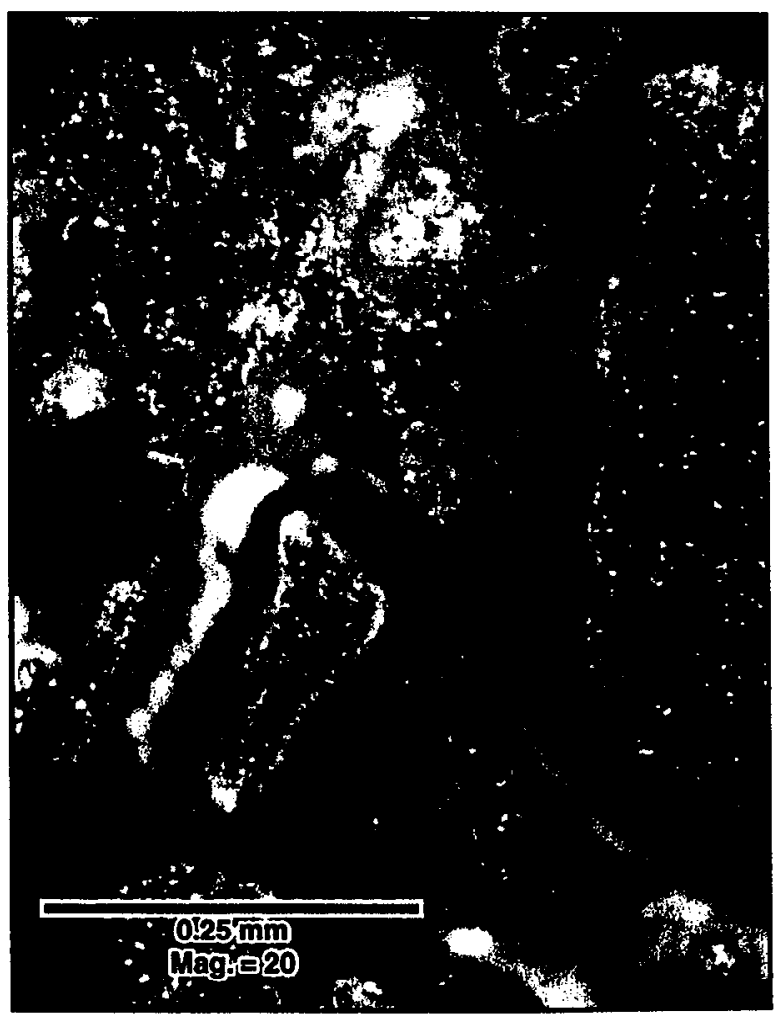

Figure 10 (continued). Photographs of sample SH-6. (e) A third stainless steel fiber also occurs with the black/red phase on its surface. (f) Typical view of the sample surface, showing abundant white rims around many grains. Note the two brown biotite grains. (g) A higher-magnification photo of the white rims around both large and small aggregate. 


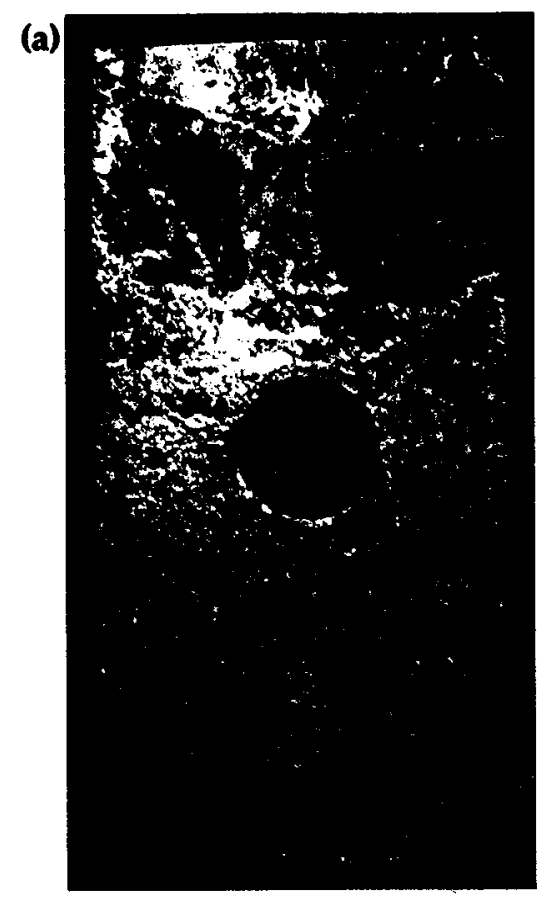

(b)

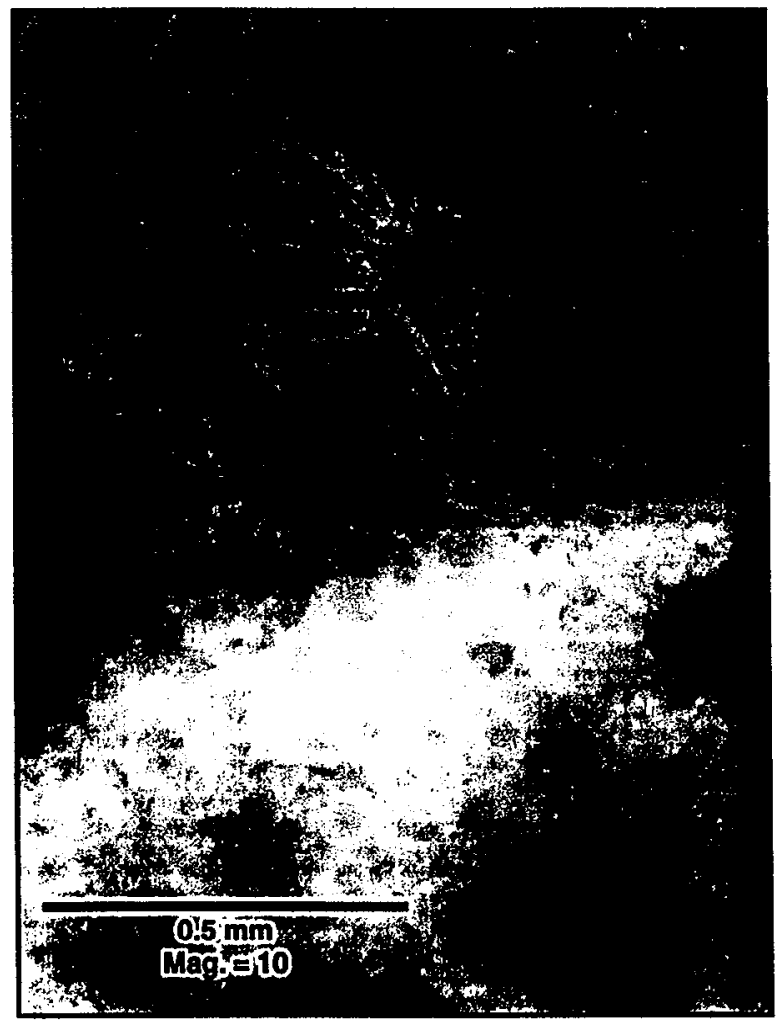

(c)

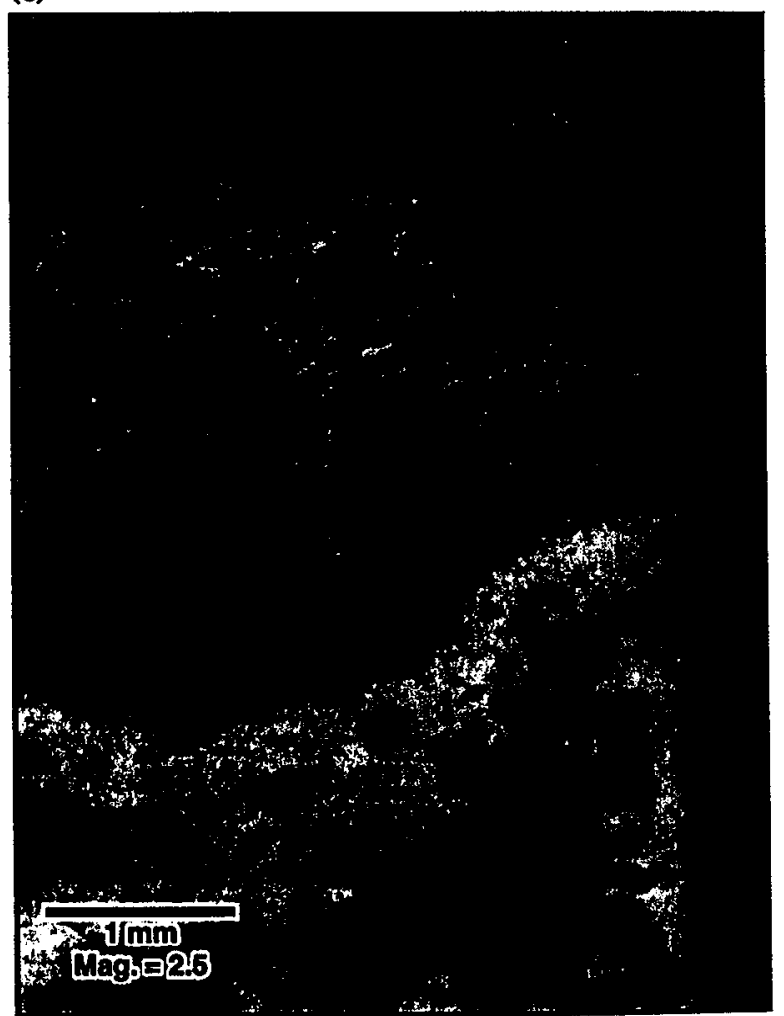

Figure 11. Photographs of sample INV-23a, side 1. (a) Both sides of this sample were photographed because they were so different. Side 1 is nearly covered with a white crust, which we attribute to evaporated droplets of the solution. This crust, upon further inspection with SEM, appears to have preserved some of the more delicate secondary reaction phases. (b) At least two patterns emerge on the white crust, over a large, gray aggregate grain. One resembles a radiating web, and the other, mud cracks. (c) A lower-magnification view of the white crust in the same area of the sample. 
(a)

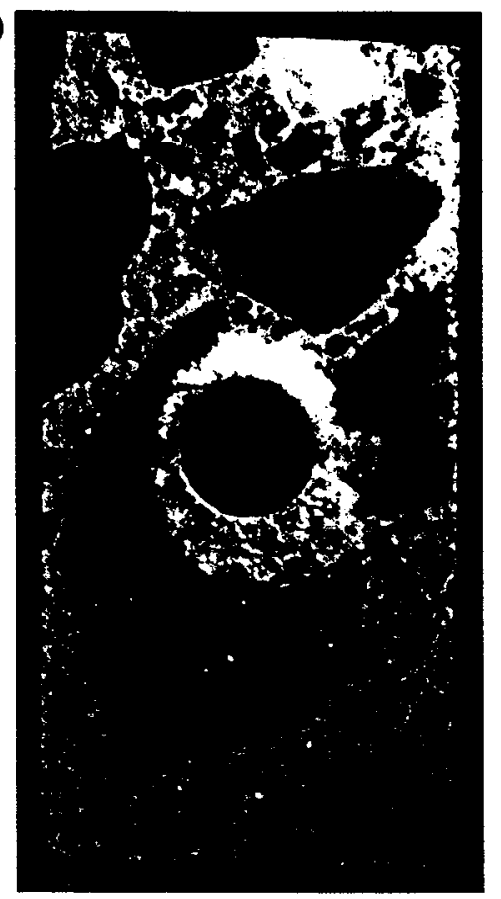

(c)

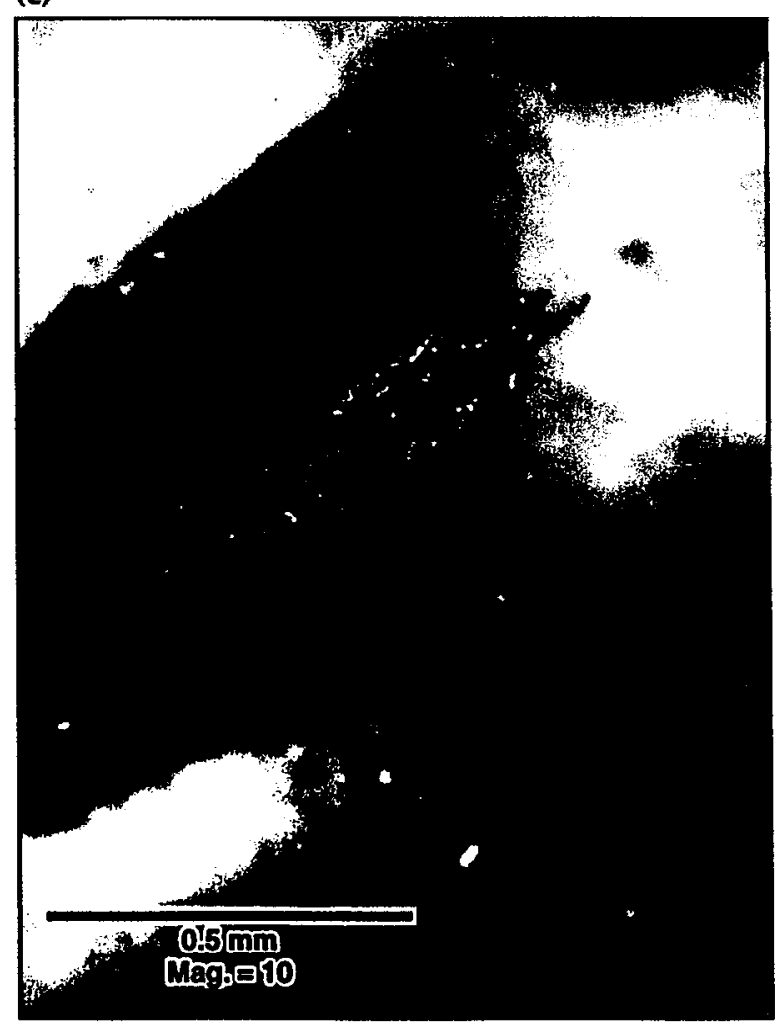

(b)

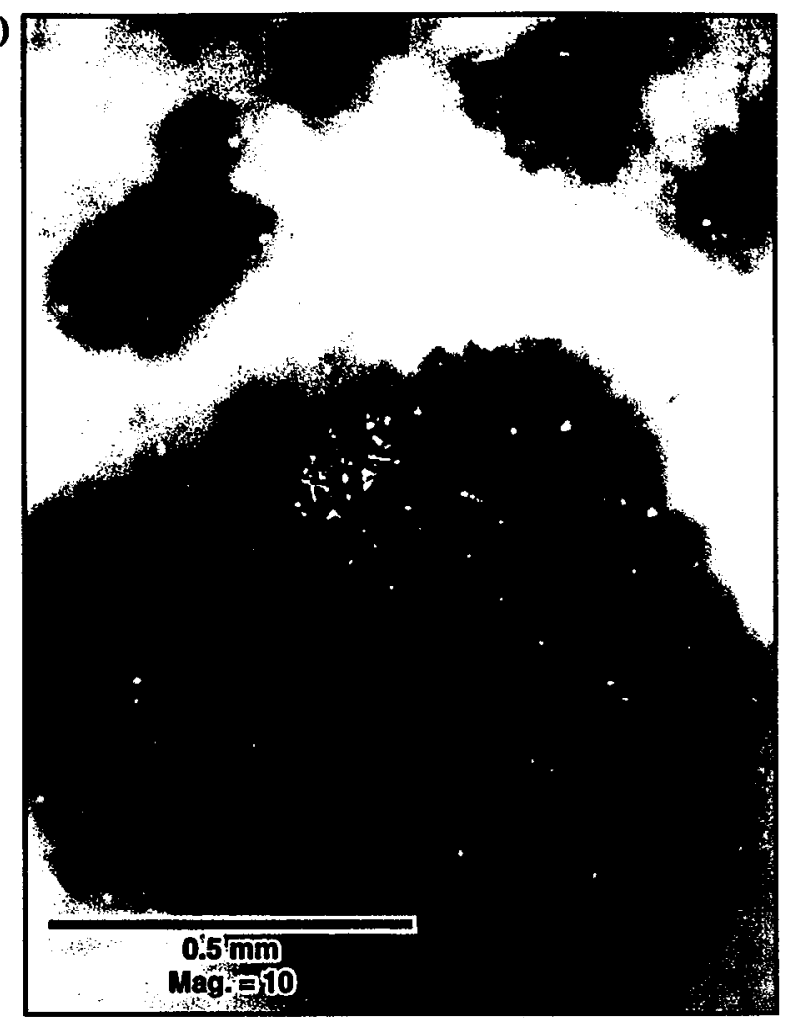

(d)

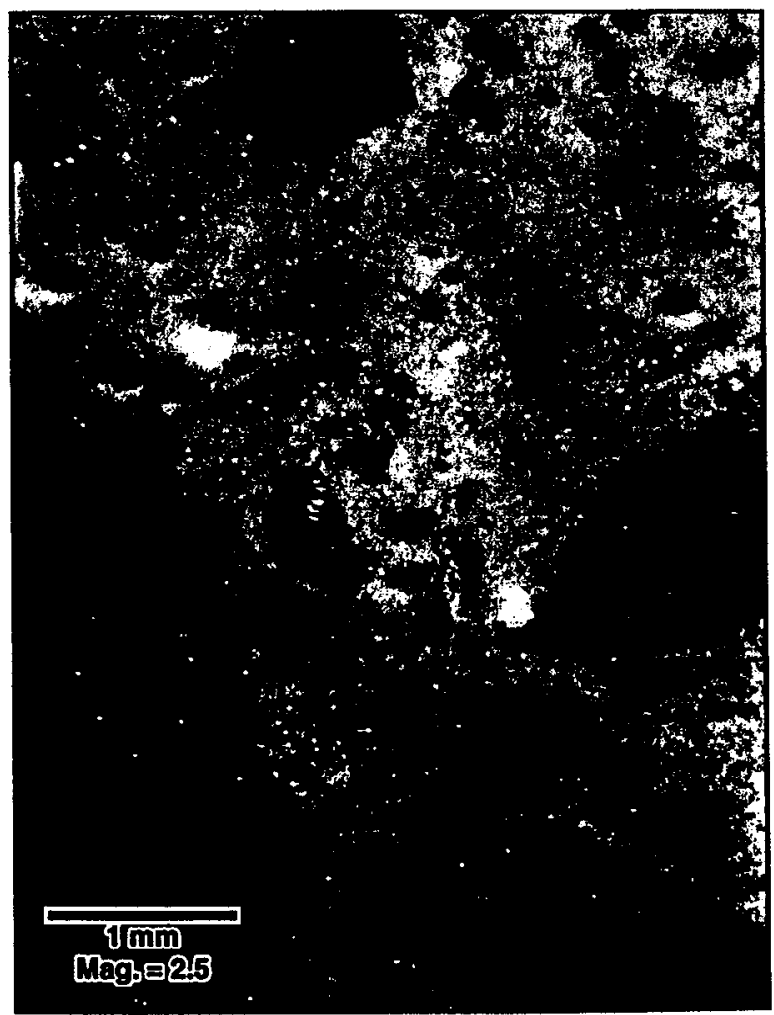

Figure 12. Photographs of sample INV-23a, side 2. (a) In contrast to side 1 , side 2 only shows crust around the central hole. (b) A brown crystal on an aggregate grain. (c) A second brown crystal on aggregate. (d) Lowermagnification photo of the brown crystals, one at each end of the photo. 
(e)

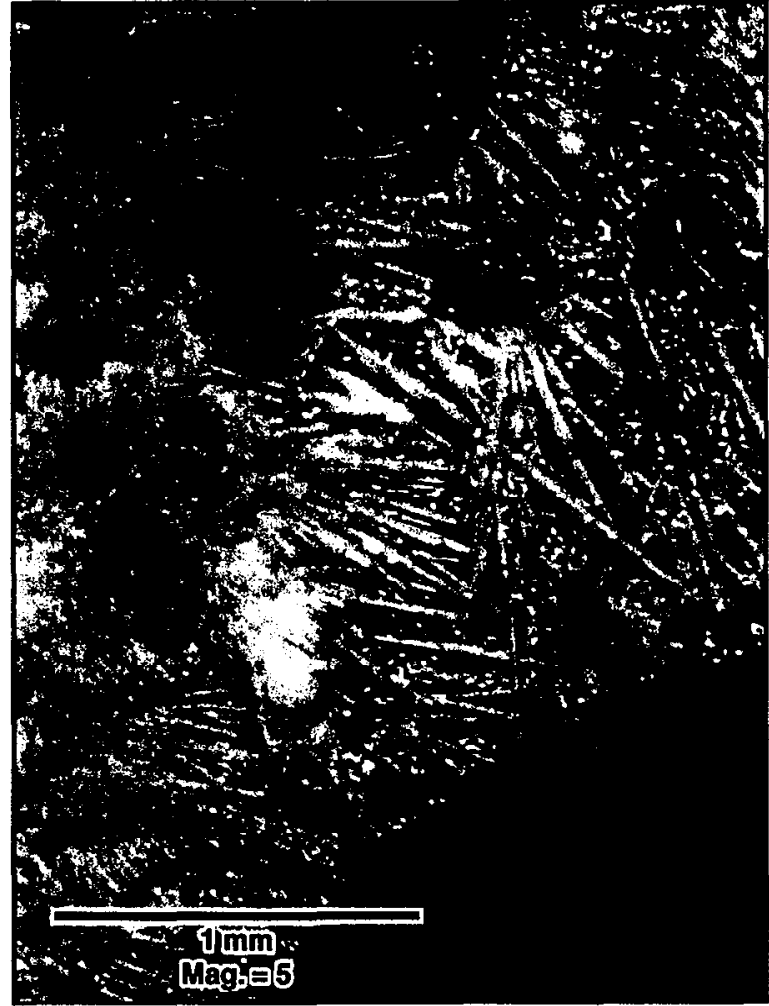

(f)

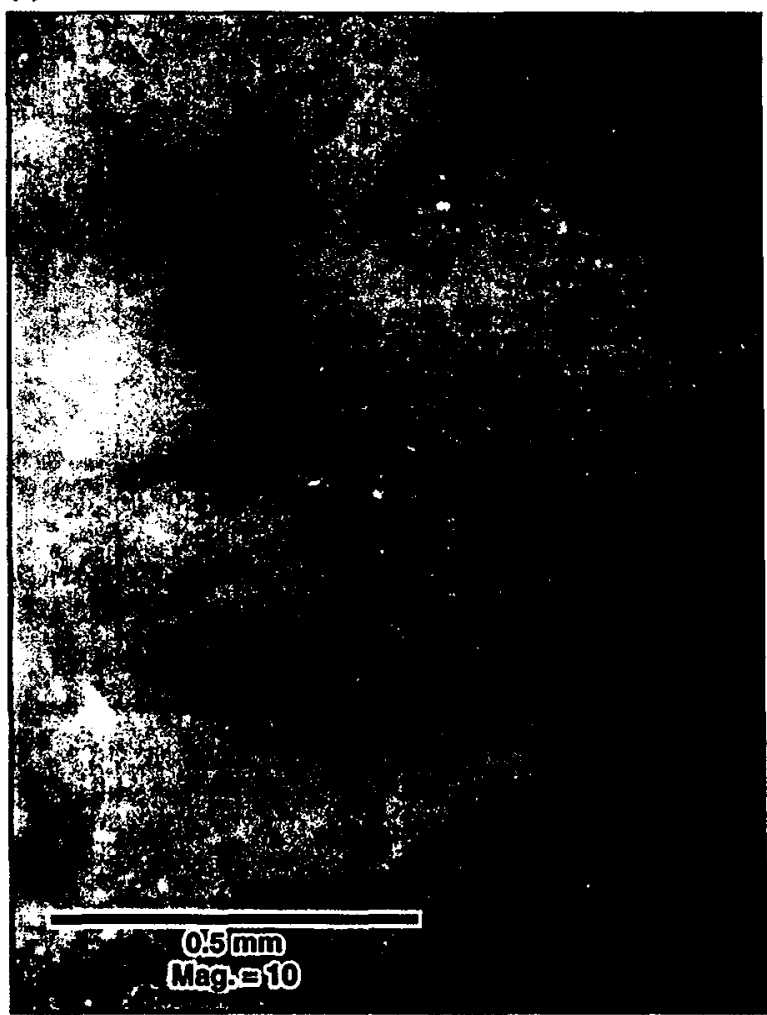

(g)

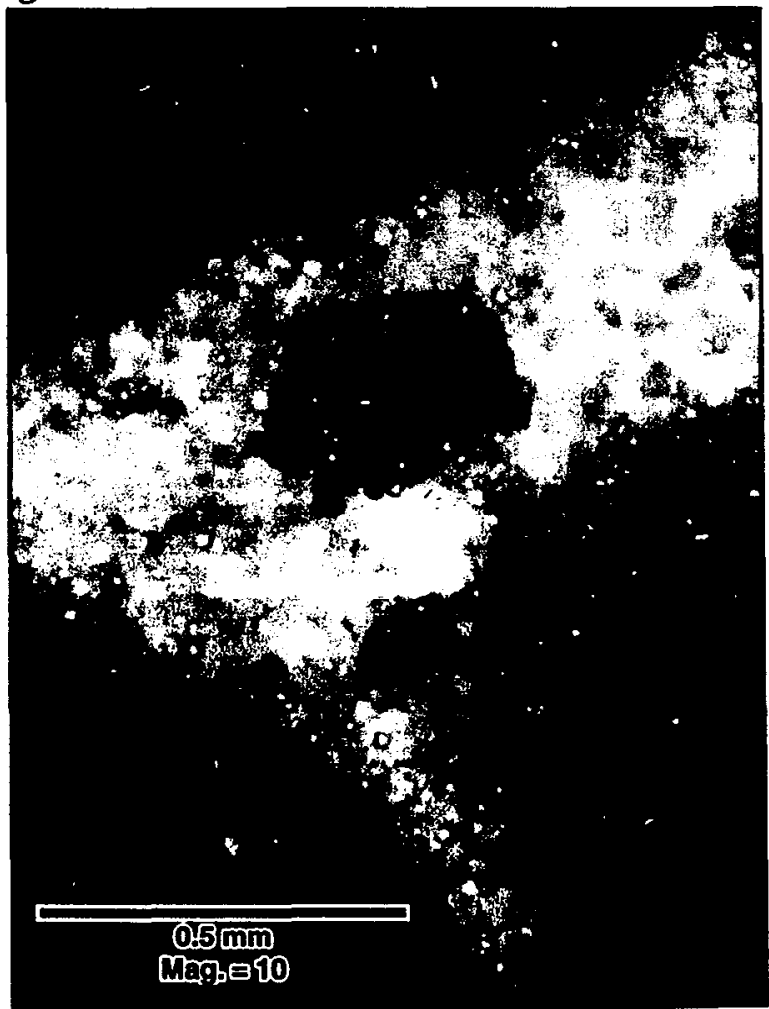

Figure 12 (continued). Photographs of sample INV-23a, side 2. (e) A white, fan-shaped phase occurs around the central hole on both aggregate and grout. (f) A white, granular phase occurs near the edge of the sample on both aggregate and grout. (g) Typical view of the sugary texture of the grout in this sample. 
(a)

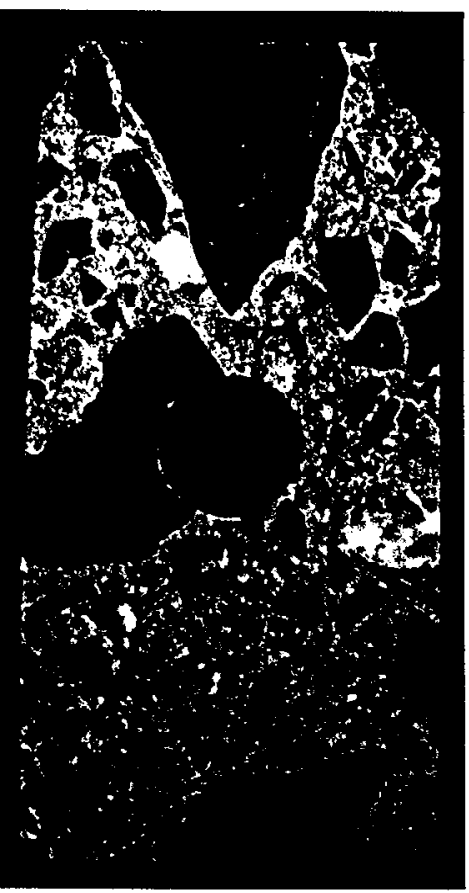

(c)

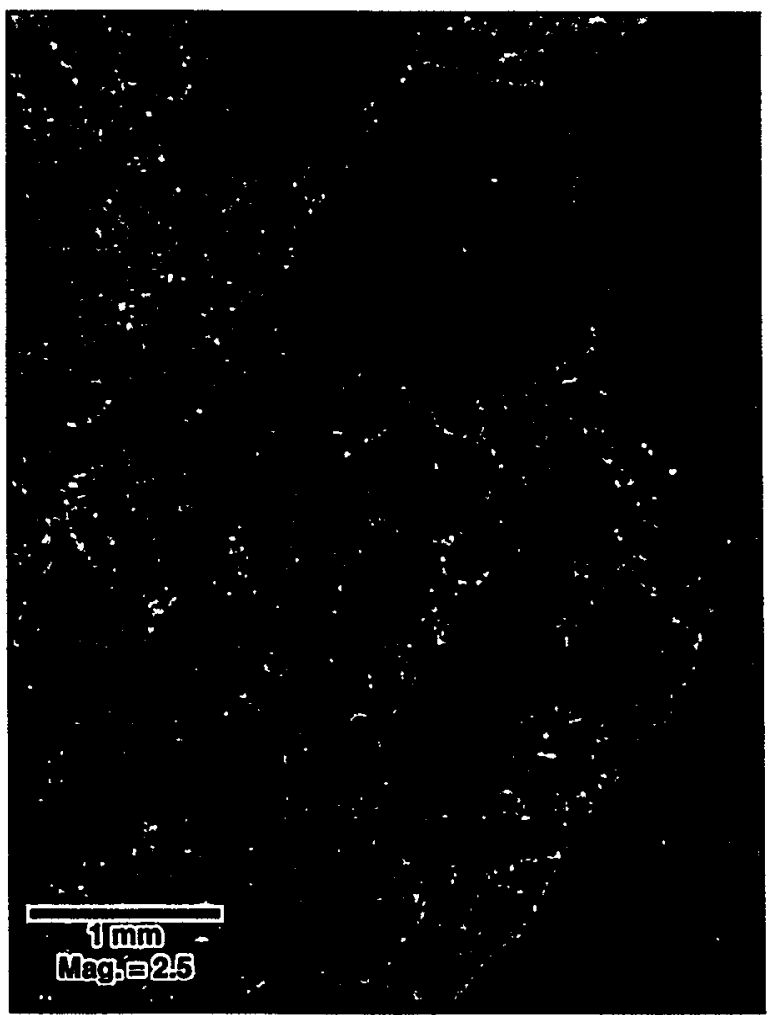

(b)

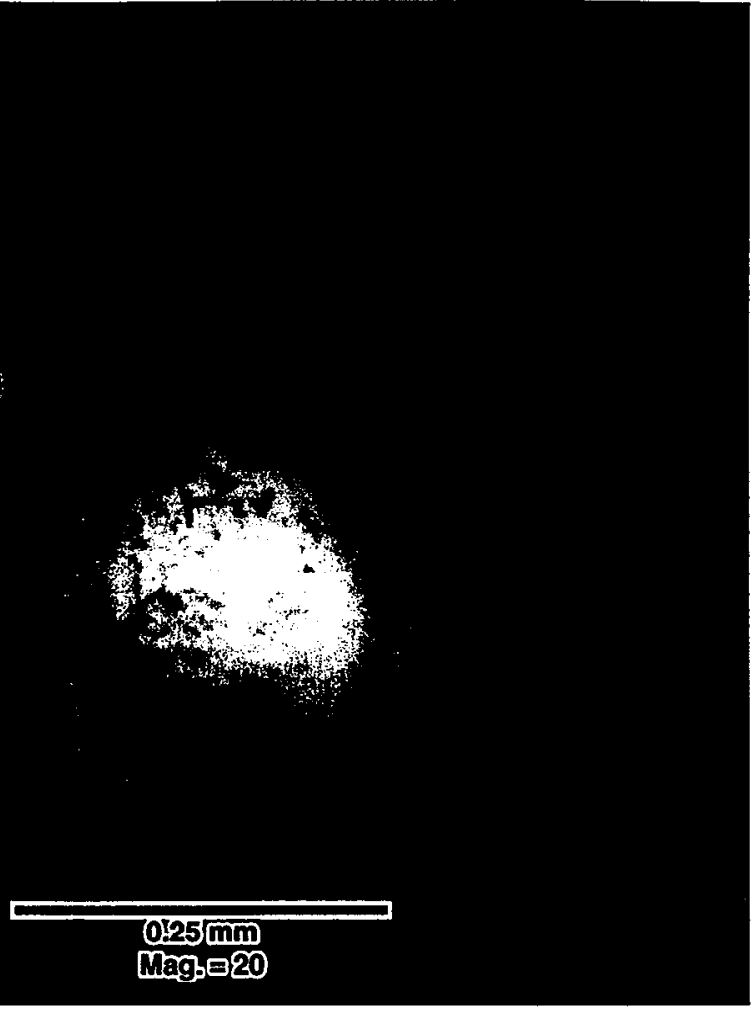

(d)

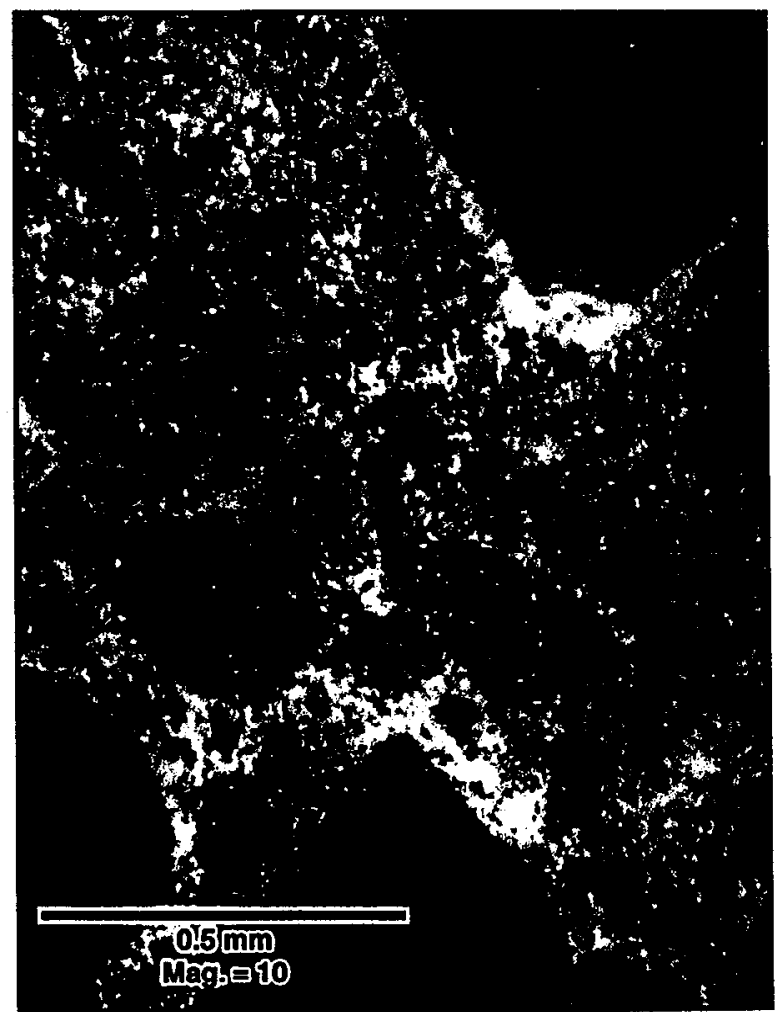

Figure 13. Photographs of sample INV-23b. (a) At this magnification, the sample does not appear to have white rims or other white crystals on it. (b) A pit in grout. Note the white granular phase at the bottom of the pit.

(c) Representative photo showing reddish colored grout and lack of white rims. (d) At higher magnification, faint, flat white rims come into view. 


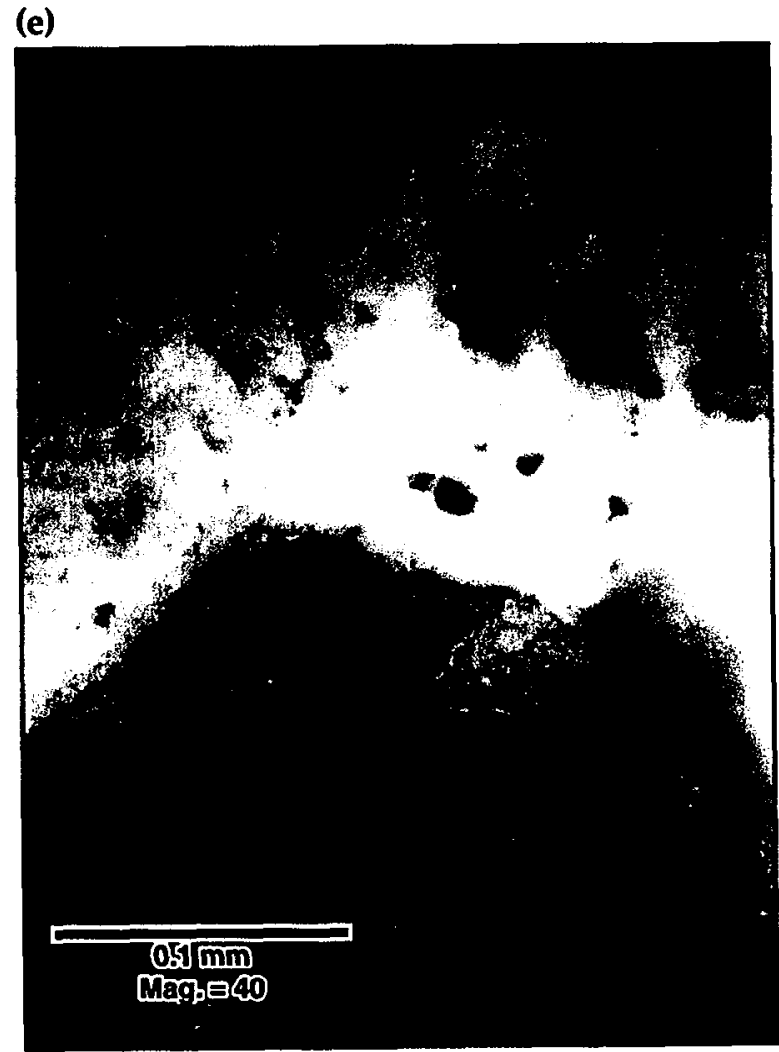

Figure 13 (continued). Photograph of sample INV-23b. (e) At higher magnification, the white rims appear sugary, not spindly. 


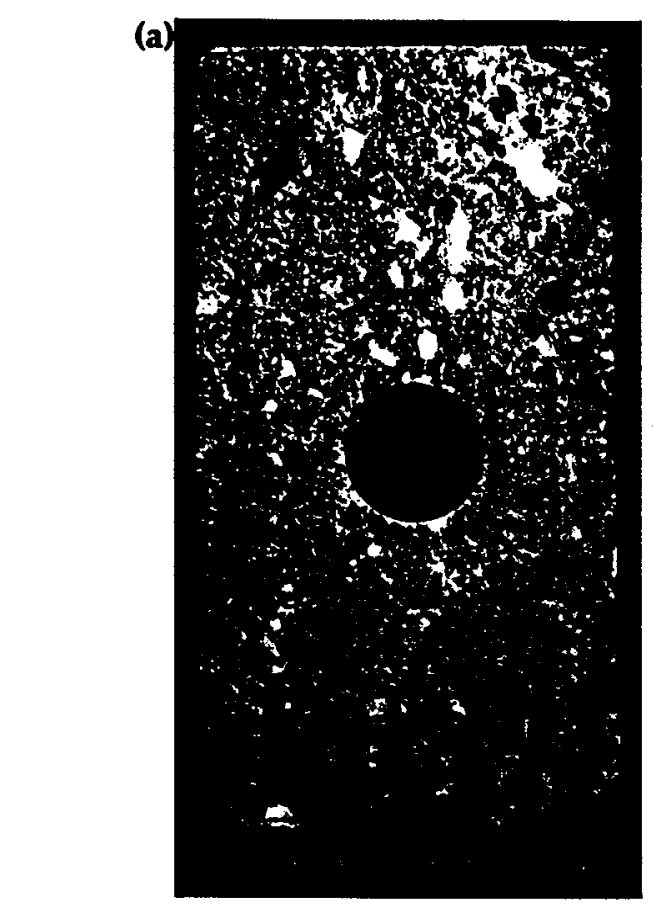

(b)

(c)
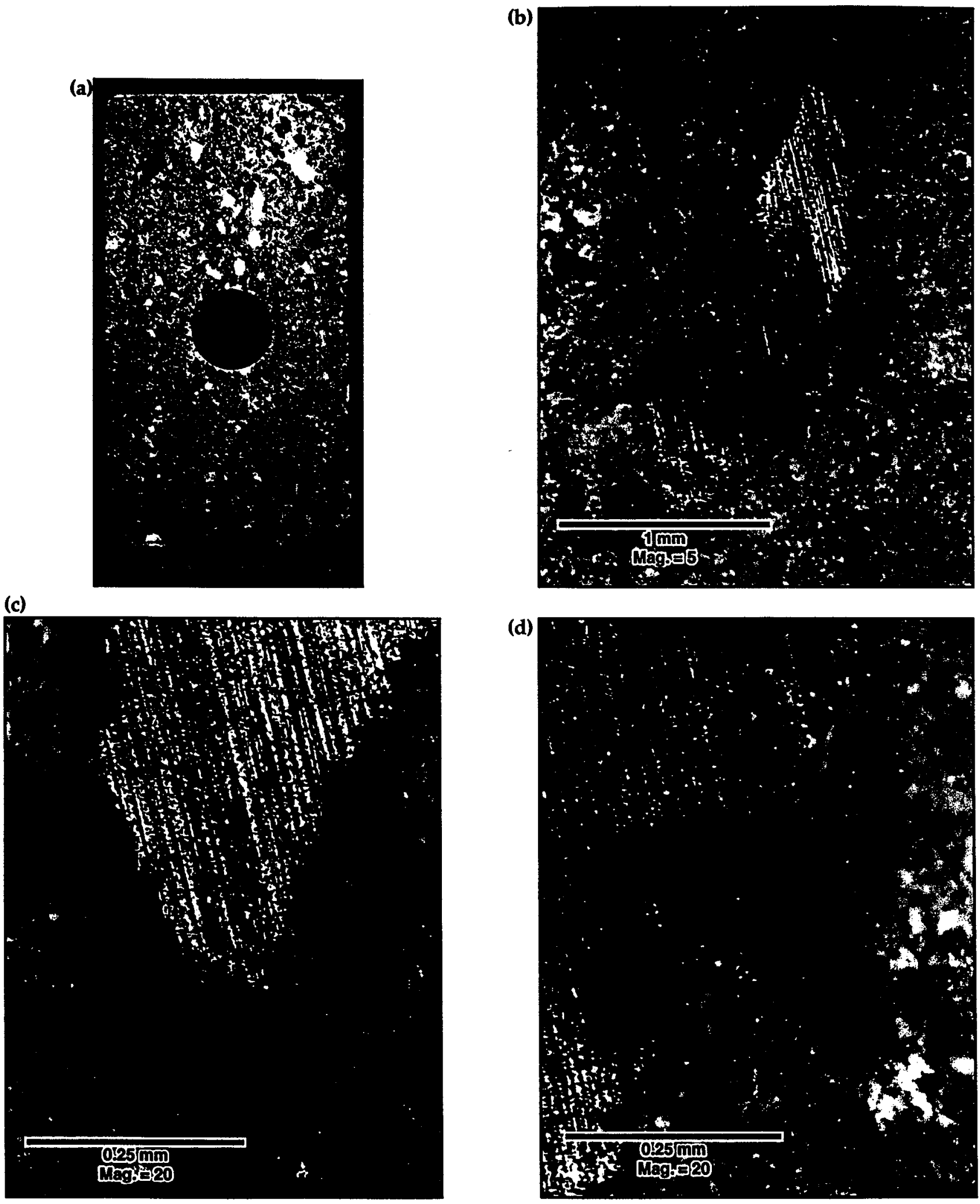

(d)

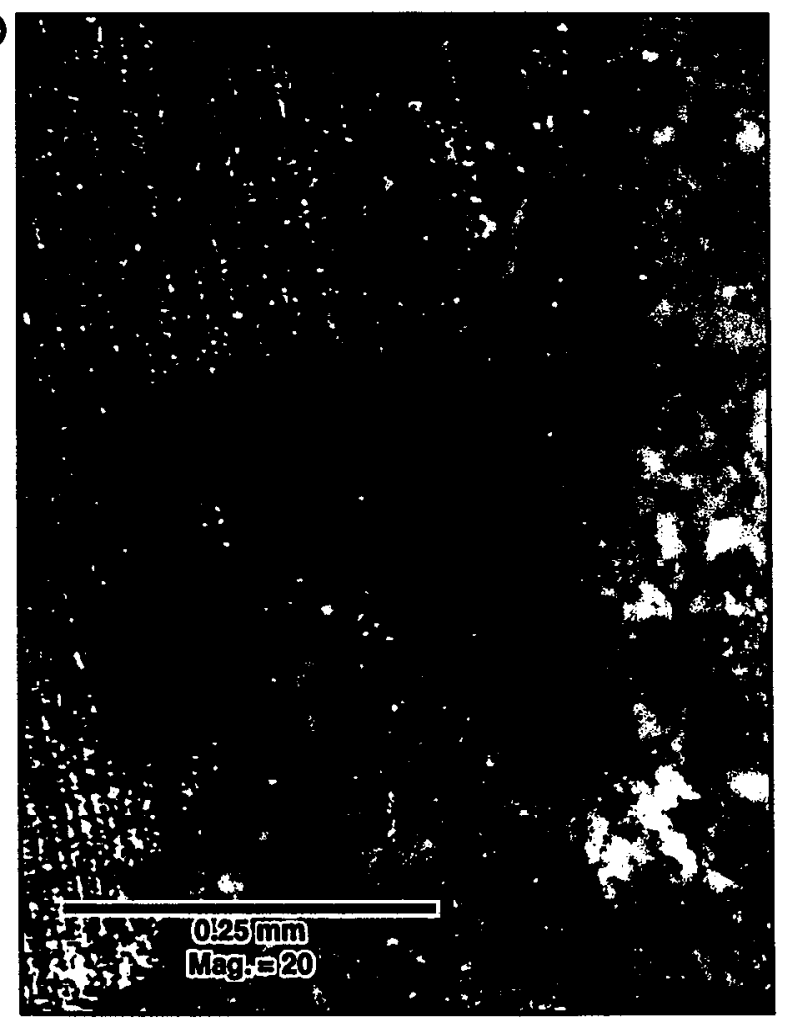

Figure 14. Photographs of sample SH-10. (a) Sample appears relatively unreacted. (b) Probably a stainless steel fiber. (c) A higher-magnification view of a black colored phase on the edge of the fiber. (d) A higher-magnification view of a white stripe and orange stain at the edge of the fiber. 
(e)

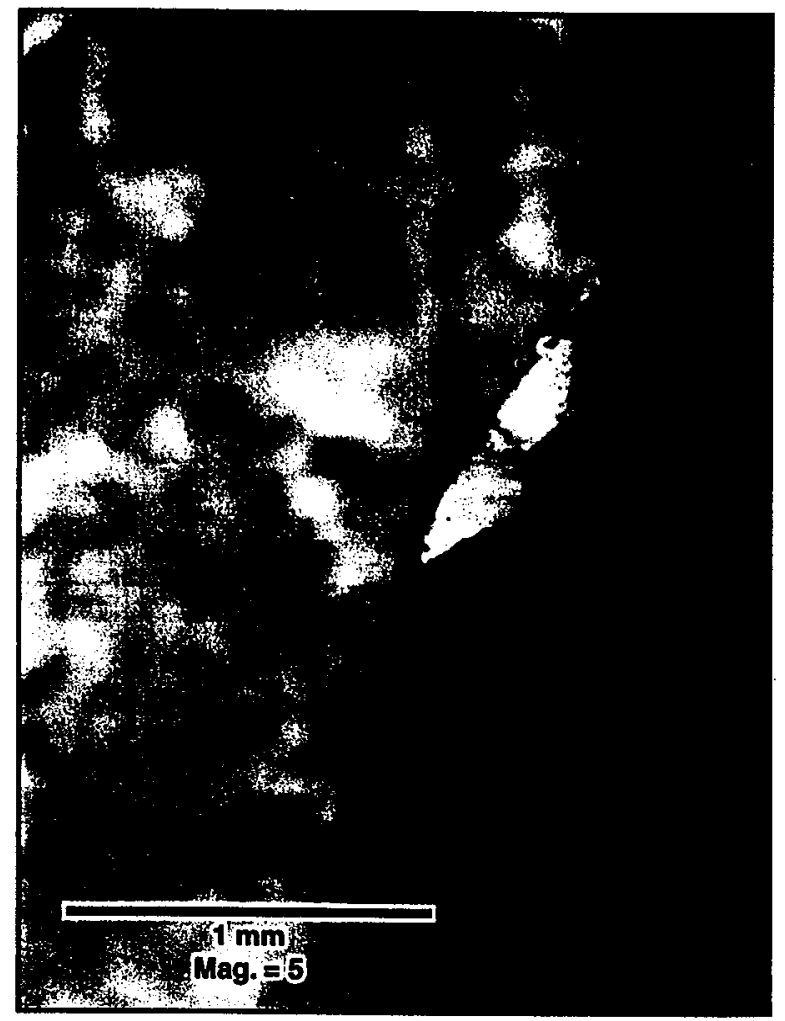

(g)

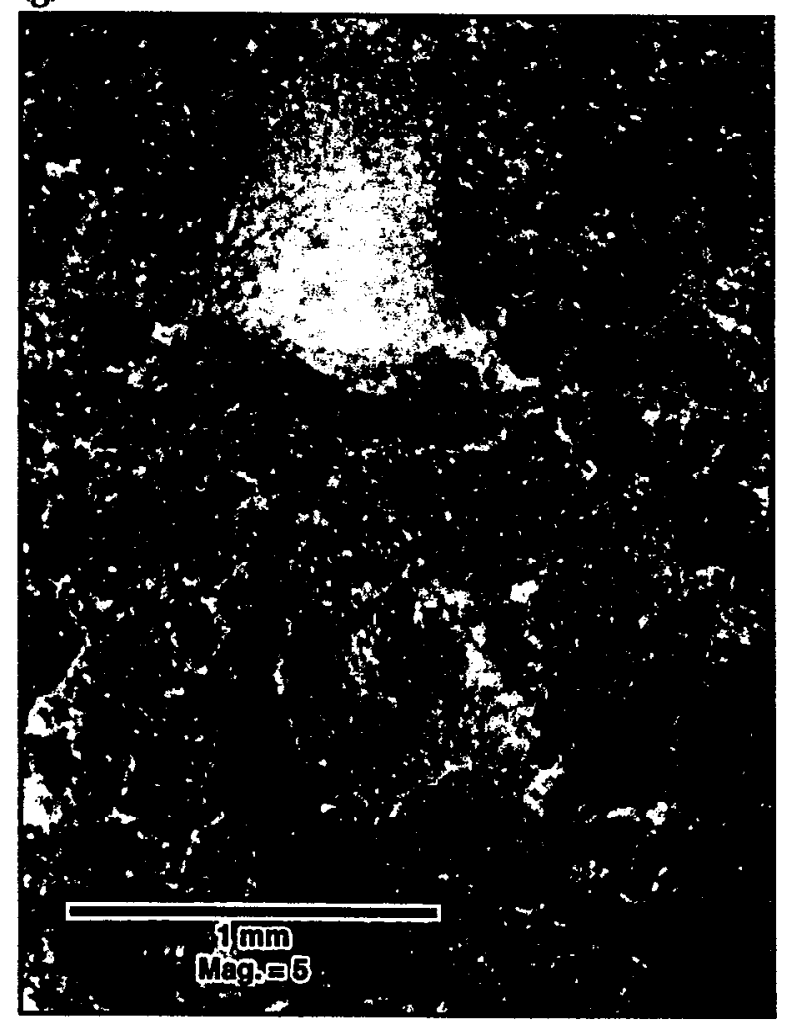

(f)

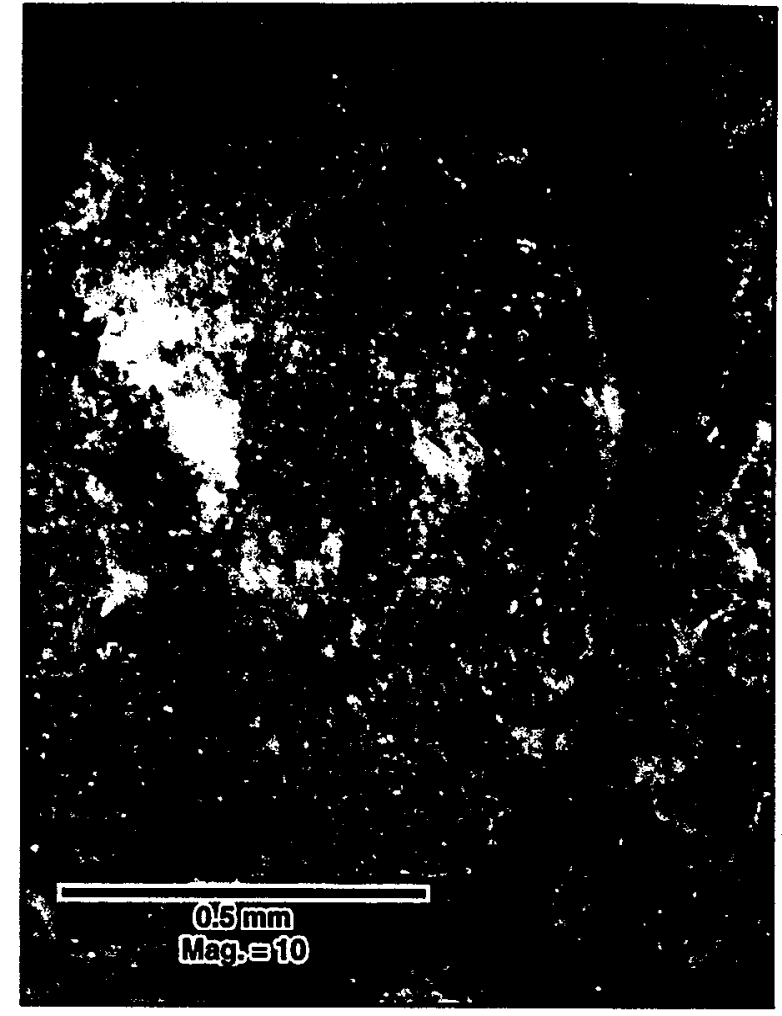

(h)

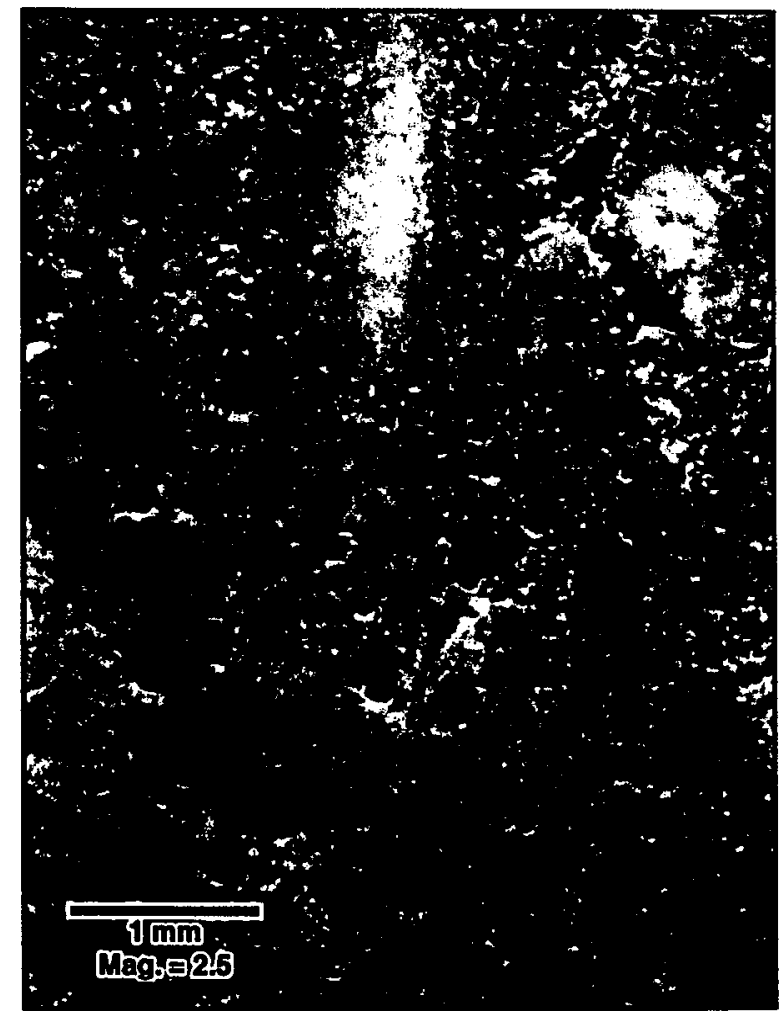

Figure 14 (continued). Photographs of sample SH-10. (e) Two white crystals attached to the central hole. (f) An aggregate grain with a yellow colored phase or stain within it. $(\mathrm{g})$ Lower-magnification view of the grain with the yellow patch. (h) Representative photo showing the abundance of pits in this sample. 
(a)

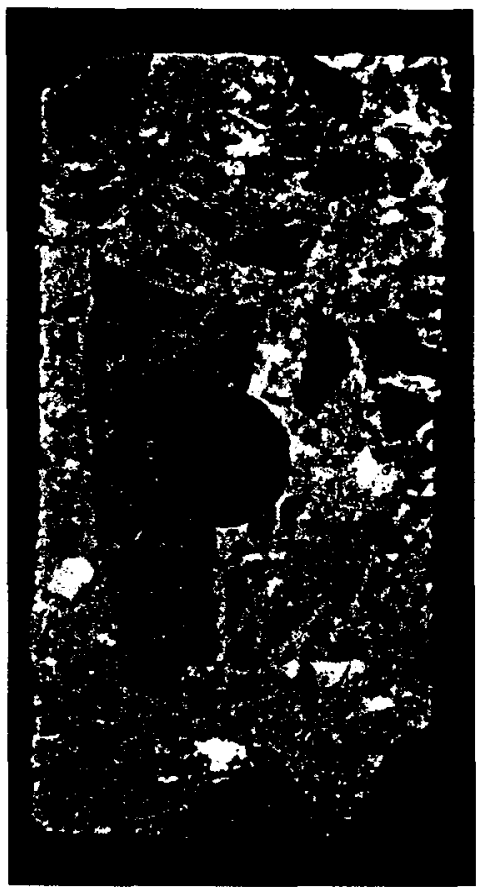

(c)

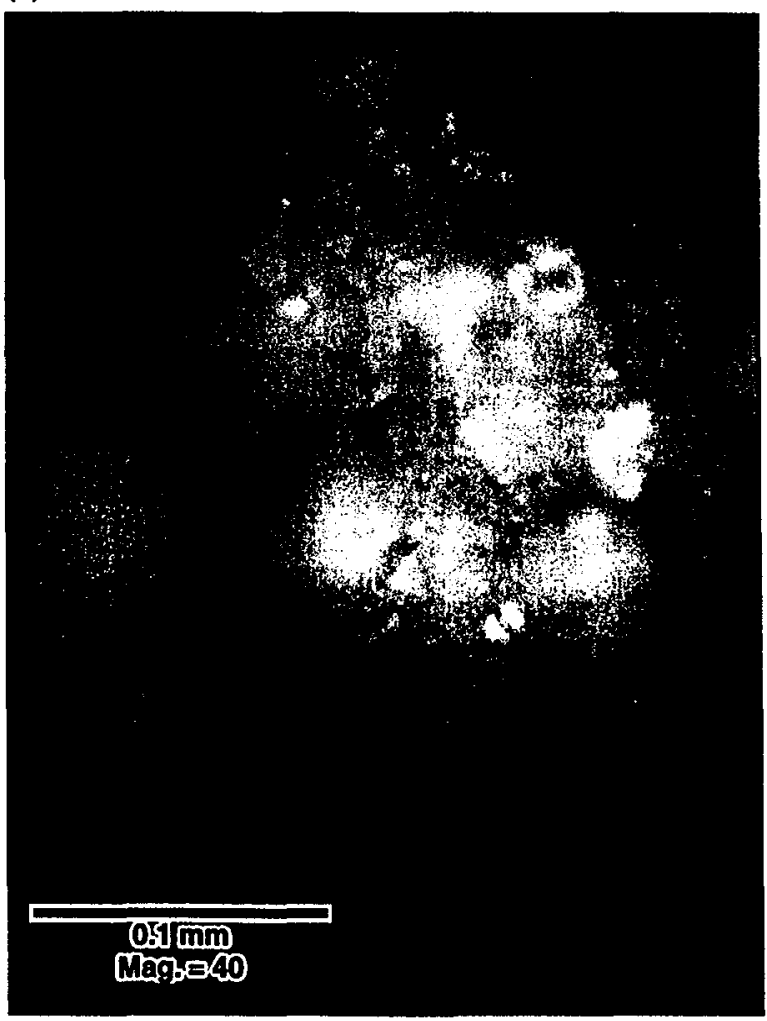

(b)

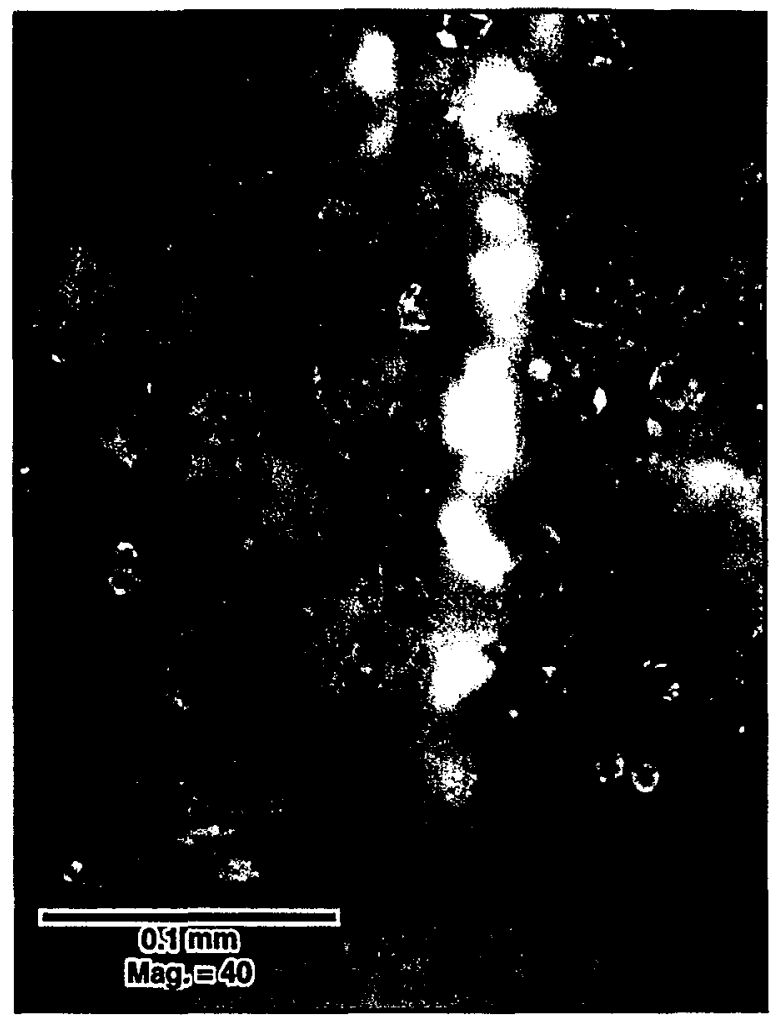

(d)

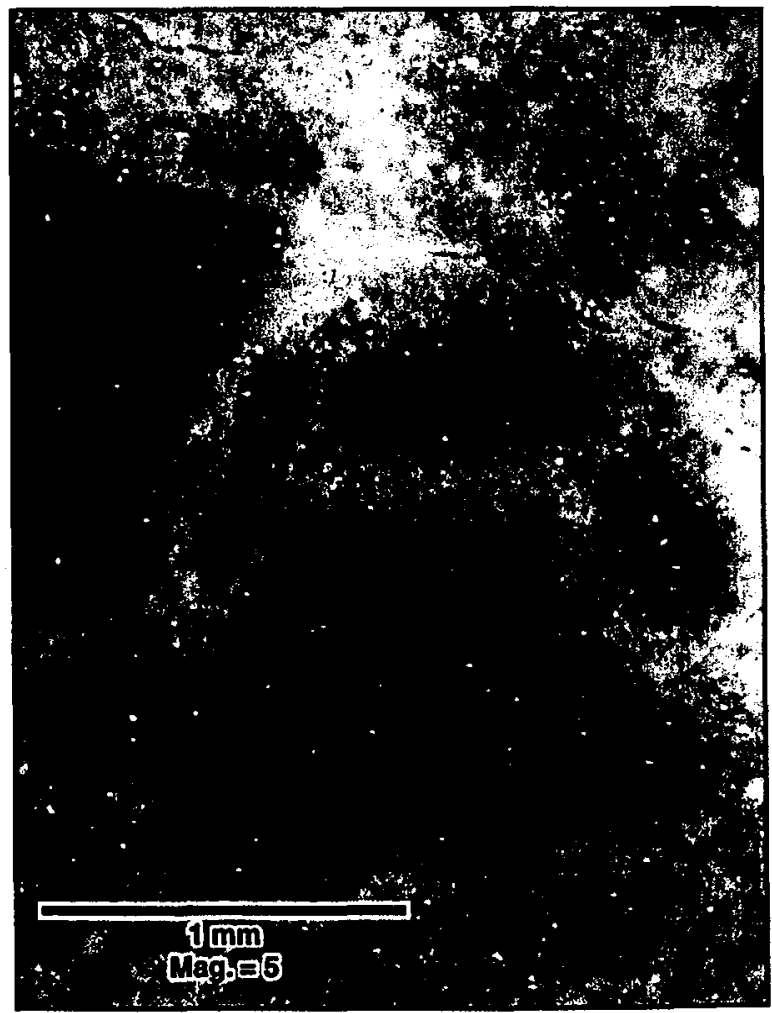

Figure 15. Photograph of sample INV-28, side 1. (a) Both sides of this sample were photographed because they were so different. Side 1 has no white crust. (b) Euhedral crystals coating aggregate. (c) Euhedral crystals on grout. (d) Typical texture with no white rims present. 
(a)

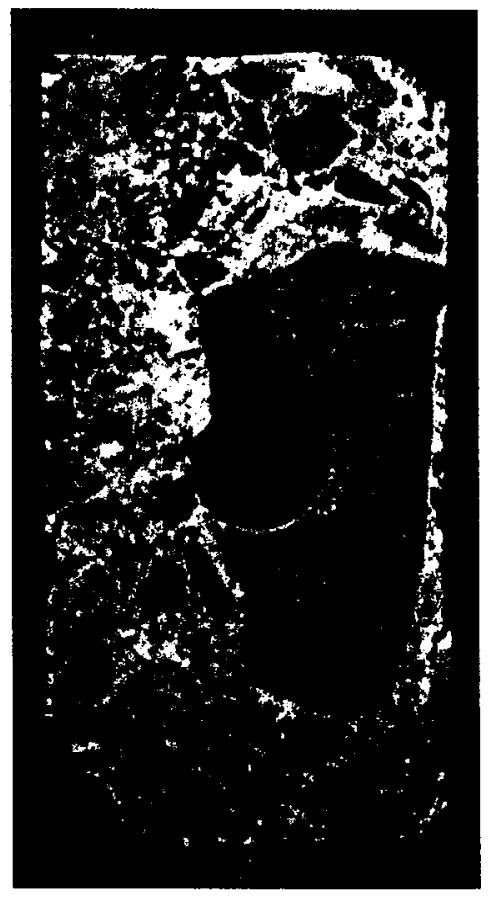

(b)

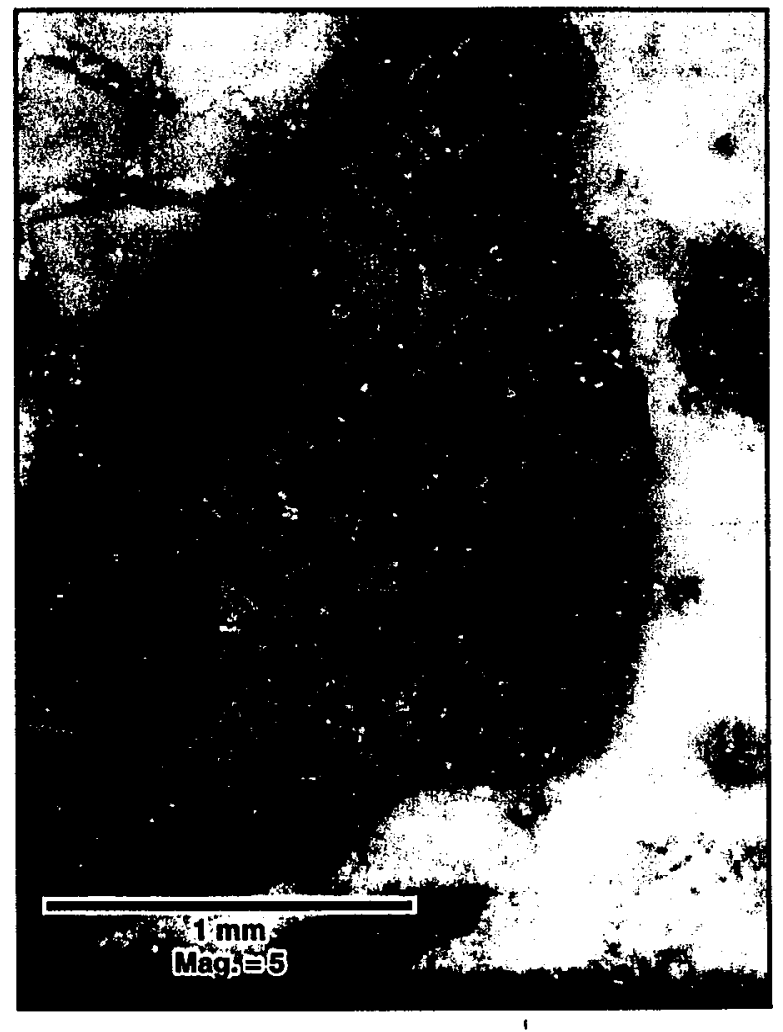

Figure 16. Photograph of sample INV-28, side 2. (a) Side 2 is nearly covered with a white crust. (b) White crust partially coating aggregate and grout. Euhedral crystals also occur on this side of the sample, however they are not as abundant. 
(a)

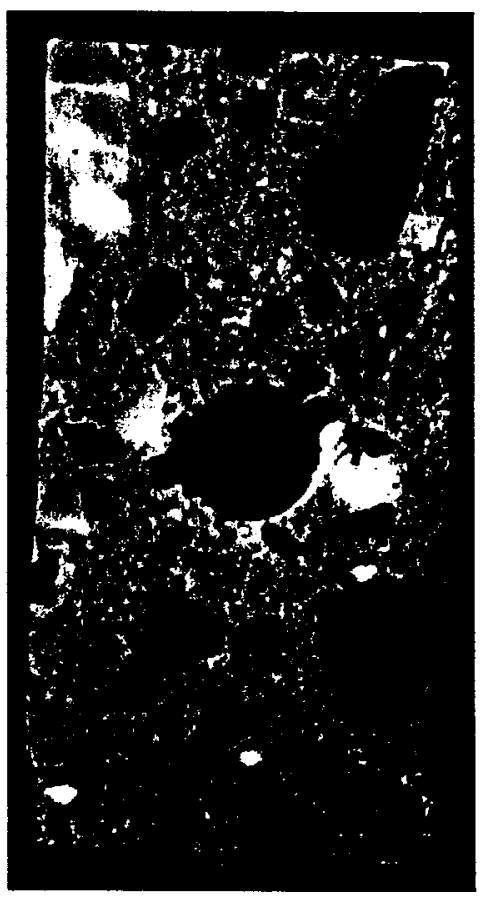

(b)

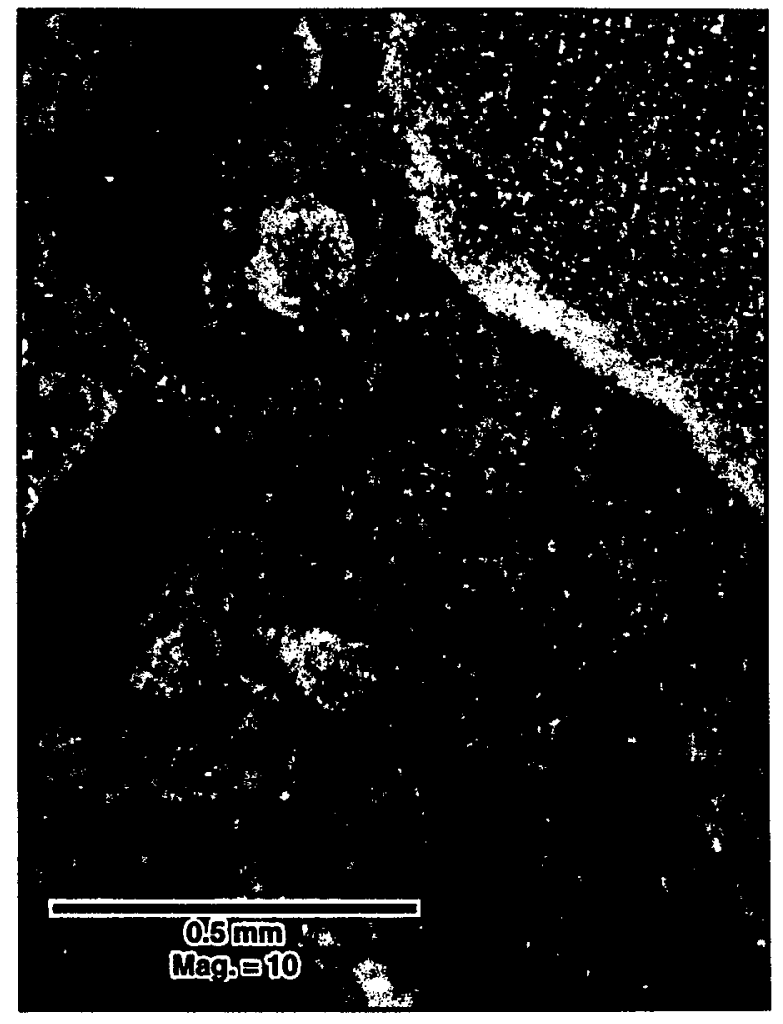

Figure 17. Photographs of sample INV-29. (a) Whole specimen. (b) Typical view of the sample with very few, if any, white rims on grains. The light gray grain may have a white rim, but not of the thickness and development of rims seen in other samples. 
(b)

(a)

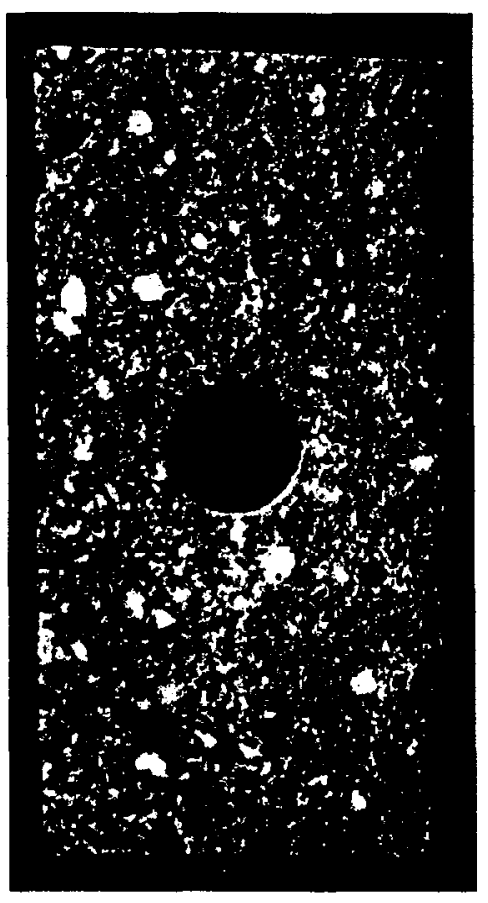

\section{(b)}

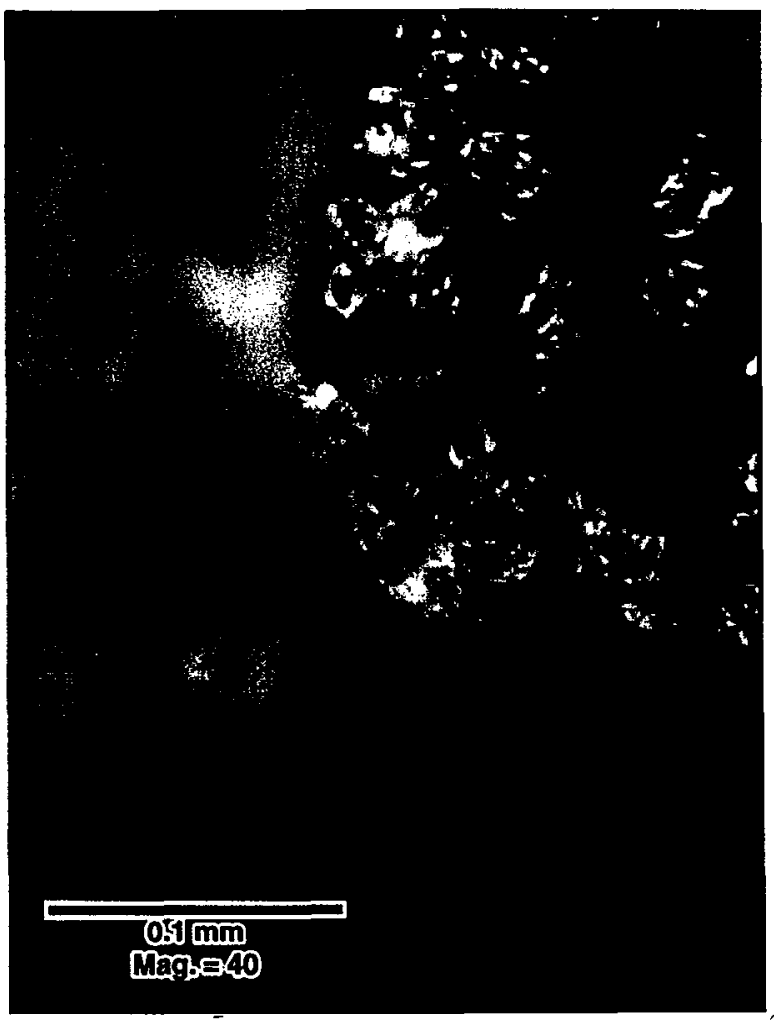

Figure 18. Photograph of sample SH-3. (a) Whole specimen. (b) Tiny crystals on aggregate are widespread on the sample, and occur sparsely on grout also. Note the orange hue of the grout (out of focus). 
(a)

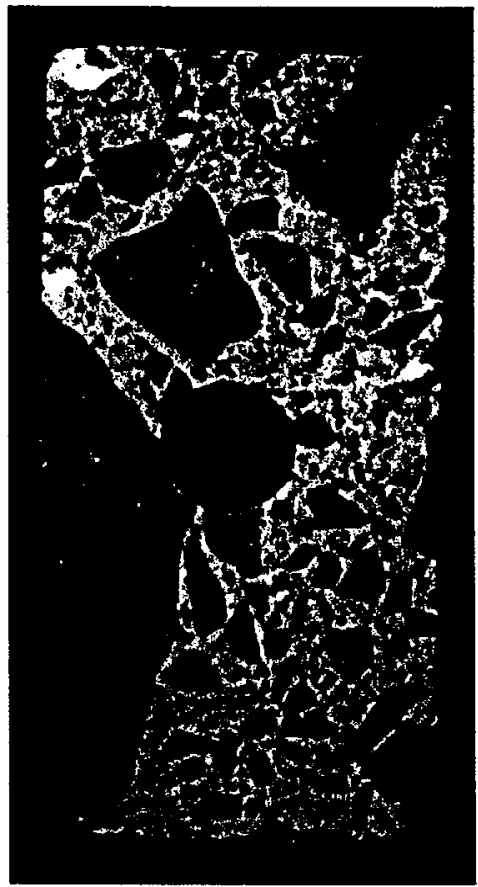

(c)

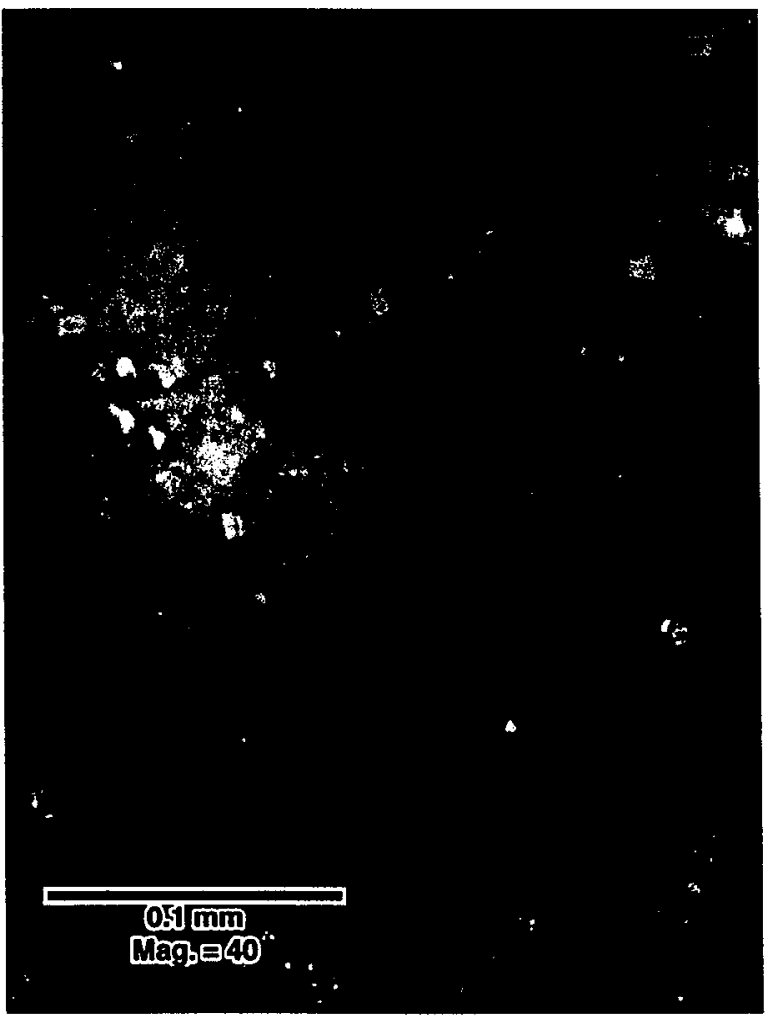

(b)

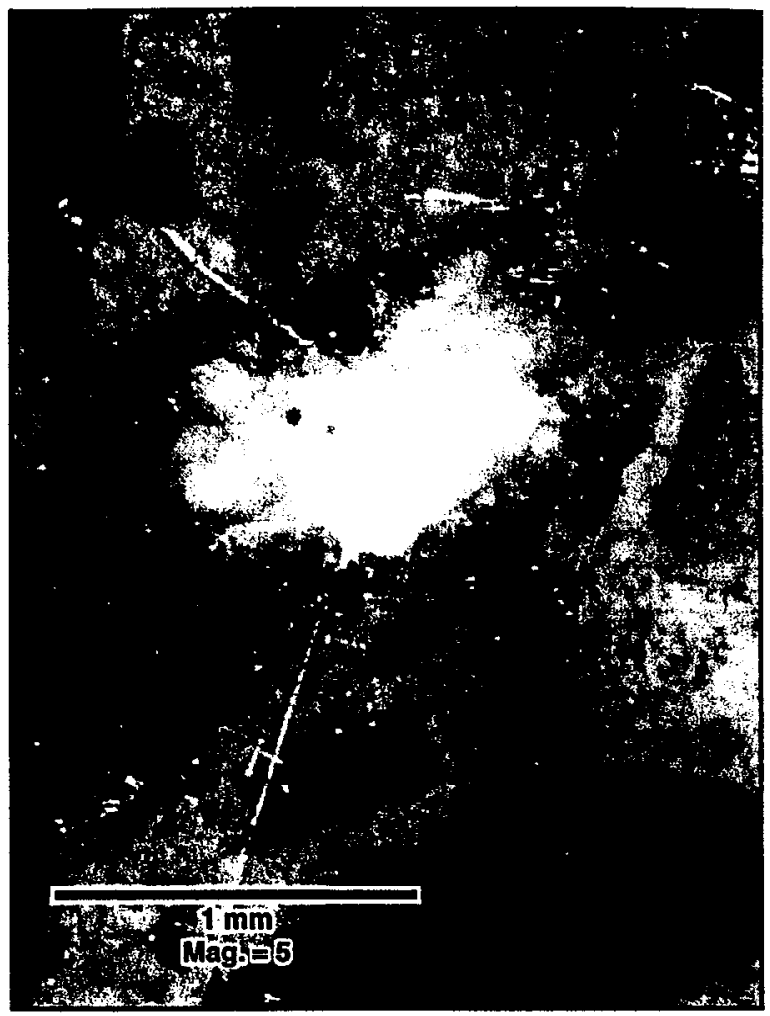

(d)

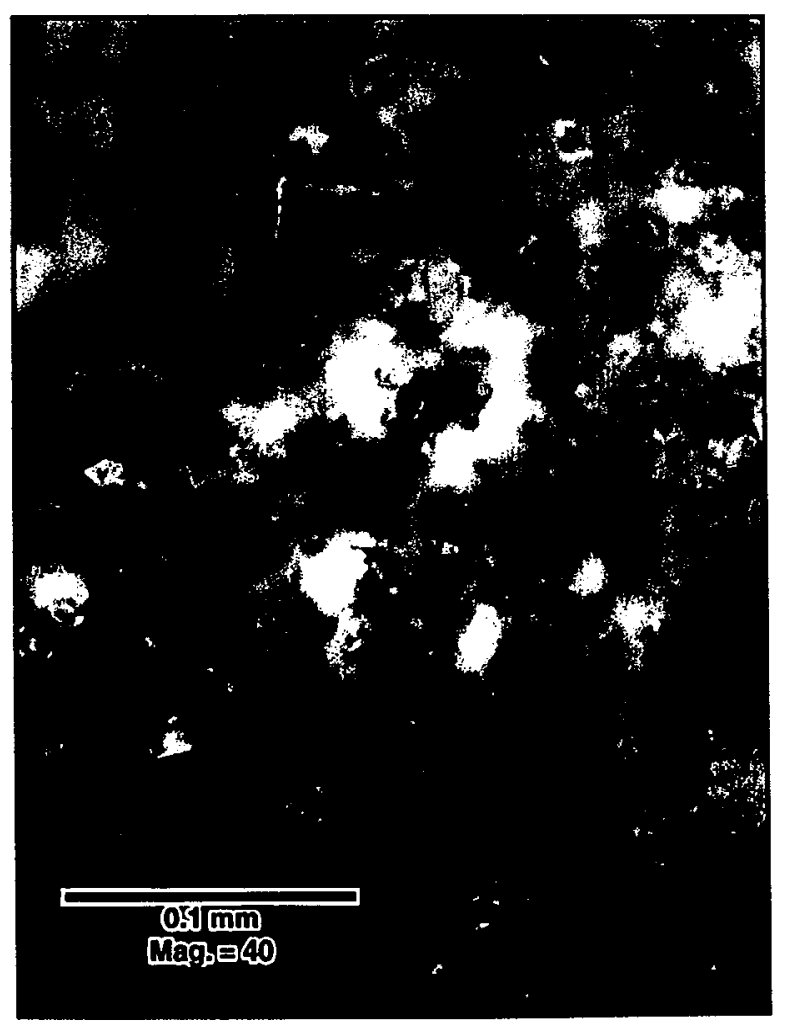

Figure 22. Photographs of sample INV-32. (a) Sample appears to be relatively unreacted. (b) A white, radiating crystal cluster on an aggregate grain. Four crystal clusters occur on the sample, all on aggregate. The photo also illustrates the typical texture of the grains and grout in this sample. (c) Tiny cubic crystals on the surface of a reddish aggregate grain. The focus is above the aggregate grain, on the tiny crystals. (d) Tiny cubic crystals on the surface of a gray aggregate grain. The focus is above the aggregate grain, on the tiny crystals. 


\section{(e)}

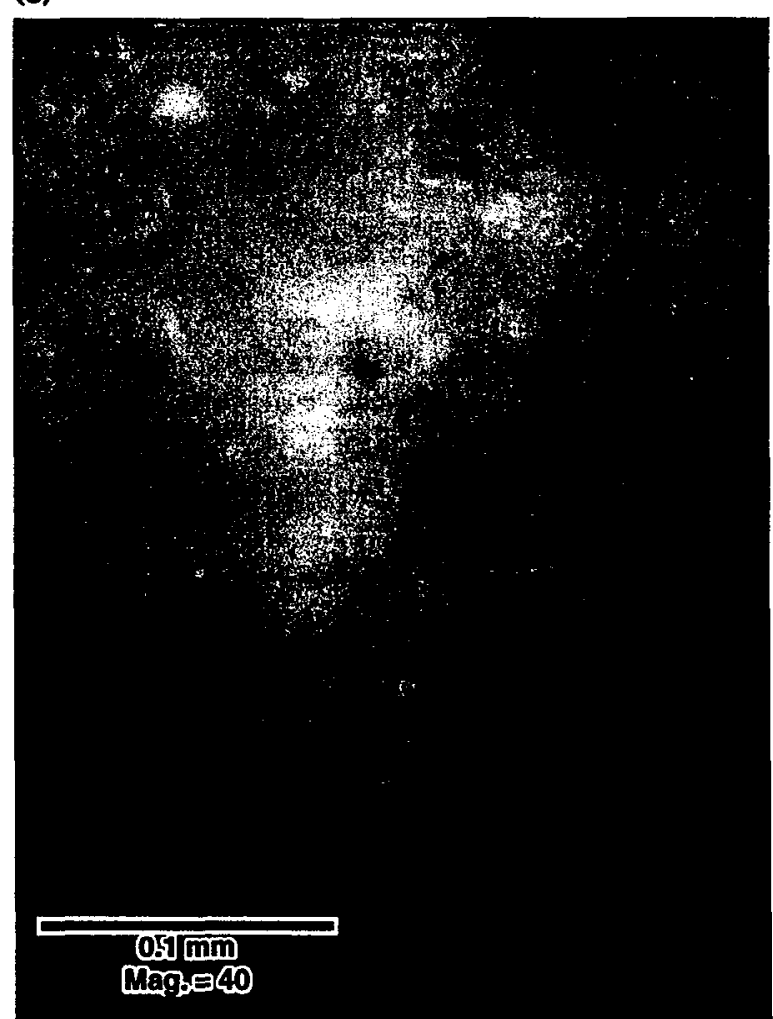

Figure 22 (continued). Photograph of sample INV-32. (e) Tiny cubic crystals on grout. The crystals are more difficult to see on grout, possibly due to the light color. 
(a)

(c)
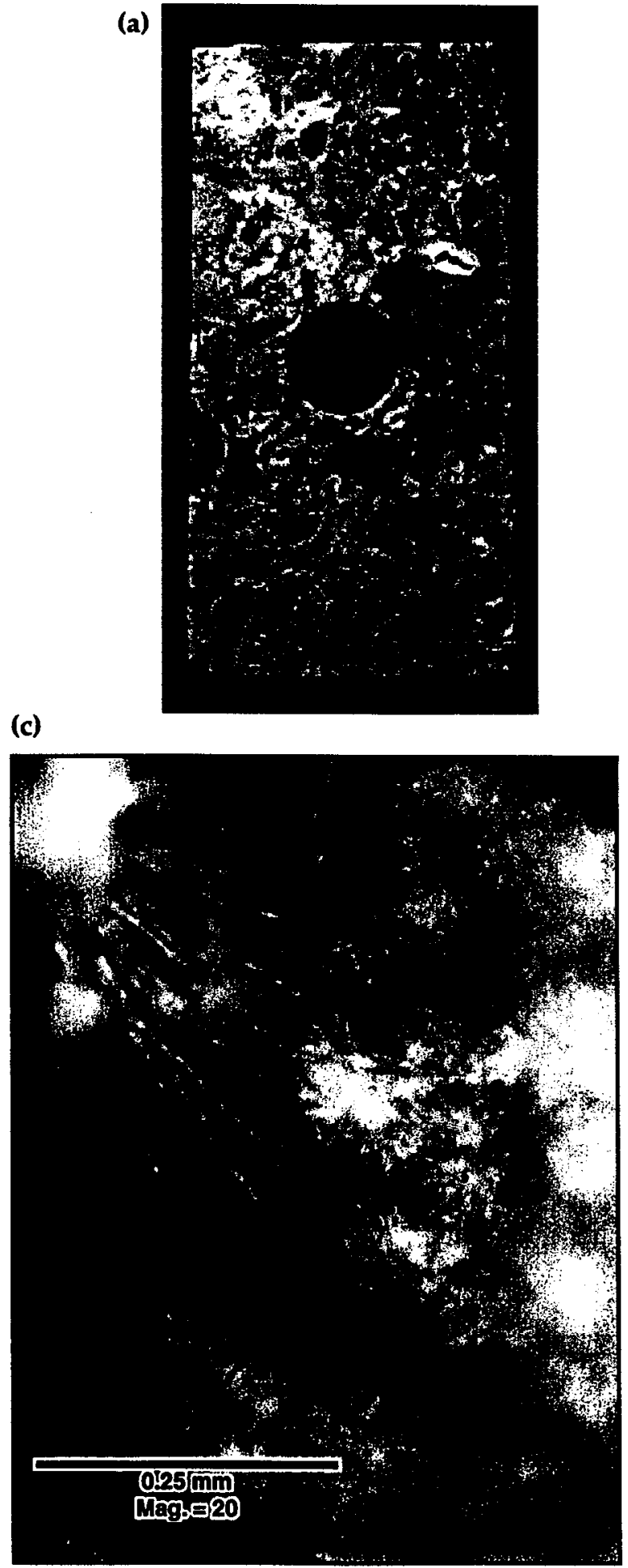

(b)

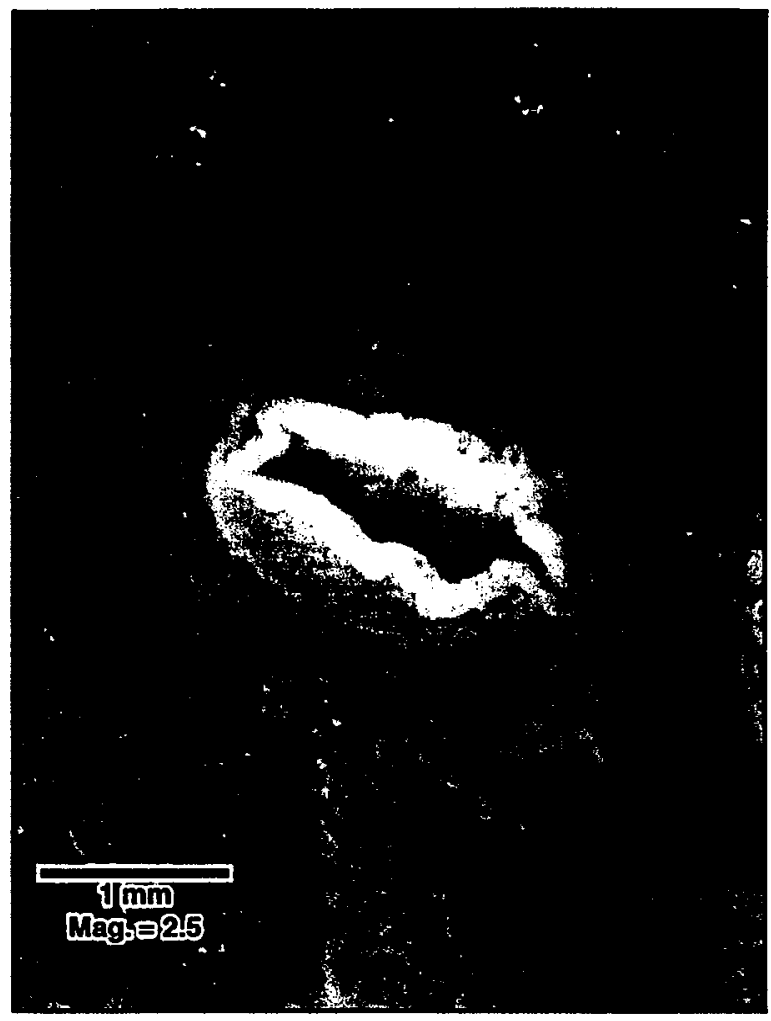

(d)

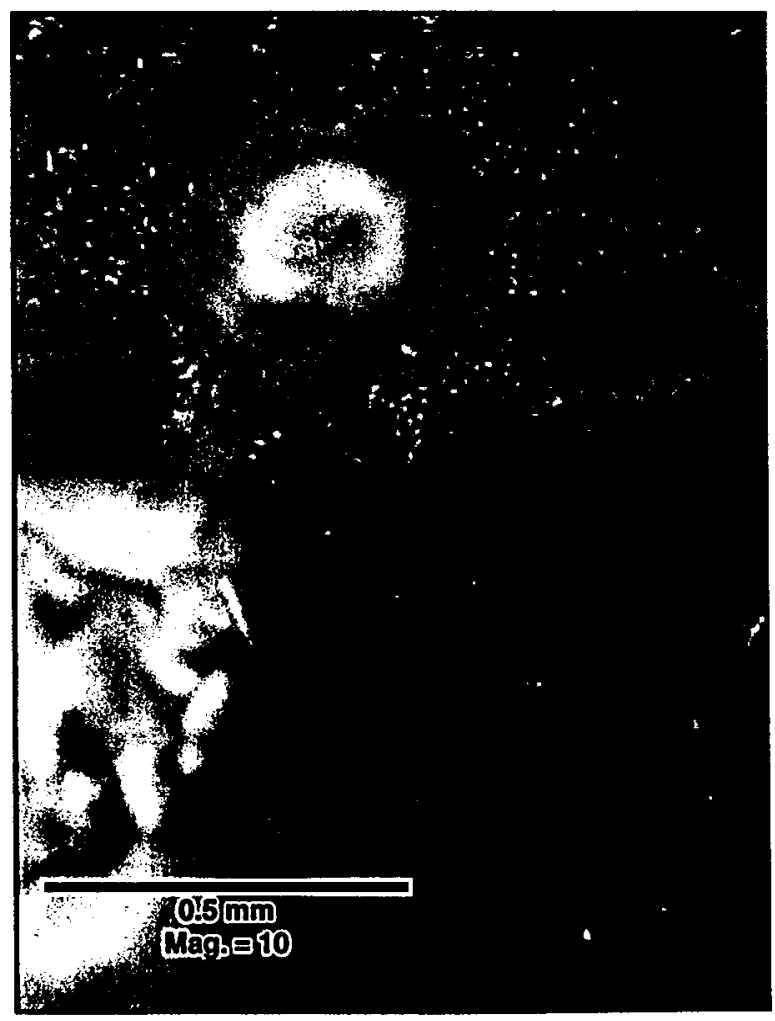

Figure 23. Photographs of sample INV-33. (a) White rims occur around some aggregate grains. A white crust sparsely coats some of the sample. (b) A raised white rim within an aggregate grain. Only one raised rim occurs on each side of the sample. (c) Two morphologies of the white crust that sparsely coat the sample. The examples in the photo are shown on aggregate. (d) A patch of noncoated area containing a small grain with a white rim. 
(a)

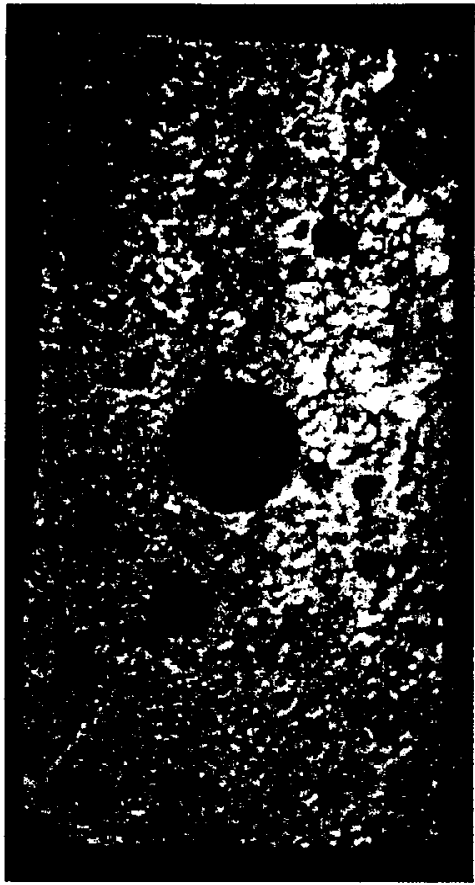

(b)

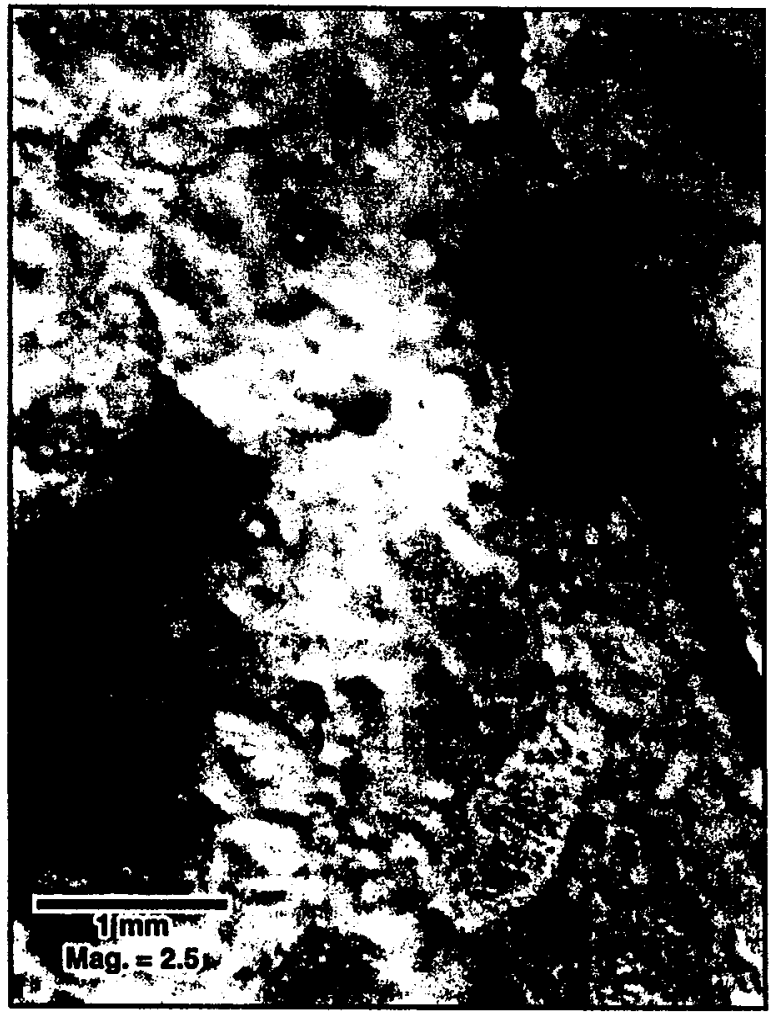

(c)

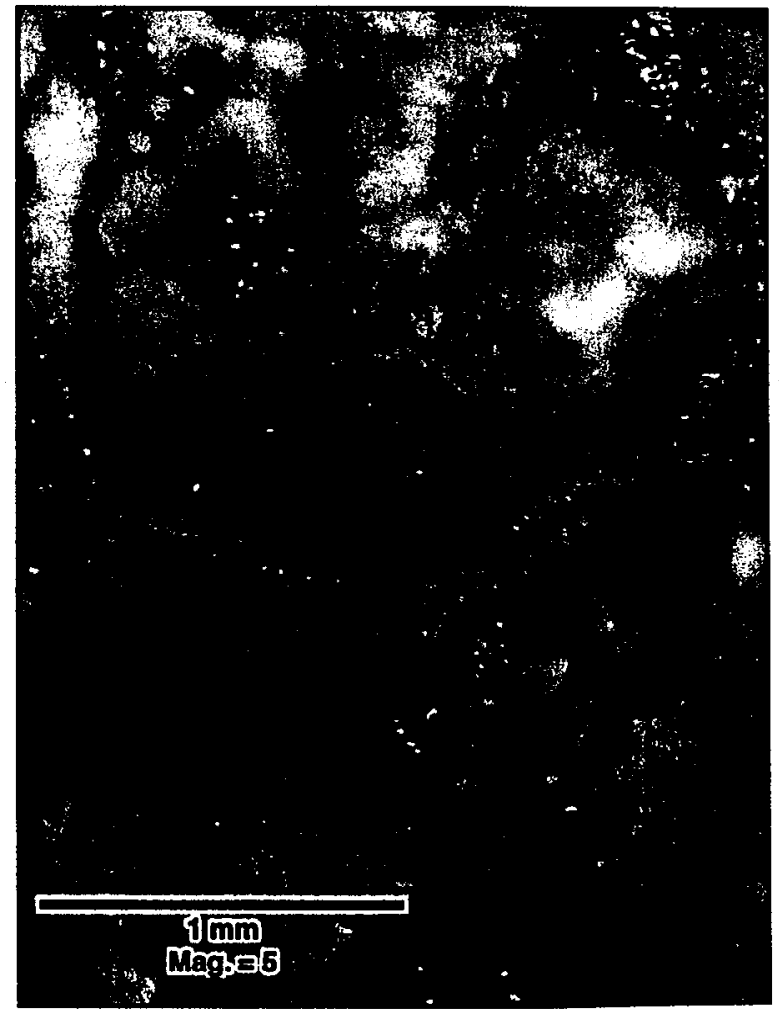

Figure 24. Photographs of sample SH-4. (a) The sample contains numerous grains with white rims. Note the crack in the corner of the sample. (b) A grain with a rusty appearance occurs in the crack near the corner of the sample. (c) Higher-magnification view of the white rims around many of the grains in the sample. 
(a)

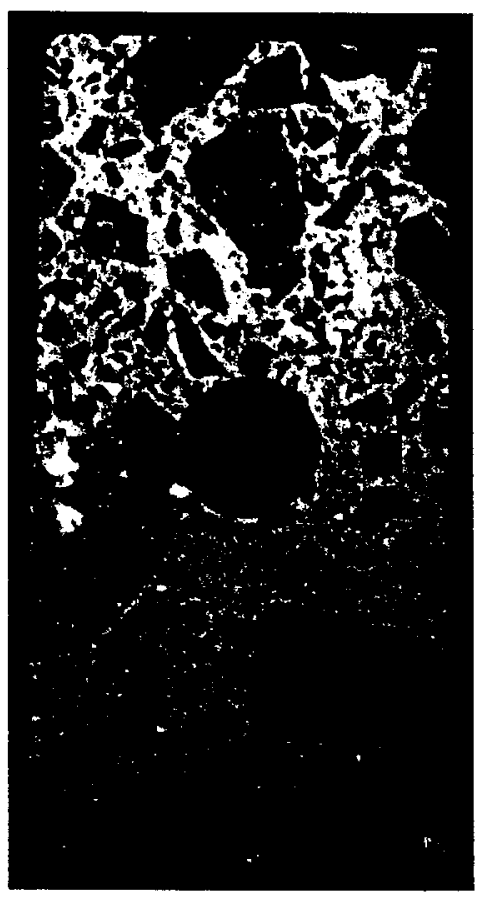

(c)

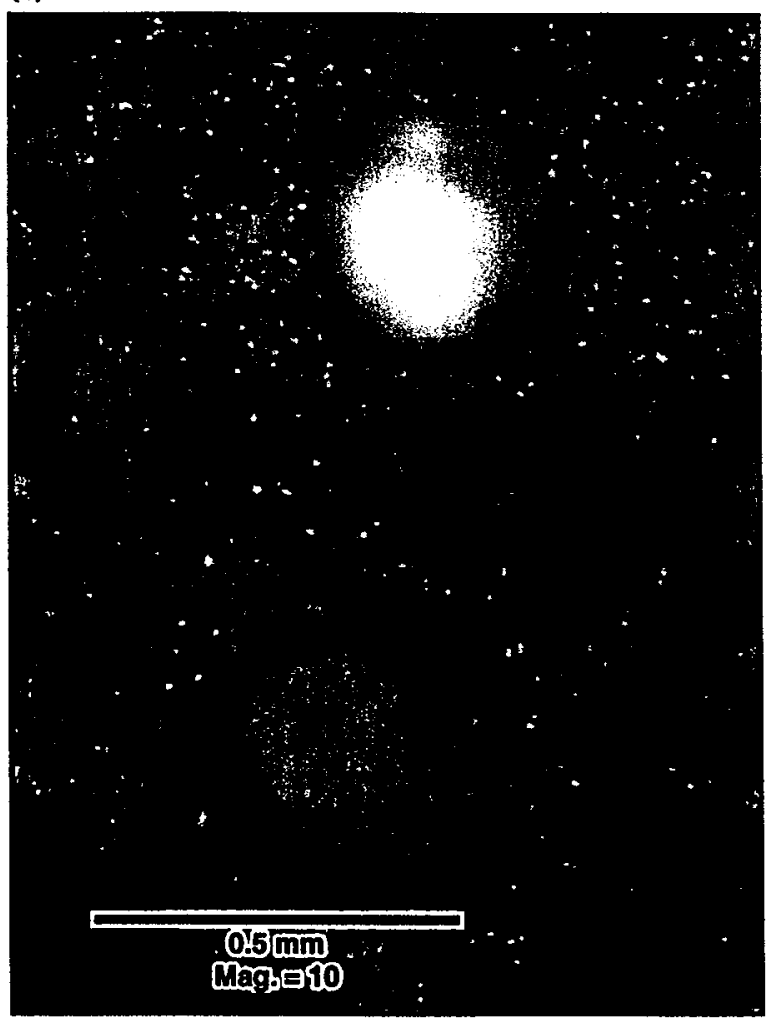

(b)

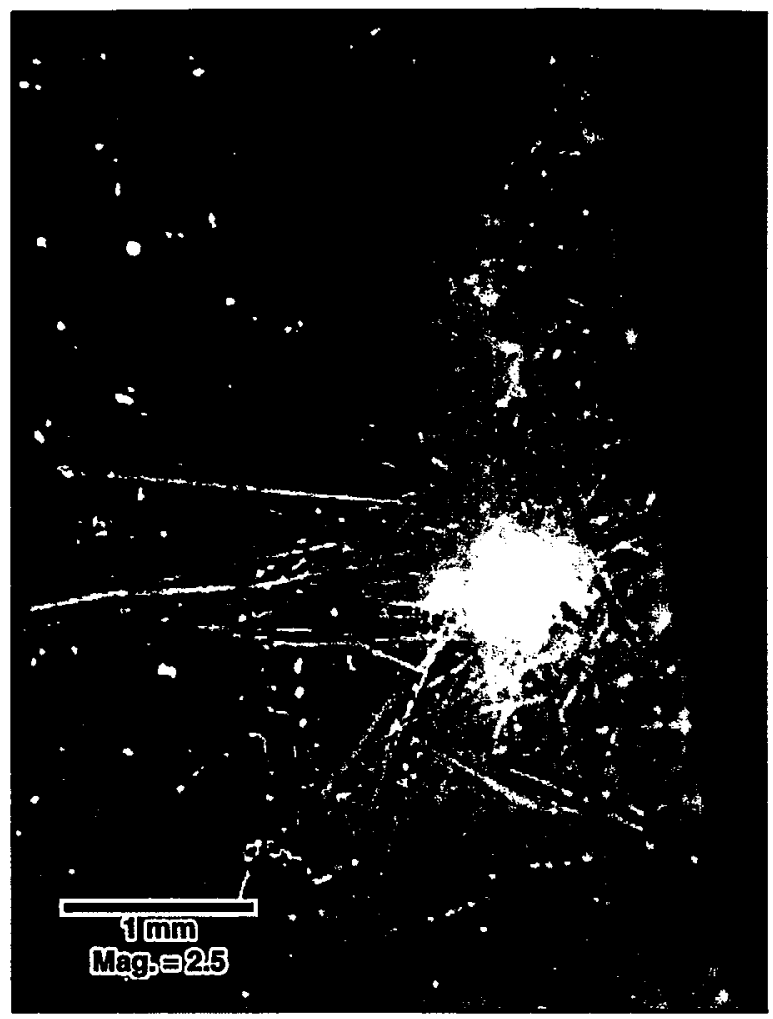

(d)

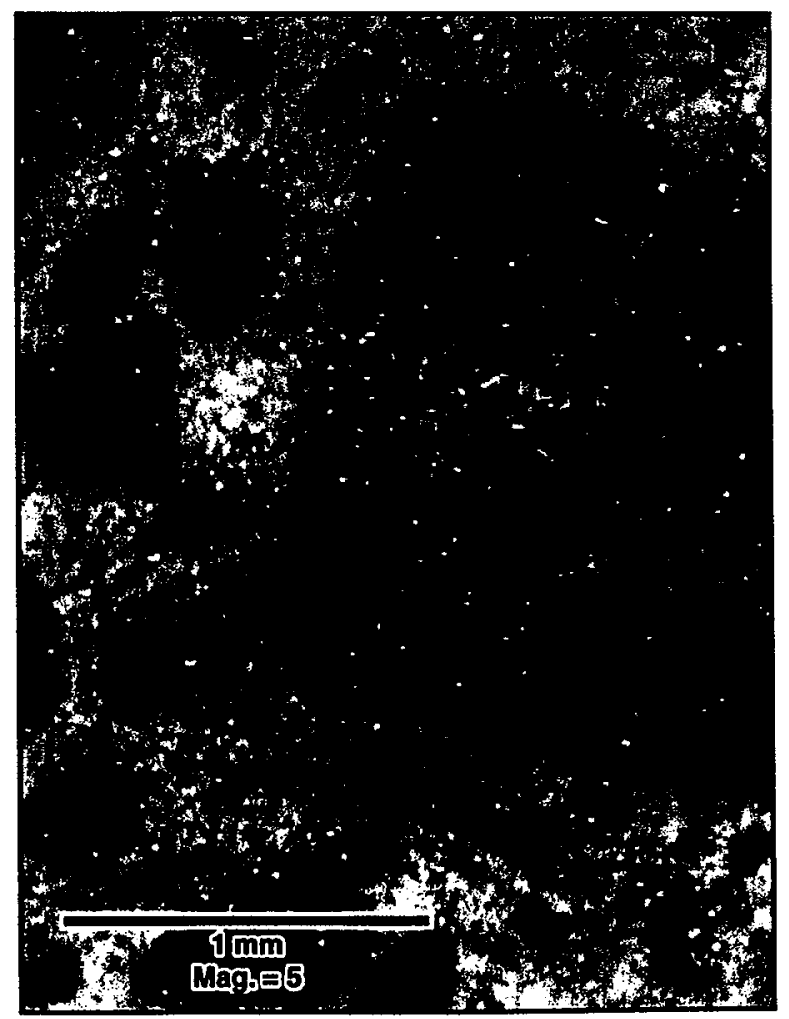

Figure 19. Photographs of sample INV-21. (a) Two clusters of white radiating crystals are visible near the edge of the sample. (b) The white radiating crystal clusters occur on the brownish aggregate grain. (c) Two pits in grout, filled with an out-of-focus, white substance. On focusing, the white substance has a sugary texture. There were several such pits on this sample. The small aggregate grains in this photo do not appear to have reaction rims. (d) Another white radiating crystal cluster on an aggregate grain. 
(e)

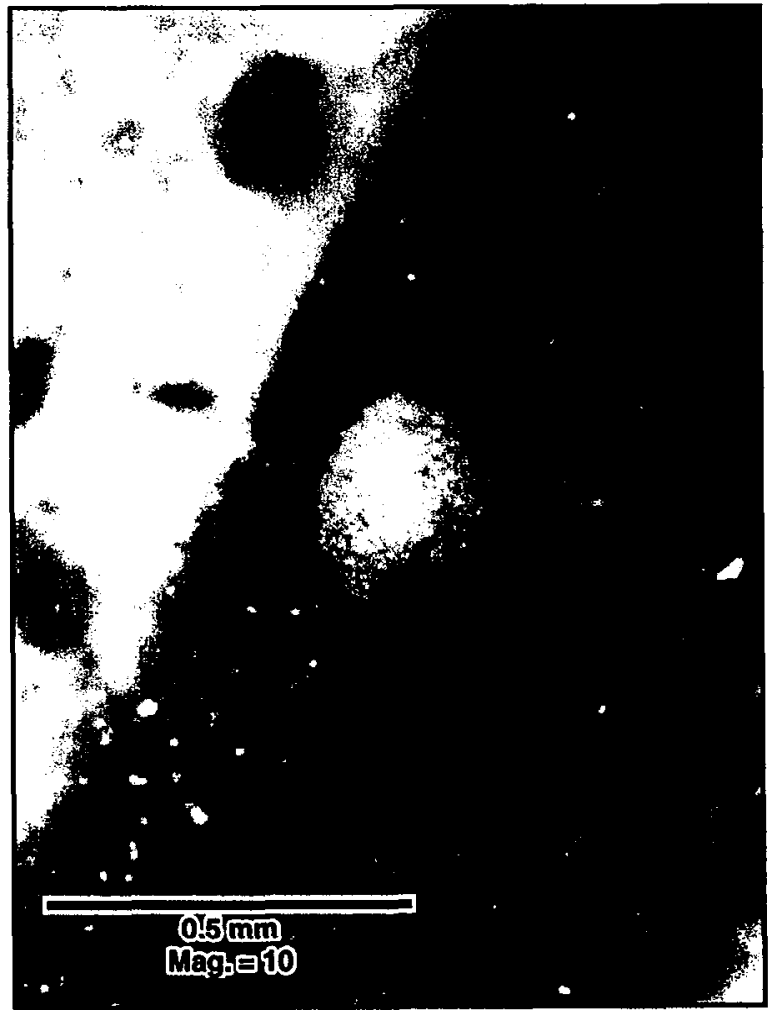

Figure 19 (continued). Photograph of sample INV-21. (e) Tiny crystal cluster on aggregate. There were approximately five of these on the sample, all occurring on aggregate. 
(a)

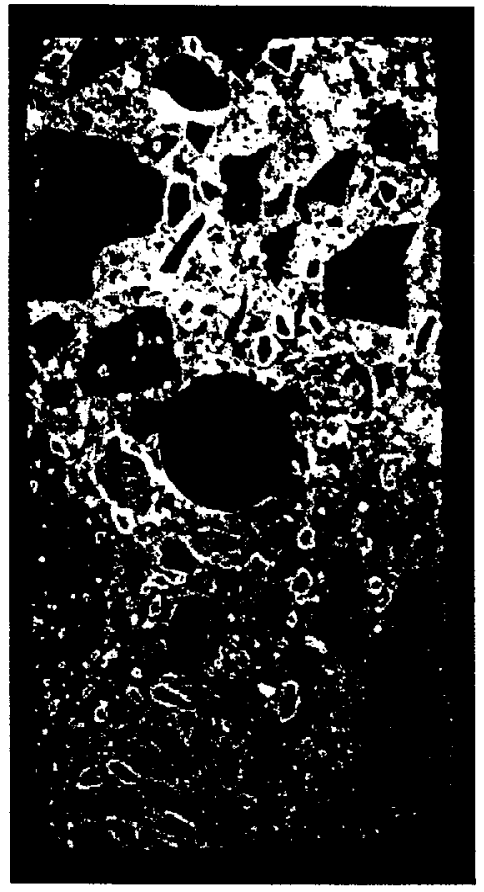

(c)

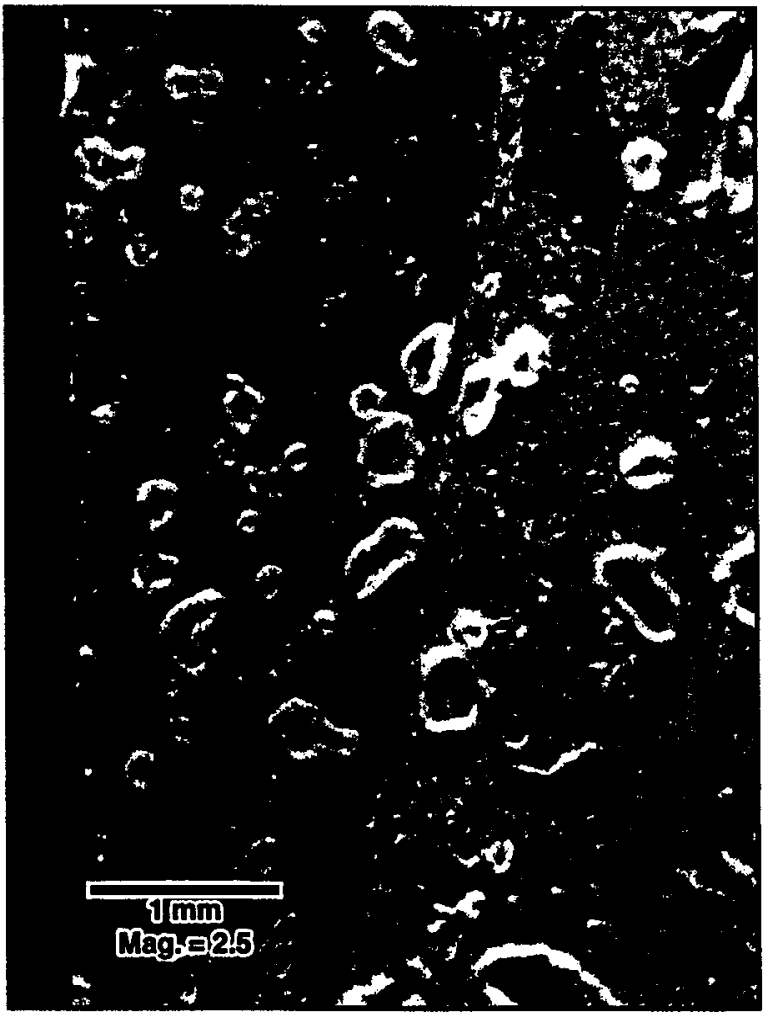

(b)

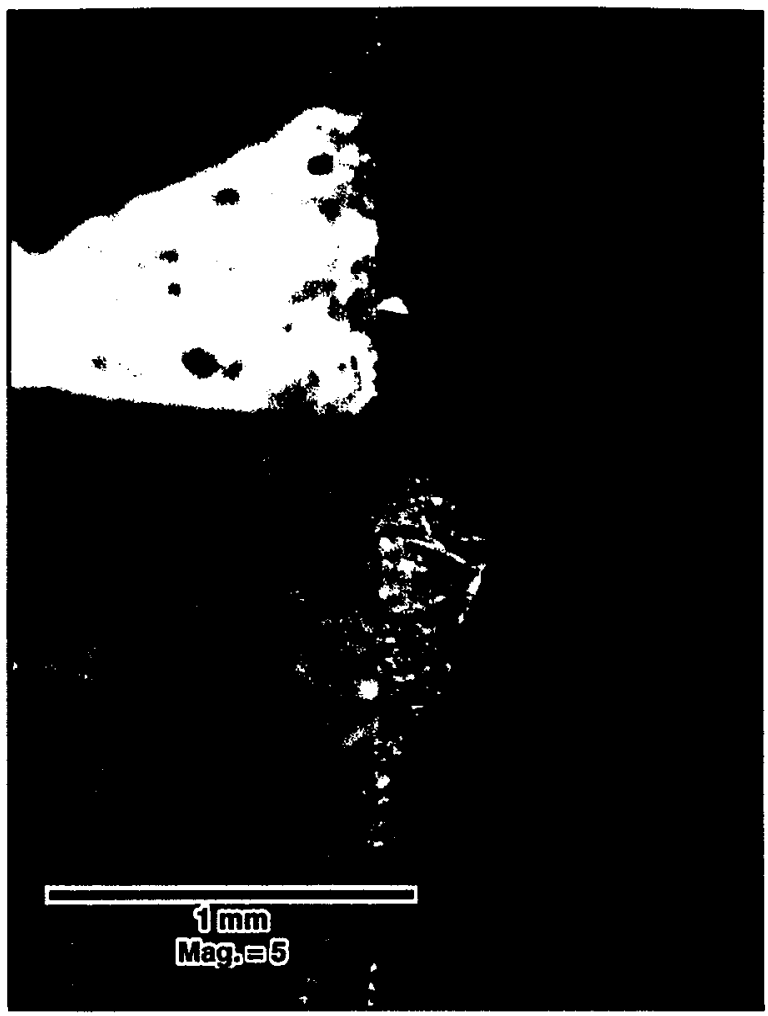

(d)

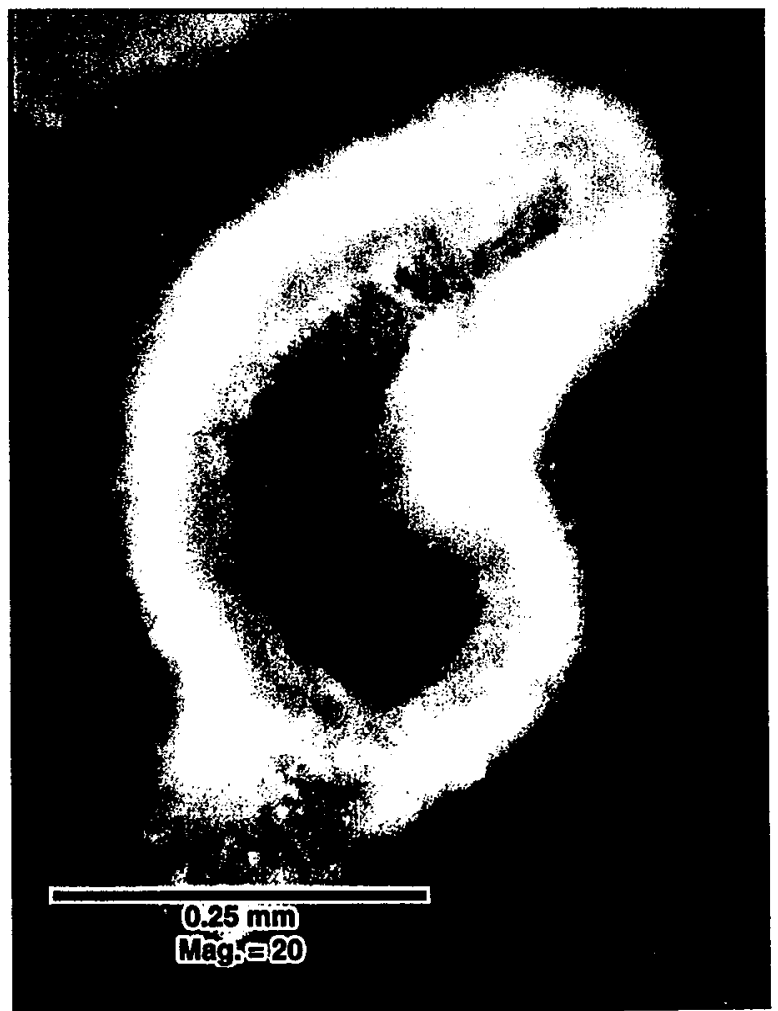

Figure 20. Photographs of sample INV-36. (a) White rims occur around the smaller aggregate grains and within the large grains. A large pit is visible. (b) A white fibrous mat of crystals attached to an aggregate grain on the edge of the sample. (c) White rims around smaller aggregate grains, and within a large aggregate grain. (d) A closer look at a white rim within an aggregate grain. 
(e)

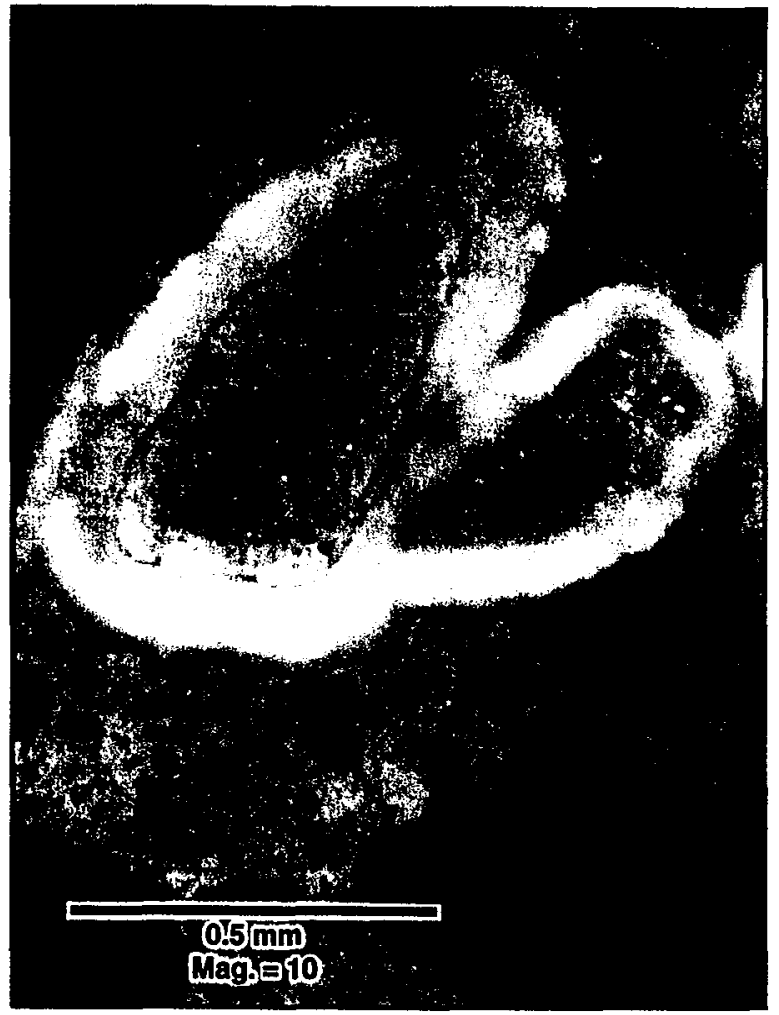

(g)

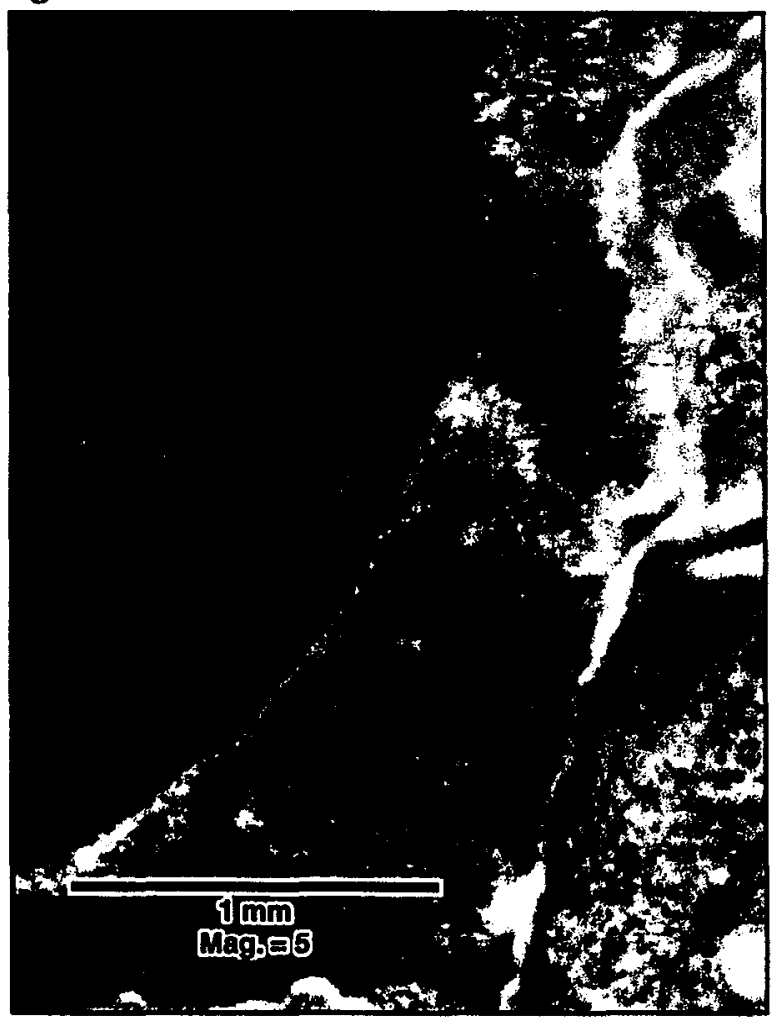

(f)

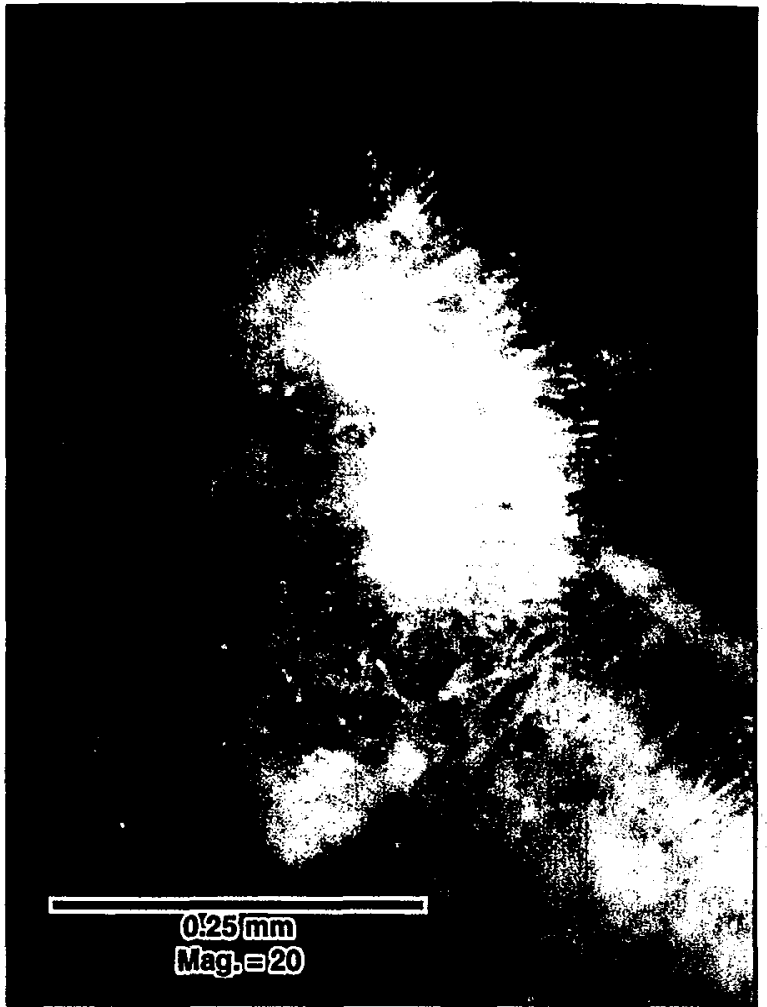

(h)

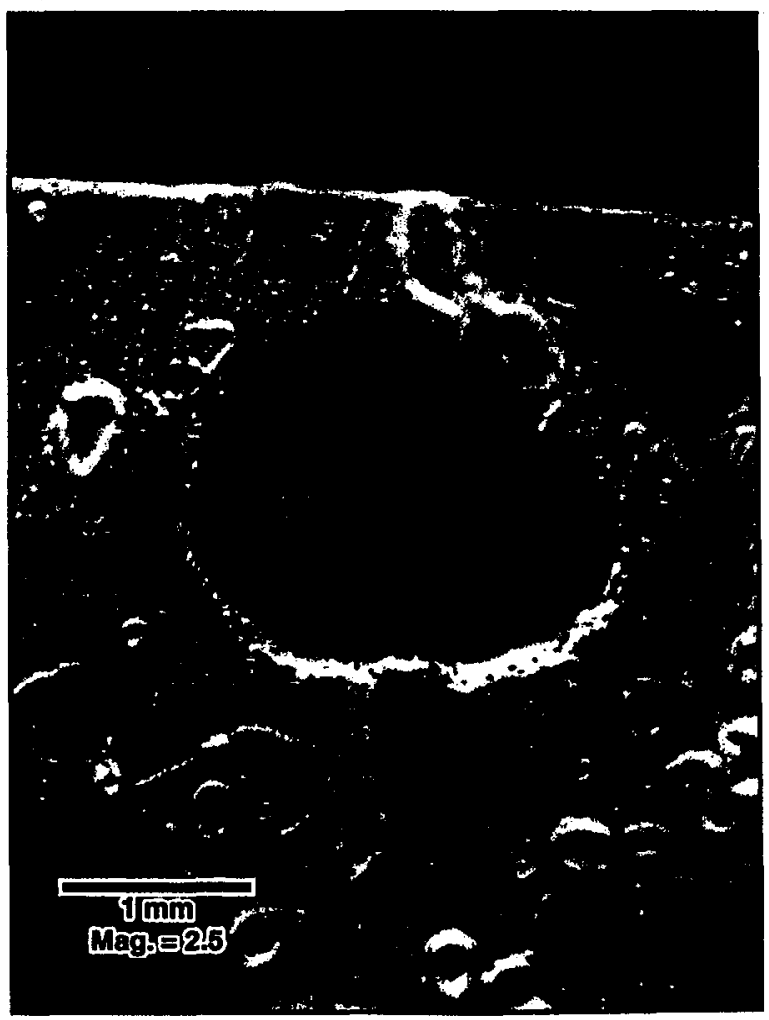

Figure 20 (continued). Photographs of sample INV-36. (e) Aggregate grains with no white rims. Two white rims also appear to be in grout. Note the fine, white spindles on the inside of one of the white rims. (f) A fibrous mat of crystals near the central hole in the sample. The crystals radiate into the hole, but are out of focus in this photo. (g) A lower-magnification view of the area in the previous photo. (h) Pit in grout. The bottom of the pit is out of focus. 
(a)

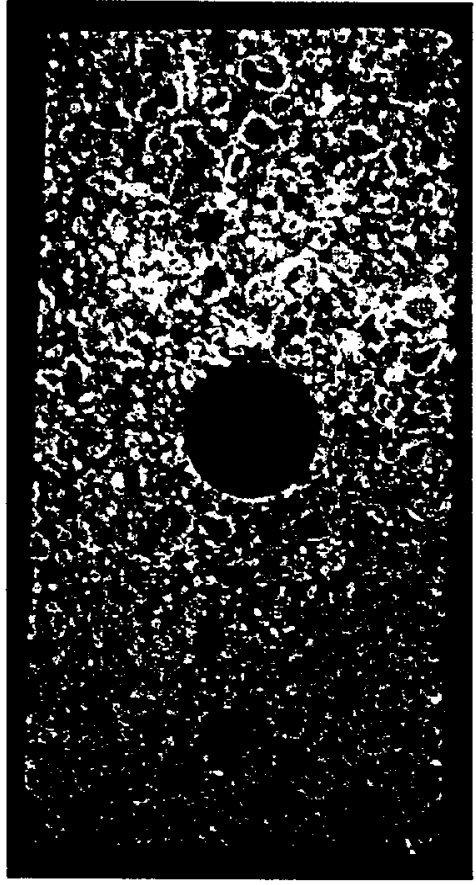

(c)

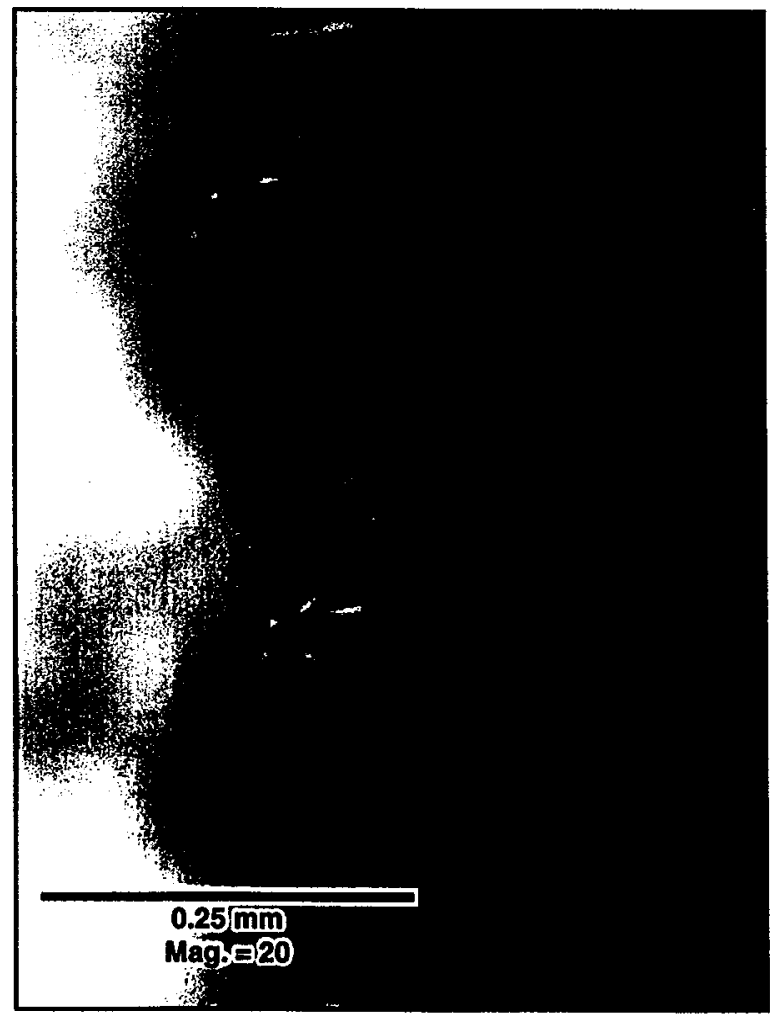

(b)

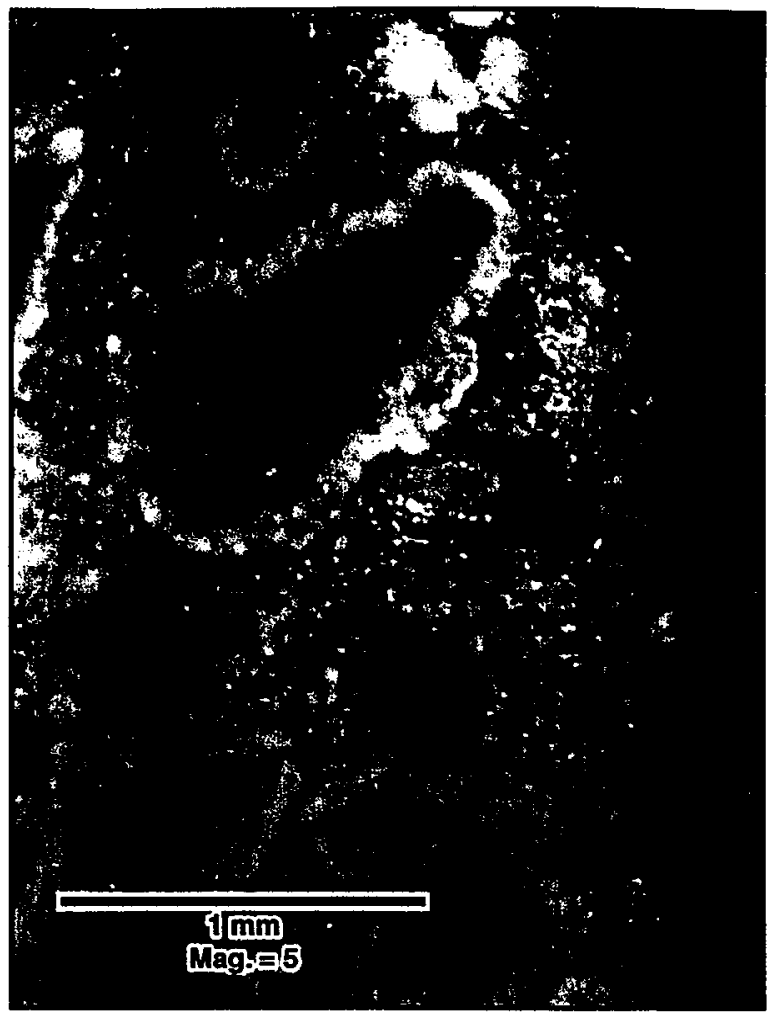

(d)

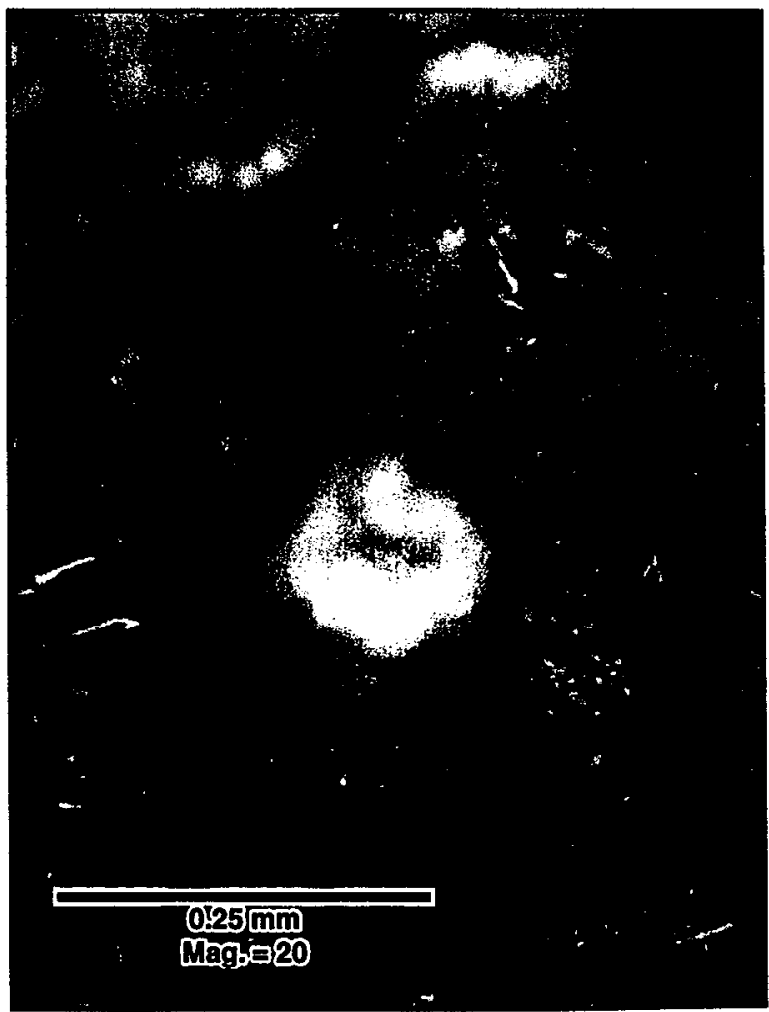

Figure 21. Photographs of sample SH-13. (a) Eighty to ninety percent of all the grains have visible white rims. (b) Representative view of sample. The grout generally sparkles in this sample. (c) Tiny white crystals radiate from the edge of the sample. (d) Needle-shaped crystals radiating from a mound of other crystals. The brown mineral is probably biotite and does not have a white rim. 

(e)

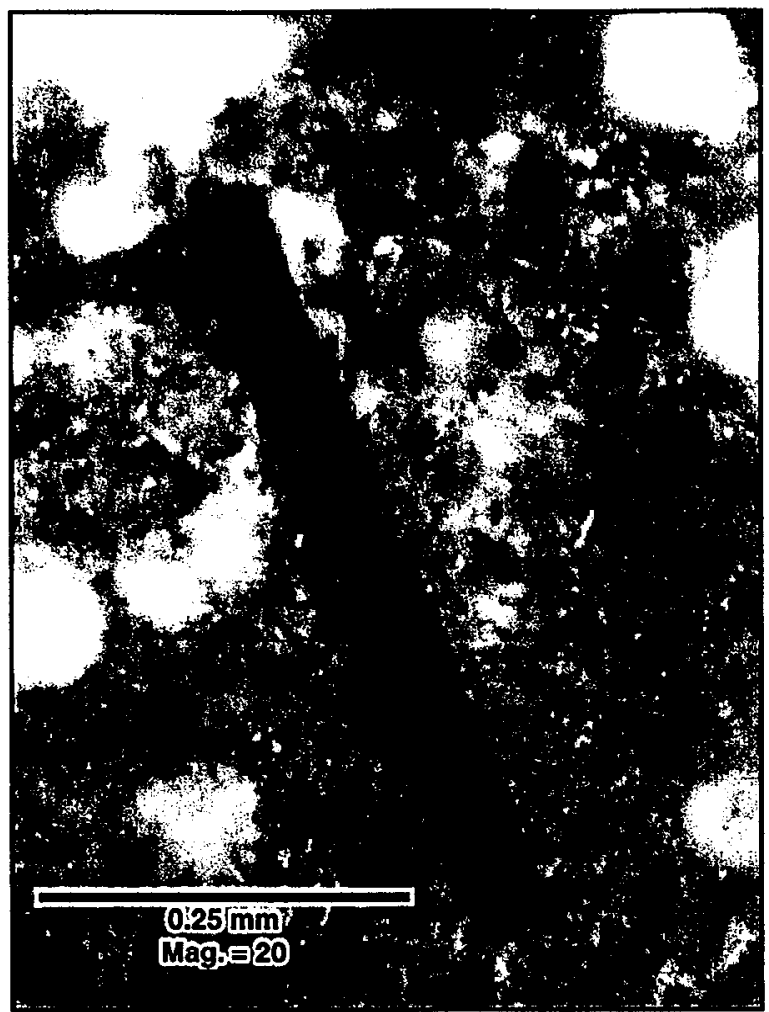

(f)

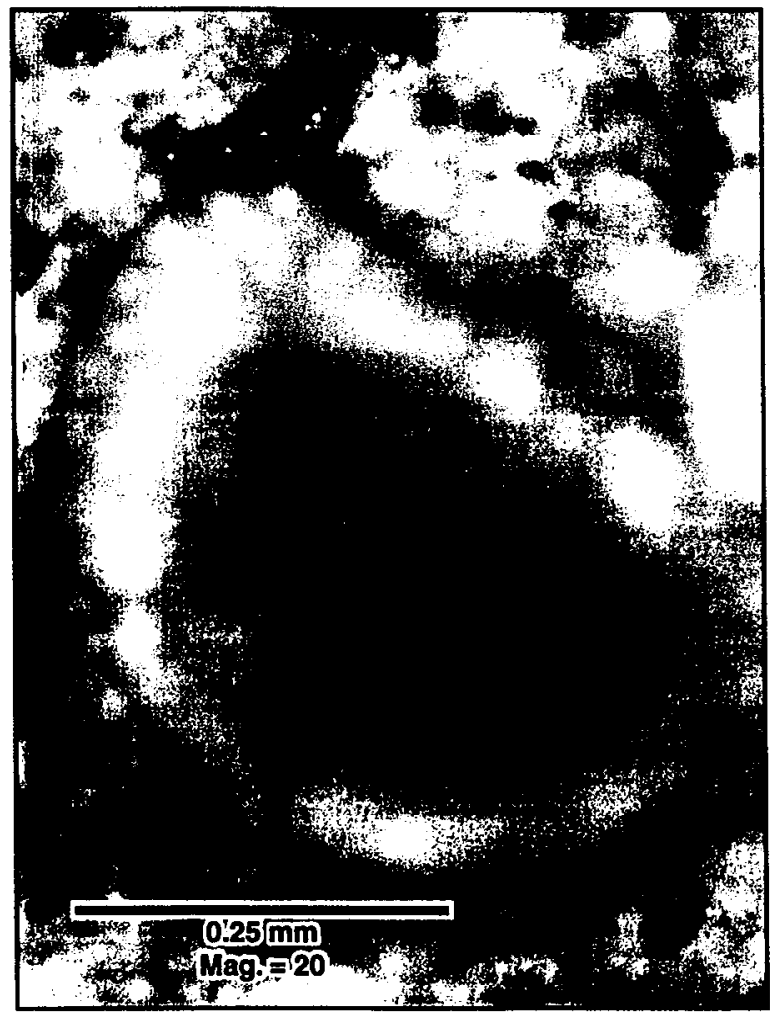

(g)

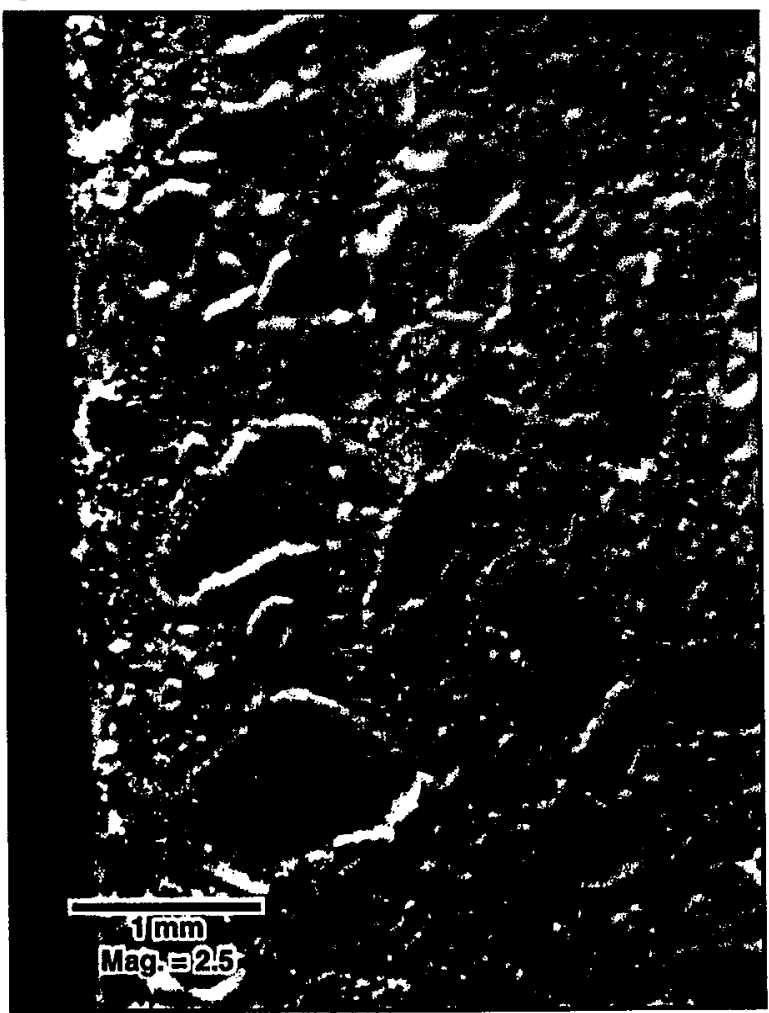

Figure 21 (continued). Photographs of sample SH-13 (e) Another biotite grain with no white rim, and several white crystal mounds in view. (f) A white rim with inward radiating spines. (g) Another typical view of the sample, illustrating the abundance of white rims. 
(a)

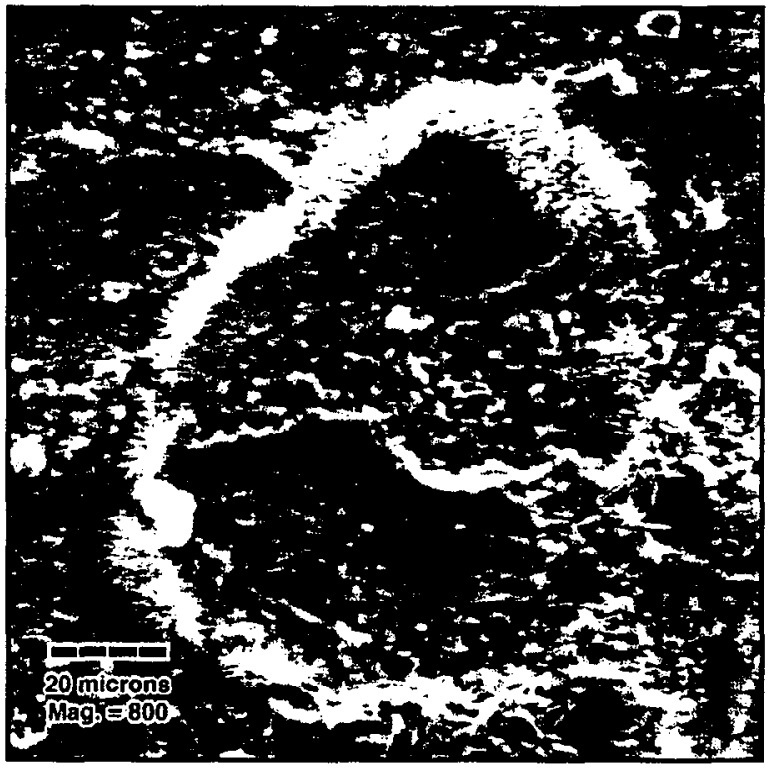

(b)

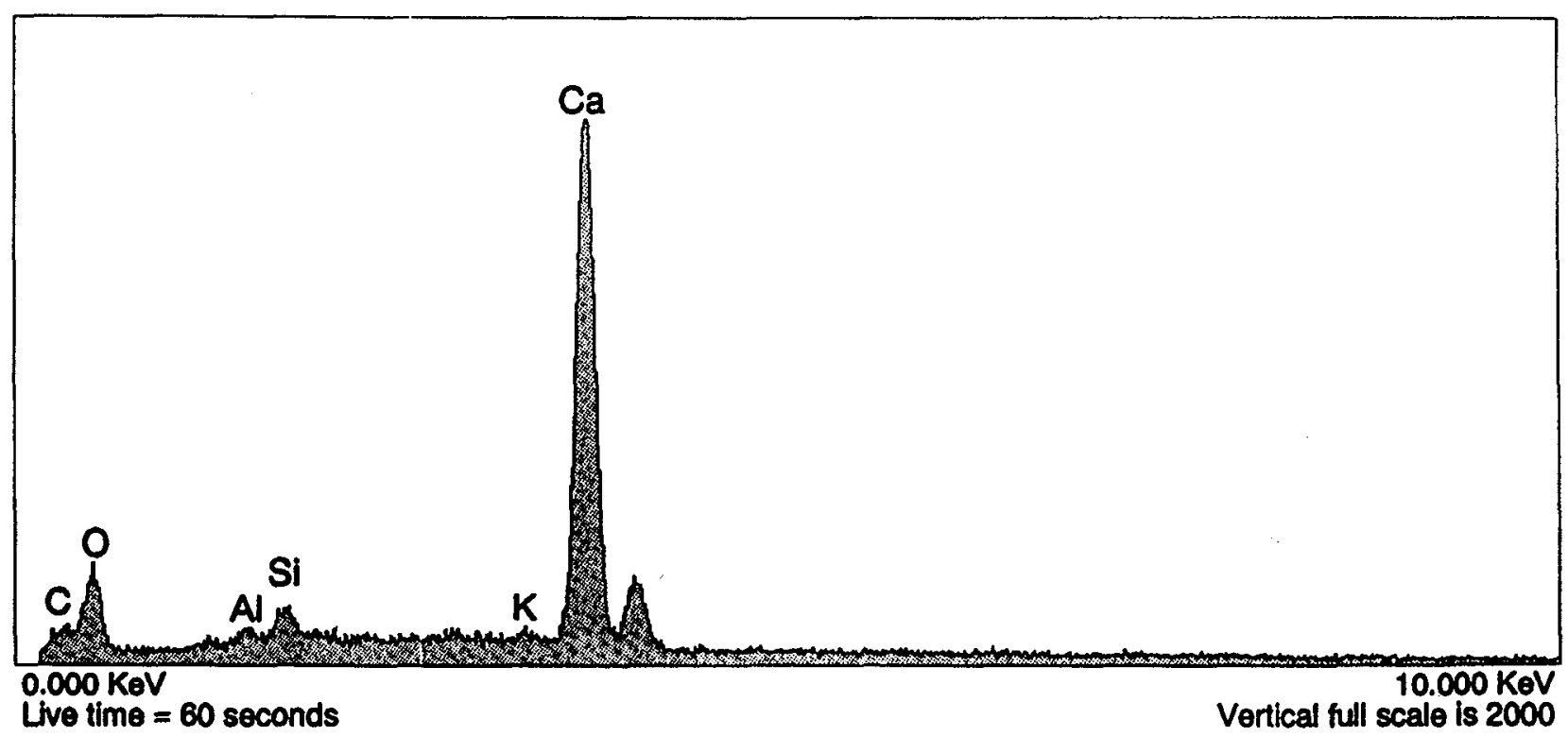

Figure 25. INV-37 (PV-13-37). (a) SEM photomicrograph of an aggregate grain, showing reaction phases around the rim. Reaction phases illustrated at higher magnification in Figures 26(a), 27(a), and 28(a). (b) EDS suggests that the grain is carbonate. 
(a)

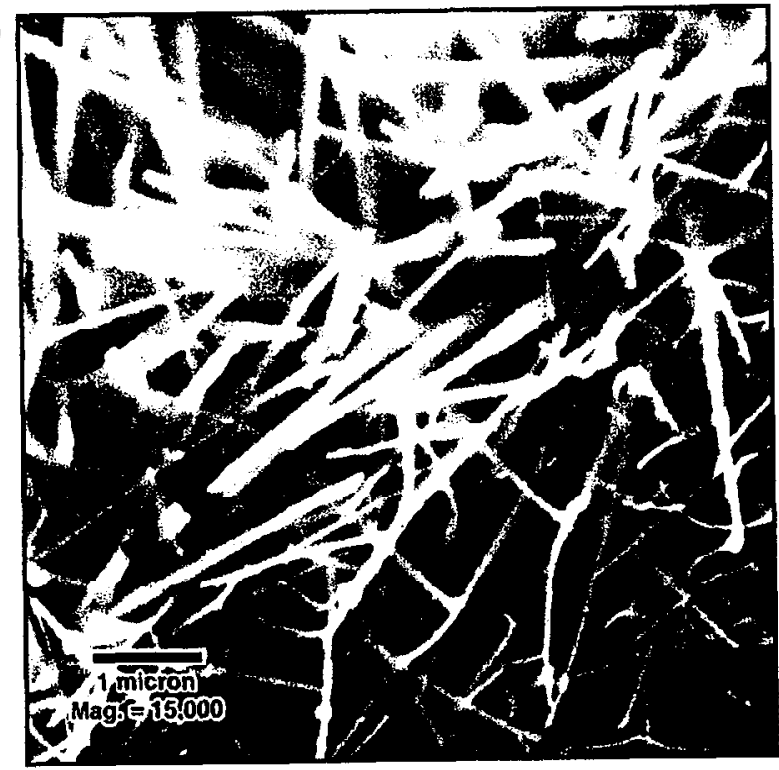

(b)

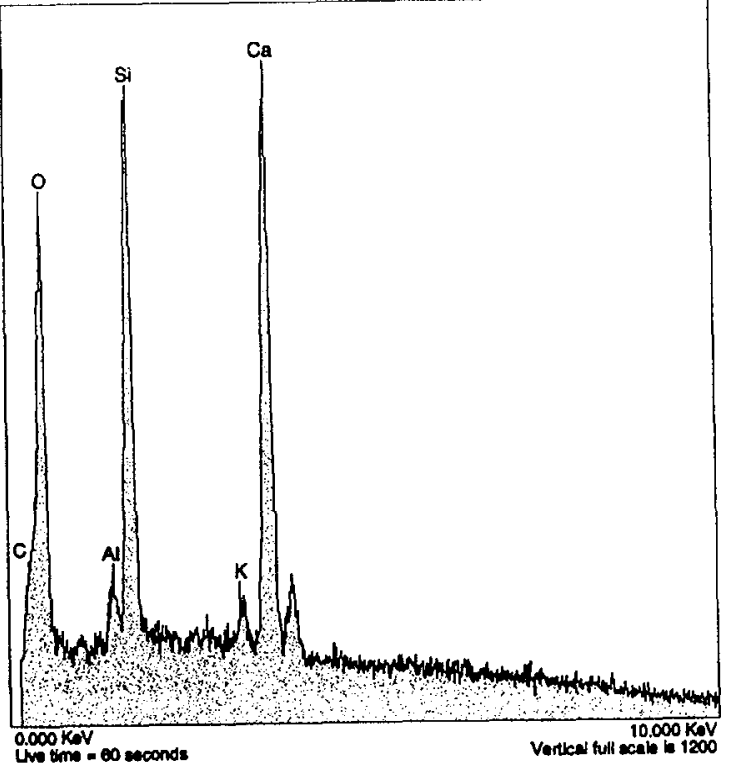

Figure 26. INV-37 (PV-13-37). (a) SEM photomicrograph of a needle-shaped reaction phase on left side of grain shown in Figure 25(a). This phase also occurs elsewhere on the grain rim. (b) EDS indicates that this phase contains $\mathrm{Ca}, \mathrm{Si}$, and $\mathrm{O}$ in abundance, and minor amounts of $\mathrm{Al}, \mathrm{C}$, and $\mathrm{K}$. 
(a)

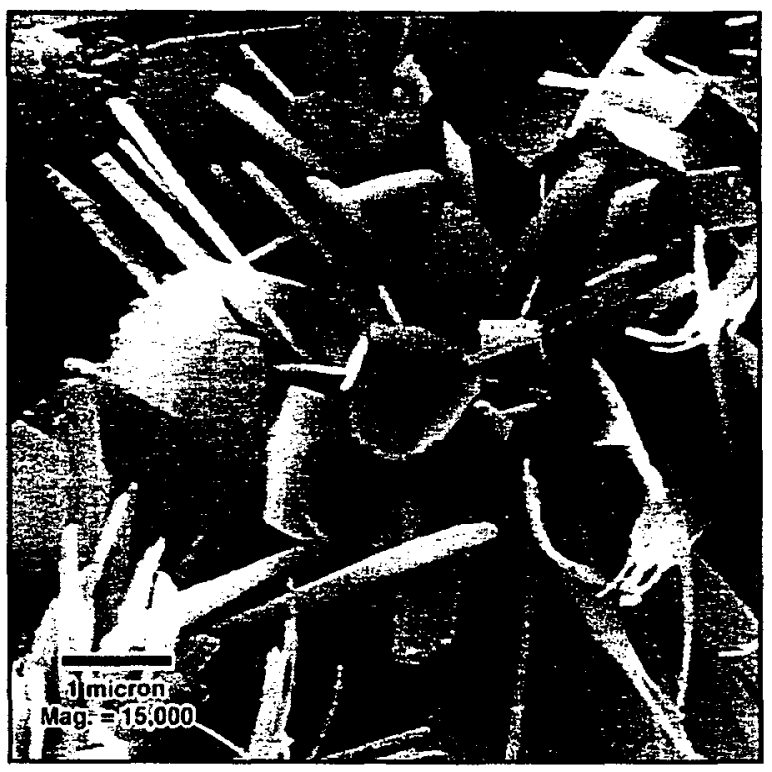

(b)

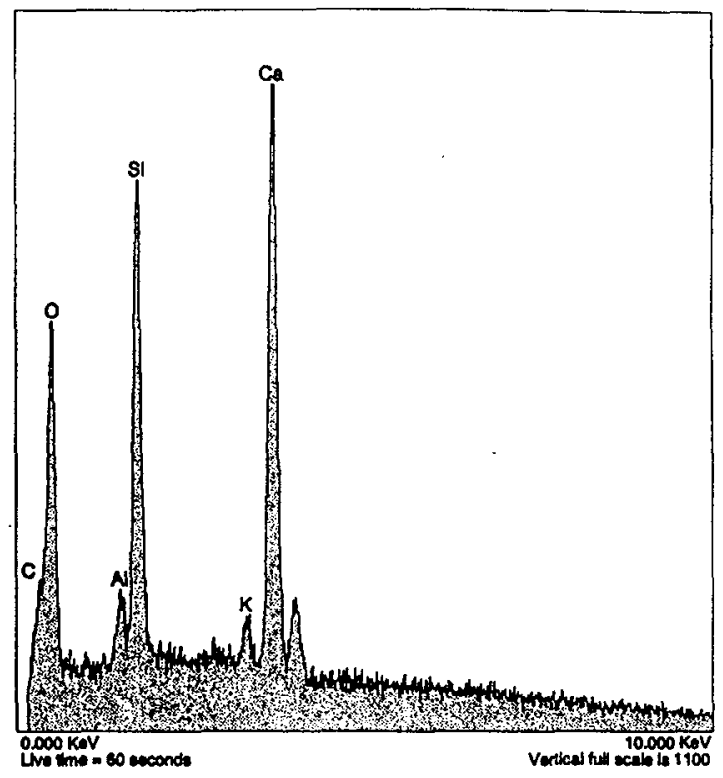

(c)

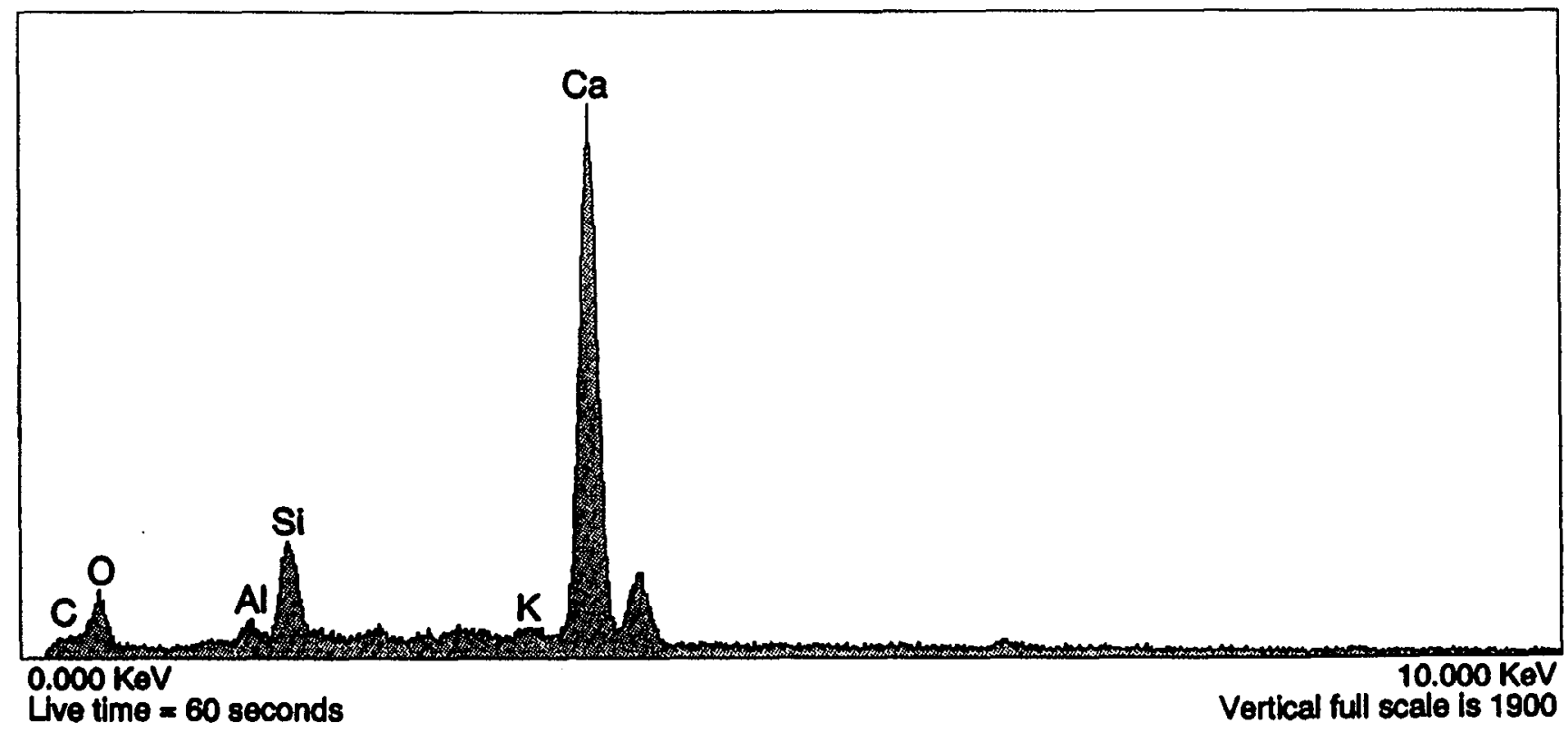

Figure 27. INV-37 (PV-13-37). (a) SEM photomicrograph of tabular crystals that occur on the upper-left side of the grain shown in Figure 25(a). (b) EDS indicates that the tabular crystals contain $\mathrm{Ca}$, $\mathrm{Si}$, and $\mathrm{O}$ in abundance, and minor amounts of $\mathrm{Al}, \mathrm{C}$, and $\mathrm{K}$. (c) EDS from a smooth area in the grout just to the left of the crystals, indicates the presence of $\mathrm{Ca}$, with lesser amounts of $\mathrm{Si}, \mathrm{O}, \mathrm{Al}$, and $\mathrm{K}$. 
(a)

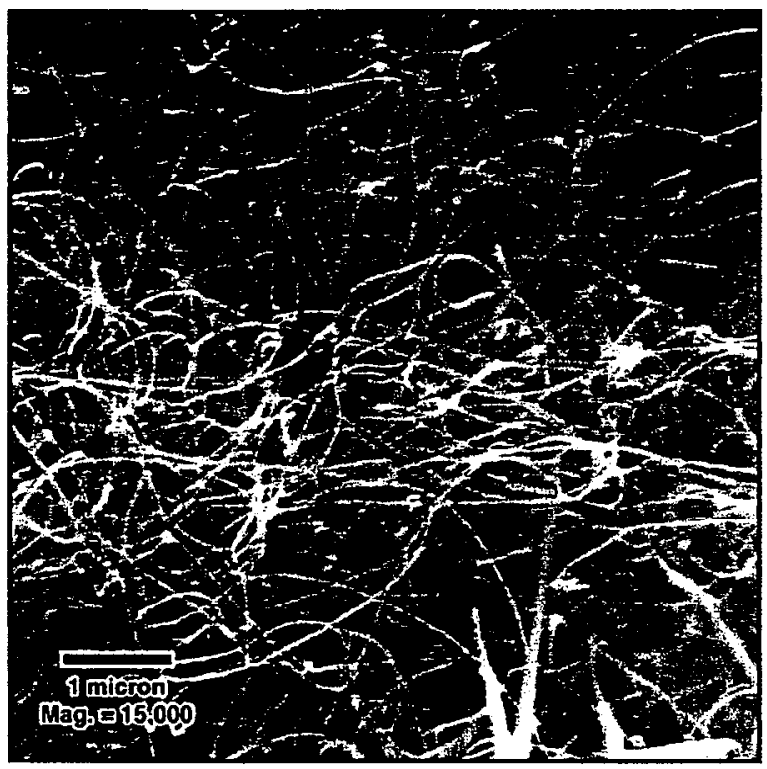

(b)

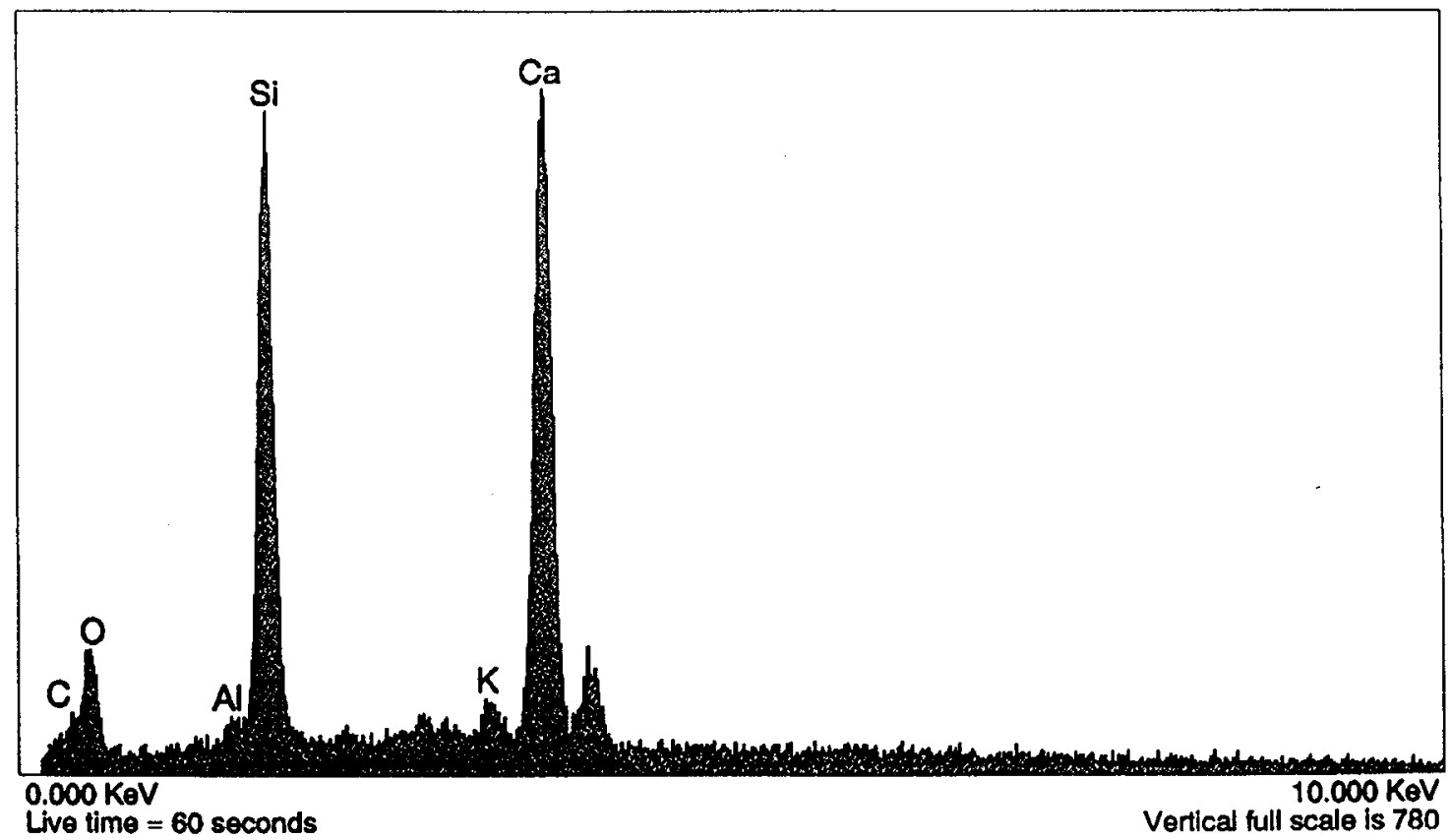

Figure 28. INV-37 (PV-13-37). (a) SEM photomicrograph of a thin stringy reaction phase that occurs on the surface of the grain, inboard of the needle-shaped and tabular crystals shown in Figures 26(a) and 27(a). (b) EDS, although not directly quantitative, indicates nearly equal amounts of $\mathrm{Si}$ and $\mathrm{Ca}$, with minor amounts of $\mathrm{O}, \mathrm{K}, \mathrm{C}$, and $\mathrm{Al}$. 
(a)

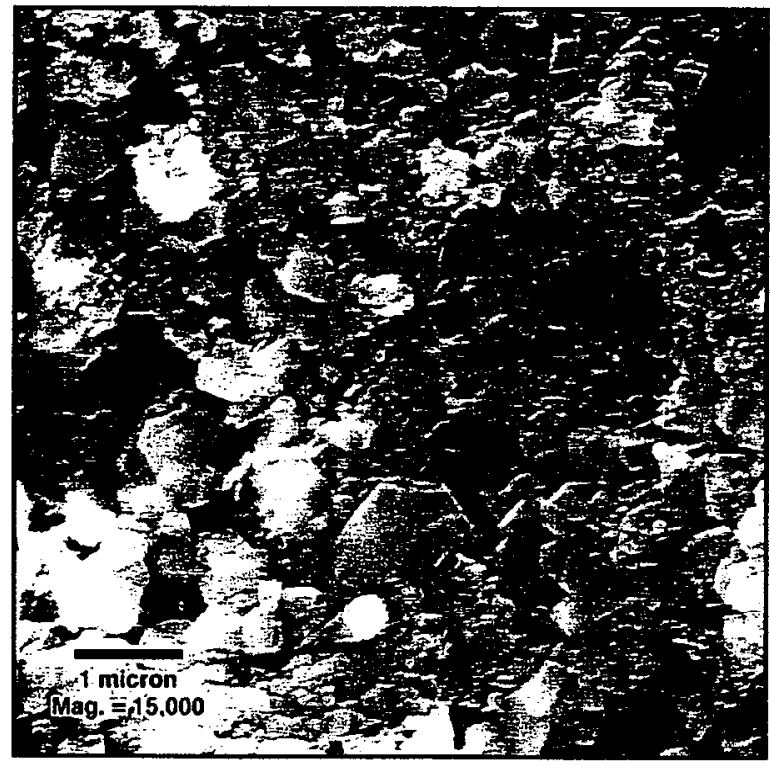

(b)

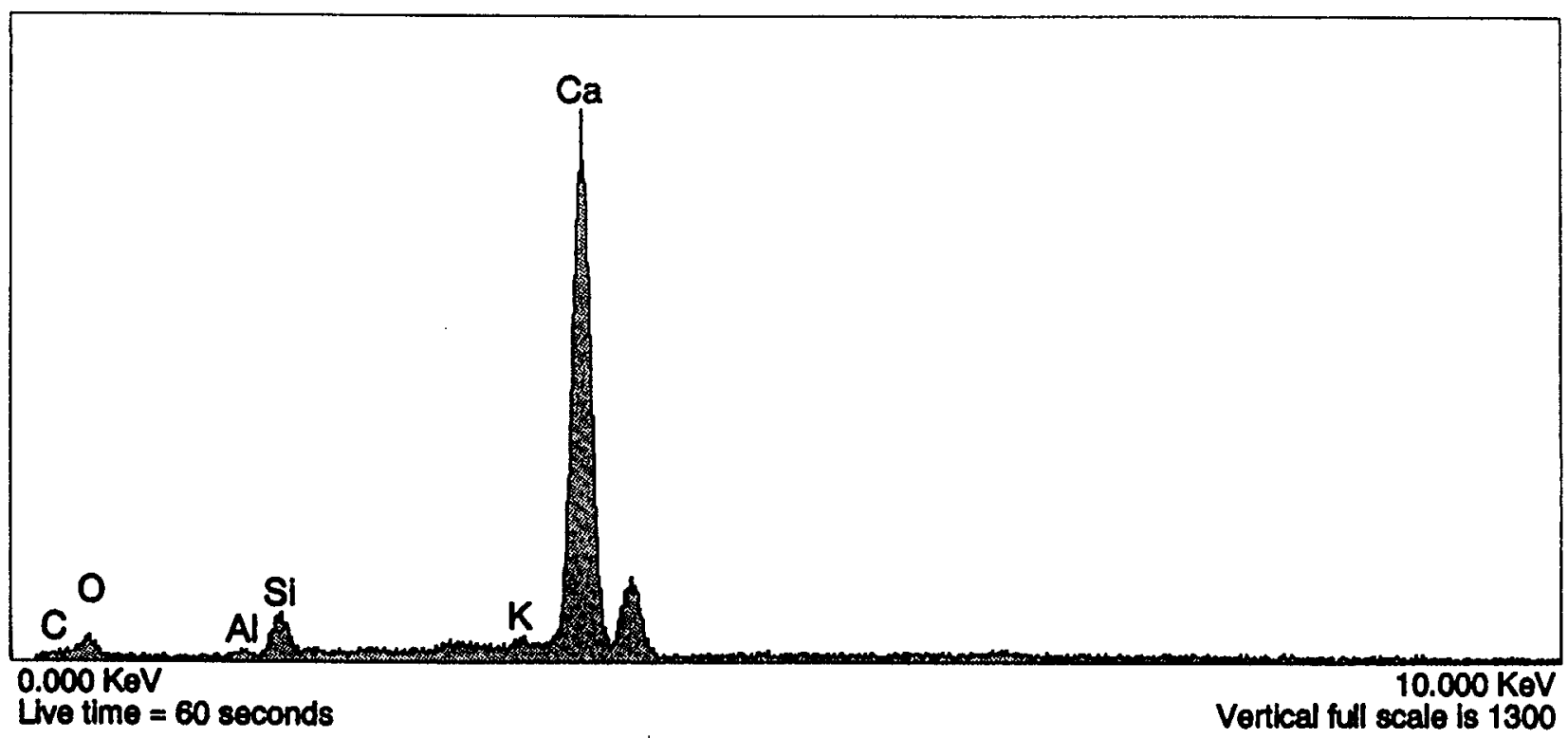

Figure 29. INV-37 (PV-13-37). (a) SEM photomicrograph of granular crystals outside of the grain, in the grout, to the left of the phase in Figure 27(a). (b) EDS indicates the presence of Ca with minor amounts of Si and O. 
(a)

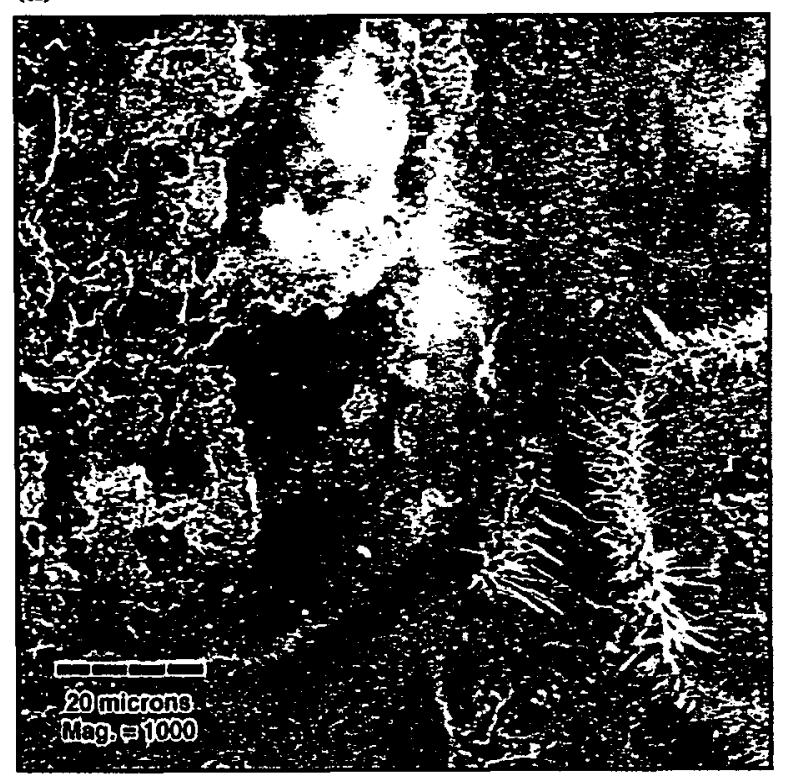

(b)

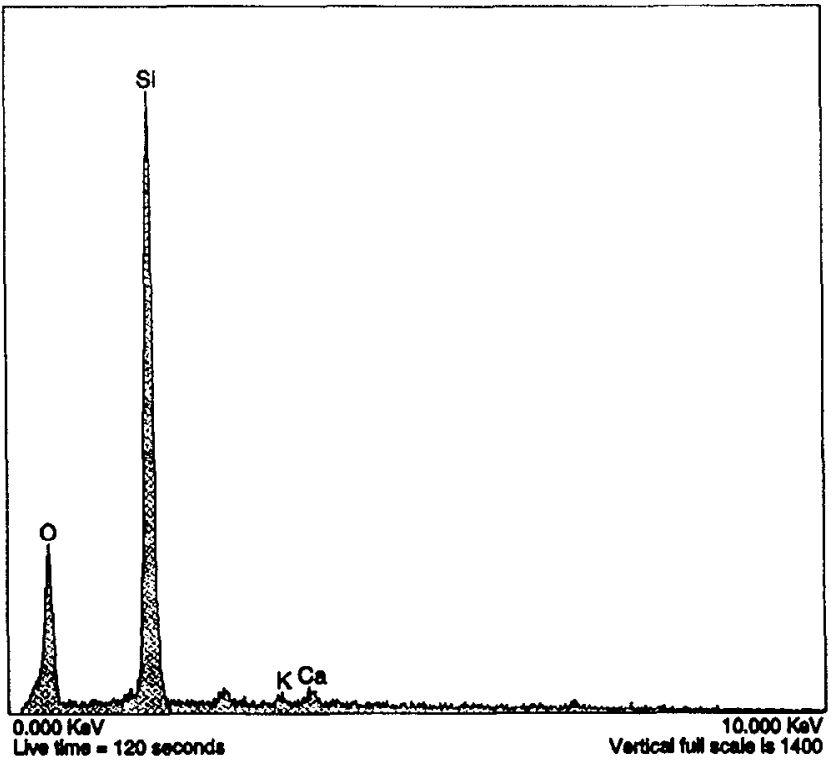

(c)

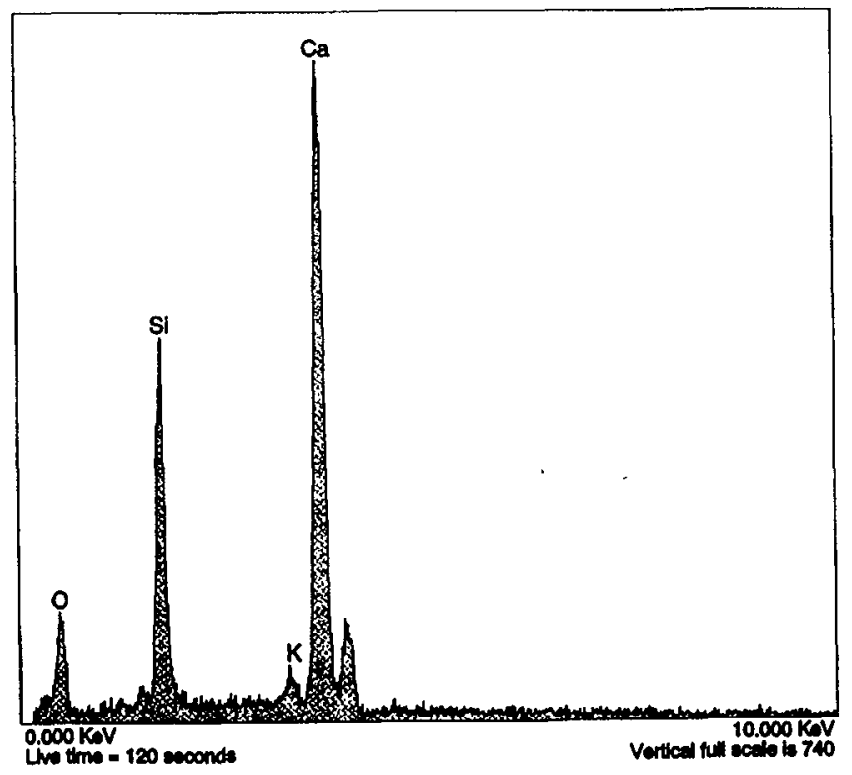

Figure 30. INV-38 (PV-13-38). (a) SEM photomicrograph of an aggregate grain and reaction phases. (b) EDS of the aggregate grain indicates that it is quartz or another $\mathrm{SiO}_{2}$ phase. (c) EDS of the grout suggests the presence of $\mathrm{Ca}$, $\mathrm{Si}, \mathrm{O}$, and $\mathrm{K}$. 
(a)

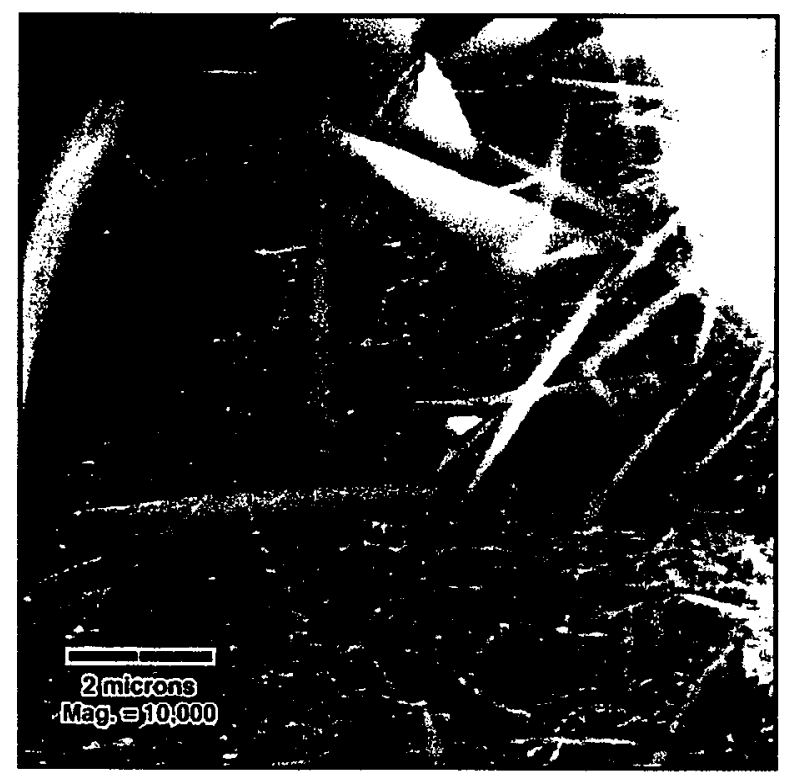

(b)

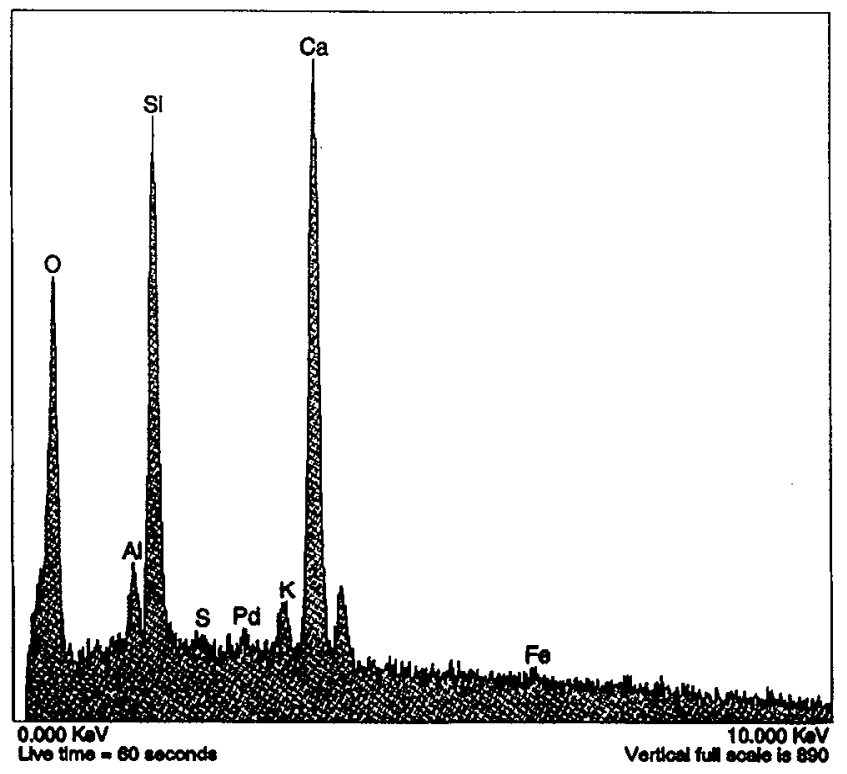

(c)

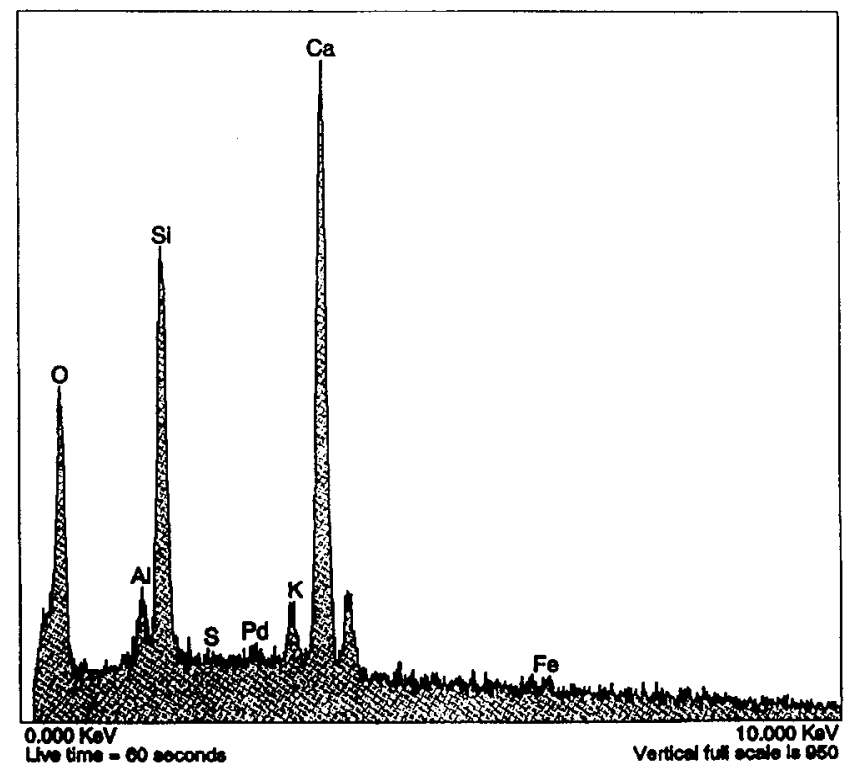

Figure 31. INV-38 (PV-13-38). (a) SEM photomicrograph of the grain-grout interface shown in Figure 30, at higher magnification. Two reaction phases are evident, a fine fibrous phase, and a tabular phase. (b) EDS of the fine fibrous phase indicates the presence of $\mathrm{Ca}, \mathrm{Si}, \mathrm{O}, \mathrm{Al}$, and $\mathrm{K}$. (c) EDS of the tabular phase suggests the presence of $\mathrm{Ca}, \mathrm{Si}, \mathrm{O}, \mathrm{Al}$, and $\mathrm{K}$. The $\mathrm{Ca}: \mathrm{Si}: \mathrm{O}$ ratios are slightly different between the two phases. 
(a)

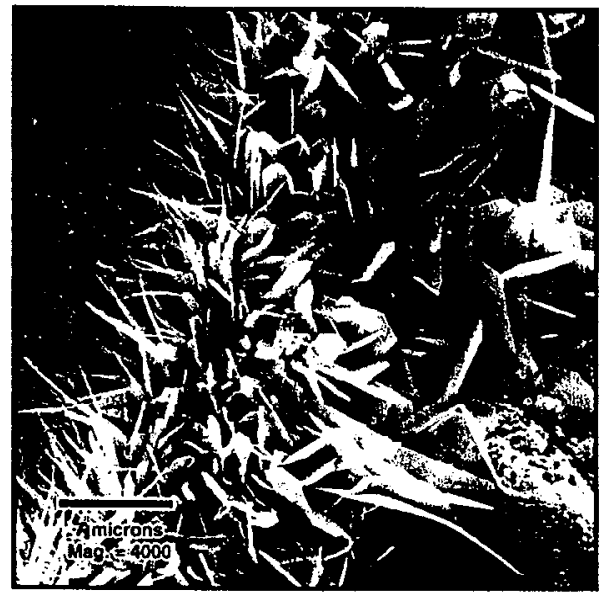

(c)

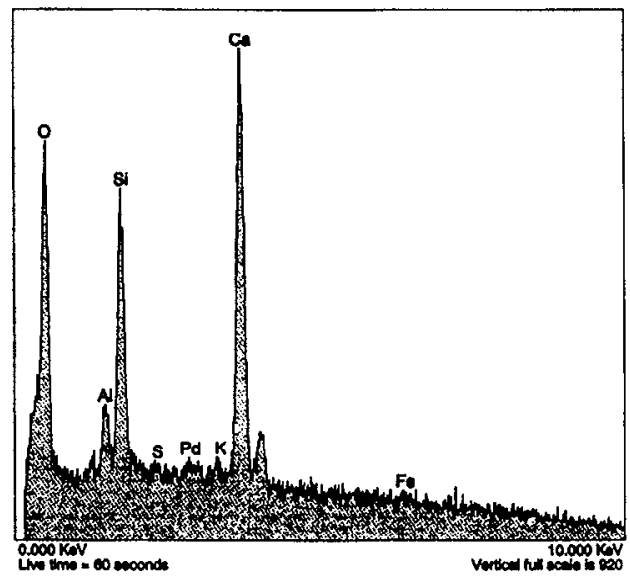

(e)

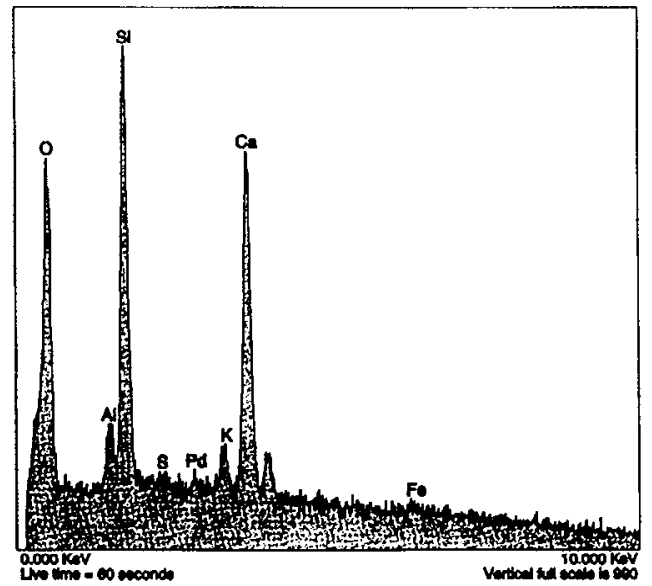

(b)

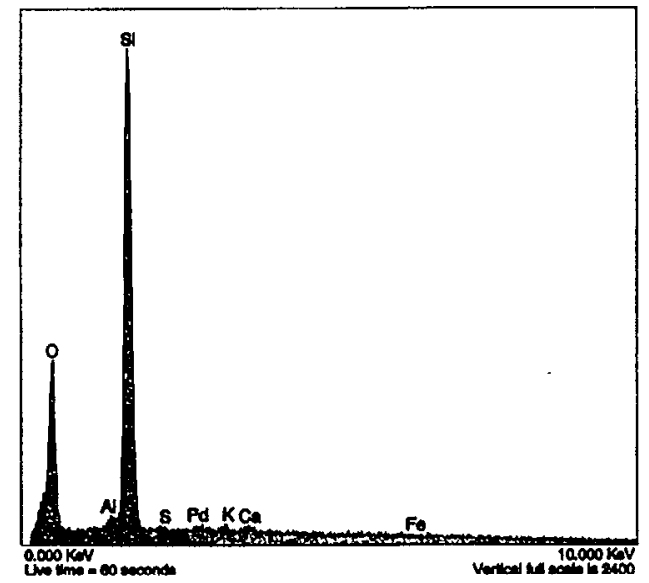

(d)

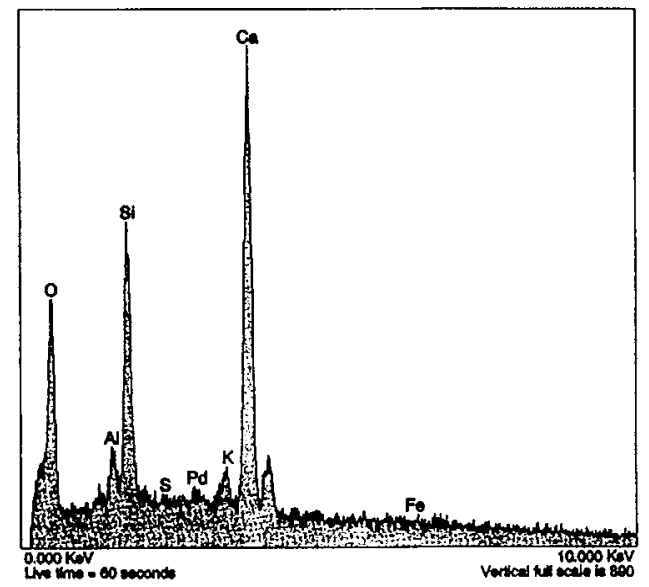

(f)

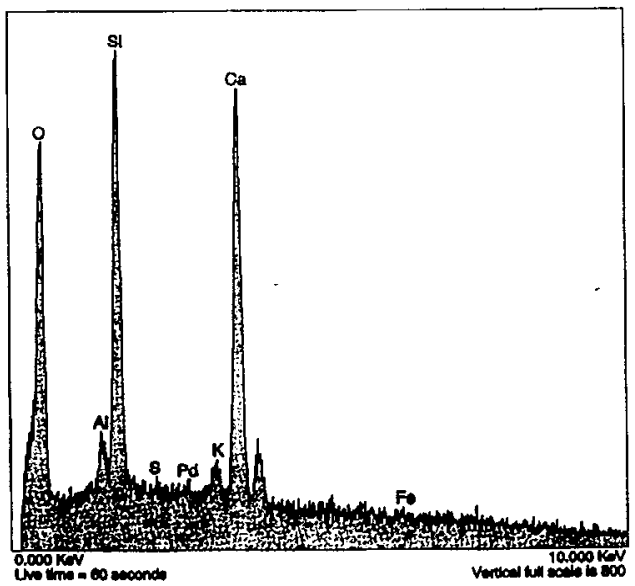

Figure 32. INV-38 (PV-13-38). (a) SEM photomicrograph of the interface between an aggregate grain and grout. At least two reaction phases are discernible, a flat tabular phase and a needle-shaped phase. (b) EDS of the aggregate grain indicates that it is quartz or another $\mathrm{SiO}_{2}$ phase. (c) EDS of the grout indicates the presence of $\mathrm{Ca}, \mathrm{O}$, and $\mathrm{Si}$ with minor amounts of $\mathrm{Al}$ and $\mathrm{K}$. (d) EDS of the tabular phase indicates the presence of $\mathrm{Ca}, \mathrm{Si}$, and $\mathrm{O}$ with minor amounts of $\mathrm{Al}$ and $\mathrm{K}$. (e) EDS of the needle-shaped phase indicates the presence of $\mathrm{Si}, \mathrm{Ca}$, and $\mathrm{O}$, . with minor amounts of $\mathrm{Al}$ and $\mathrm{K}$. This spectrum shows more $\mathrm{Si}$ than $\mathrm{Ca}$, unlike the spectrum of the tabular crystals. (f) EDS of another needle-shaped phase indicates the presence of $\mathrm{Si}, \mathrm{Ca}$, and $\mathrm{O}$ with minor amounts of $\mathrm{Al}$ and $\mathrm{K}$. This spectrum is quite similar to the other needle-like phase. 
(a)

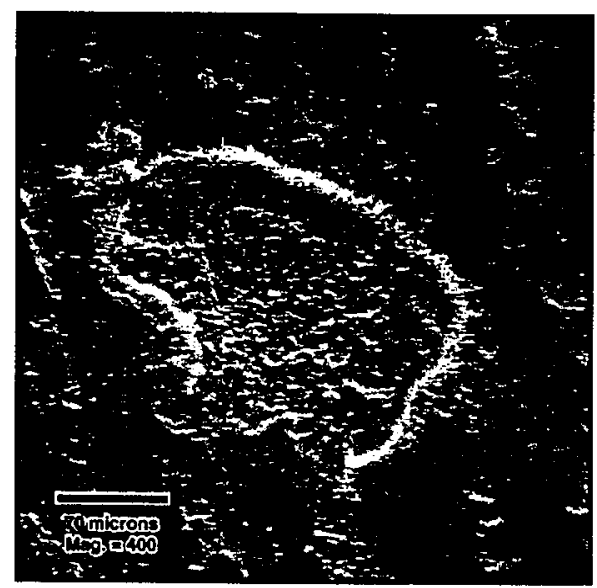

(c)

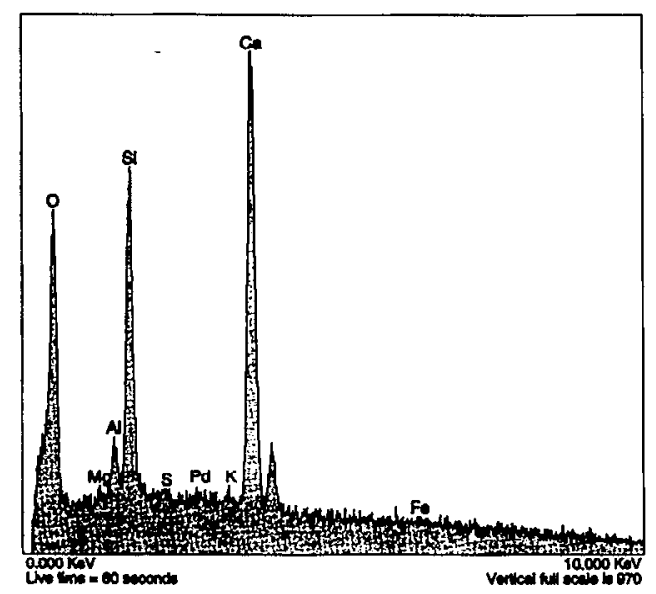

(b)

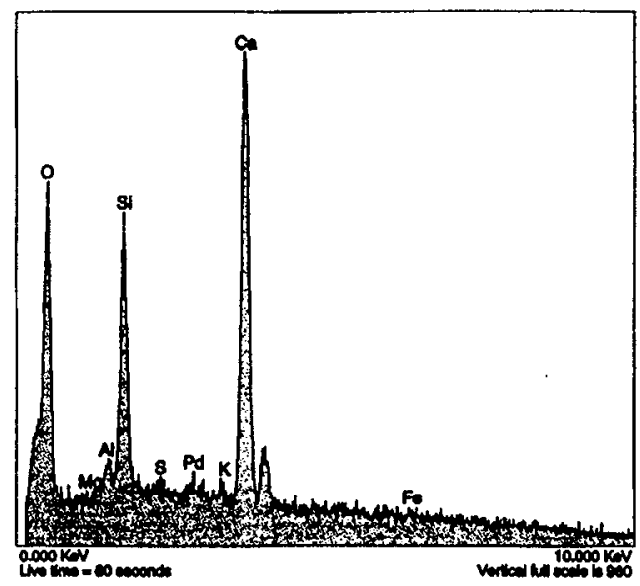

(d)

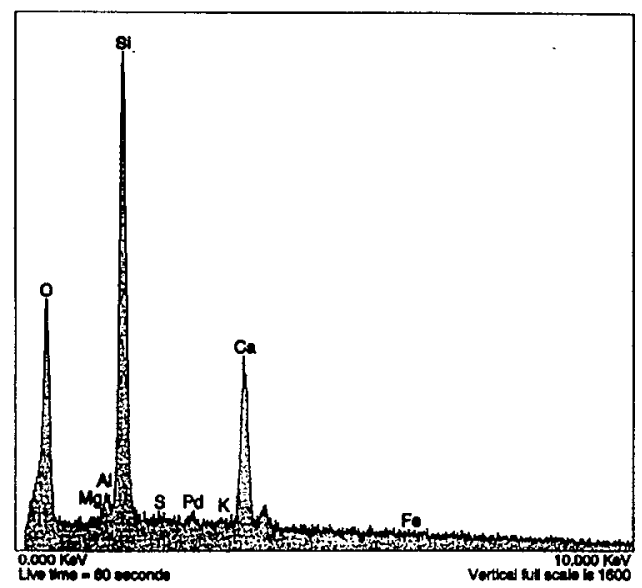

(e)

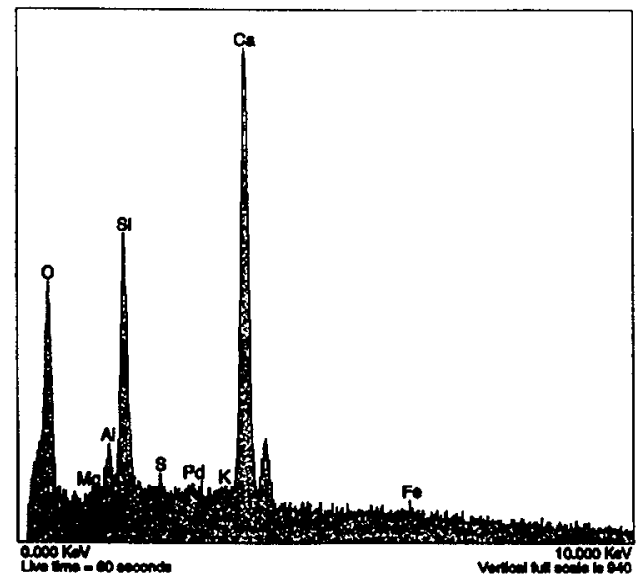

Figure 33. INV-38 (PV-13-38). (a) SEM photomicrograph of an aggregate grain with a halo of tabular crystals and fine crystals. (b) EDS of the center of the grain indicates the presence of $\mathrm{Ca}, \mathrm{Si}$, and $\mathrm{O}$ with minor amounts of $\mathrm{Al}$. (c) EDS of the grout outboard of the tabular crystals and the aggregate grain indicates the presence of $\mathrm{Ca}, \mathrm{Si}$, and $\mathrm{O}$ with minor amounts of $\mathrm{Al}$ [fairly similar to (b)]. (d) EDS of a grain near the fine crystals indicates the presence of $\mathrm{Si}, \mathrm{O}$, and Ca with minor amounts of Al. (e) EDS of another grain near the fine crystals indicates the presence of $\mathrm{Ca}, \mathrm{Si}$, and $\mathrm{O}$ with minor amounts of $\mathrm{Al}$. 
(a)

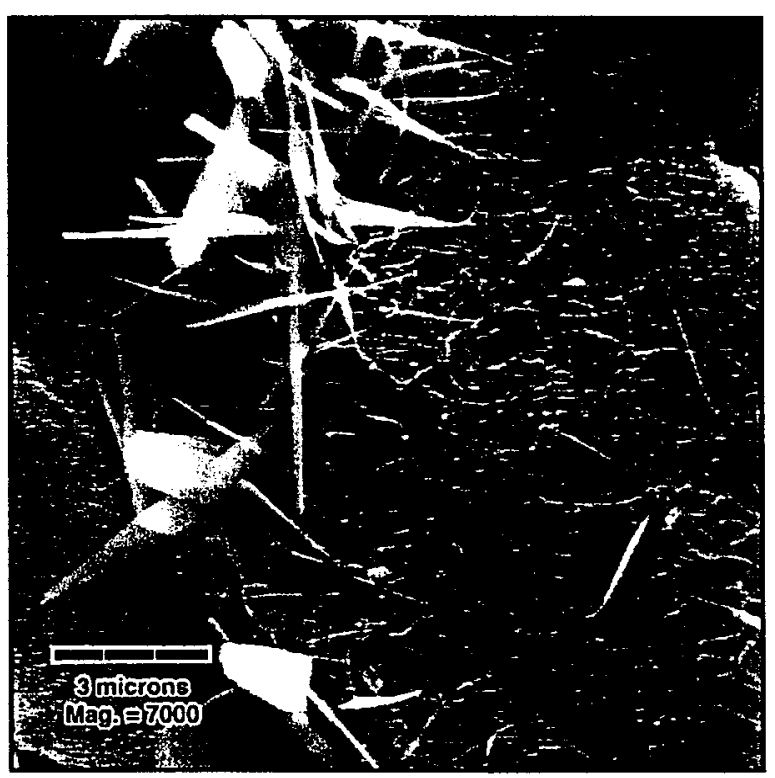

(c)

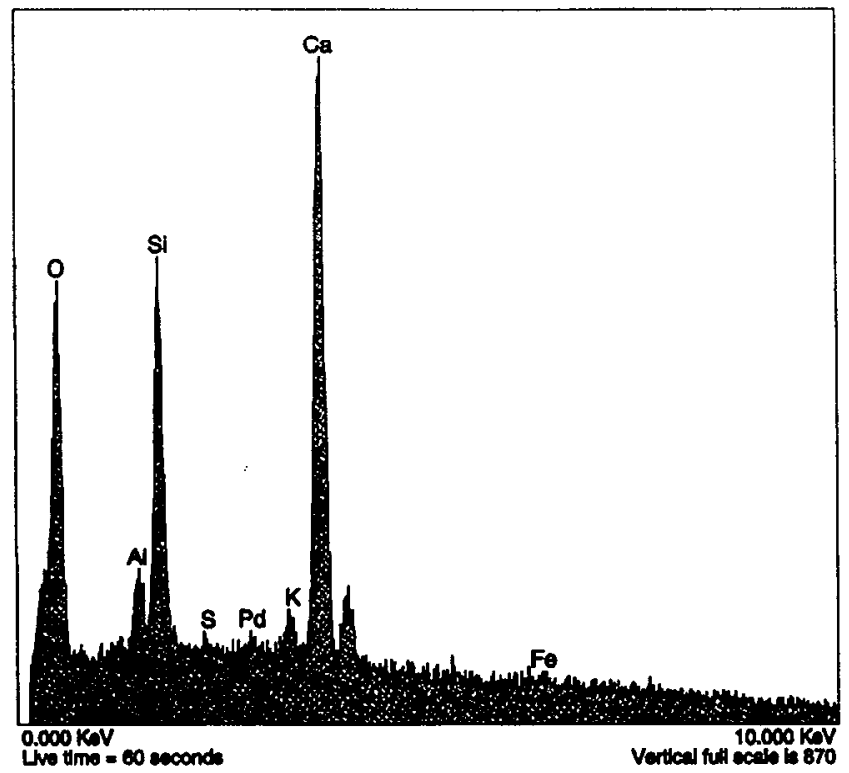

(b)

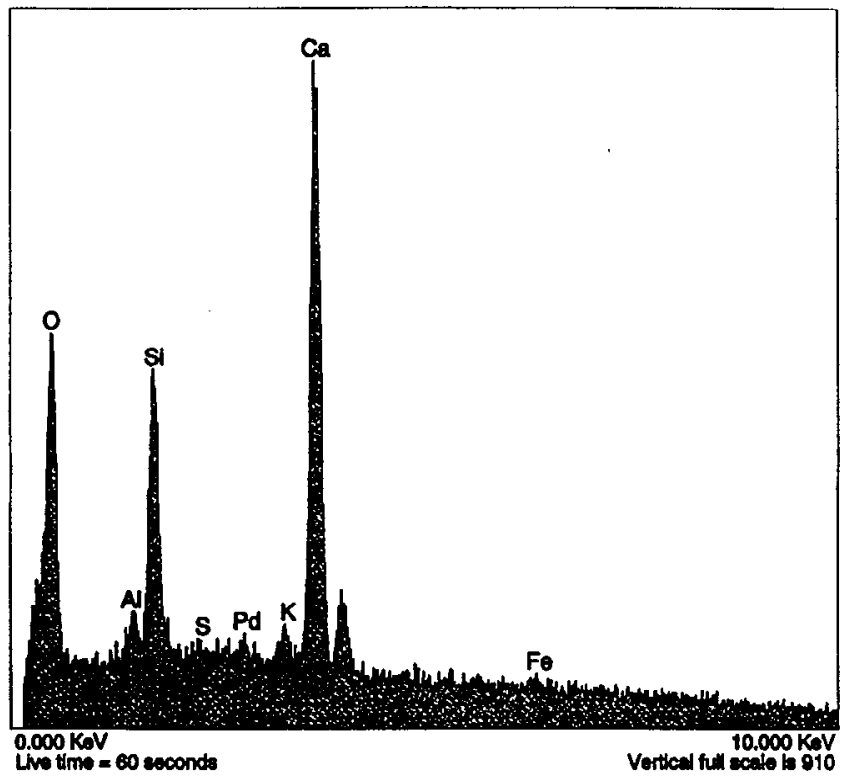

(d)

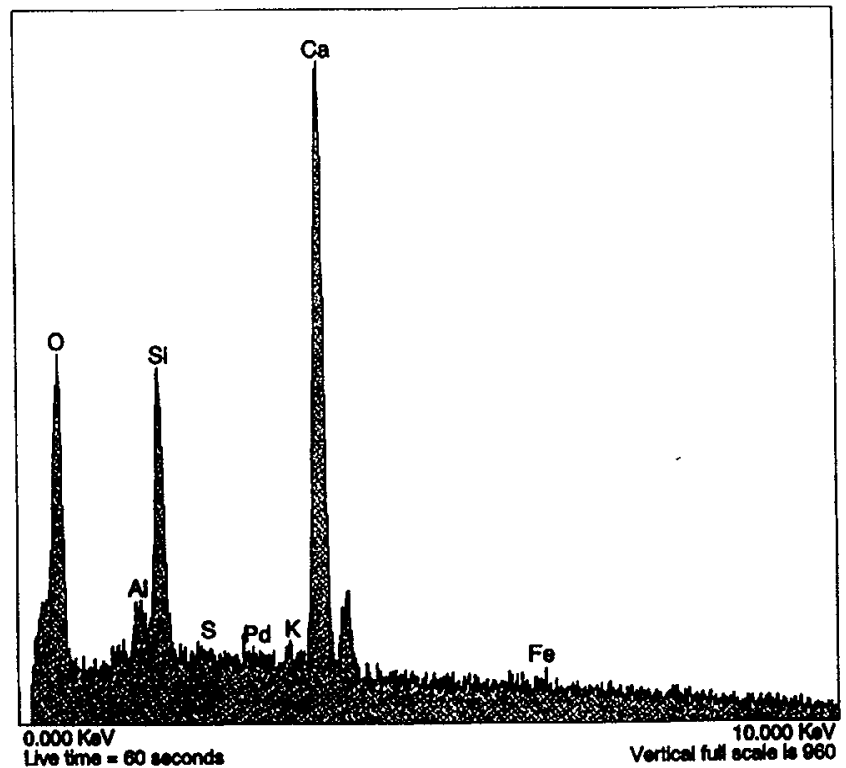

Figure 34. INV-38 (PV-13-38). (a) SEM photomicrograph of the interface between tabular and fibrous crystals. Note the similarity of this photo to Figure 31(a). (b) EDS of the tabular crystals suggests Ca, $\mathrm{O}$, and $\mathrm{Si}$ with minor amounts of $\mathrm{Al}$ and $\mathrm{K}$. (c) EDS of the fibrous crystals suggests $\mathrm{Ca}, \mathrm{Si}$, and $\mathrm{O}$ with minor amounts of $\mathrm{Al}$ and $\mathrm{K}$. (d) EDS of one side of the fibrous crystals indicates the presence of $\mathrm{Ca}, \mathrm{Si}$, and $\mathrm{O}$ with minor amounts of $\mathrm{K}$ and $\mathrm{Al}$. 
(e)

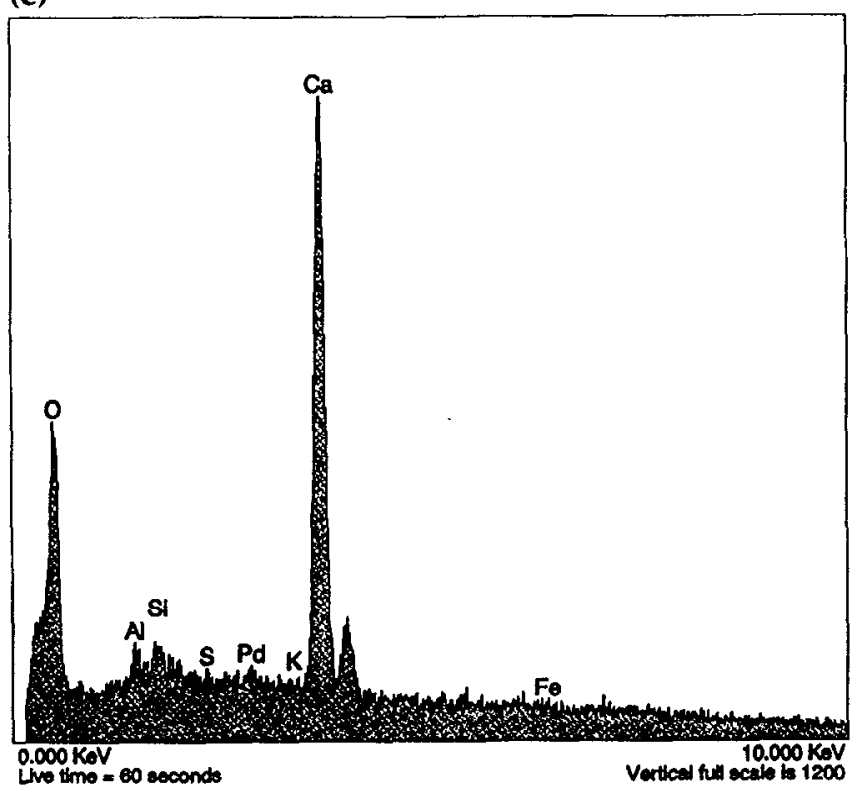

(f)

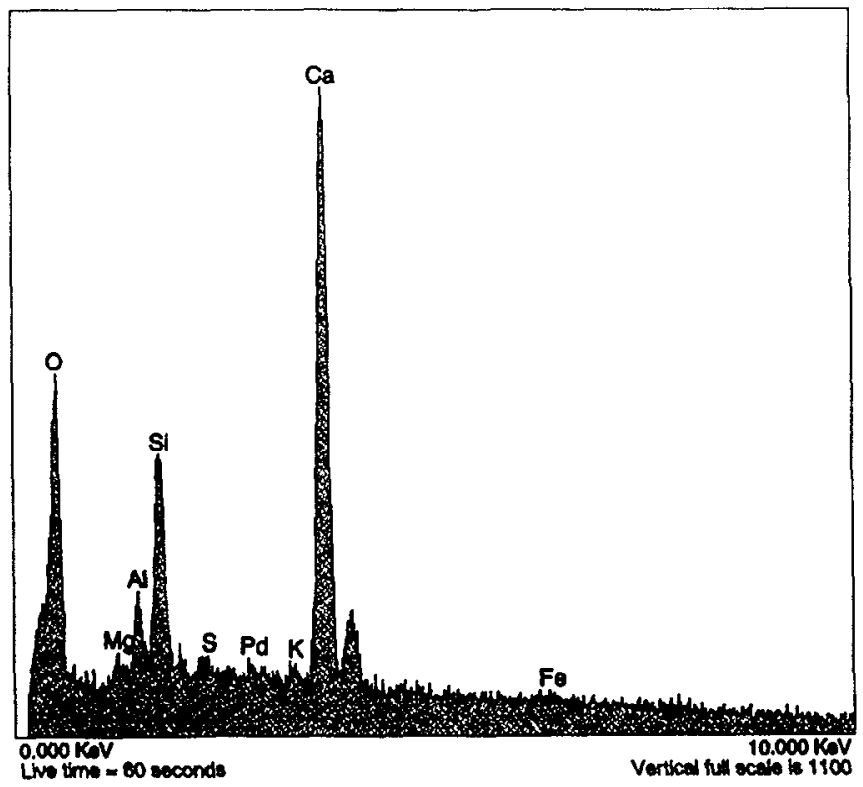

(g)

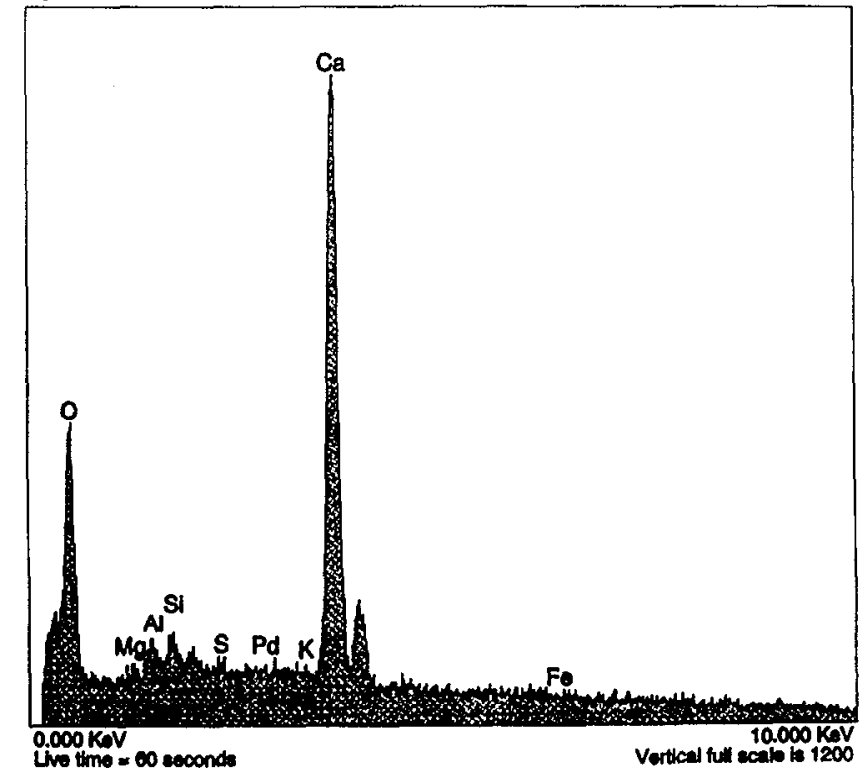

Figure 34 (continued). INV-38 (PV-13-38). (e) EDS of the other side of the fibrous crystals indicates a carbonate composition with $\mathrm{Ca}, \mathrm{O}$, and $\mathrm{C}$ with possible minor amounts of $\mathrm{Si}$ and $\mathrm{Al}$. ( $\mathrm{f}$ ) EDS of one side of the tabular crystals indicates the presence of $\mathrm{Ca}, \mathrm{O}$, and $\mathrm{Si}$ with minor amounts of $\mathrm{Al}, \mathrm{Mg}$, and possible $\mathrm{S}$. $(\mathrm{g})$ EDS of the other side of the tabular crystals indicates the presence of $\mathrm{Ca}, \mathrm{O}$, and $\mathrm{C}$ (probably carbonate), with possible minor amounts of $\mathrm{Al}$ and $\mathrm{Si}$. 
(a)

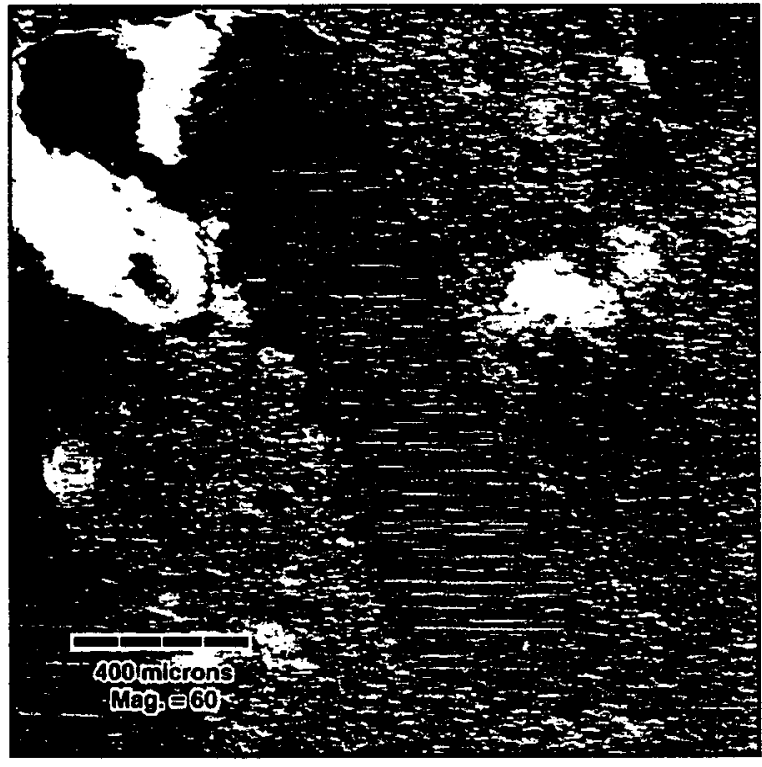

(b)

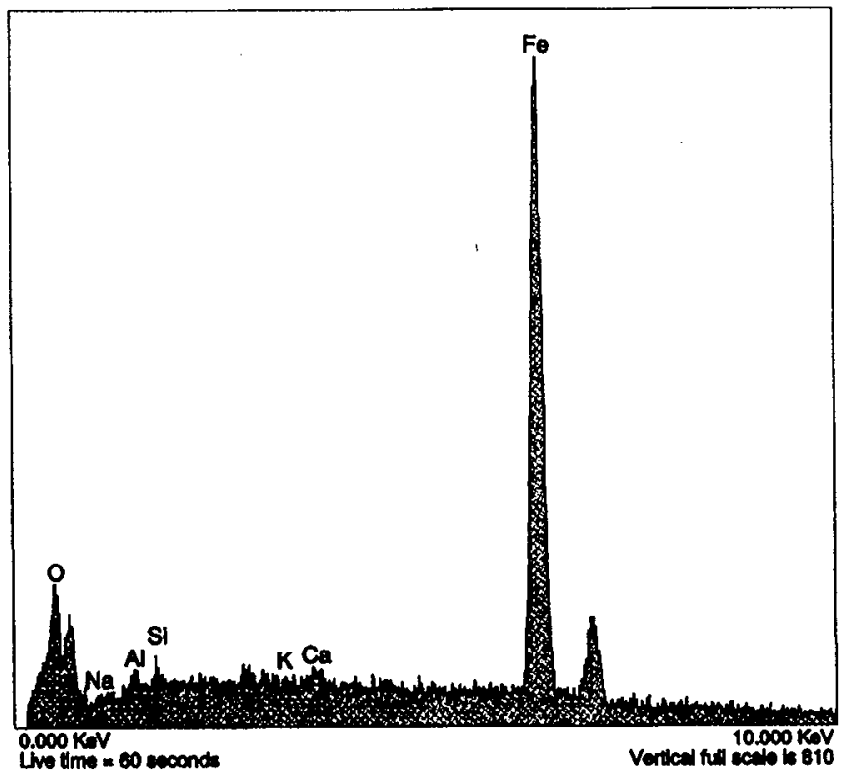

Figure 35. SH-9 (PV-13-9). (a) SEM photomicrograph of a stainless steel fiber. Closer examination reveals no alteration phases. (b) EDS of the fiber suggests a composition of predominantly $\mathrm{Fe}$, which is typical for stainless steel. 
(a)

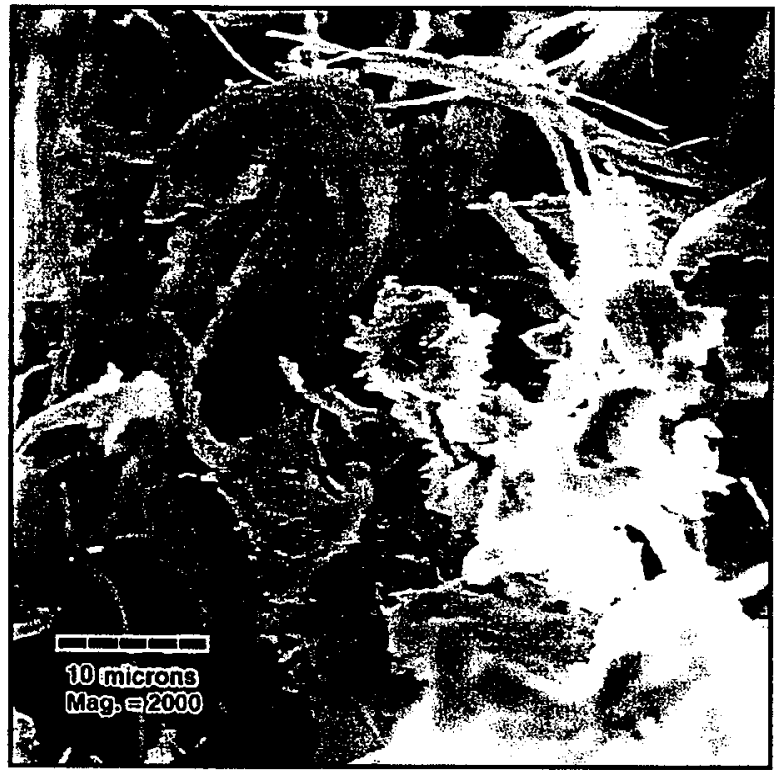

(b)

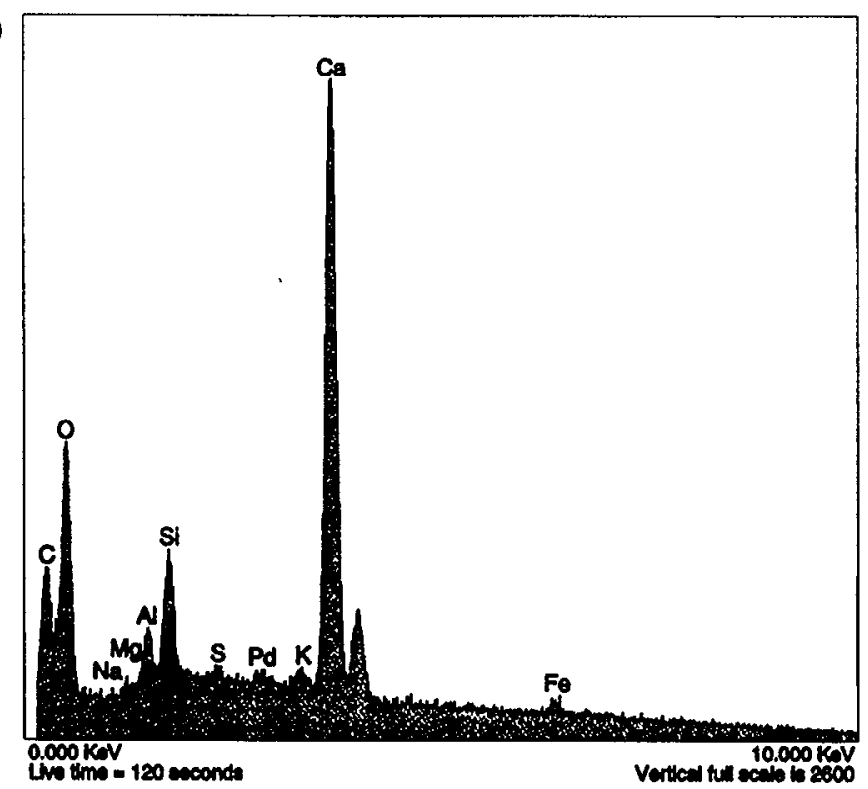

Figure 36. SH-9 (PV-13-9). (a) SEM photomicrograph of crystals in and around the drilled-out hole in the center of the sample. (b) EDS indicates the presence of $\mathrm{Ca}, \mathrm{O}, \mathrm{Si}, \mathrm{C}, \mathrm{Al}, \mathrm{K}$, and $\mathrm{Fe}$. Dominant elements indicate that the phase is probably a carbonate. 
(a)

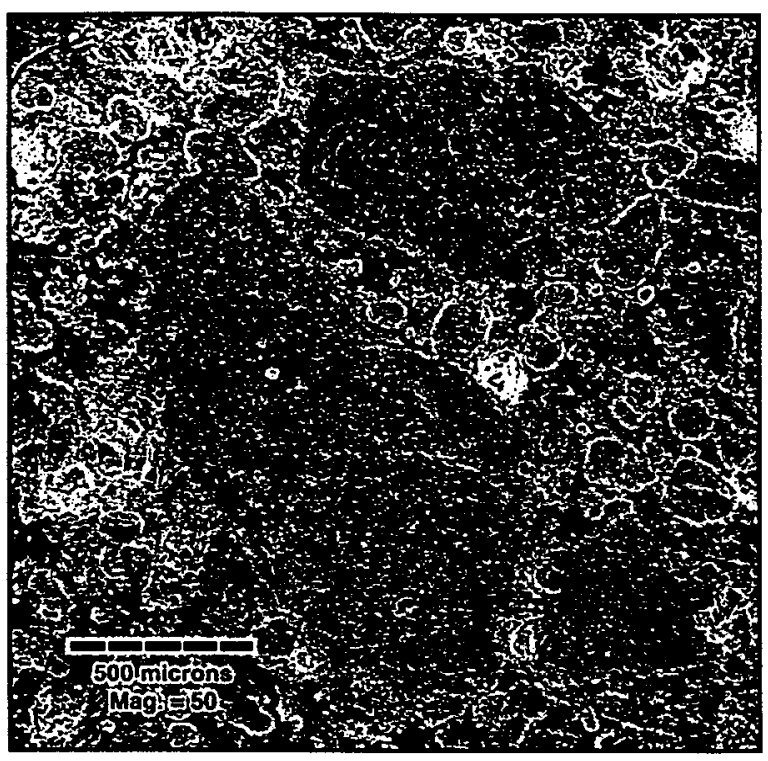

(c)

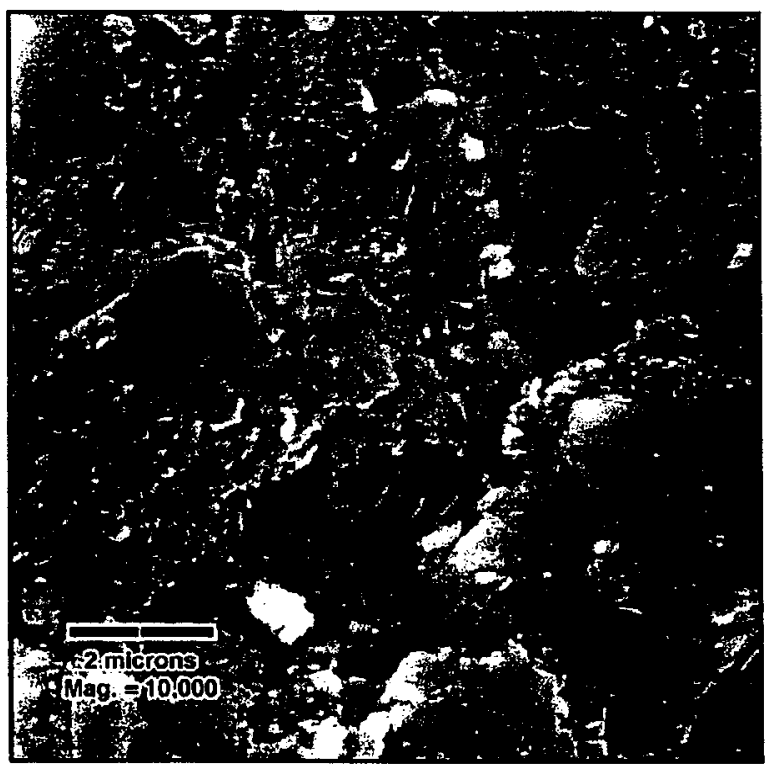

(b)

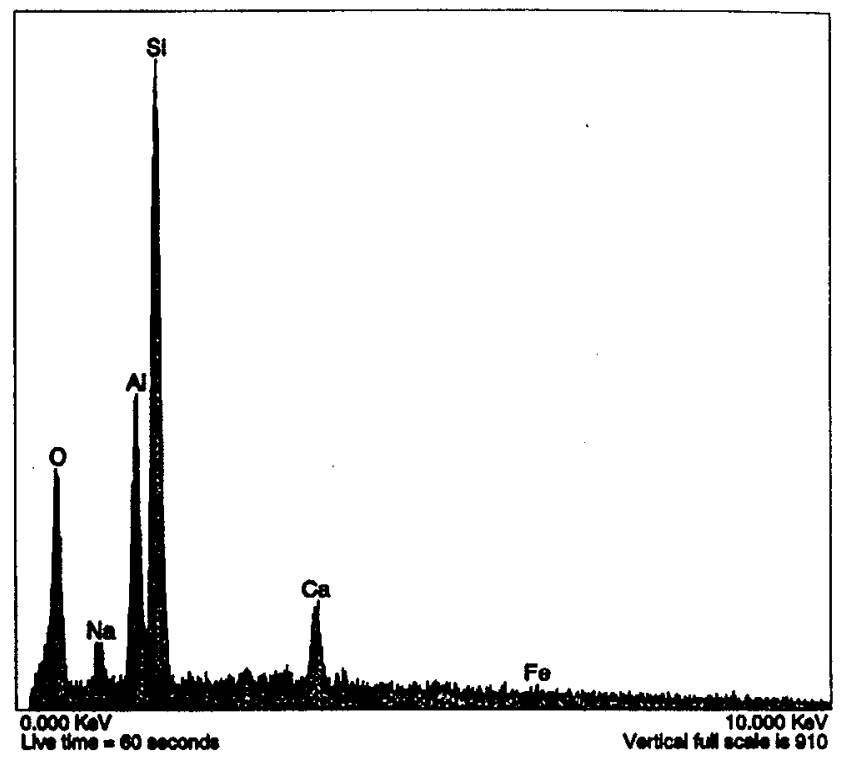

(d)

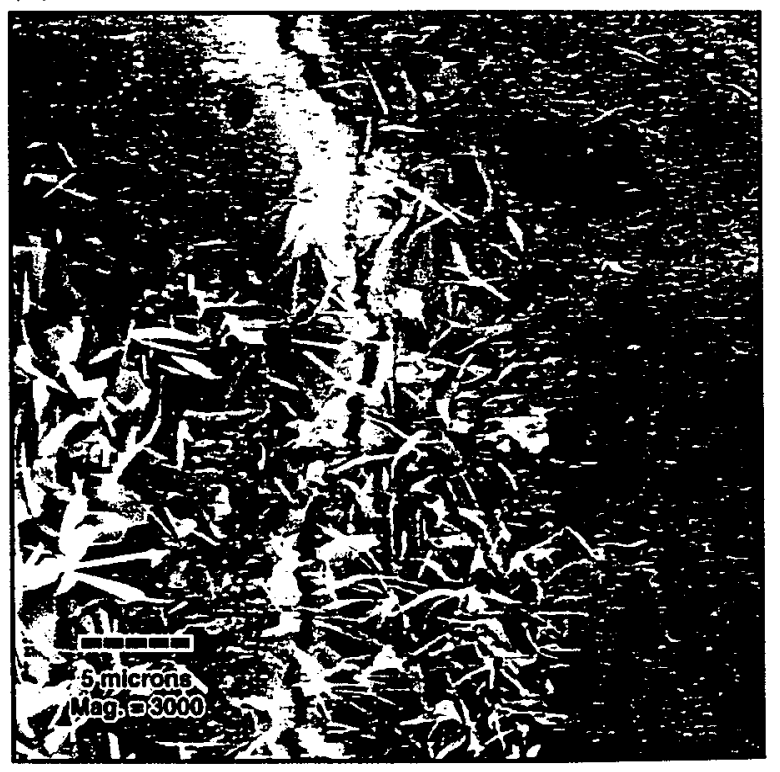

Figure 37. SH-9 (PV-13-9). (a) SEM photomicrograph of several aggregate grains. (b) EDS of largest grain indicates a plagioclase composition including $\mathrm{Si}, \mathrm{Al}, \mathrm{O}, \mathrm{Ca}$, and $\mathrm{Na}$. (c) SEM photomicrograph of the center of the plagioclase grain. No alteration or reaction phases are evident. (d) SEM photomicrograph of a crack along the edge of the plagioclase grain. Note the presence of one or two different tabular reaction phases. 
Part Il: Secondo nno Third Batch of Samples

(a)

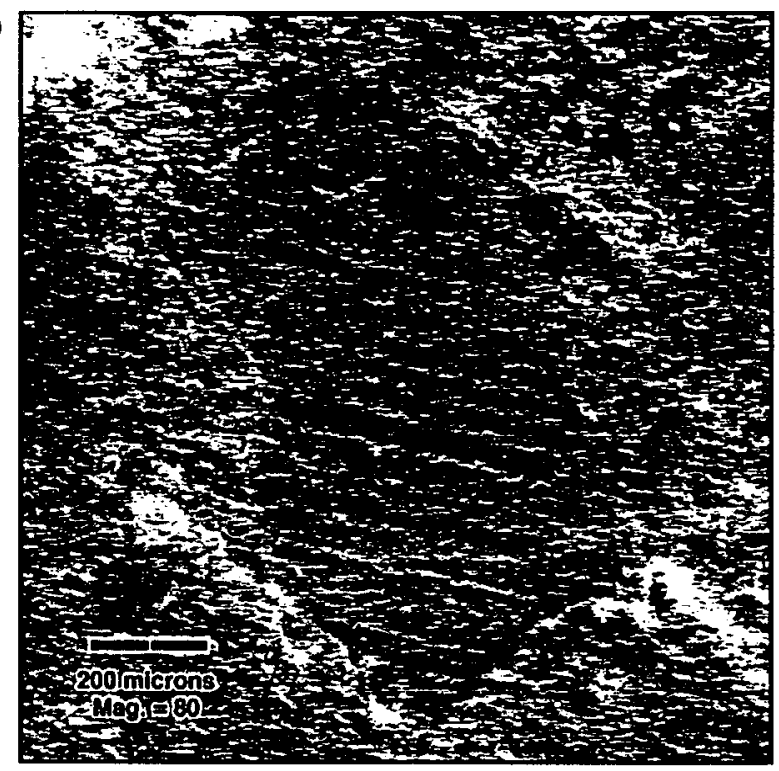

(b)

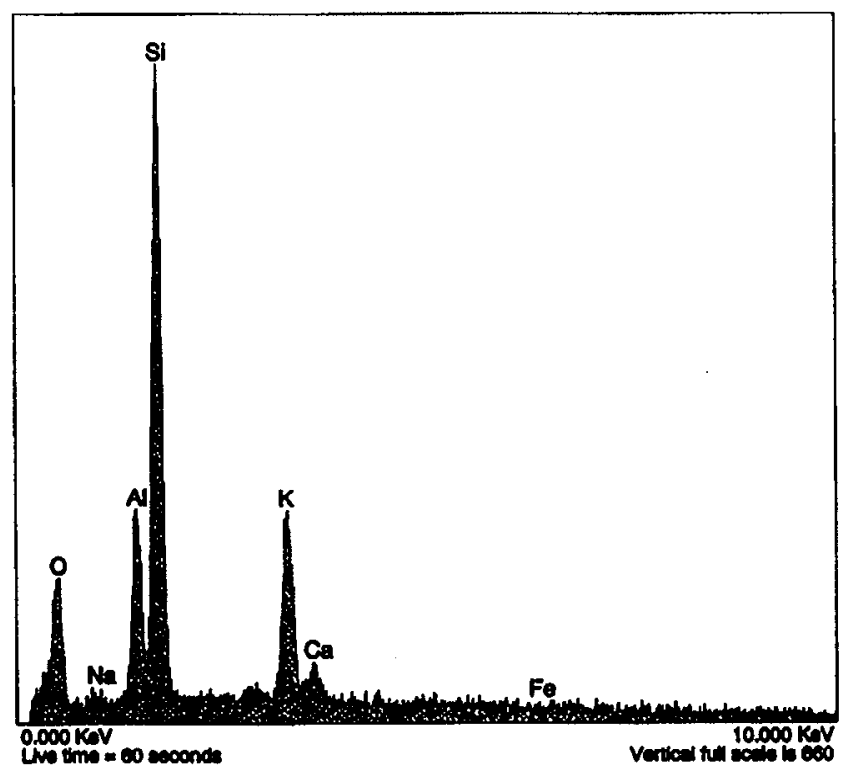

Figure 38. SH-9 (PV-13-9). (a) SEM photomicrograph of an aggregate grain. Closer examination around the grain edge does not reveal reaction phases. (b) EDS of the grain indicates the presence of $\mathrm{Si}, \mathrm{Al}, \mathrm{O}$, and $\mathrm{K}$ with minor amounts of $\mathrm{Ca}$ and $\mathrm{Na}$, possibly a potassium feldspar grain. 
(a)

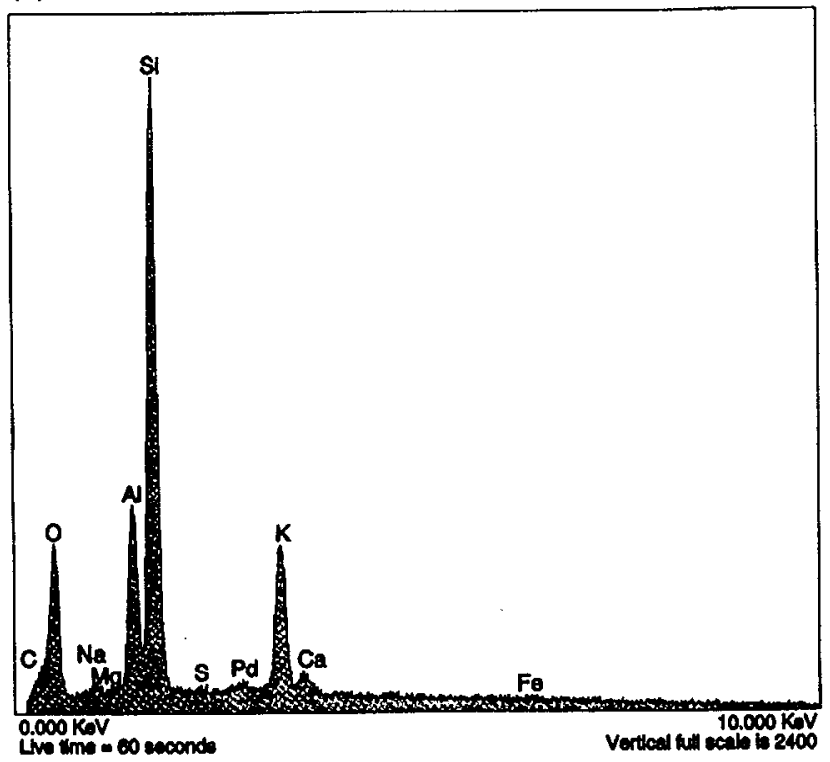

(b)

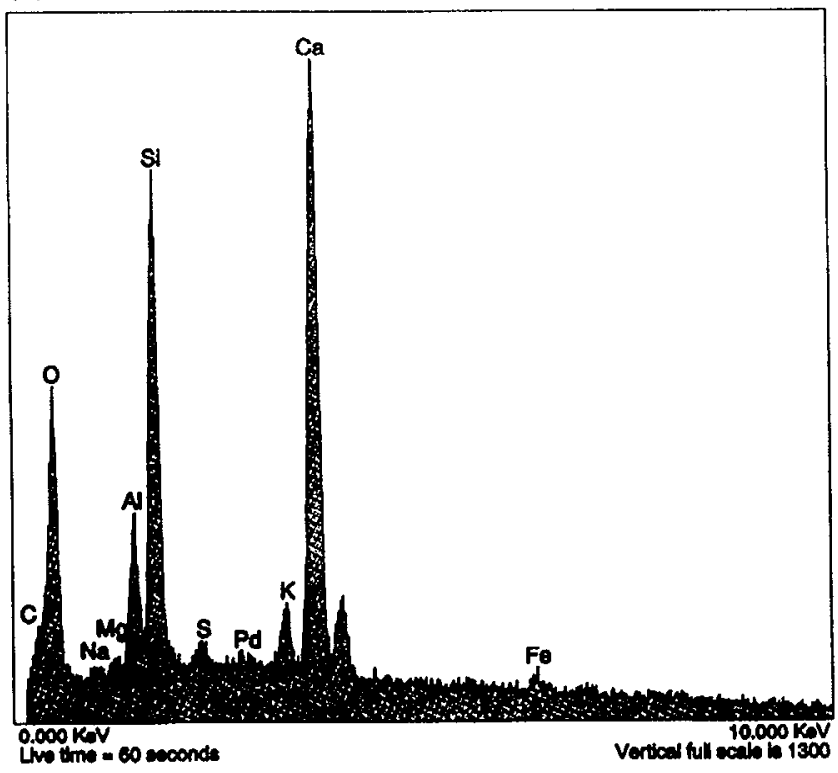

(c)

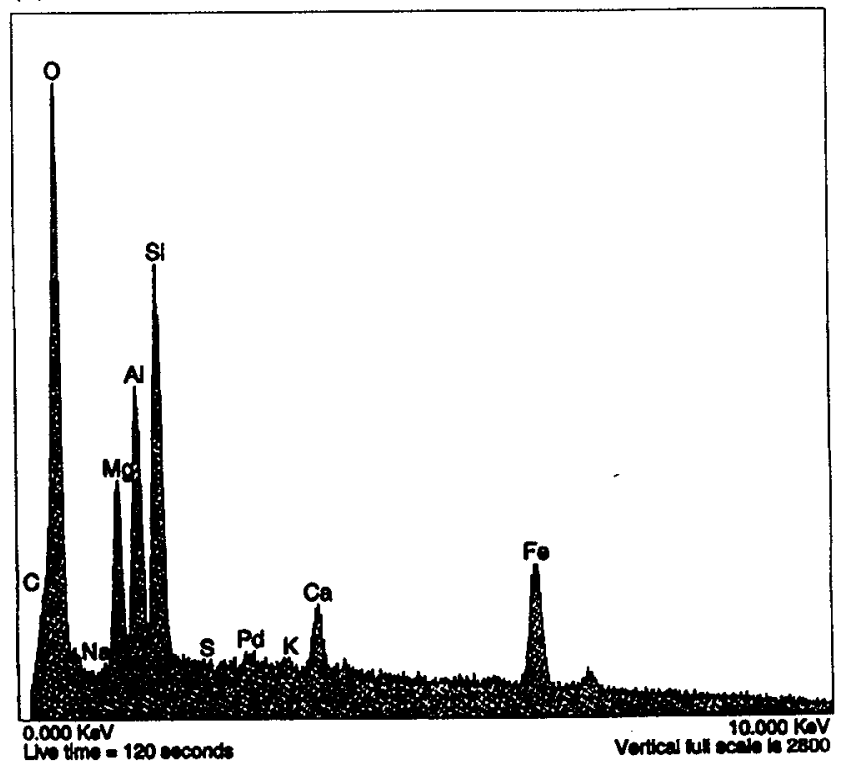

Figure 39. SH-9 (PV-13-9). (a) No photomicrograph observation of relationship between secondary mineralization and primary material. EDS of the interior of a grain surrounded by secondary minerals located adjacent to the central hole. The spectrum indicates the presence of $\mathrm{Si}, \mathrm{Al}, \mathrm{O}, \mathrm{K}$ with minor $\mathrm{Ca}$. The grain is probably potassium feldspar. (b) EDS of grout with no visible reactant phases located near the central hole. The spectrum shows the presence of $\mathrm{Ca}, \mathrm{Si}, \mathrm{O}, \Lambda \mathrm{l}$, and $\mathrm{K}$ with minor amounts of $\mathrm{S}, \mathrm{Fe}, \mathrm{C}$, and $\mathrm{Mg}$. (c) EDS of a grain located between reaction phases shown in Figure 36(a) and the grout described in Figure (b). The spectrum indicates the presence of $\mathrm{O}, \mathrm{Si}, \mathrm{Al}, \mathrm{Mg}, \mathrm{Fe}$, and $\mathrm{Ca}$. The grain is probably a pyroxene or amphibole. 
(a)

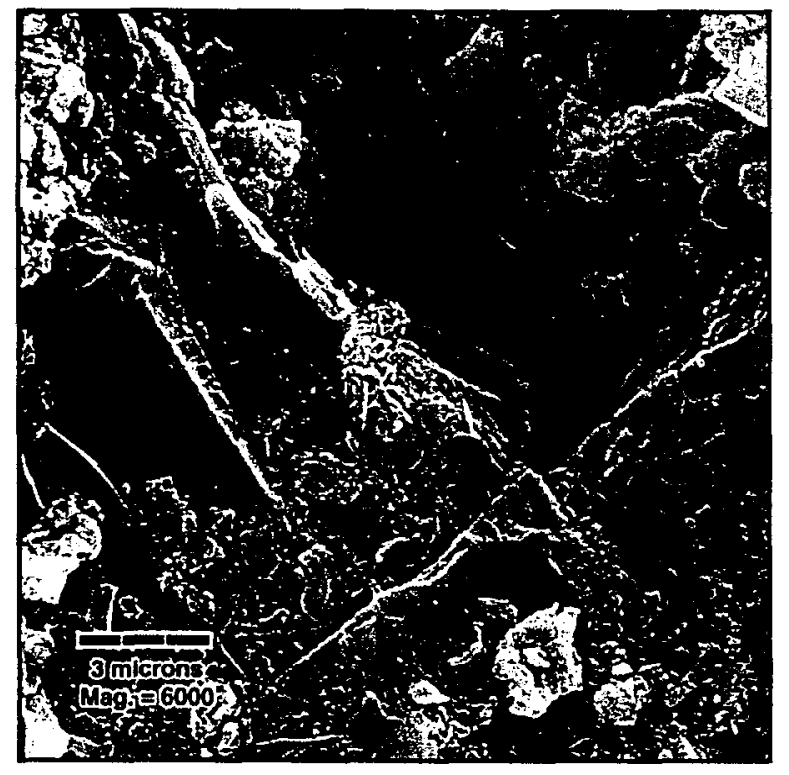

(c)

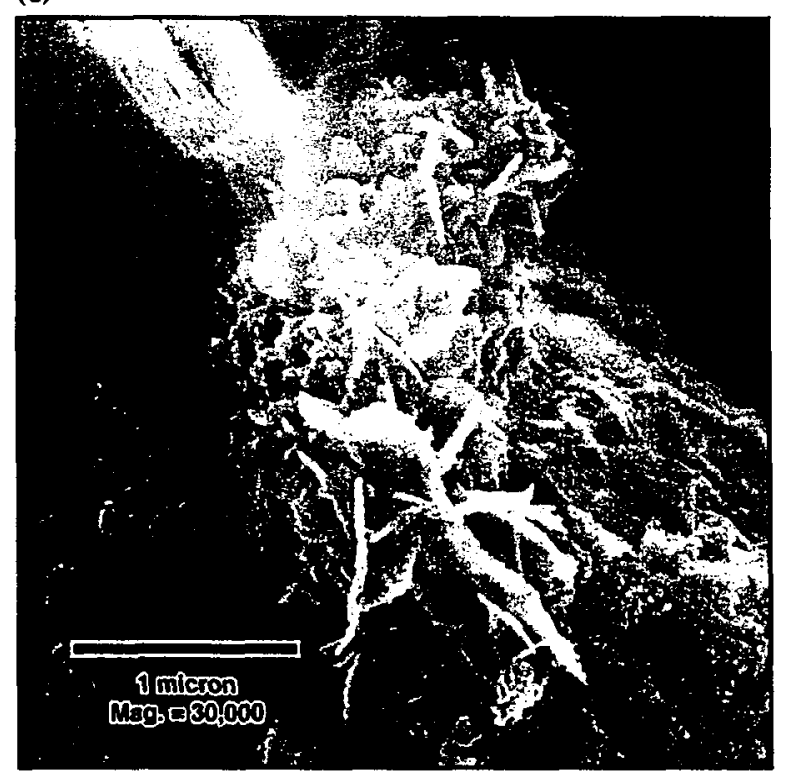

(b)

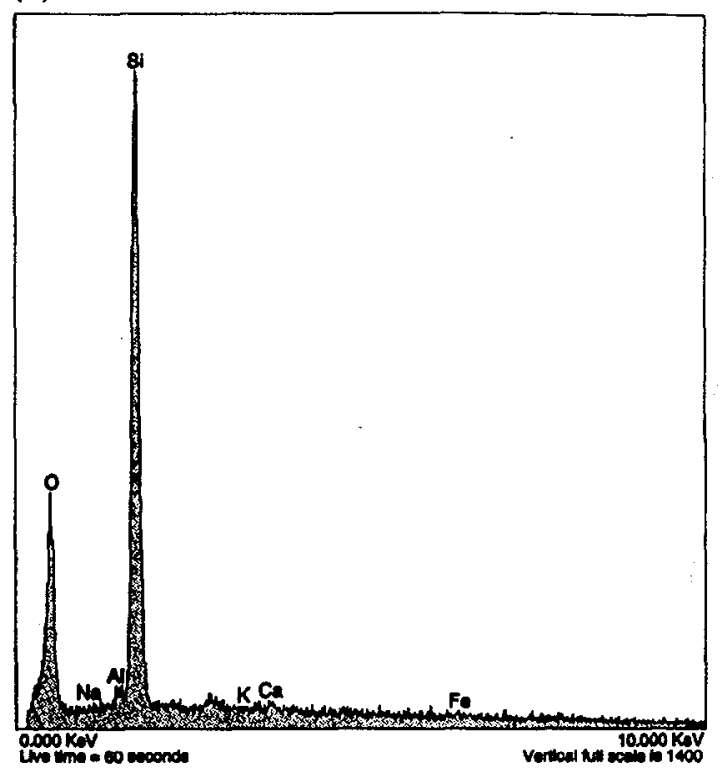

(d)

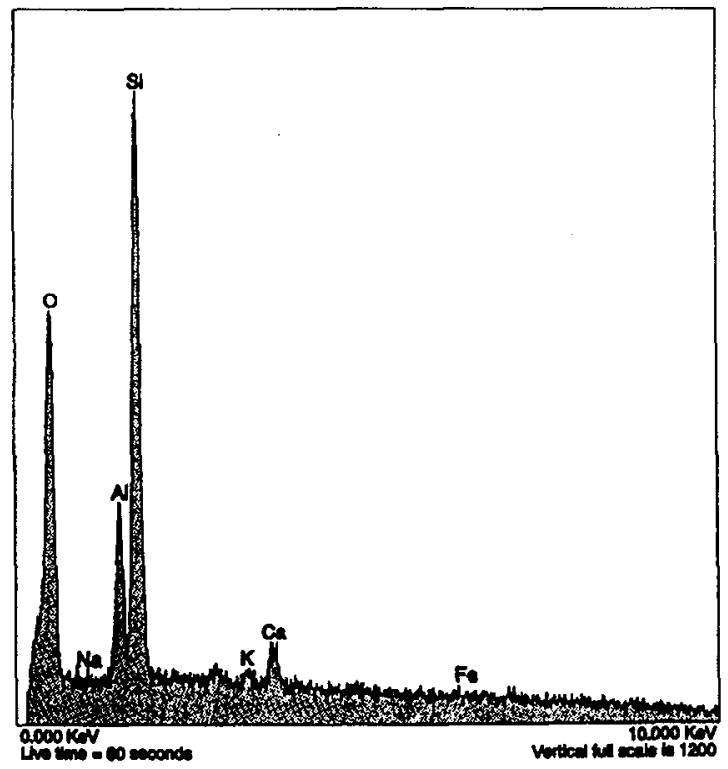

Figure 40. SH-9 (PV-13-9). (a) SEM photomicrograph of a tiny platy phase (see center of photo). (b) EDS of the area indicates that the tabular phase has precipitated on a grain composed of $\mathrm{SiO}_{2}$, probably quartz. The quartz grain likely makes up the majority of the x-ray volume. (c) SEM photomicrograph of the platy phase at higher magnification. (d) EDS of the platy phase indicates the presence of $\mathrm{Si}, \mathrm{O}$, and $\mathrm{Al}$, with minor amounts of $\mathrm{Ca}$. The underlying quartz grain likely contributes most of the signal in this spectrum. 
(a)

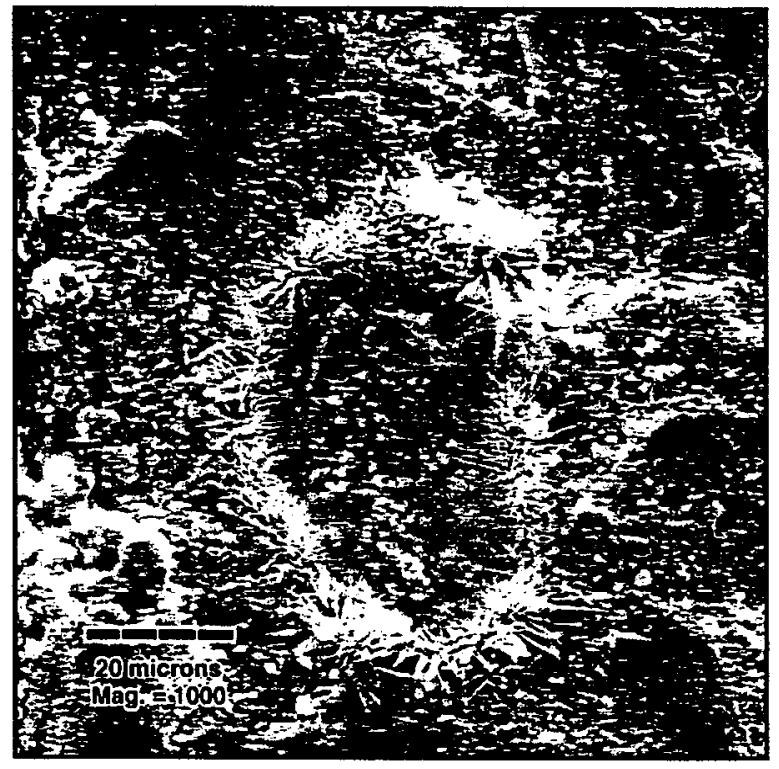

(c)

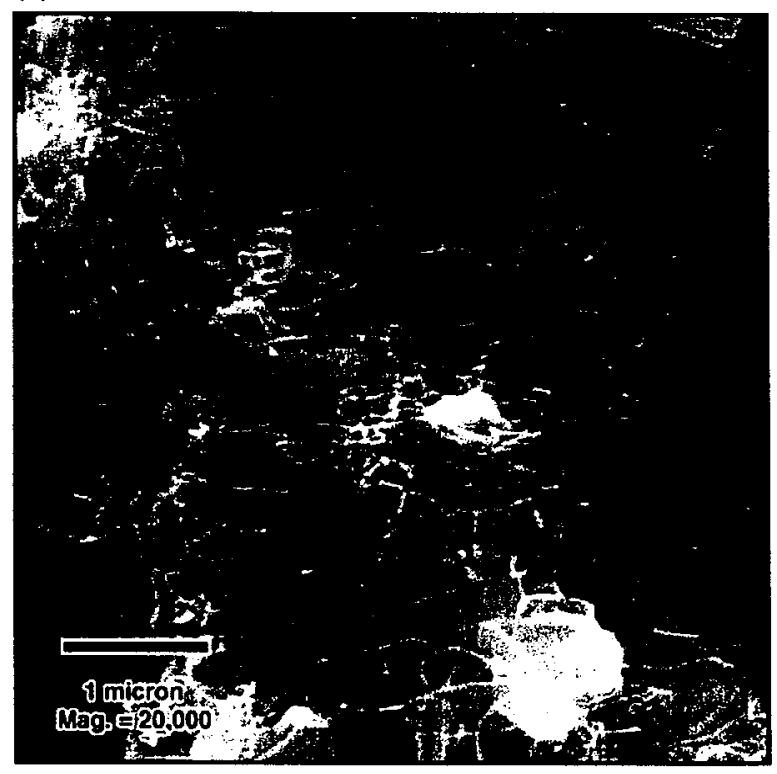

(b)

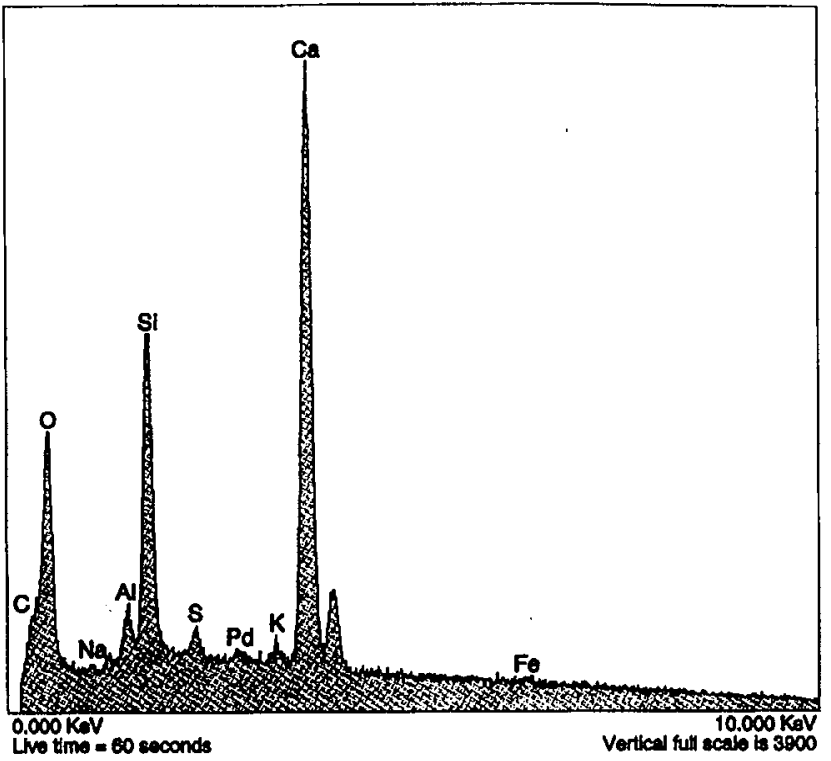

(d)

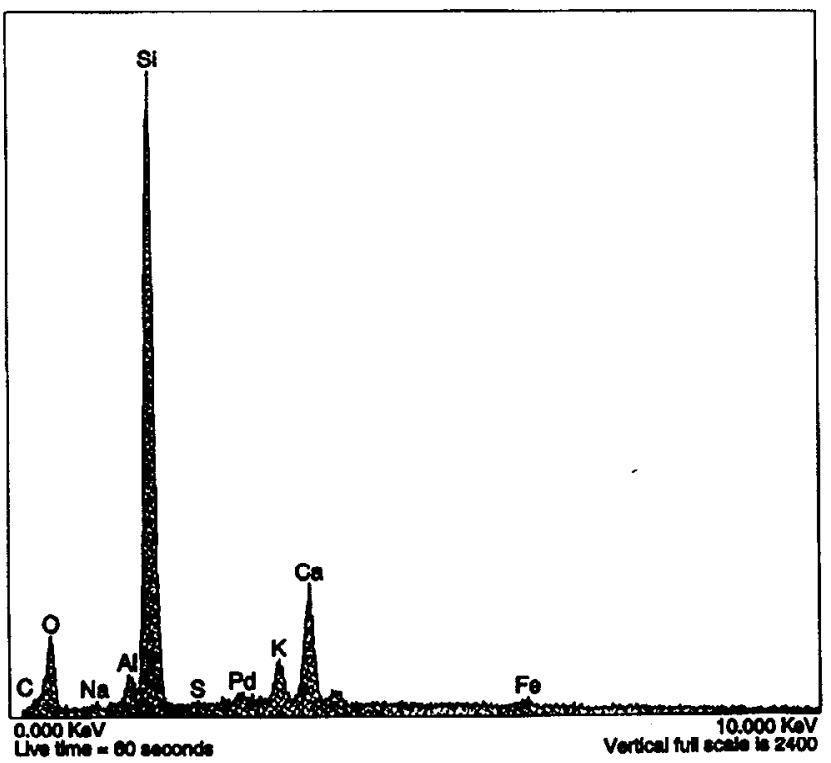

Figure 41. SH-9 (PV-13-9). (a) SEM photomicrograph of a small aggregate grain. (b) EDS of grout located outside of the aggregate grain and reaction phases suggests the presence of $\mathrm{Ca}, \mathrm{Si}, \mathrm{O}$ and minor amounts of $\mathrm{Al}, \mathrm{S}$, and $\mathrm{K}$. (c) SEM photomicrograph of the interior of the small aggregate grain shown in Figure (a). (d) EDS indicates the presence of $\mathrm{Si}$, with minor amounts of $\mathrm{Ca}, \mathrm{O}, \mathrm{K}$, and $\mathrm{Al}$. 
(a)

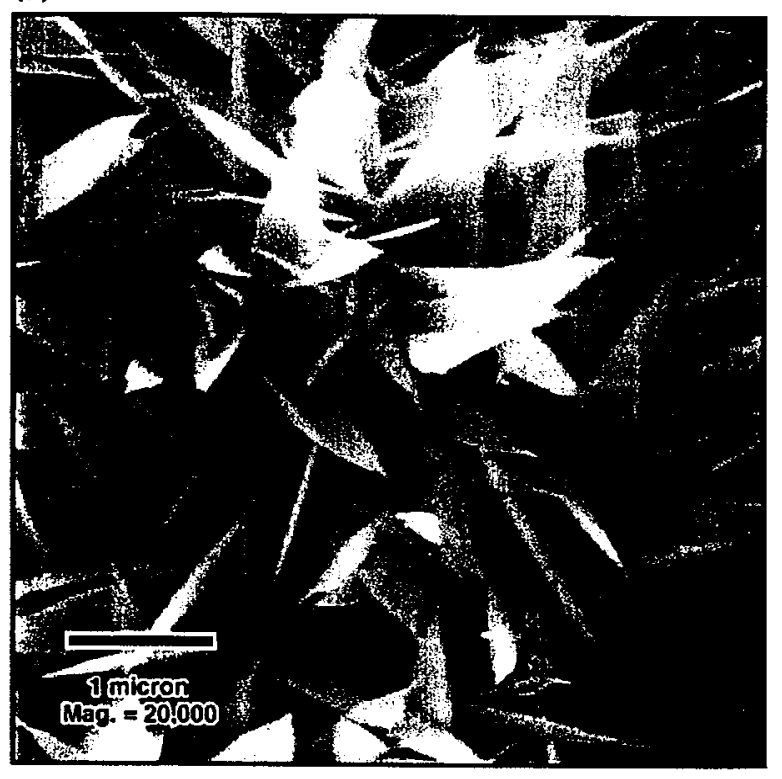

(c)

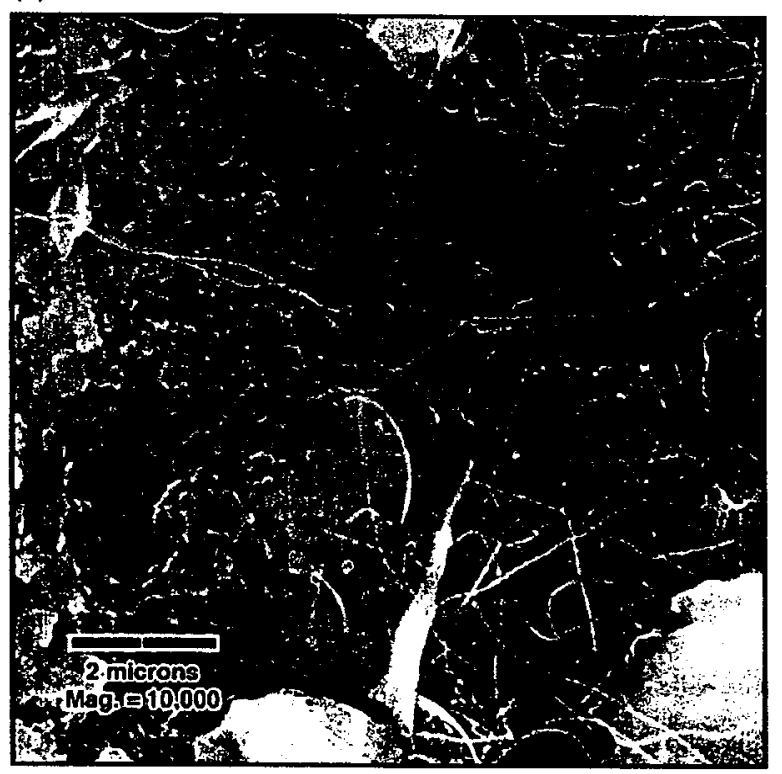

(b)

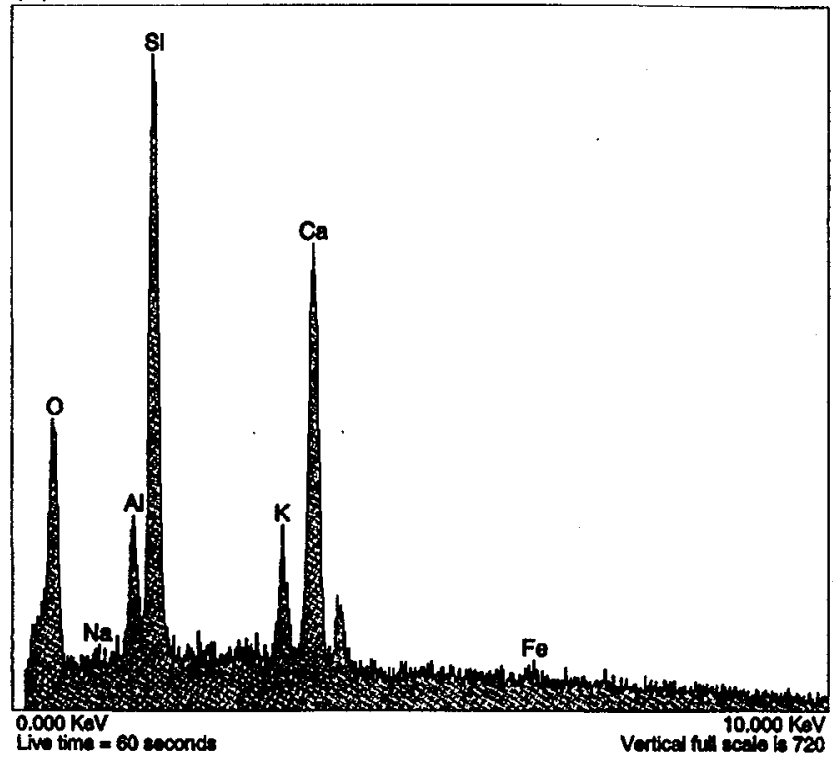

(d)

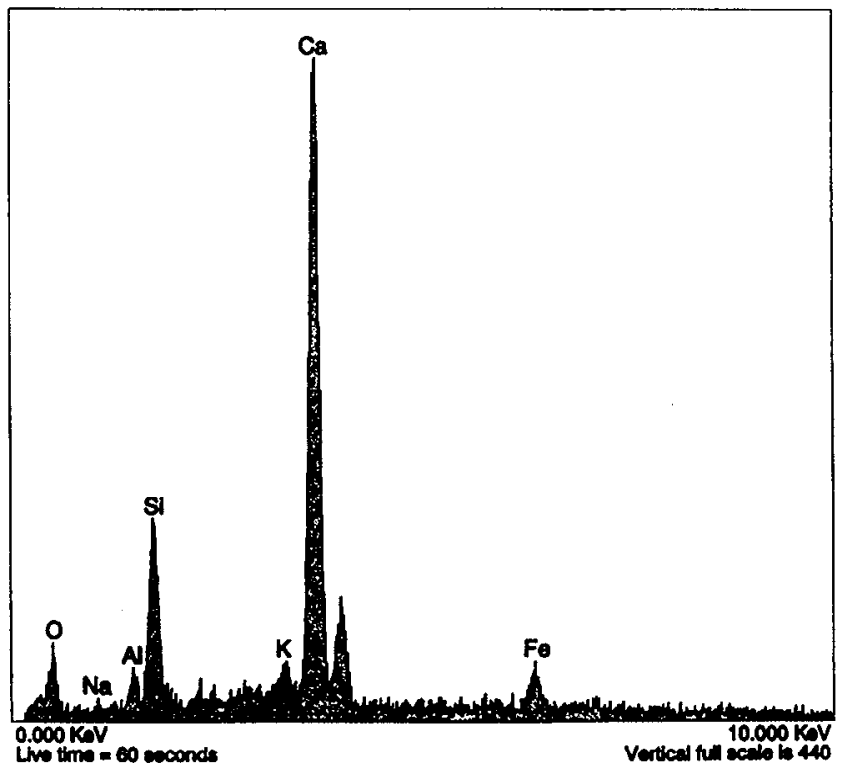

Figure 42. SH-9 (PV-13-9). (a) SEM photomicrograph of a tabular reaction phase found on the plagioclase grain boundary (same grain as Figure 37). (b) EDS indicates the presence of $\mathrm{Si}, \mathrm{Ca}, \mathrm{O}, \mathrm{Al}$, and $\mathrm{K}$, with possible minor amounts of $\mathrm{Na}$ and $\mathrm{Fe}$. (c) SEM photomicrograph of a stringy reaction phase on the same plagioclase grain. (d) EDS of the stringy phase suggests the presence of $\mathrm{Ca}$, and minor amounts of $\mathrm{Si}, \mathrm{O}, \mathrm{Al}, \mathrm{K}$, and $\mathrm{Fe}$. 


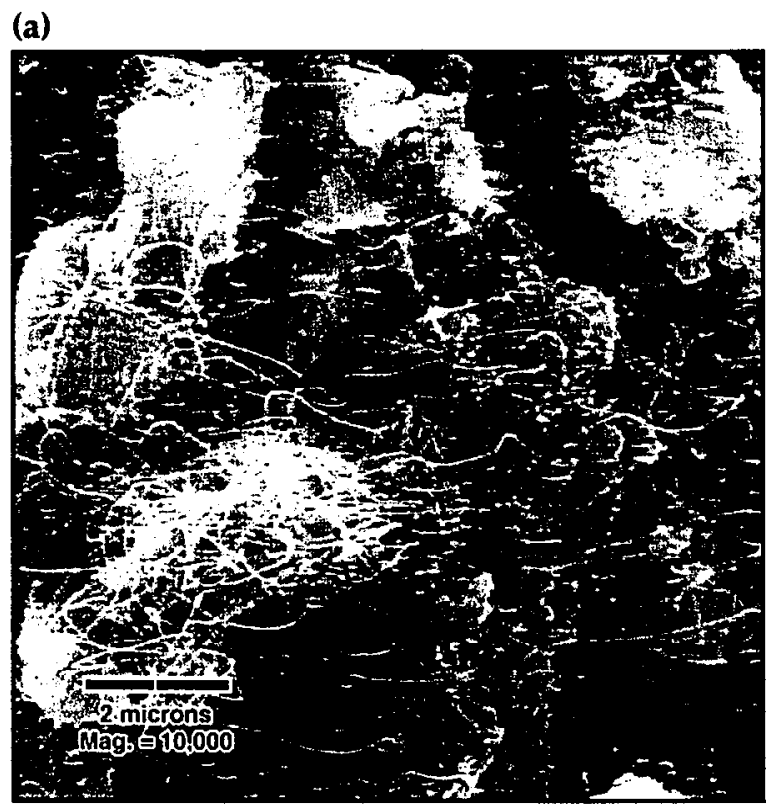

(b)

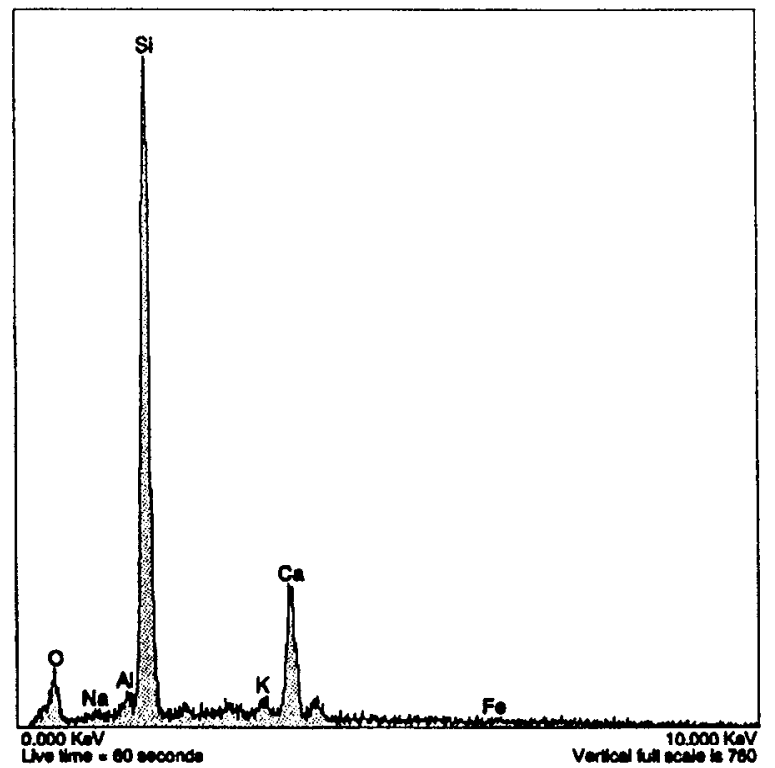

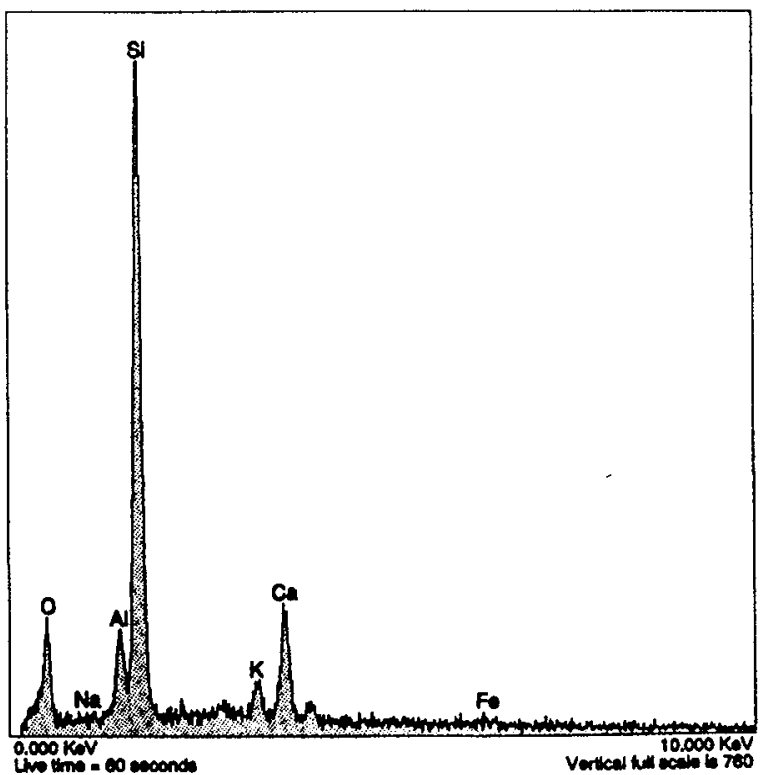

Figure 43. SH-9 (PV-13-9). (a) SEM photomicrograph of a stringy reaction phase. The phase is similar to one seen on Batch 1 sample SH-1, areas 2 and 7 (Meike et al. 1997) and elsewhere in this sample. (b) Two EDS of the phase from two different areas depicted in the above photo. The spectra indicate the presence of $\mathrm{Si}, \mathrm{Ca}$, and $\mathrm{O}$, with varying amounts of $\mathrm{Al}$ and $\mathrm{K}$. Because the phase is thin, a fair amount of the signal may be derived from the substrate. The difference in the spectra could illustrate the ability of the phase to precipitate on different substrates. 
(a)

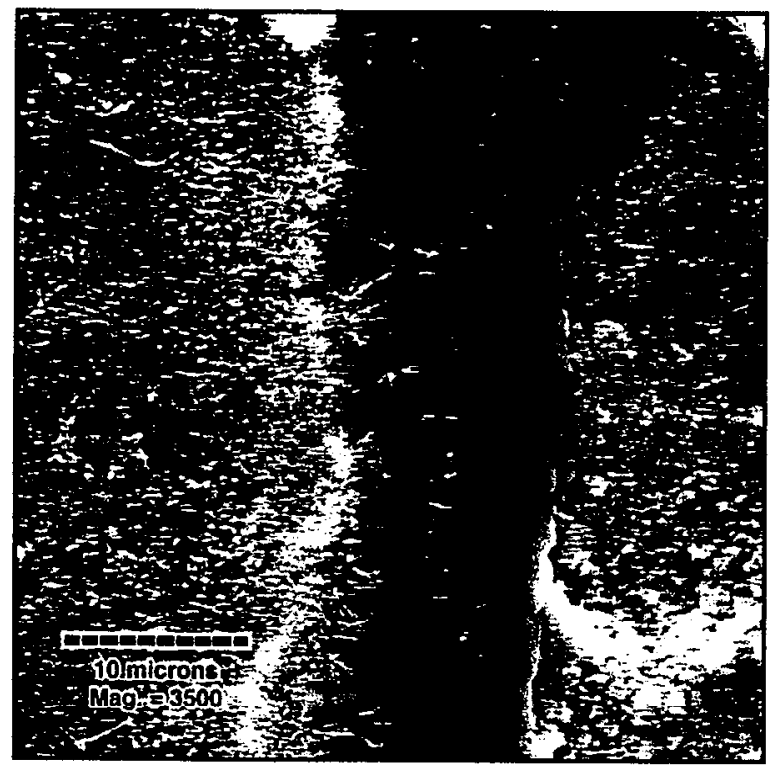

(b)

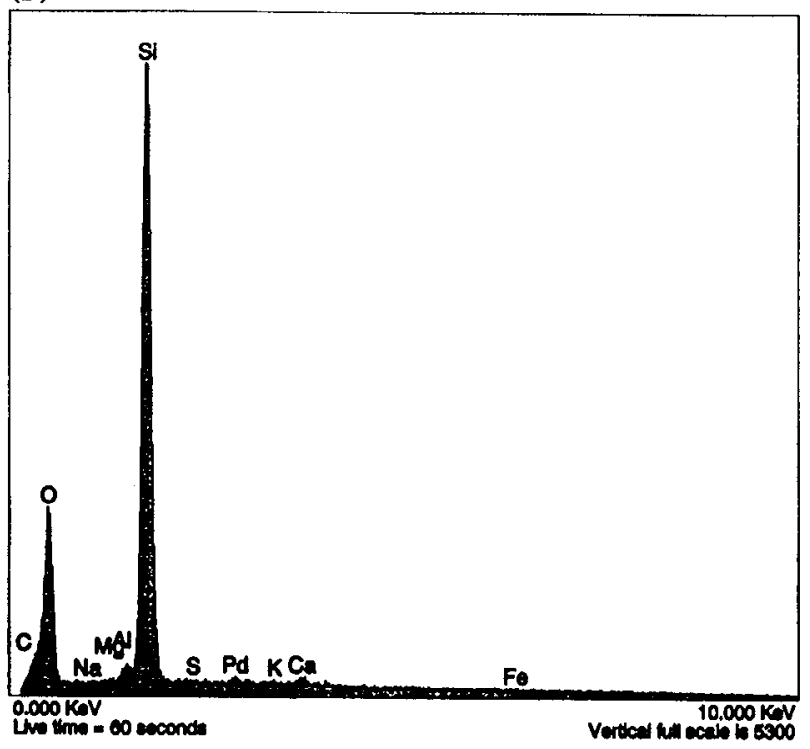

(c)

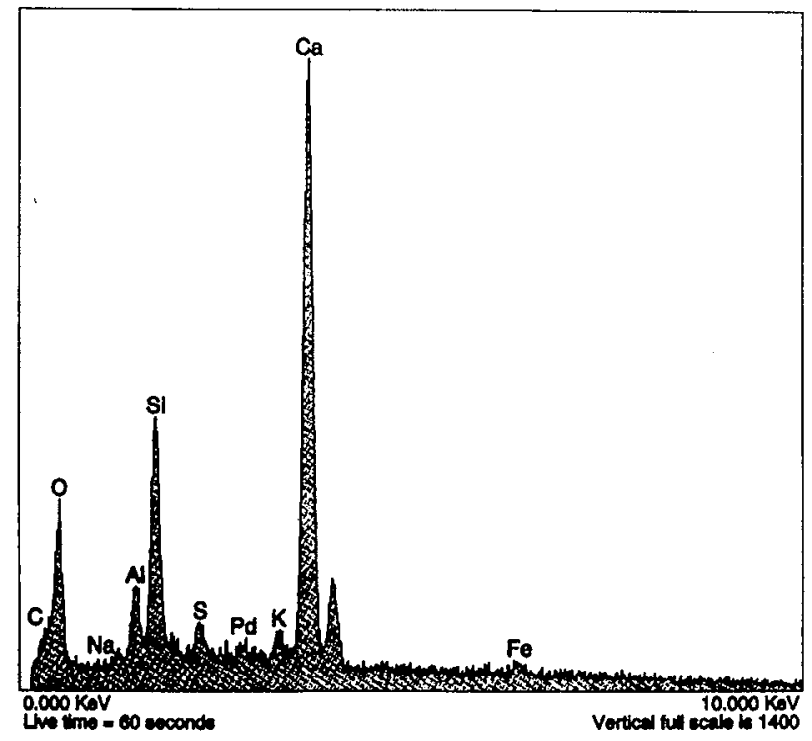

Figure 44. SH-9 (PV-13-9). (a) SEM photomicrograph of an aggregate grain (left side) with a white, stringy phase

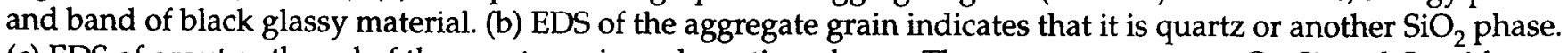
(c) EDS of grout outboard of the quartz grain and reaction phases. The spectrum suggests $\mathrm{Ca}$, $\mathrm{Si}$, and $\mathrm{O}$, with minor amounts of $\mathrm{Al}, \mathrm{S}$, and $\mathrm{K}$. 
(a)

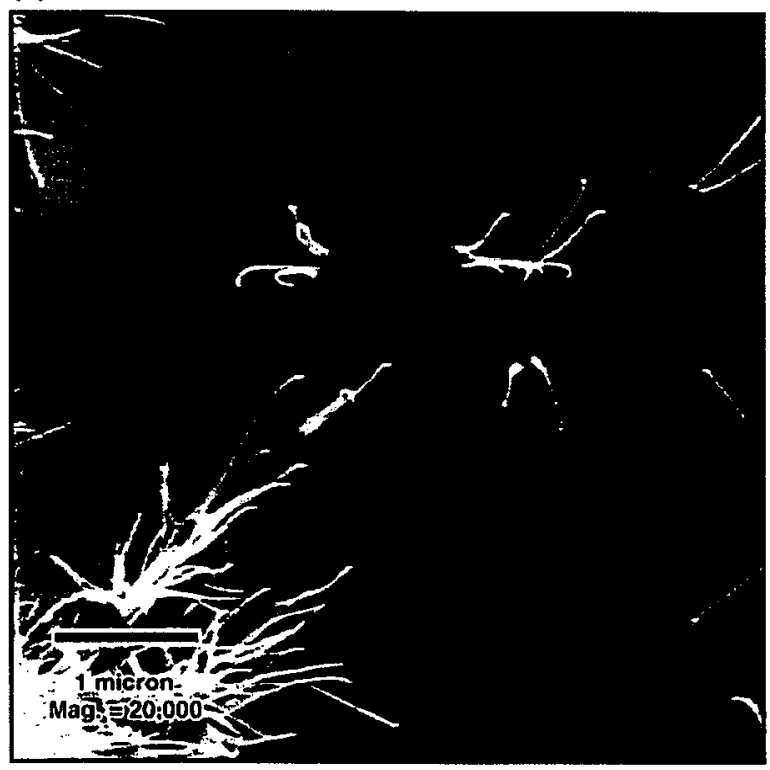

(c)

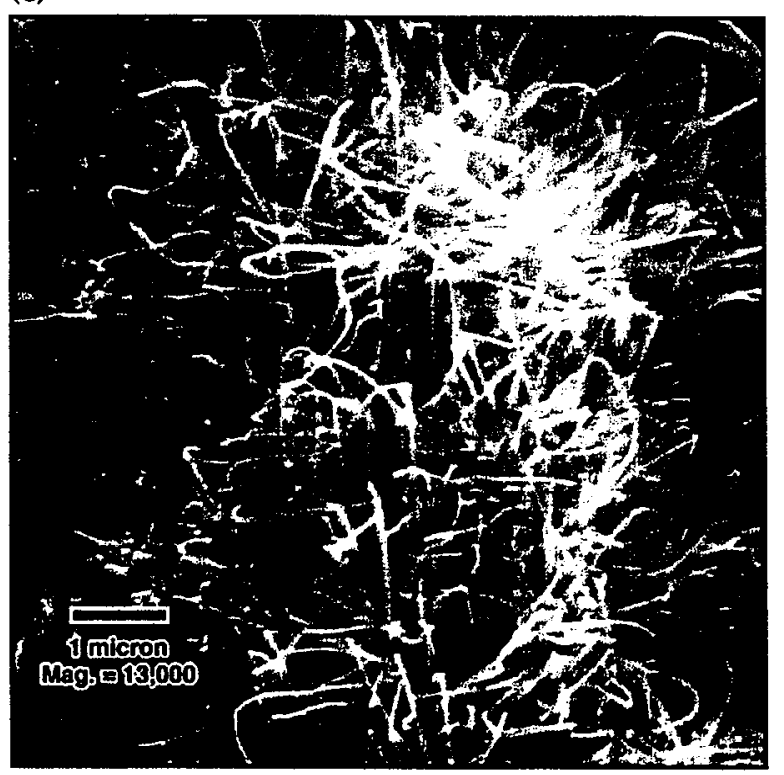

(b)

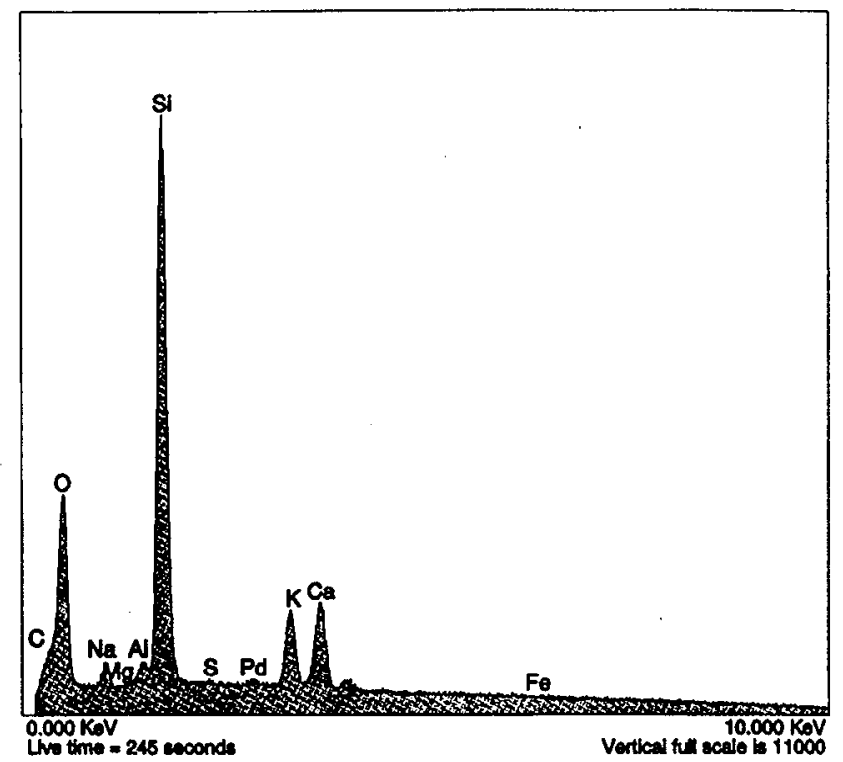

(d)

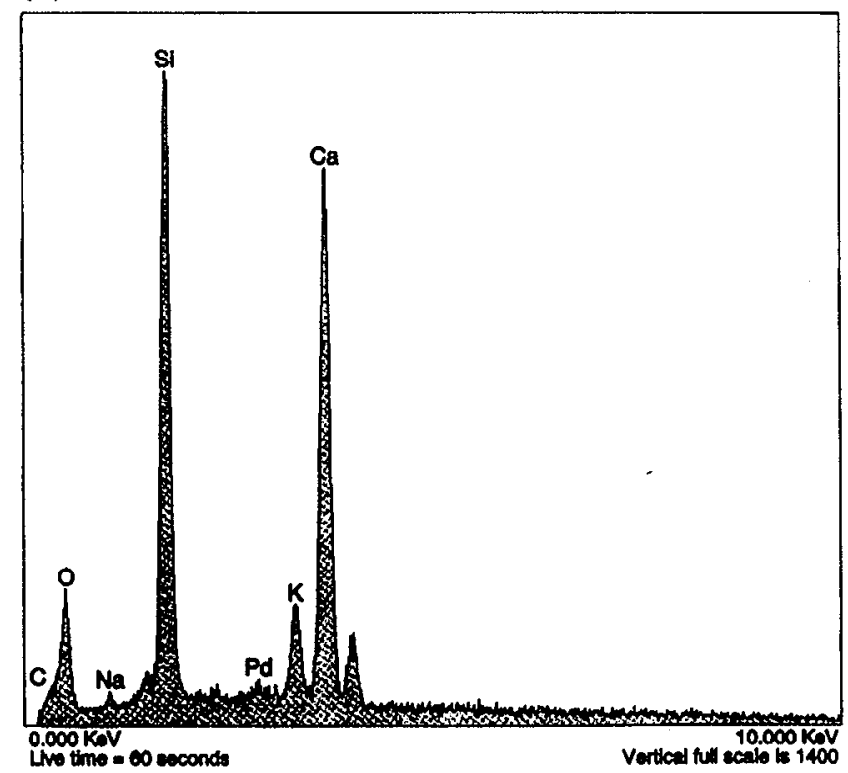

Figure 45. SH-9 (PV-13-9). (a) SEM photomicrograph of the white stringy reaction phase shown in Figure 44(a). (b)EDS of the glassy phase indicates the presence of $\mathrm{Si}$ and $\mathrm{O}$, with minor amounts of $\mathrm{Ca}, \mathrm{K}, \mathrm{Al}$, and Na. (c) SEM photomicrograph of the stringy phase shown in Figures 44(a) and 45(a). Note that it appears in the black, glassy phase. (d) EDS of the black, glassy phase. The spectrum suggests $\mathrm{Si}$ and $\mathrm{Ca}$ with minor amounts of $\mathrm{O}, \mathrm{K}$, and $\mathrm{Na}$. 
(a)

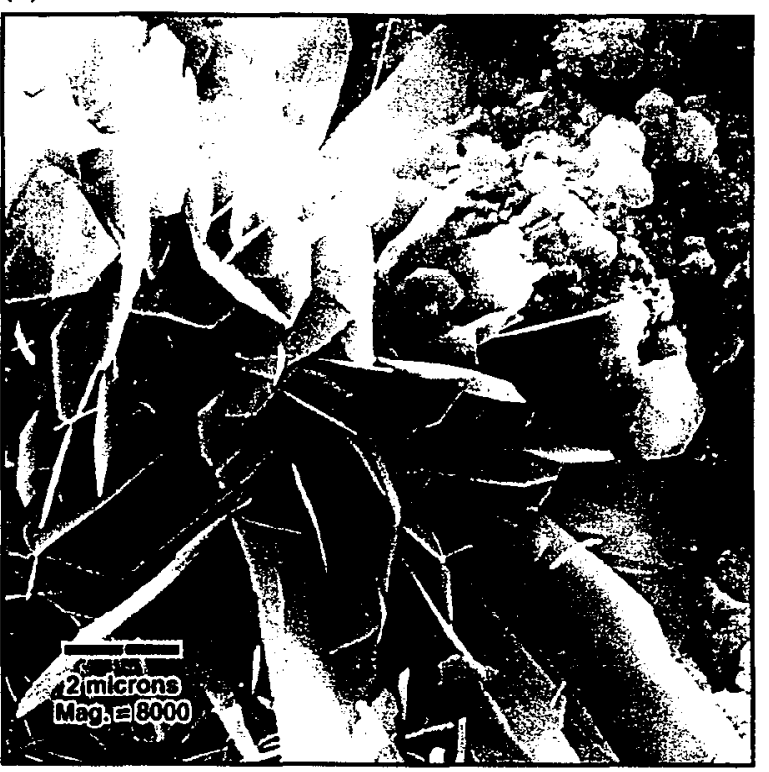

(c)

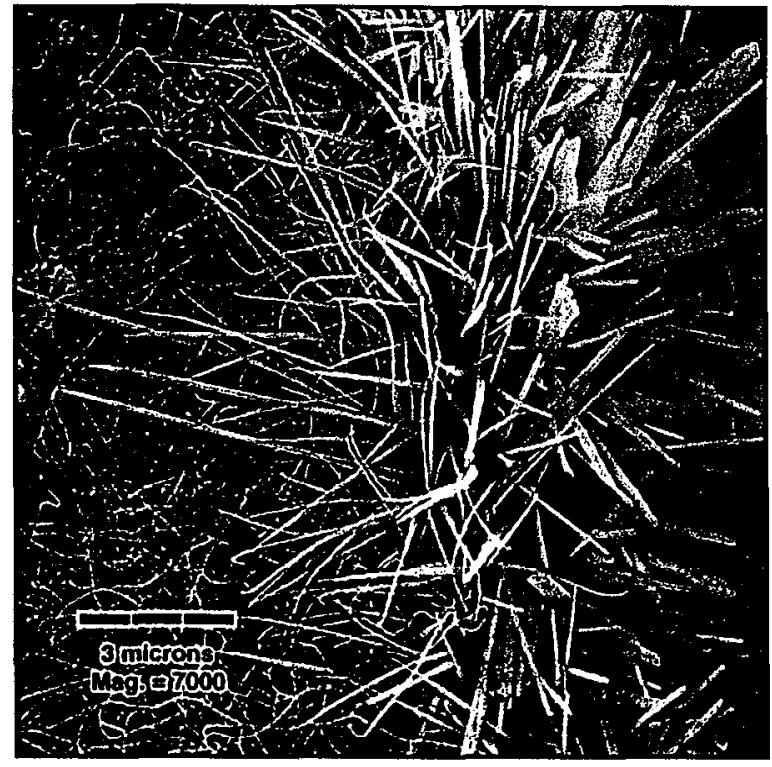

(b)

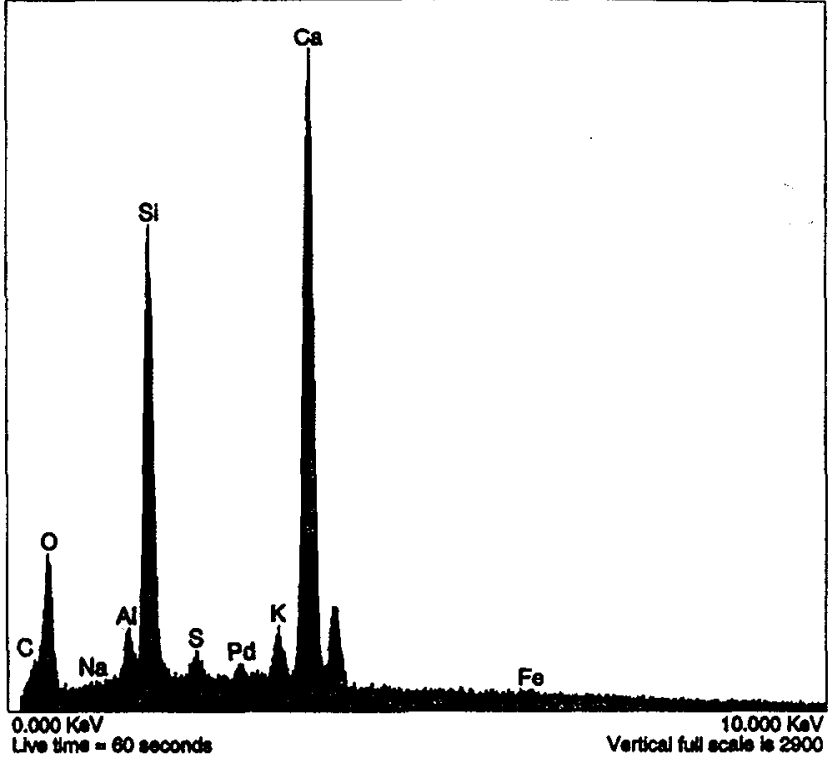

(d)

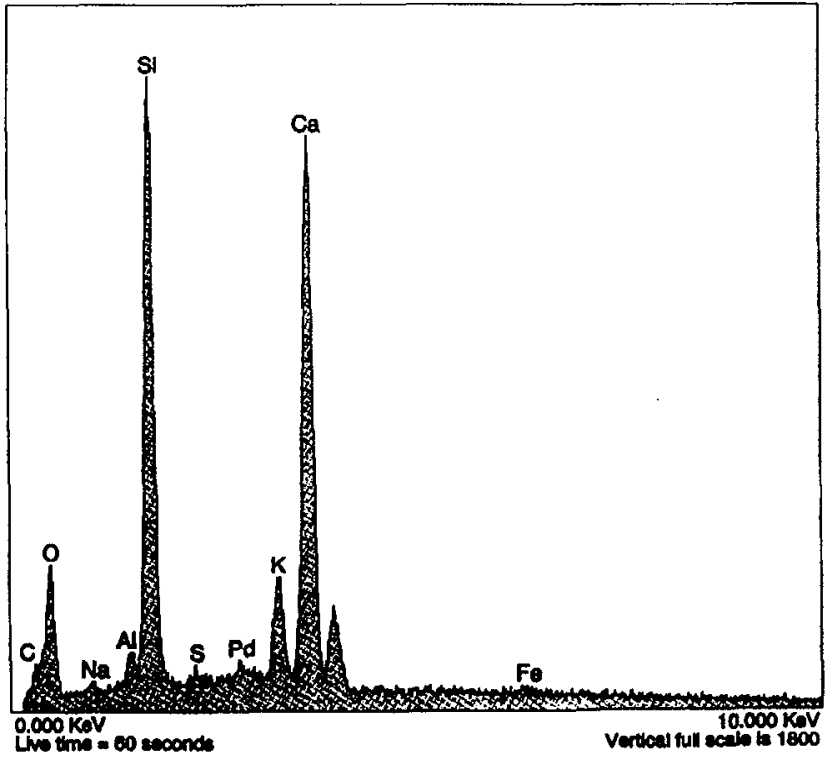

Figure 46. SH-9 (PV-13-9). (a) SEM photomicrograph of a tabular phase on the small aggregate grain. (b) EDS of the tabular phase indicates the presence of $\mathrm{Ca}, \mathrm{Si}$, and $\mathrm{O}$ with minor amounts of $\mathrm{K}, \mathrm{Al}$, and $\mathrm{S}$. (c) SEM photomicrograph of a spindle-like phase on the edge of the small aggregate grain shown in Figure 41(a). (d) EDS of the spindle-like phase suggests $\mathrm{Si}, \mathrm{Ca}$, and $\mathrm{O}$, with minor amounts of $\mathrm{K}$ and $\mathrm{Al}$. 
(a)

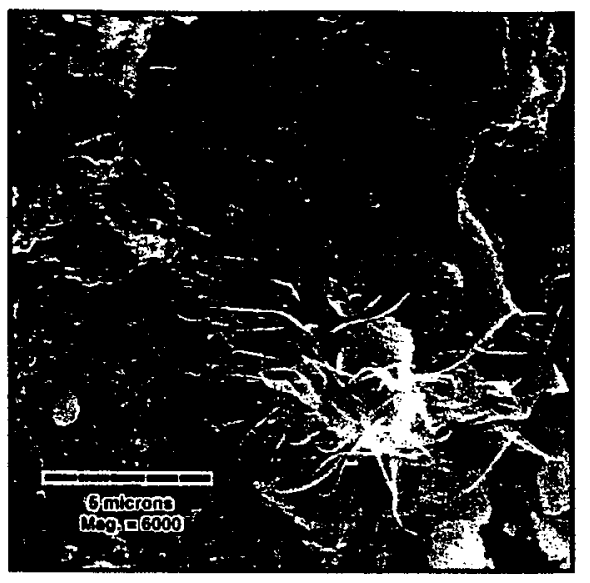

(b)

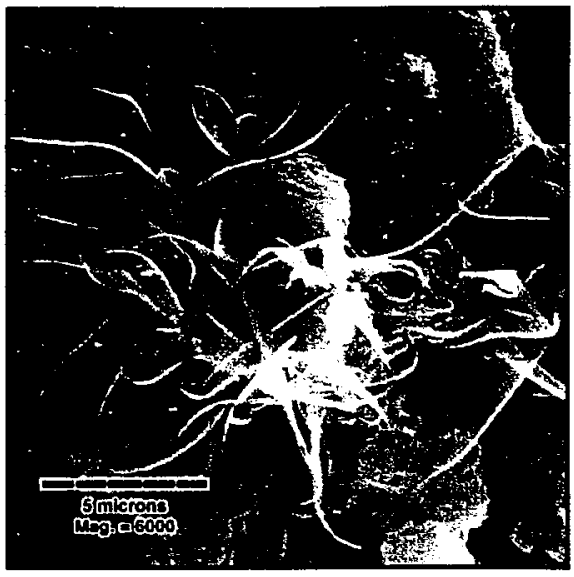

(c)

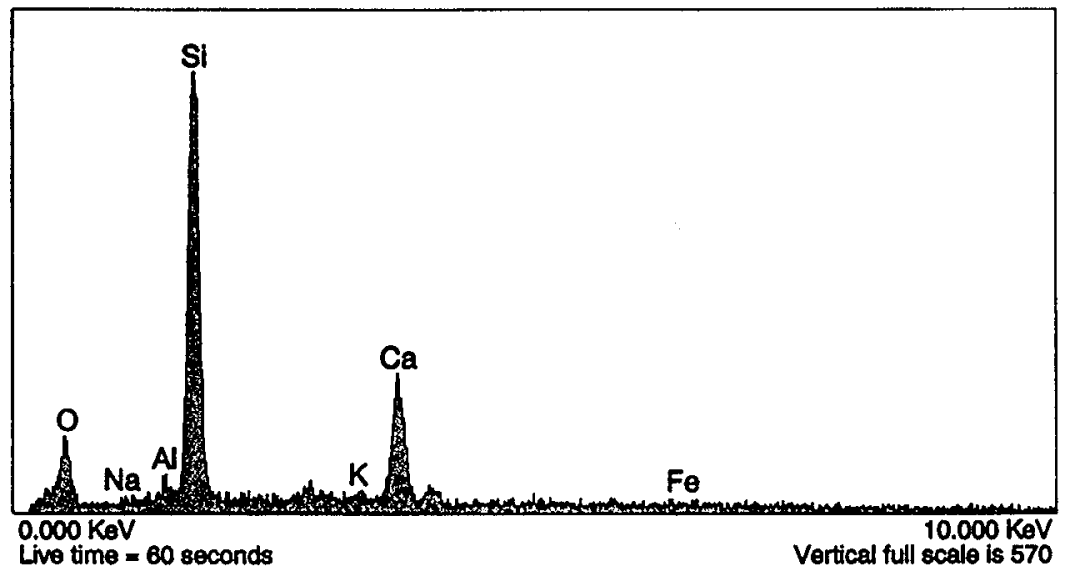

(d)

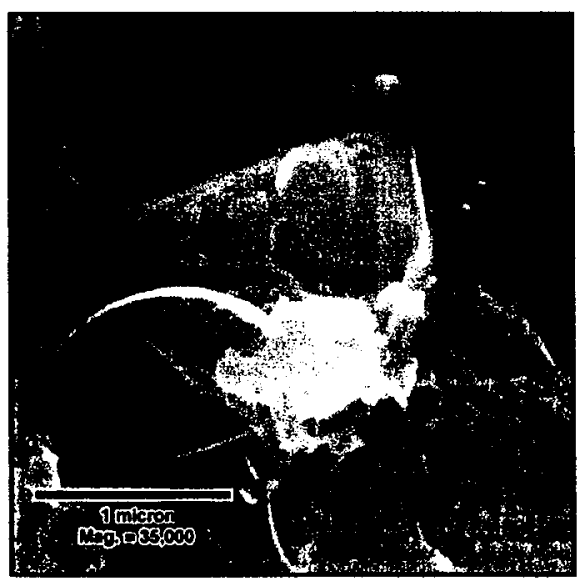

Figure 47. SH-9 (PV-13-9). (a) SEM photomicrograph of a feathery, radiating reaction phase, with a less developed example in the upper left corner. (b) SH-9. SEM photomicrograph of the more developed feathery phase at higher magnification. The radiating feathers were transparent at higher magnification, and could be as thin as 6-10 atom layers. (c) EDS of the more developed phase. Spectrum measured from the center of the phase indicates the presence of $\mathrm{Si}, \mathrm{Ca}$, and $\mathrm{O}$ with minor amounts of $\mathrm{Al}$. (d) SH-9. SEM photomicrograph of the less developed example. 


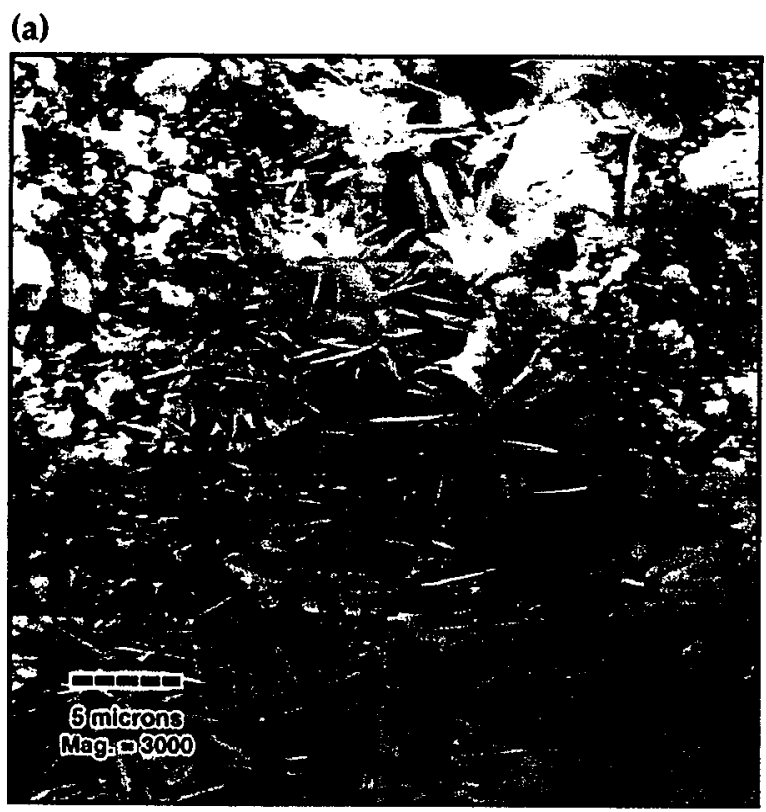

(b)

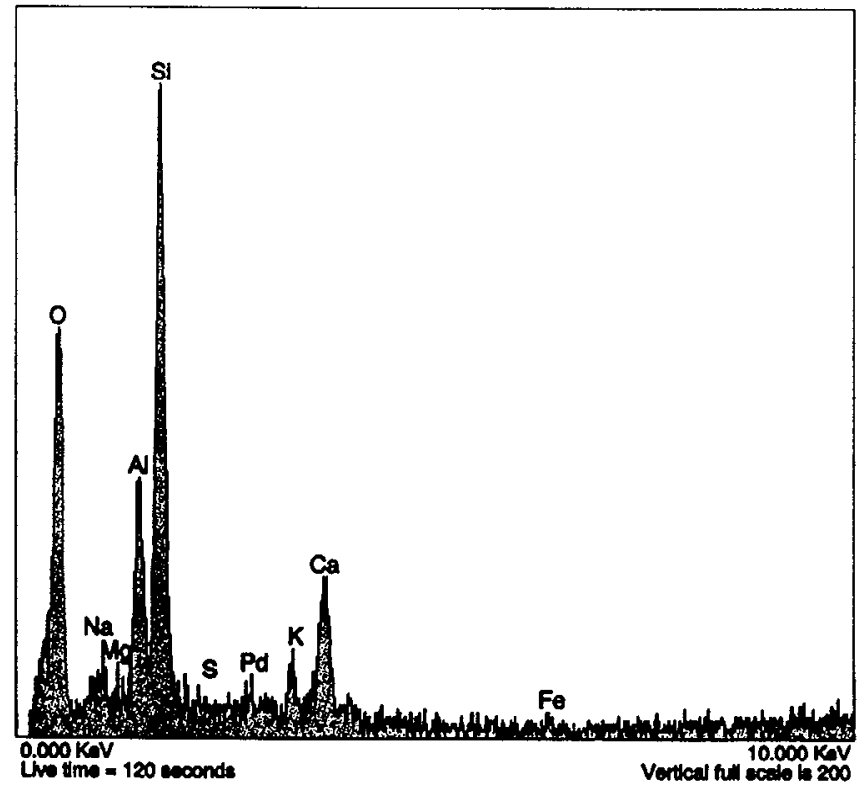

Figure 48. SH-9 (PV-13-9). (a) SEM photomicrograph of the lower left area of the pit shown in Figure 49(a). Note the similar texture as shown in Figure 49(b), with the addition of acicular crystals.(b) EDS of the acicular crystals indicates the presence of $\mathrm{Si}, \mathrm{O}, \mathrm{Al}$, and $\mathrm{Ca}$ with minor amounts of $\mathrm{K}$ and $\mathrm{Na}$. 
(a)

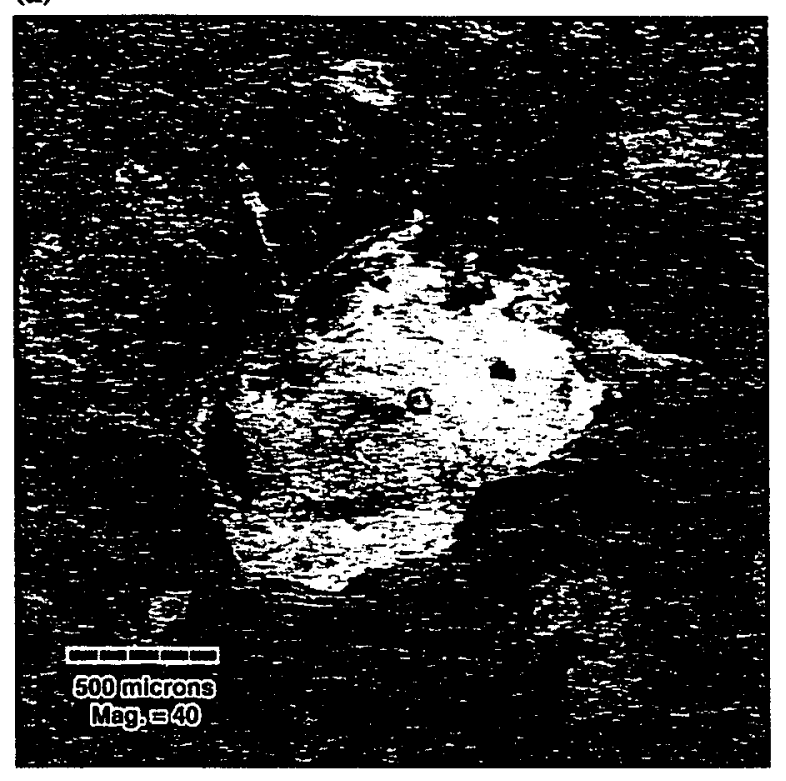

(b)

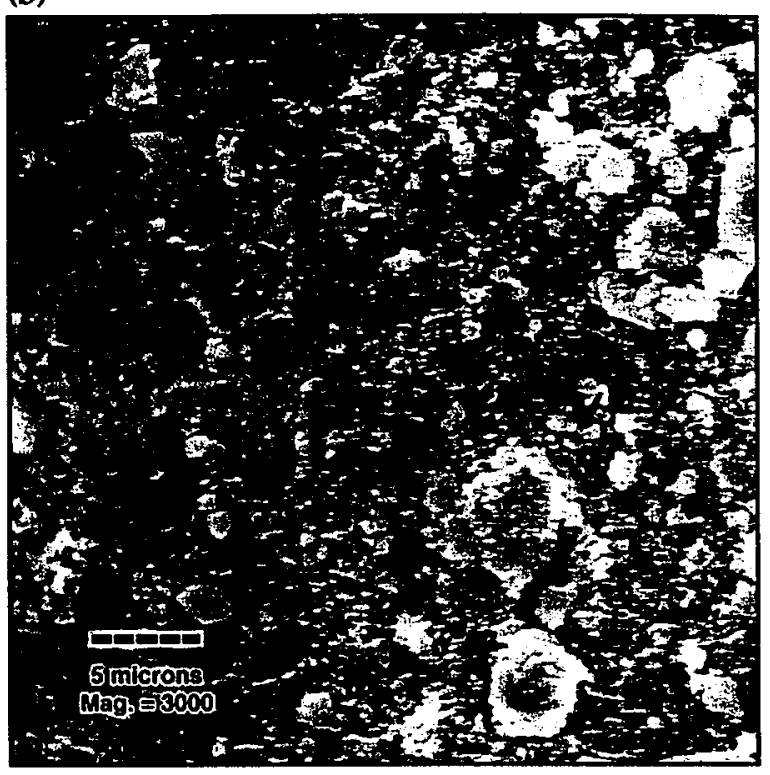

(c)

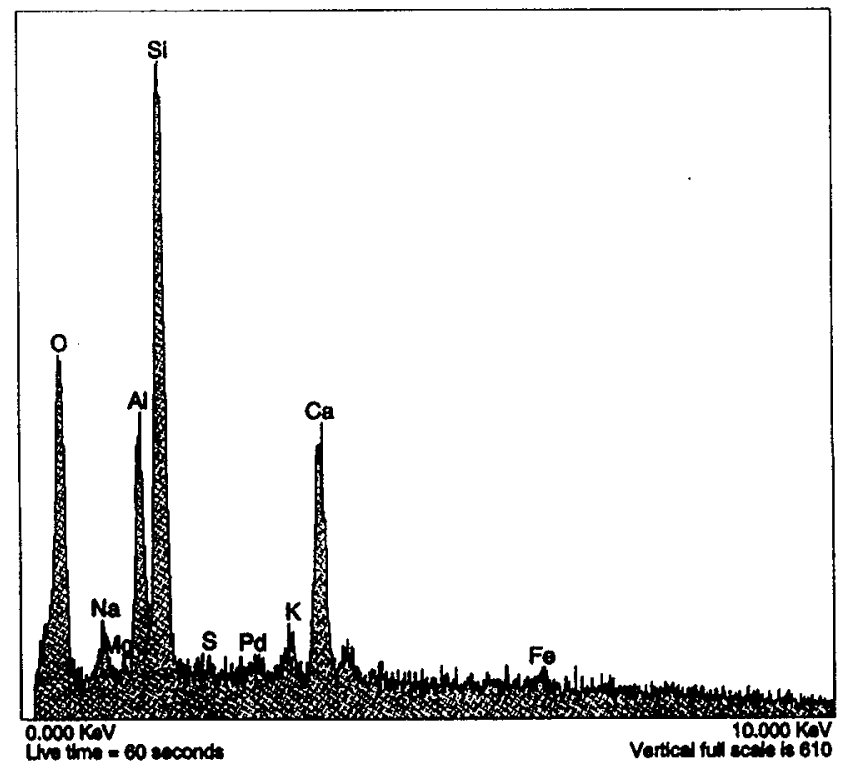

Figure 49. SH-9 (PV-13-9). (a) SEM photomicrograph of a pit in the grout. (b) SEM photomicrograph of the top end of the pit shown in Figure (a). (c) EDS indicates the presence of $\mathrm{Si}, \mathrm{Ca}$, $\mathrm{Al}$, and $\mathrm{O}$ with minor amounts of $\mathrm{Na}$ and $\mathrm{K}$. 
(a)

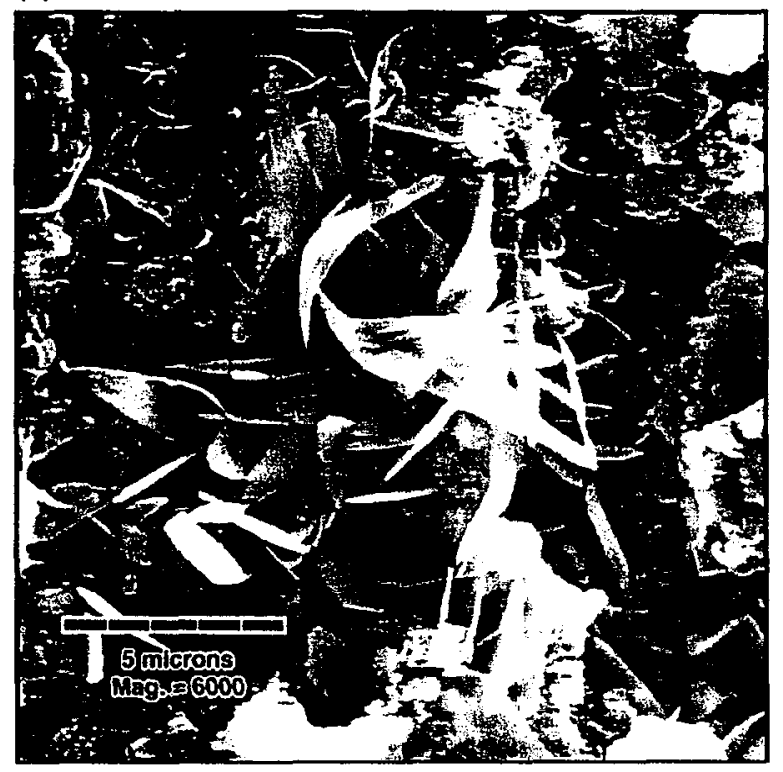

(b)

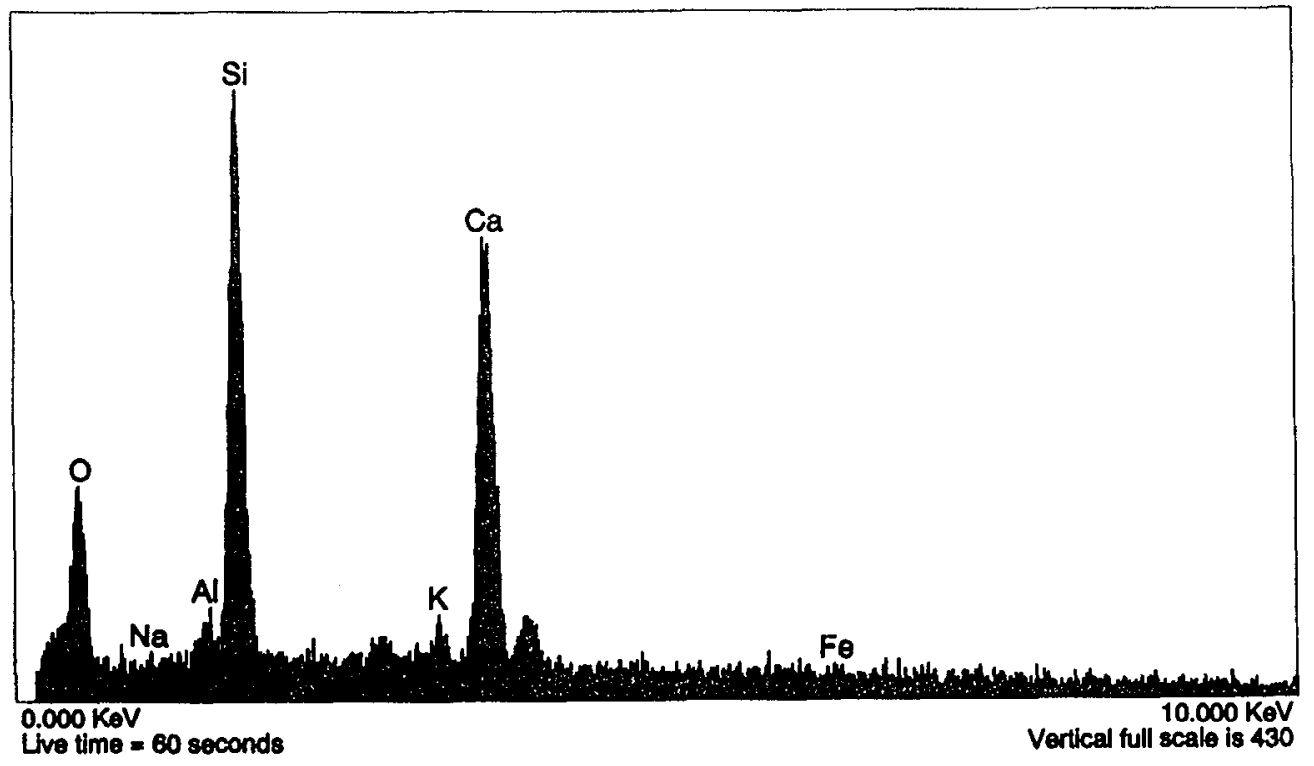

Figure 50. SH-9 (PV-13-9). (a) SEM photomicrograph of a thin veneer of a bladed phase. The crystals do not appear to be on a grain boundary, and were observed elsewhere on the sample. (b) EDS indicates the presence of $\mathrm{Si}, \mathrm{Ca}$, and $\mathrm{O}$, with minor amounts of $\mathrm{Al}$ and $\mathrm{K}$. A significant portion of the spectrum may have been contributed by the underlying material, since the veneer of crystals is thin and sparse. 
(a)

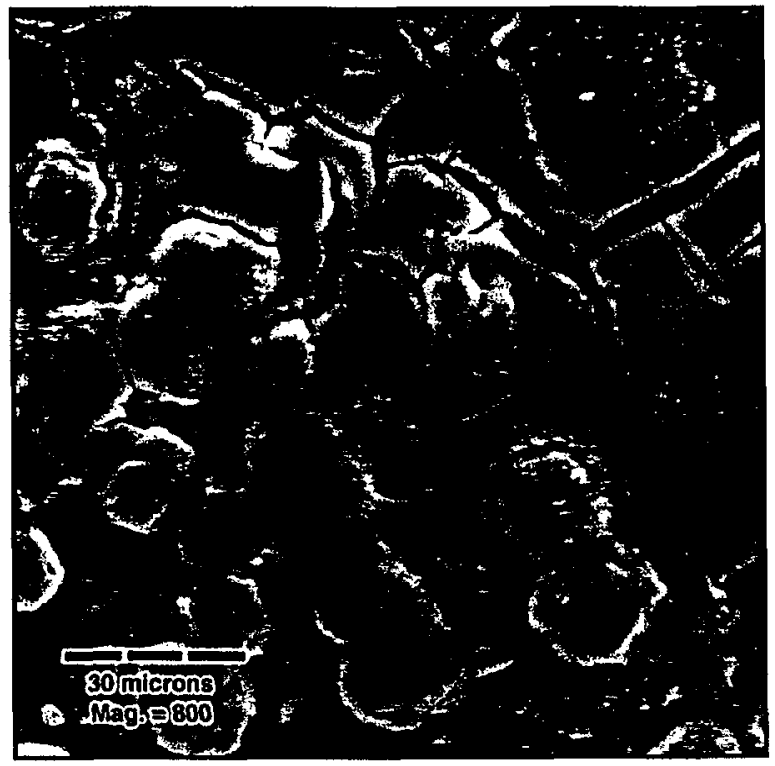

(b)

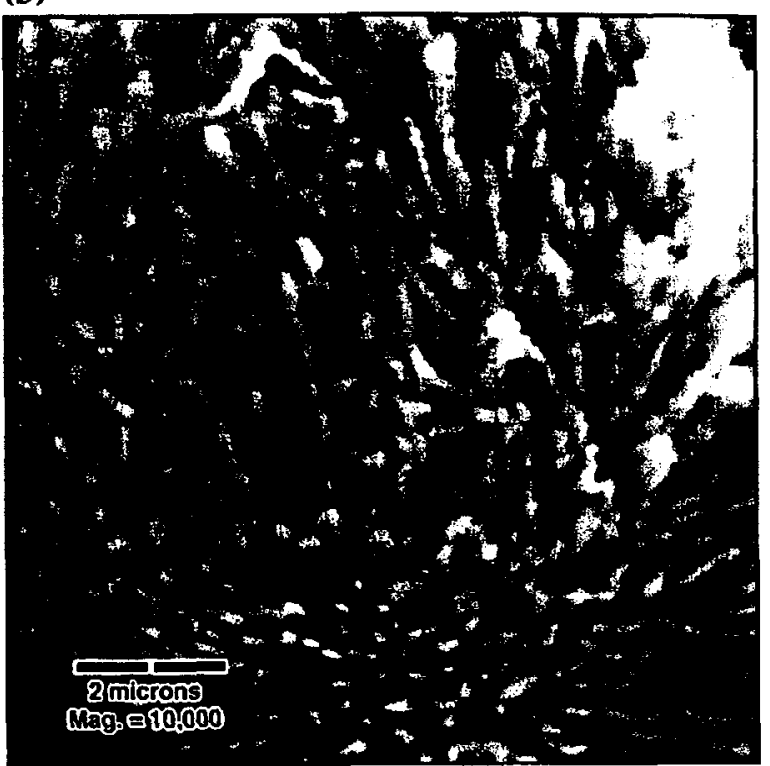

(c)

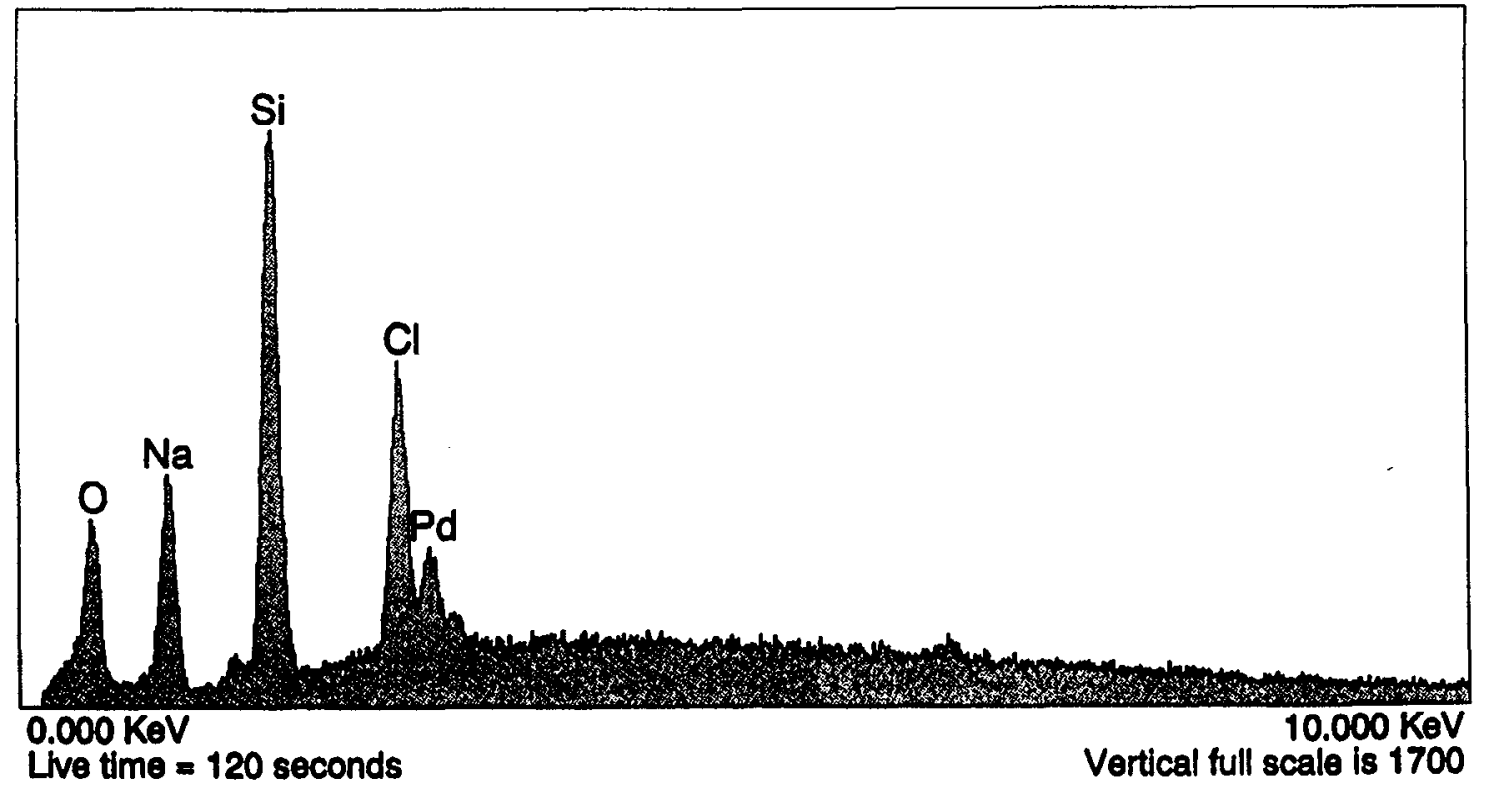

Figure 51. INV-23A, side 1 (PV-18-23a). (a) SEM photomicrograph of the various textures that occur as a white crust on the sample. (b) SEM photomicrograph of a phase that resembles fibrous clumps. (c) EDS of the fibrous phase suggests $\mathrm{Si}, \mathrm{Cl}, \mathrm{Na}$, and $\mathrm{O}$. 
(a)

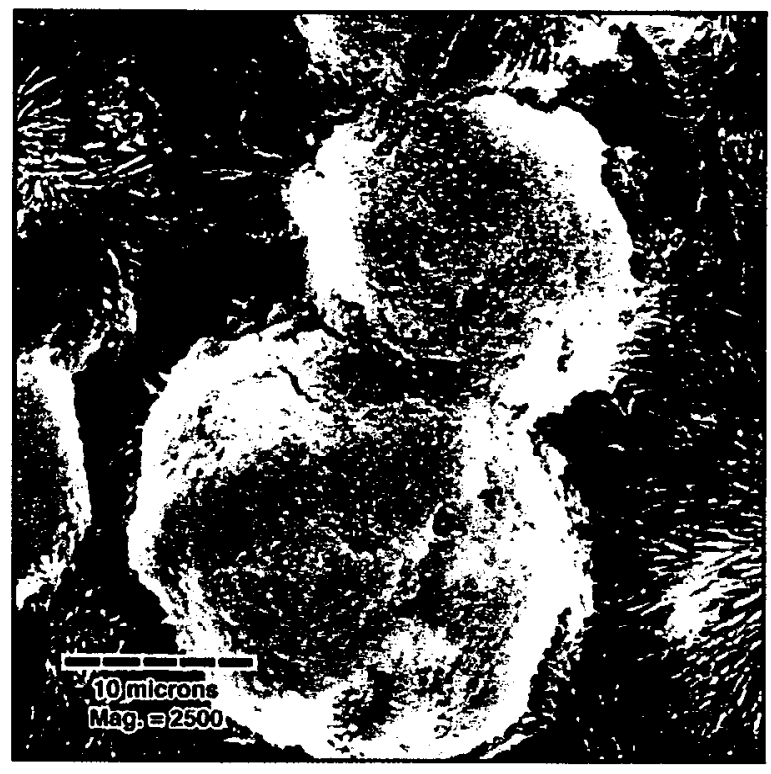

(b)

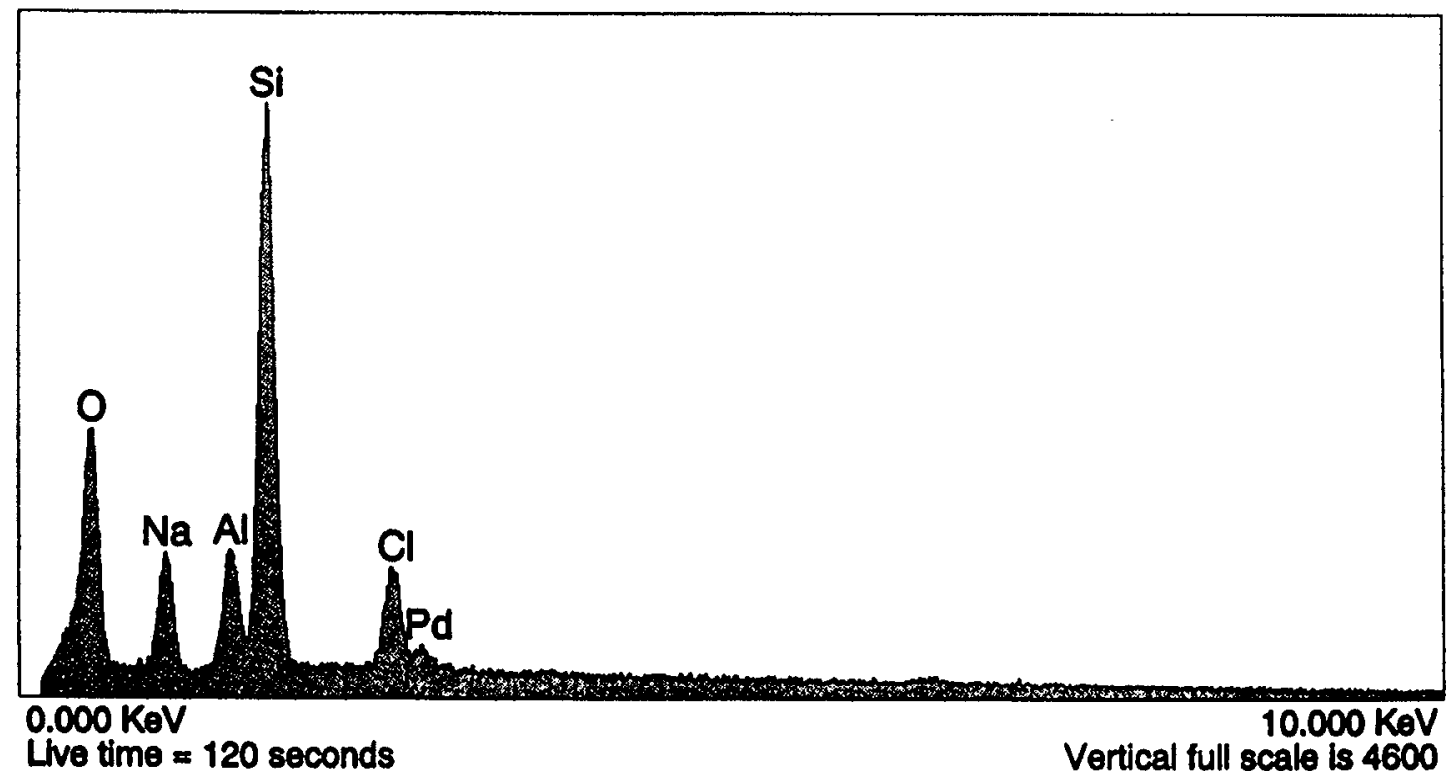

Figure 52. INV-23A, side 1 (PV-18-23a). (a) SEM photomicrograph of a globule-shaped phase. (b) EDS of the globule-shaped phase suggests $\mathrm{Si}, \mathrm{O}, \mathrm{Na}, \mathrm{Al}$, and $\mathrm{Cl}$. 
(c)

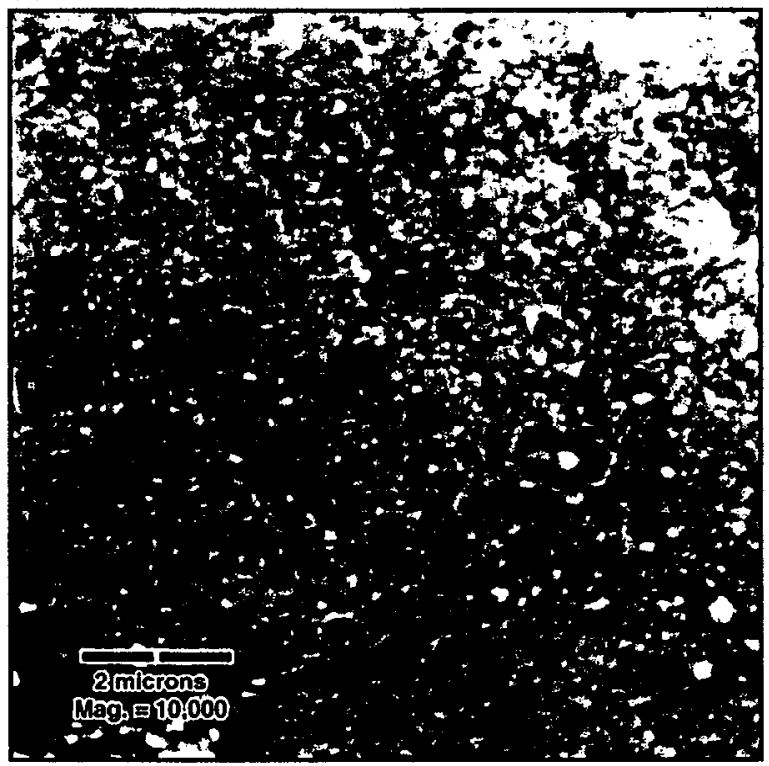

(d)

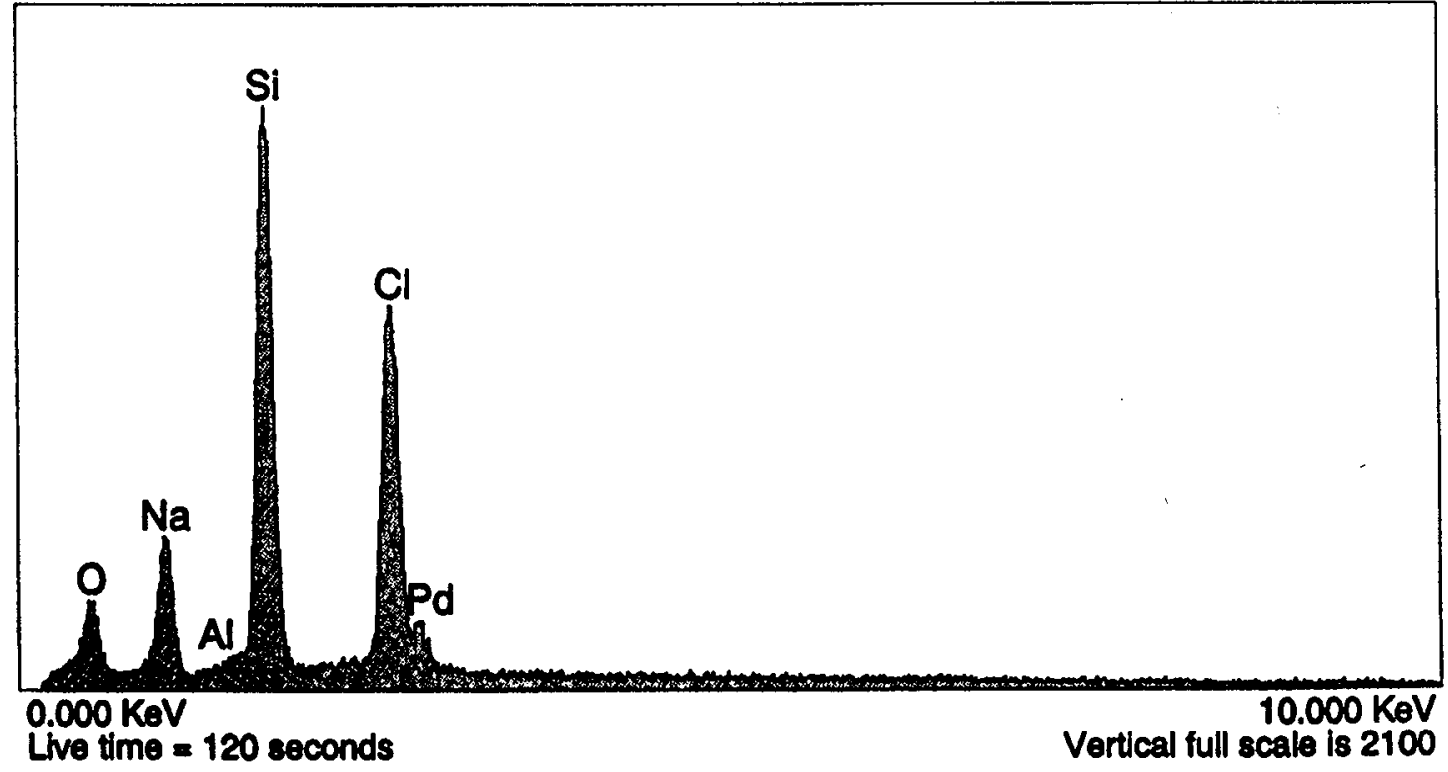

Figure 52 (continued). INV-23A, side 1 (PV-18-23a). (a) SEM photomicrograph of a phase typical of the smoother areas of the white crust. (b) EDS of the smooth phase suggests $\mathrm{Si}, \mathrm{Cl}, \mathrm{Na}$, and $\mathrm{O}$. 
(a)

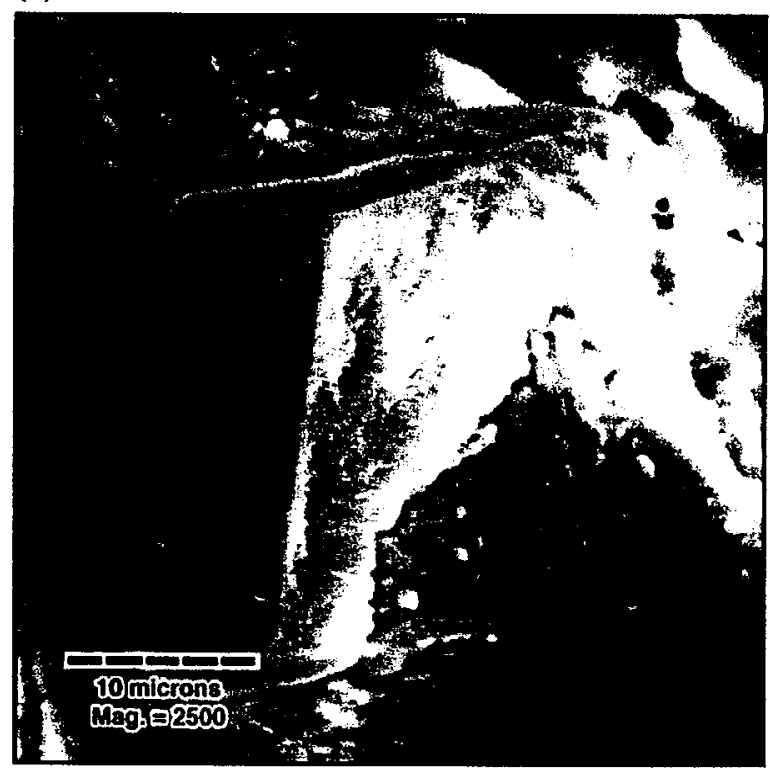

(b)

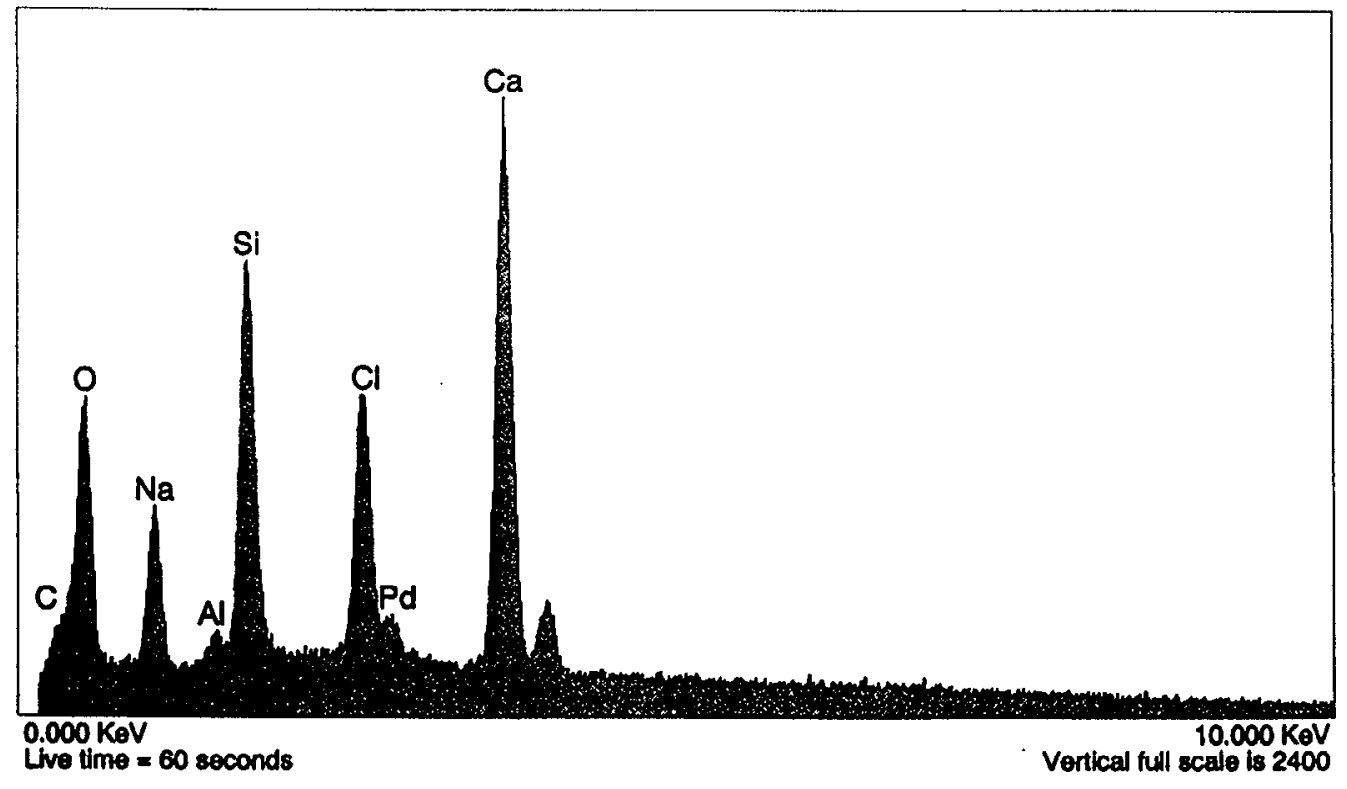

Figure 53. INV-23A, side 1 (PV-18-23a). (a) SEM photomicrograph of a rhombohedron poking through the white crust. (b) EDS of the rhombohedron suggests $\mathrm{Ca}, \mathrm{Si}, \mathrm{O}, \mathrm{Cl}$, and $\mathrm{Na}$. 
(a)

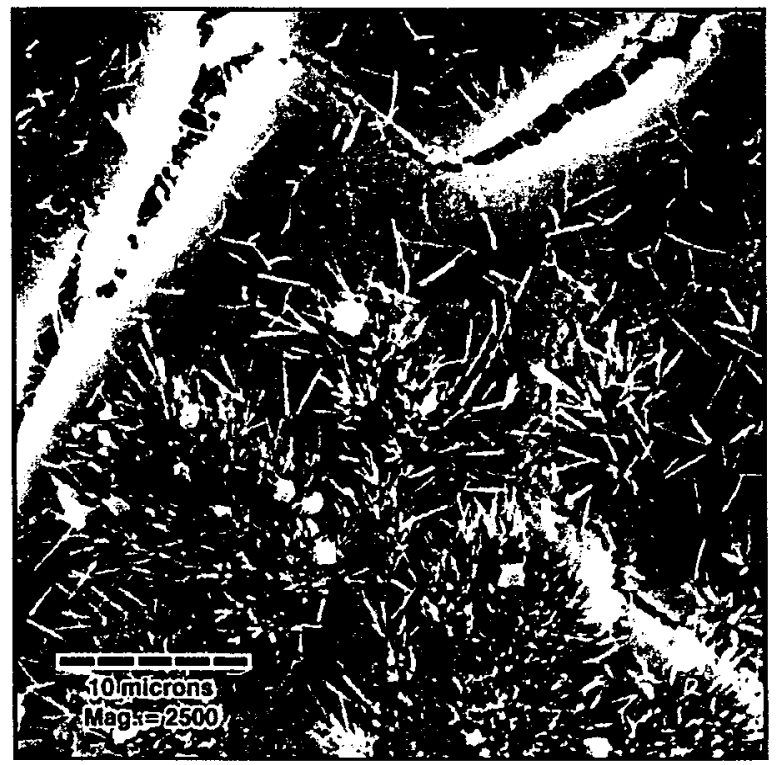

(b)

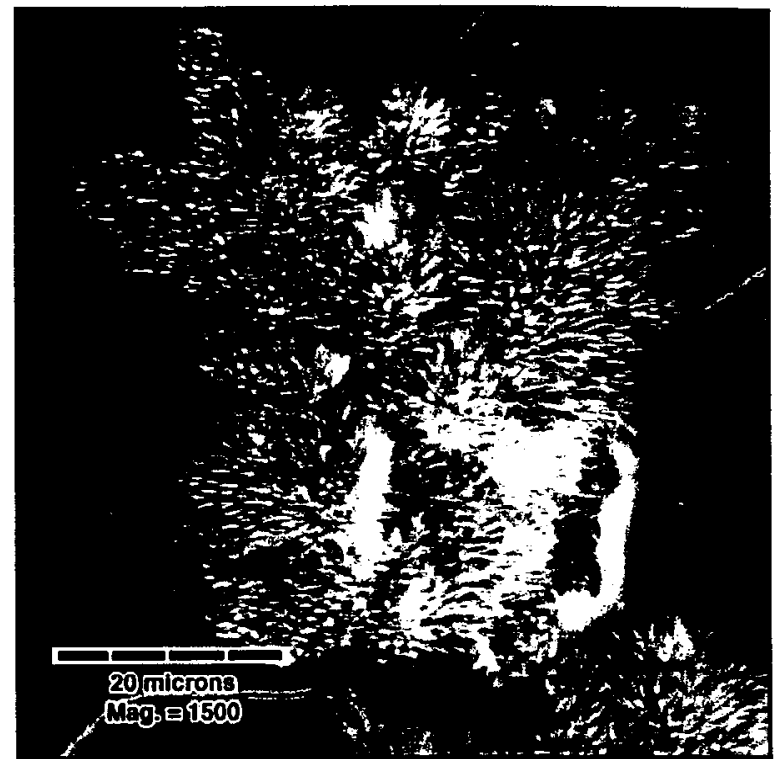

(c)

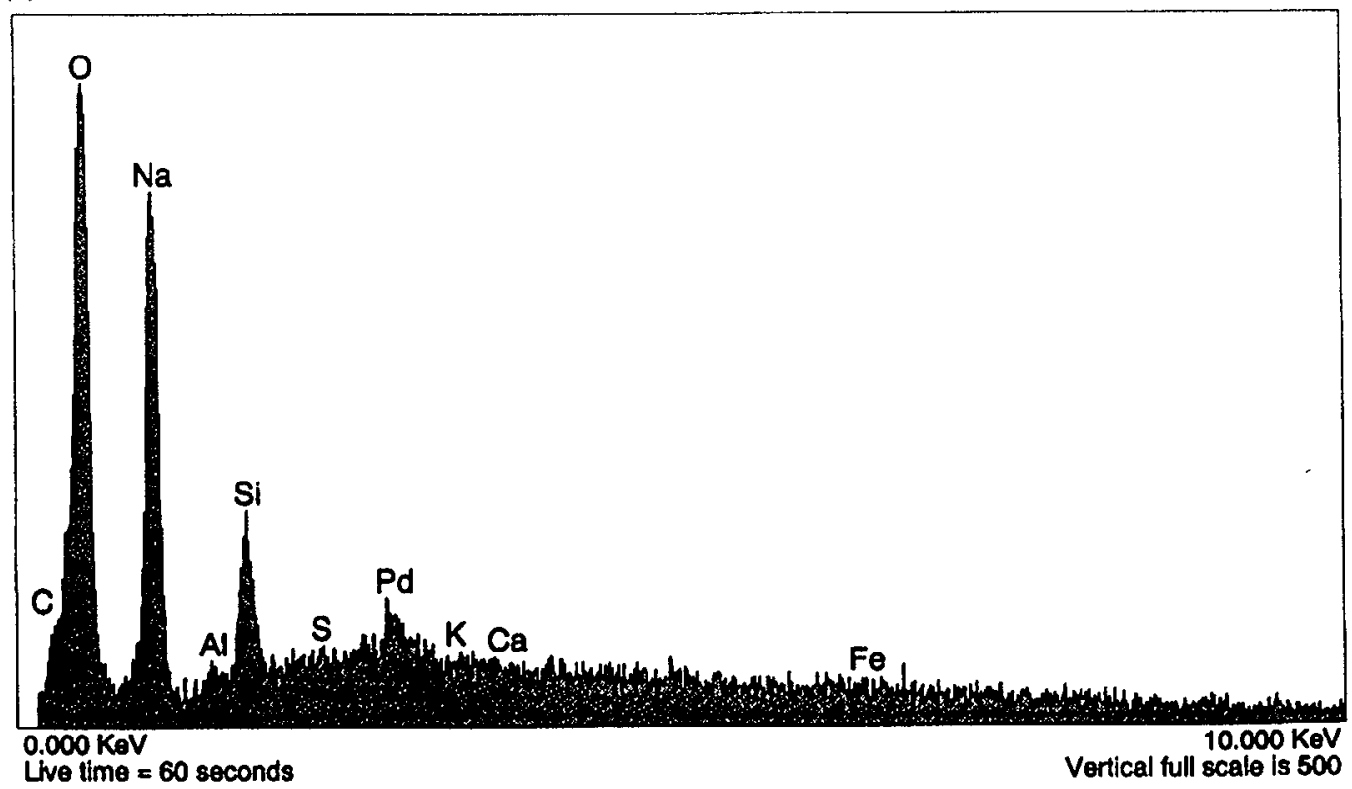

Figure 54. INV-23A, side 1 (PV-18-23a). (a) SEM photomicrograph of a fine, acicular phase that occurs on the white crust. (b) SEM photomicrograph of another acicular phase that occurs on the white crust. (c) EDS of the second acicular phase suggests $\mathrm{O}, \mathrm{Na}$, and $\mathrm{Si}$. 
(a)

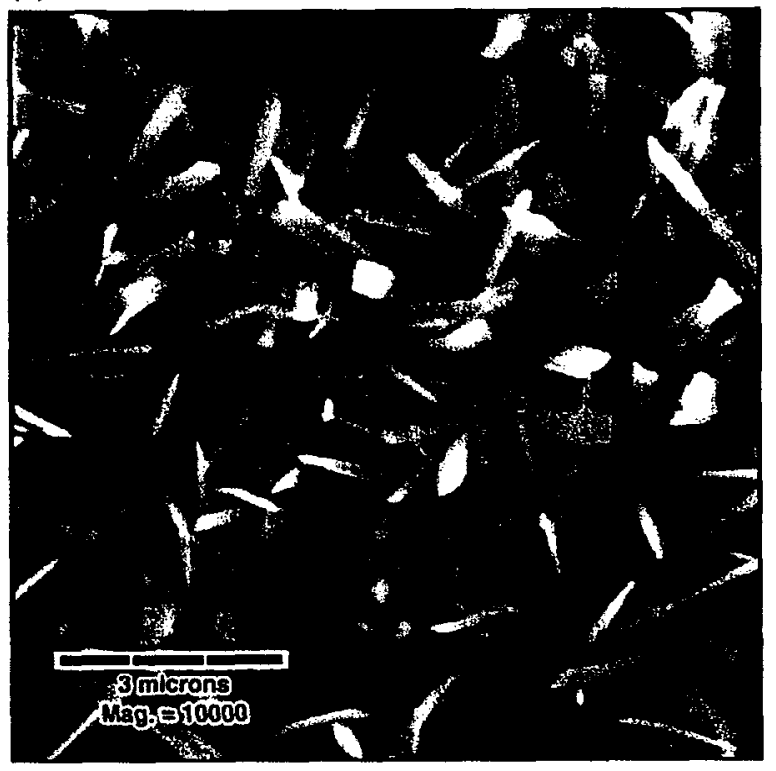

(b)

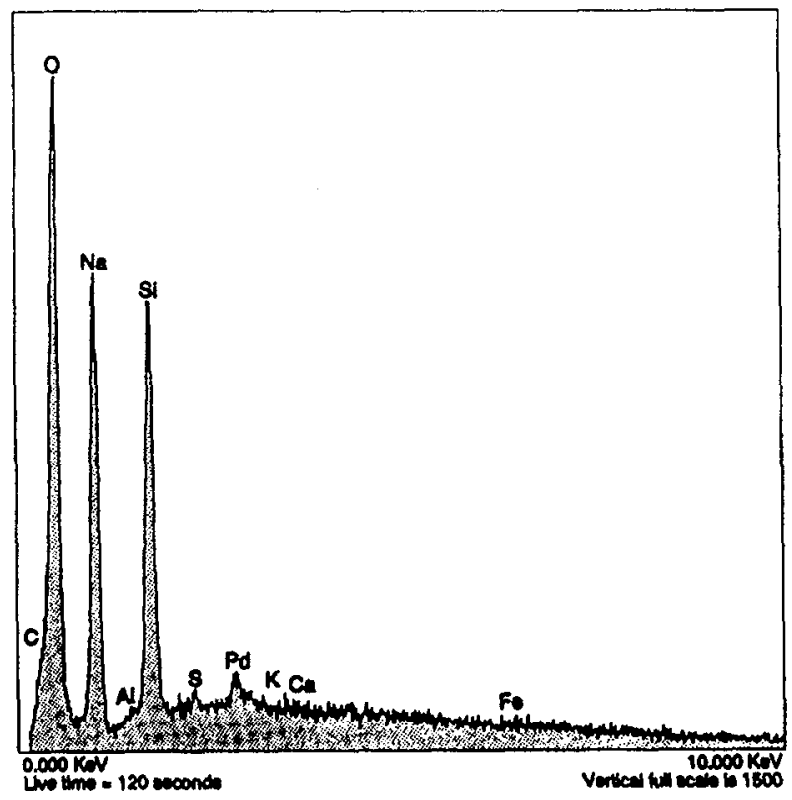

(c)

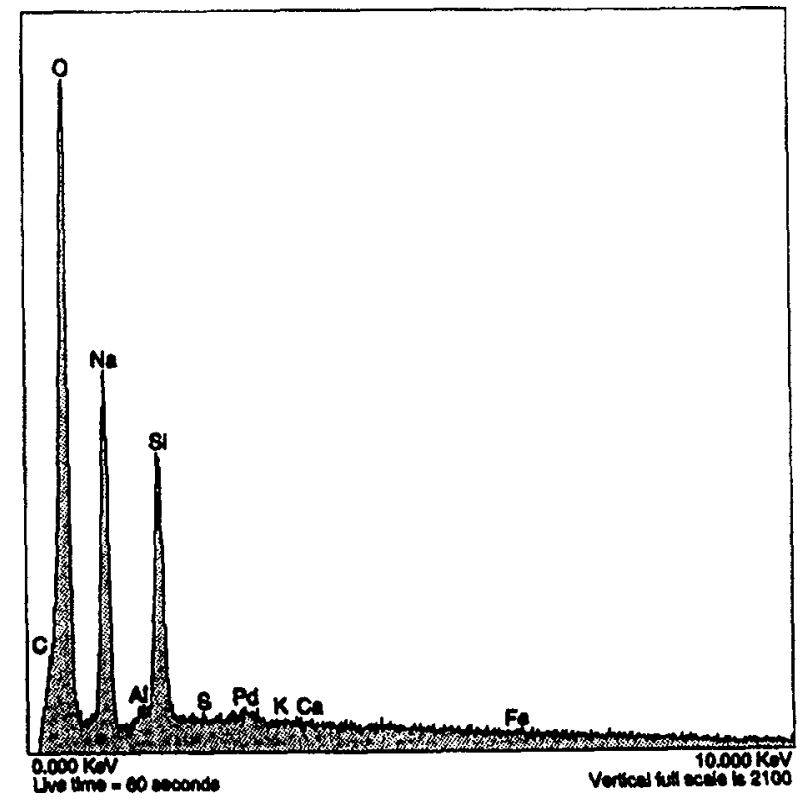

Figure 55. INV-23A, side 1 (PV-18-23a). (a) SEM photomicrograph of a needle-shaped phase that has a square cross-sectional shape. (b) EDS of the needle-shaped phase where it occurs on an aggregate grain suggests $\mathrm{O}, \mathrm{Na}$, and $\mathrm{Si}$. (c) EDS of an area adjacent to the needle-shaped phase suggests $\mathrm{O}, \mathrm{Na}$, and $\mathrm{Si}$. 
(a)

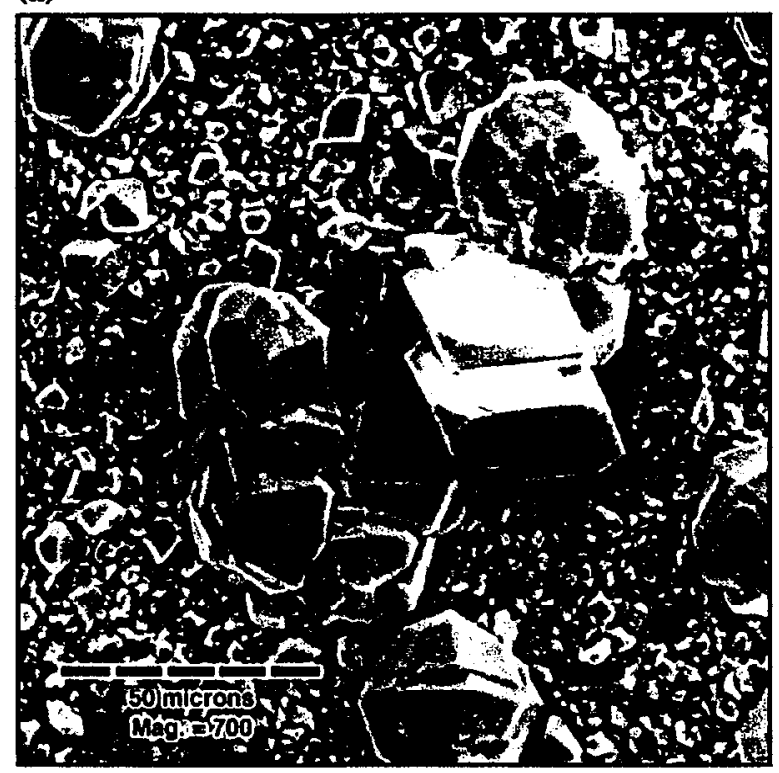

(b)

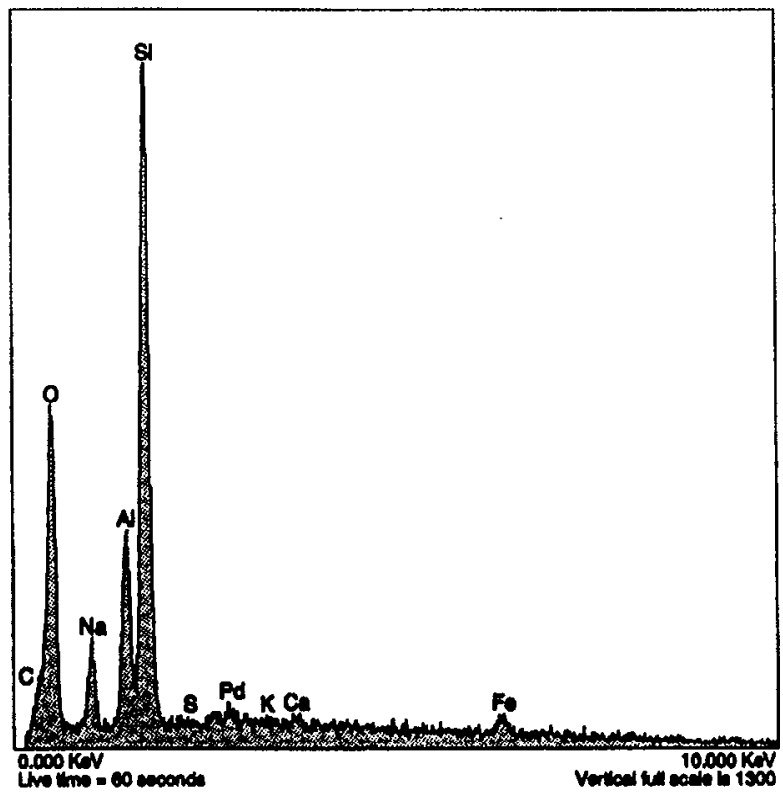

(c)

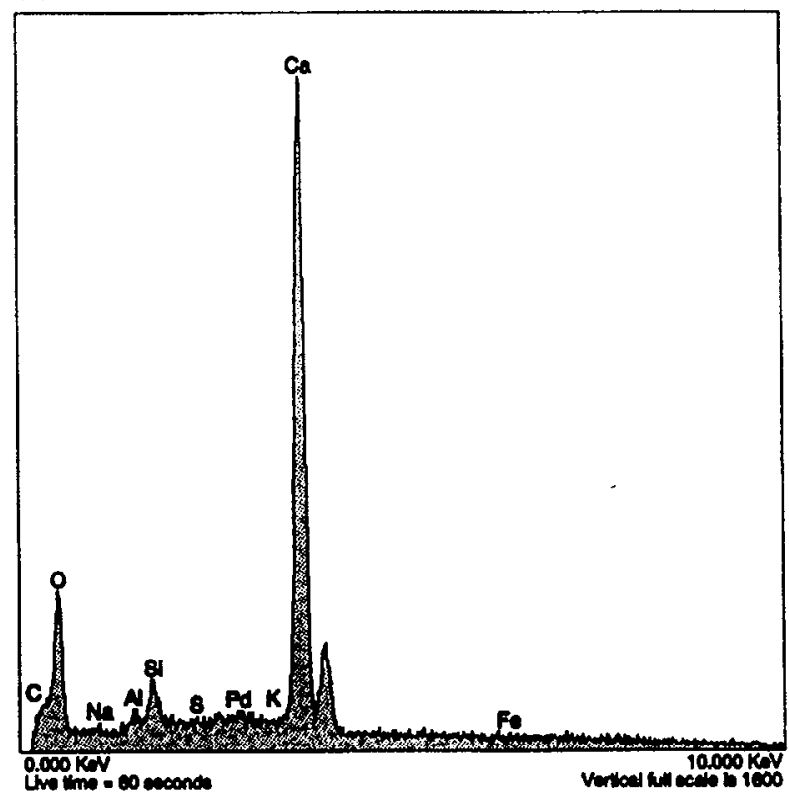

Figure 56. INV-23A, side 2 (PV-18-23a). (a) SEM photomicrograph of trapezohedral and rhombohedron phases, as well as a third smaller phase in the groundmass. (b) EDS of the trapezohedral crystals suggest $\mathrm{Si}, \mathrm{O}, \mathrm{Al}$, and Na. (c) EDS of the rhombohedral crystals suggest a calcite or calcium silicate carbonate composition. EDS of the tiny crystals in the groundmass (not shown) also suggests a calcite composition. 
(a)

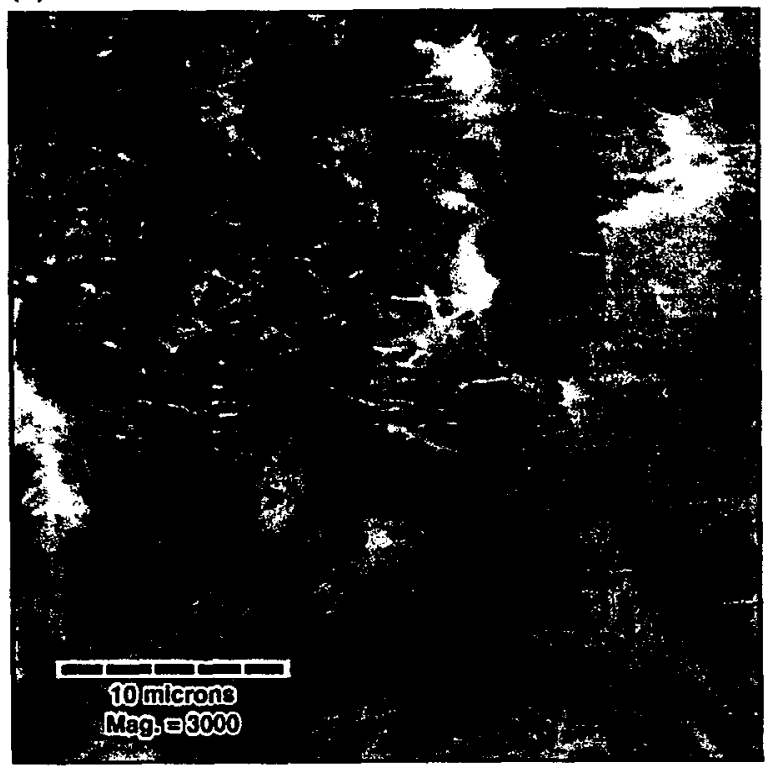

(b)

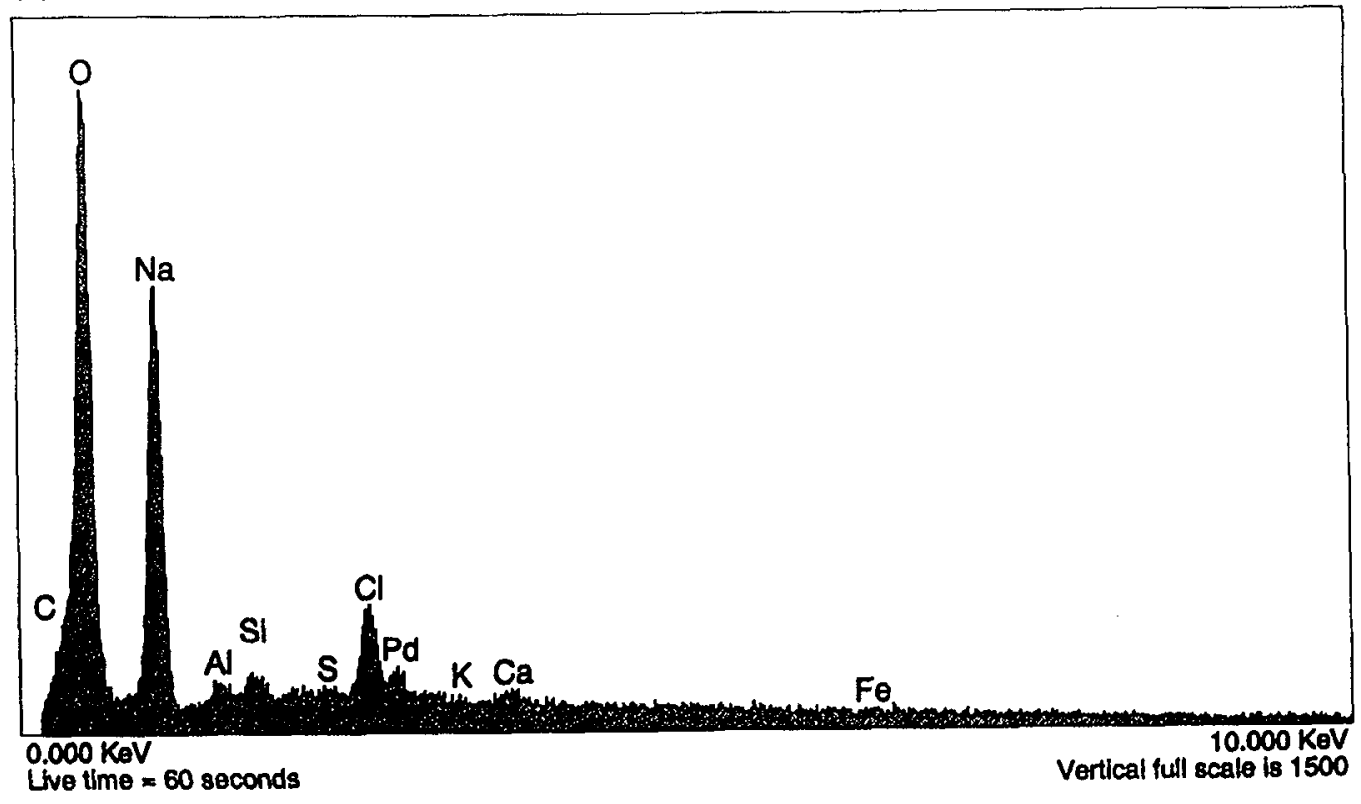

Figure 57. INV-23A, side 2 (PV-18-23a). (a) SEM photomicrograph of a fine, radiating crystalline phase. (b) EDS of the phase suggests $\mathrm{O}, \mathrm{Na}$, and $\mathrm{Cl}$. 
(a)

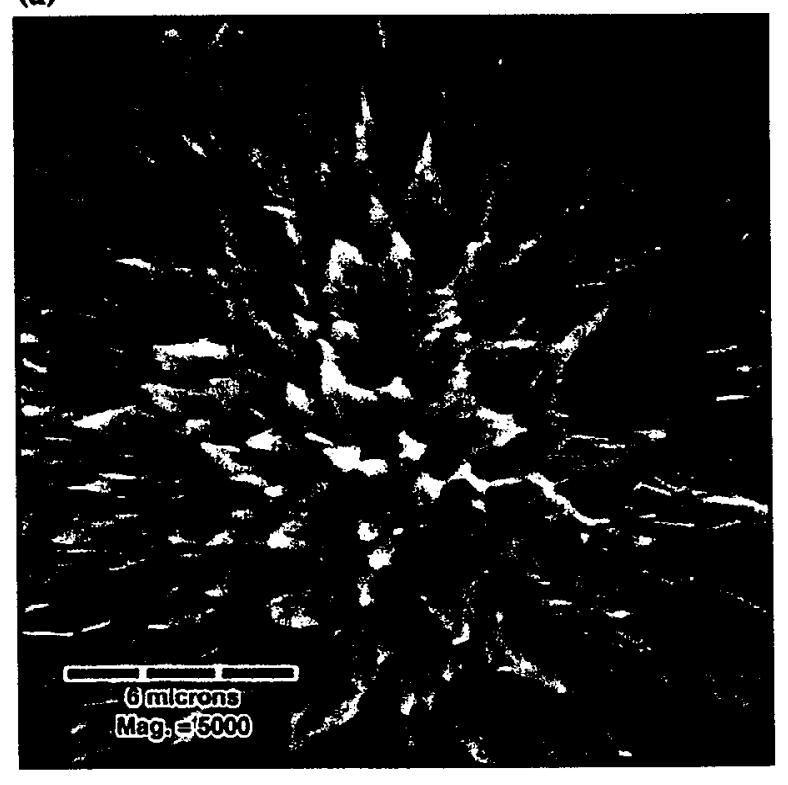

(b)

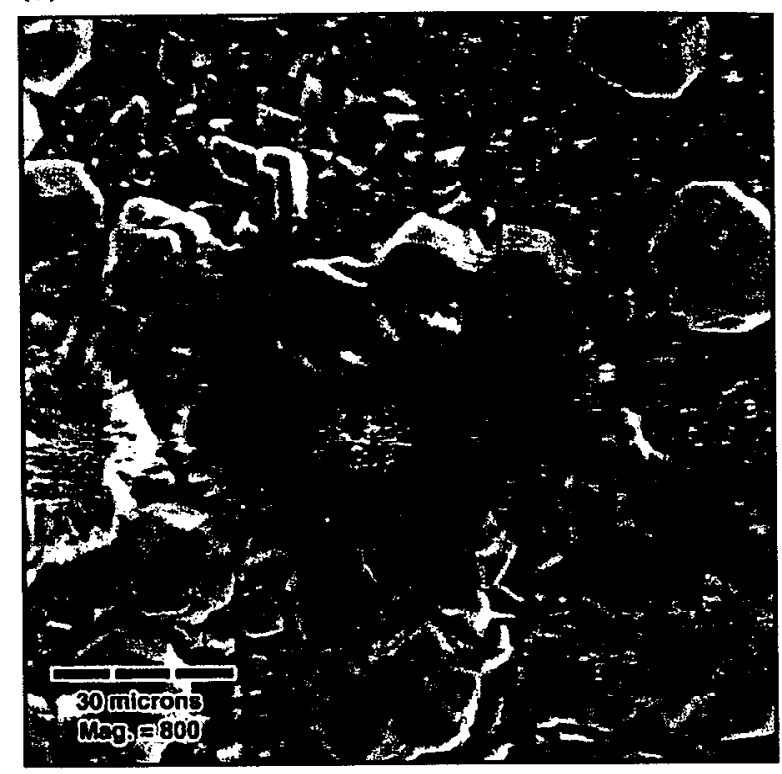

(c)

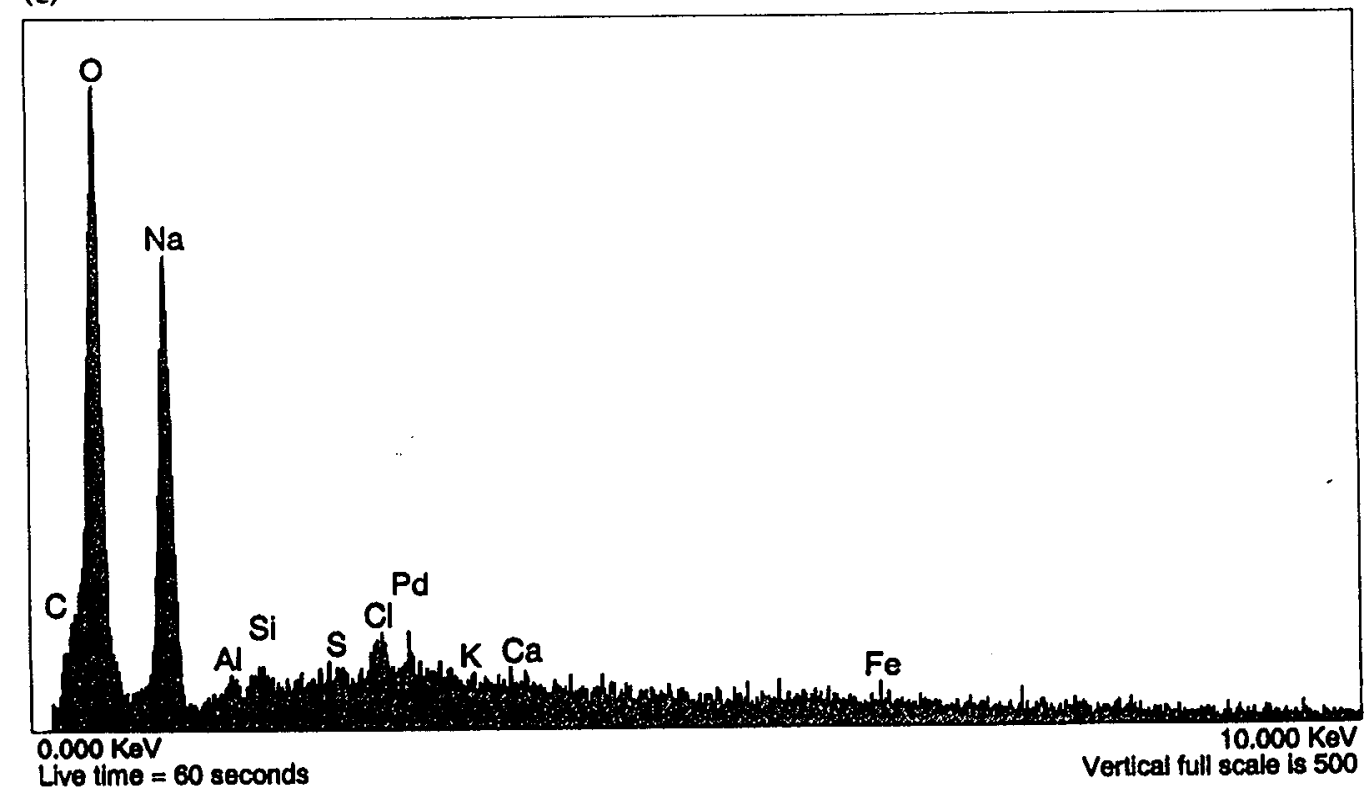

Figure 58. INV-23A, side 2 (PV-18-23a). (a) SEM photomicrograph of a radiating phase. (b) SEM photomicrograph of a radiating phase at lower magnification indicates that it occurs in mats between the abundant trapezohedrons. (c) EDS of the radiating phase suggests $\mathrm{O}$ and $\mathrm{Na}$. 
(a)

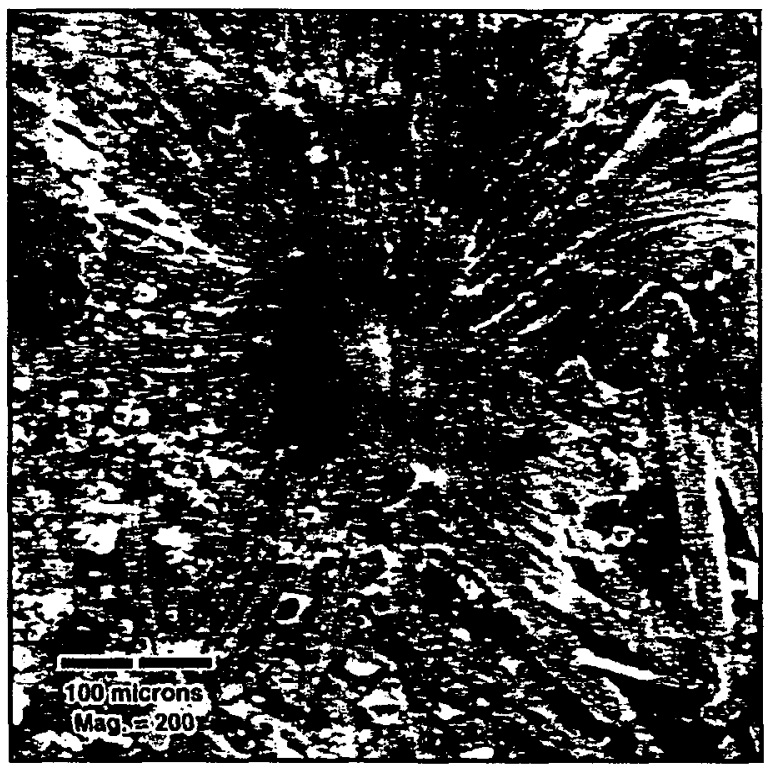

(b)

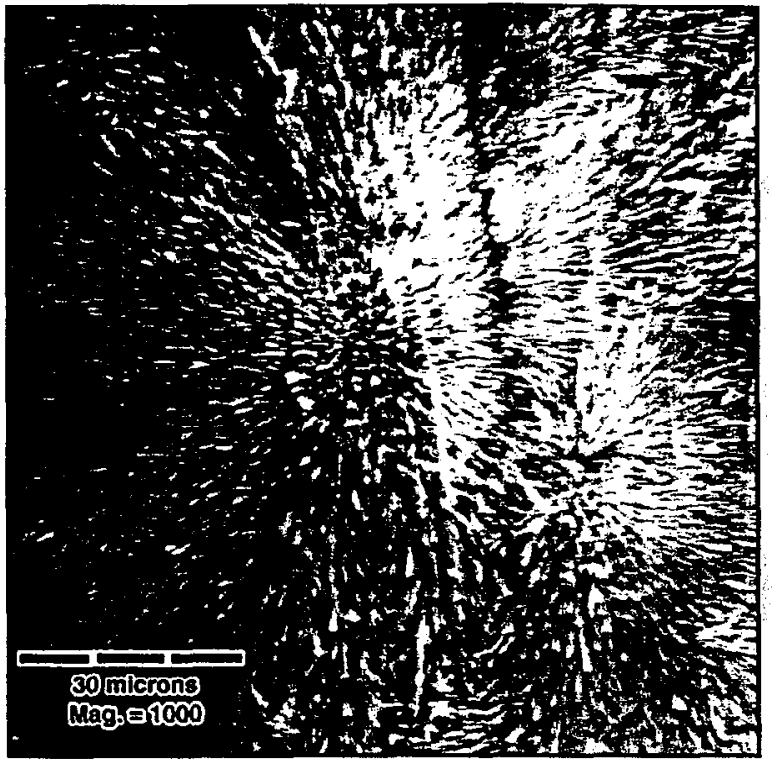

(c)

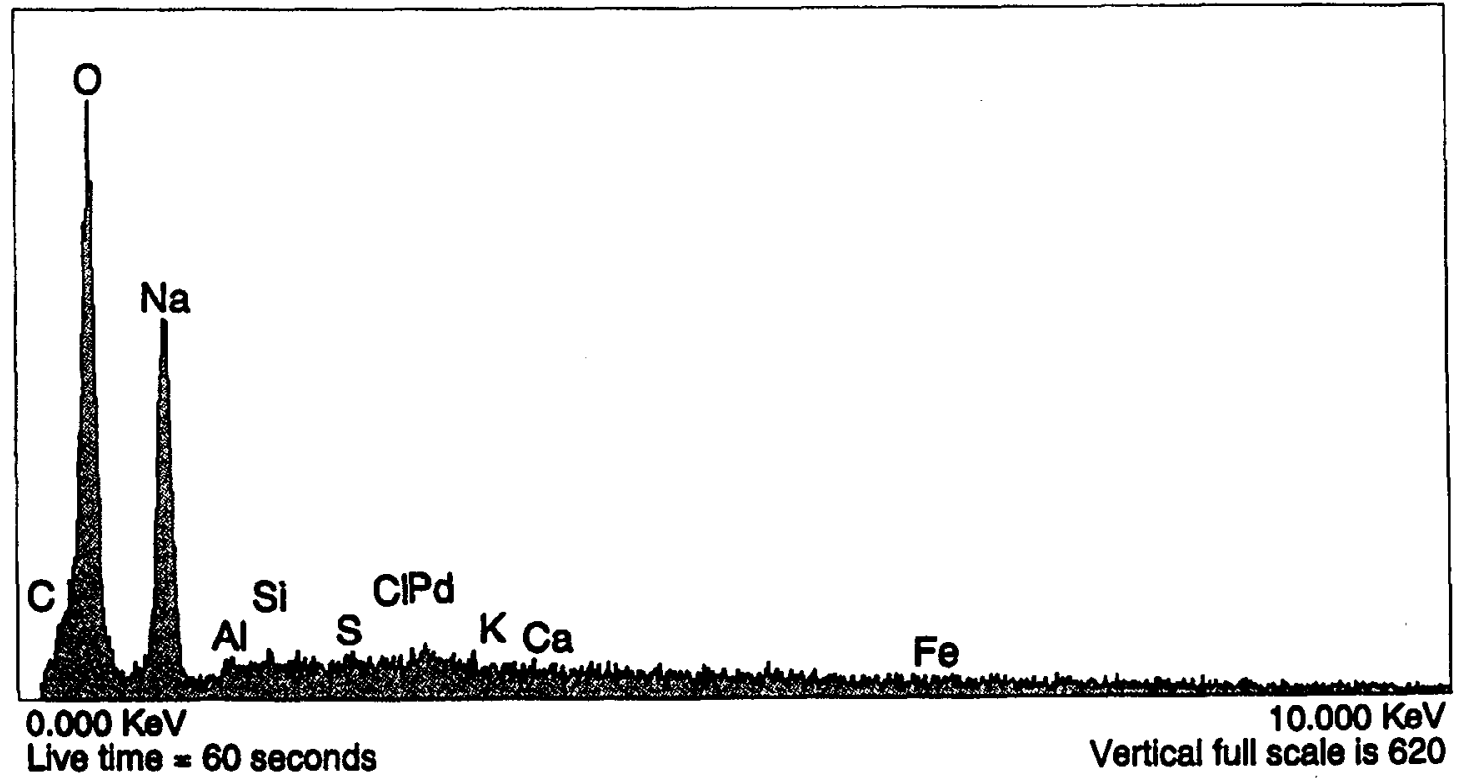

Figure 59. INV-23A, side 2 (PV-18-23a). (a) SEM photomicrograph of a lath-shaped phase at low magnification. (b) SEM photomicrograph of the lath-shaped phase at higher magnification reveals a mound of spike-shaped crystals. (c) EDS of this phase suggests $\mathrm{O}$ and $\mathrm{Na}$. 
(a)

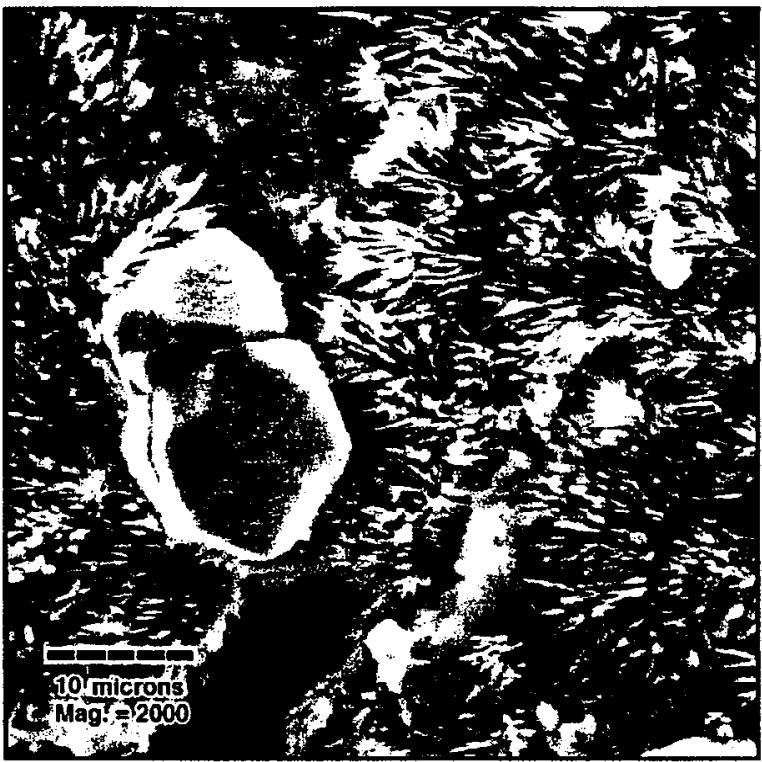

(b)

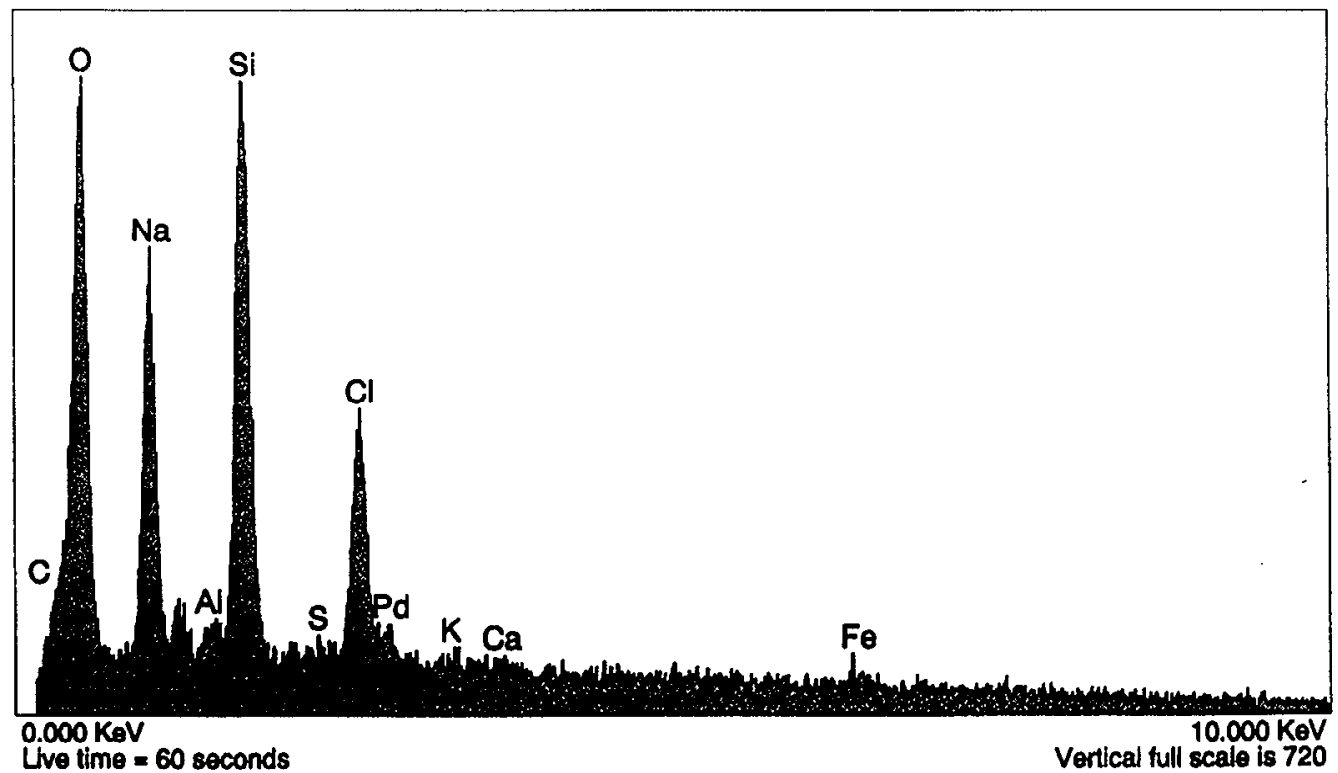

Figure 60. INV-23A, side 2 (PV-18-23a). (a) SEM photomicrograph of a 2-3 mm plate on the sample that contains lath-shaped crystals and trapezohedrons. The plate sits higher than the surrounding surface. (b) EDS of a clear area of the plate suggests $\mathrm{Si}, \mathrm{O}, \mathrm{Na}$, and $\mathrm{Cl}$. 
(c)

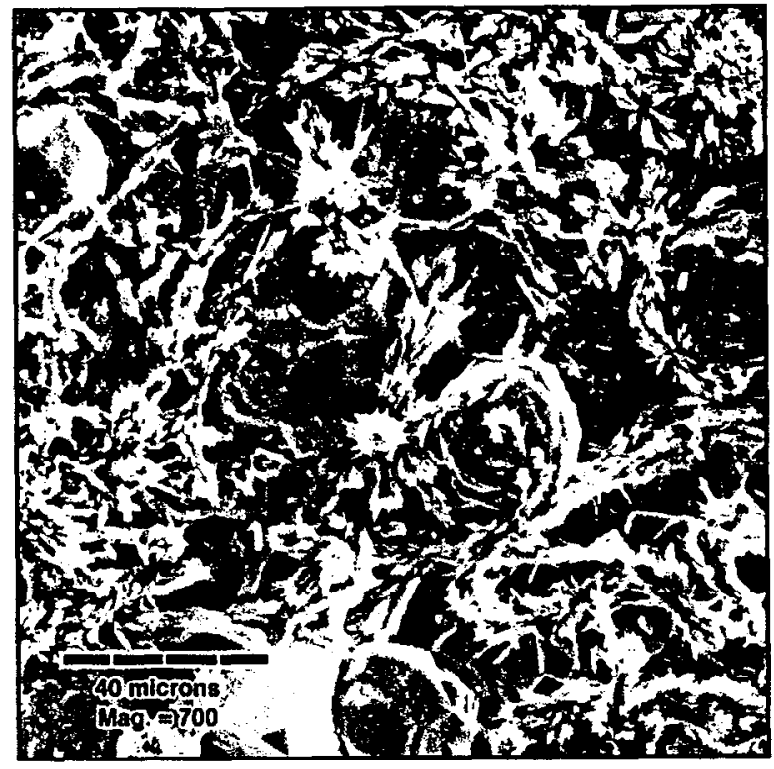

(d)

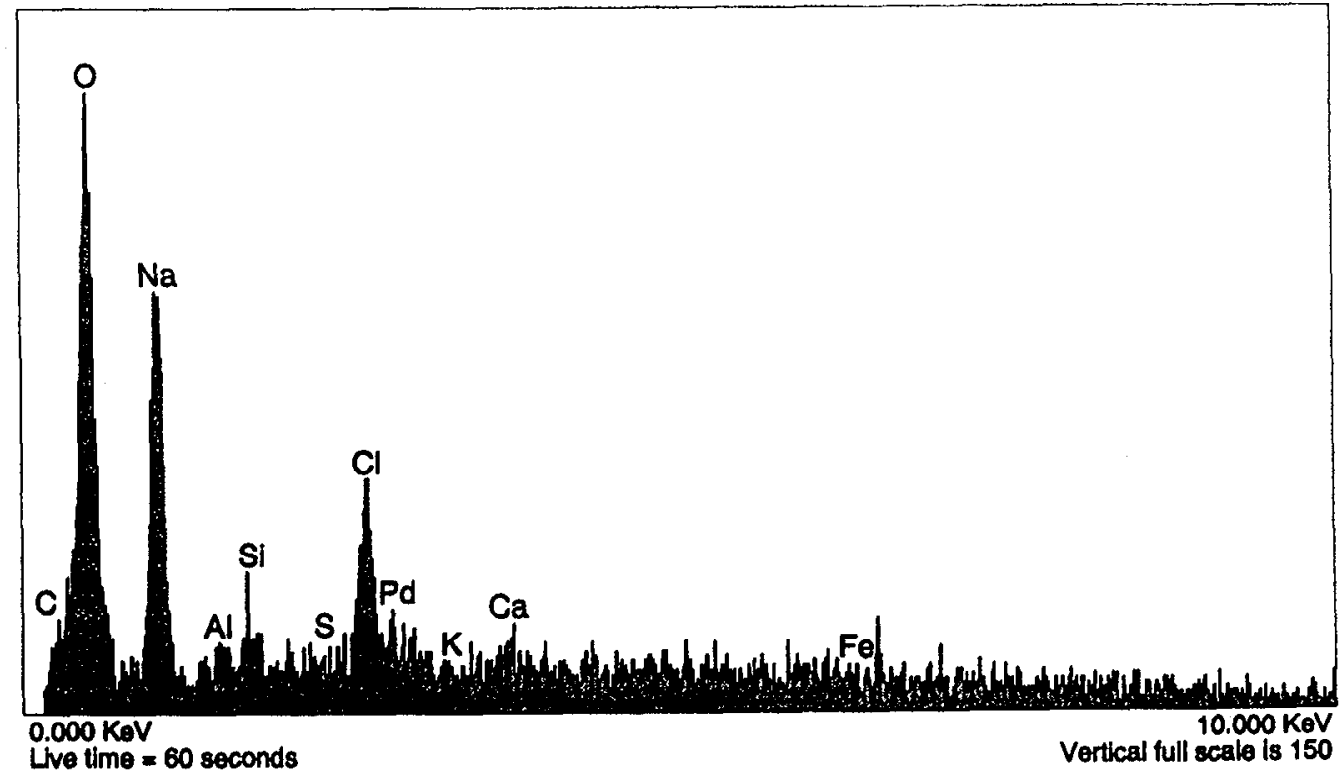

Figure 60 (continued). INV-23A, side 2 (PV-18-23a). (c) SEM photomicrograph of trapezohedrons within a web of feathery crystals. (d) EDS of the feathery web crystals suggest $\mathrm{O}, \mathrm{Na}$, and $\mathrm{Cl}$. 
(a)

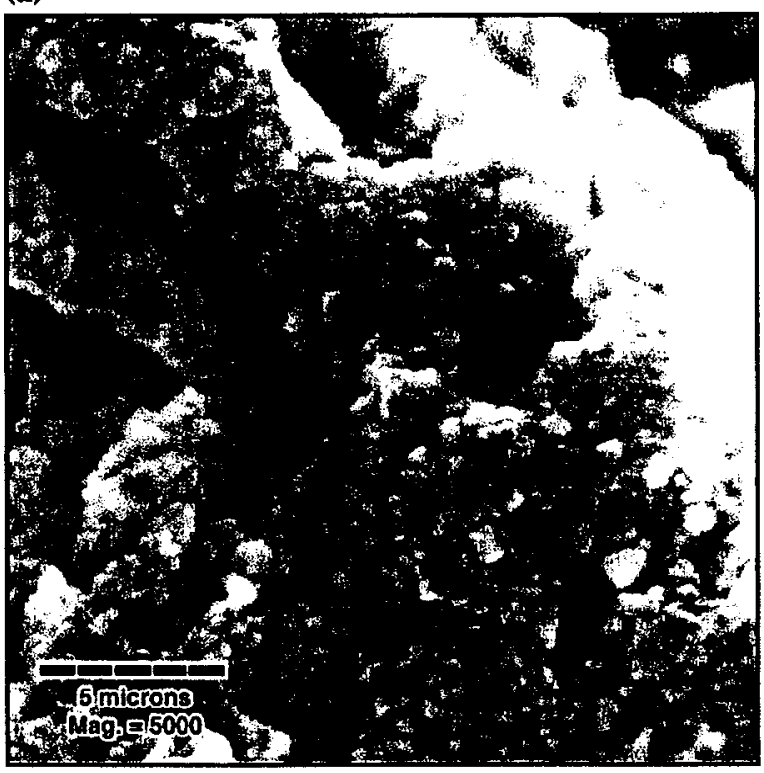

(b)

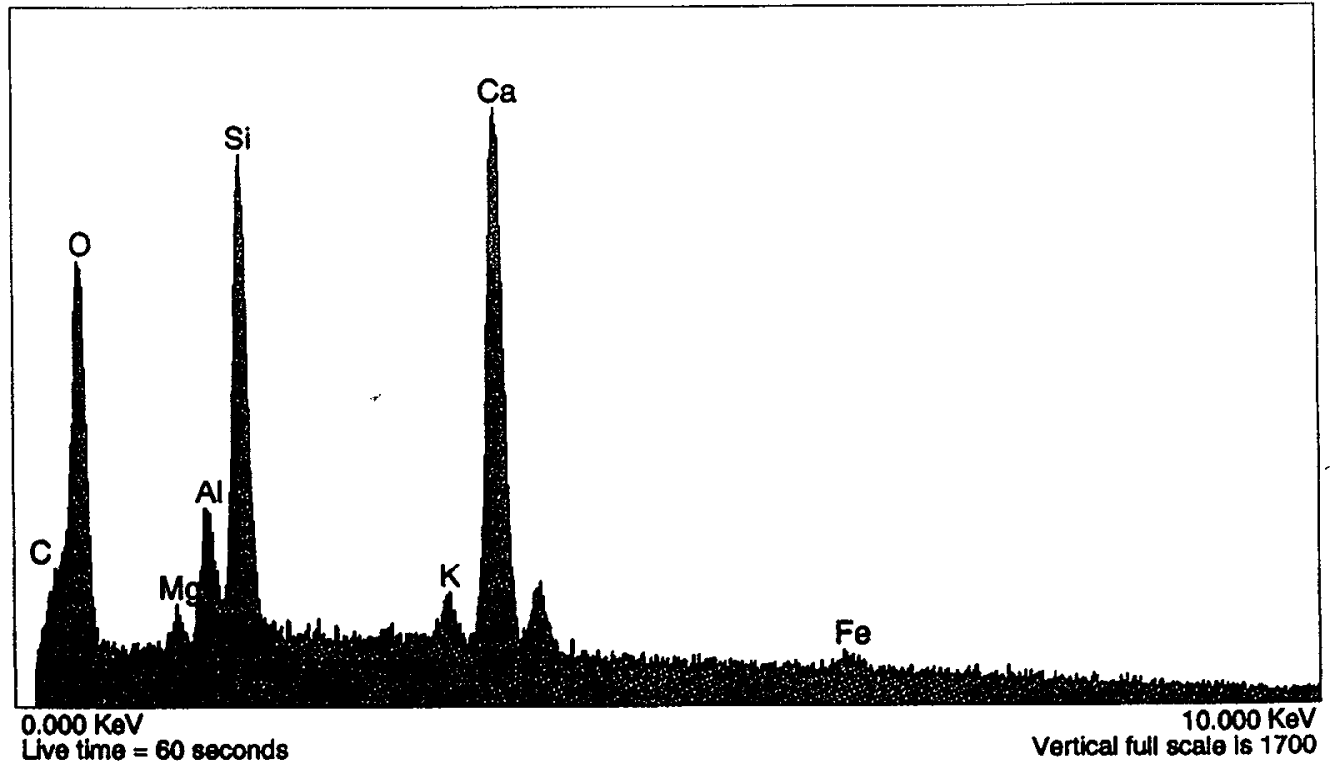

Figure 61. INV-23b (PV-18-23b). (a) SEM photomicrograph of grout outboard of a carbonate aggregate grain. (b) EDS indicates the presence of $\mathrm{Ca}, \mathrm{Si}, \mathrm{O}$, and $\mathrm{Al}$ with minor amounts of $\mathrm{K}, \mathrm{Mg}$, and $\mathrm{C}$. 
(a)

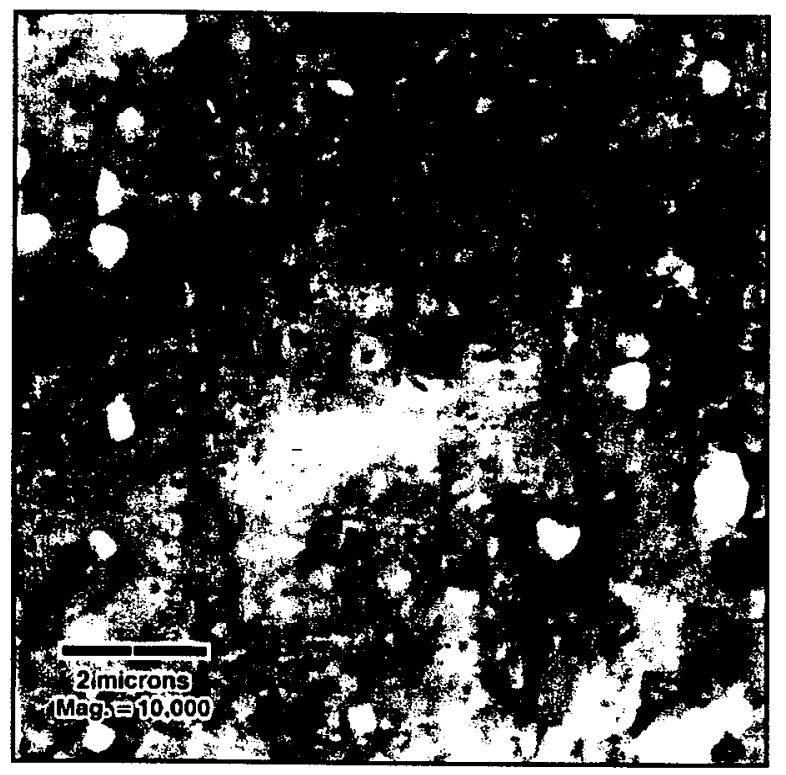

(b)

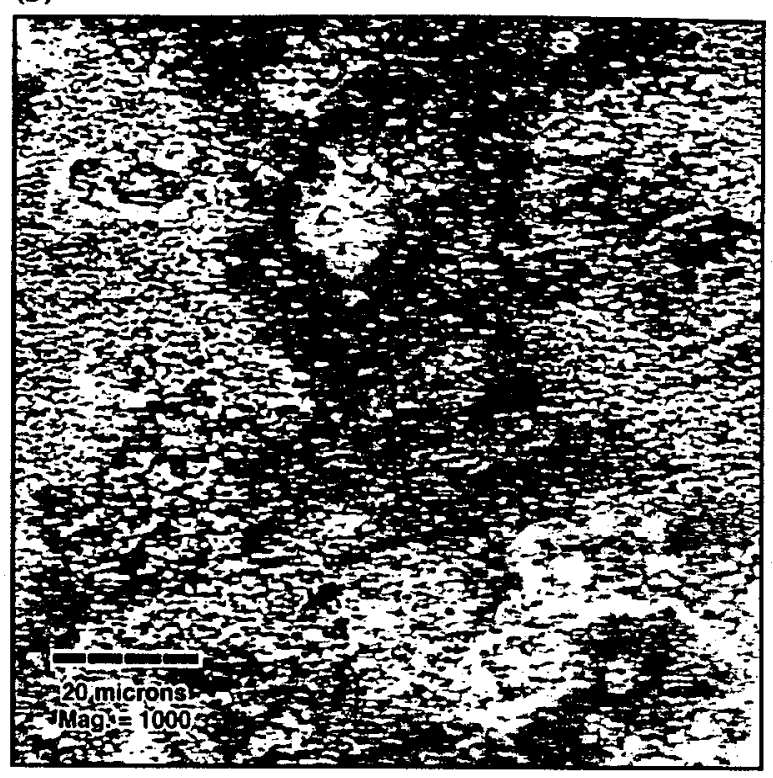

(c)

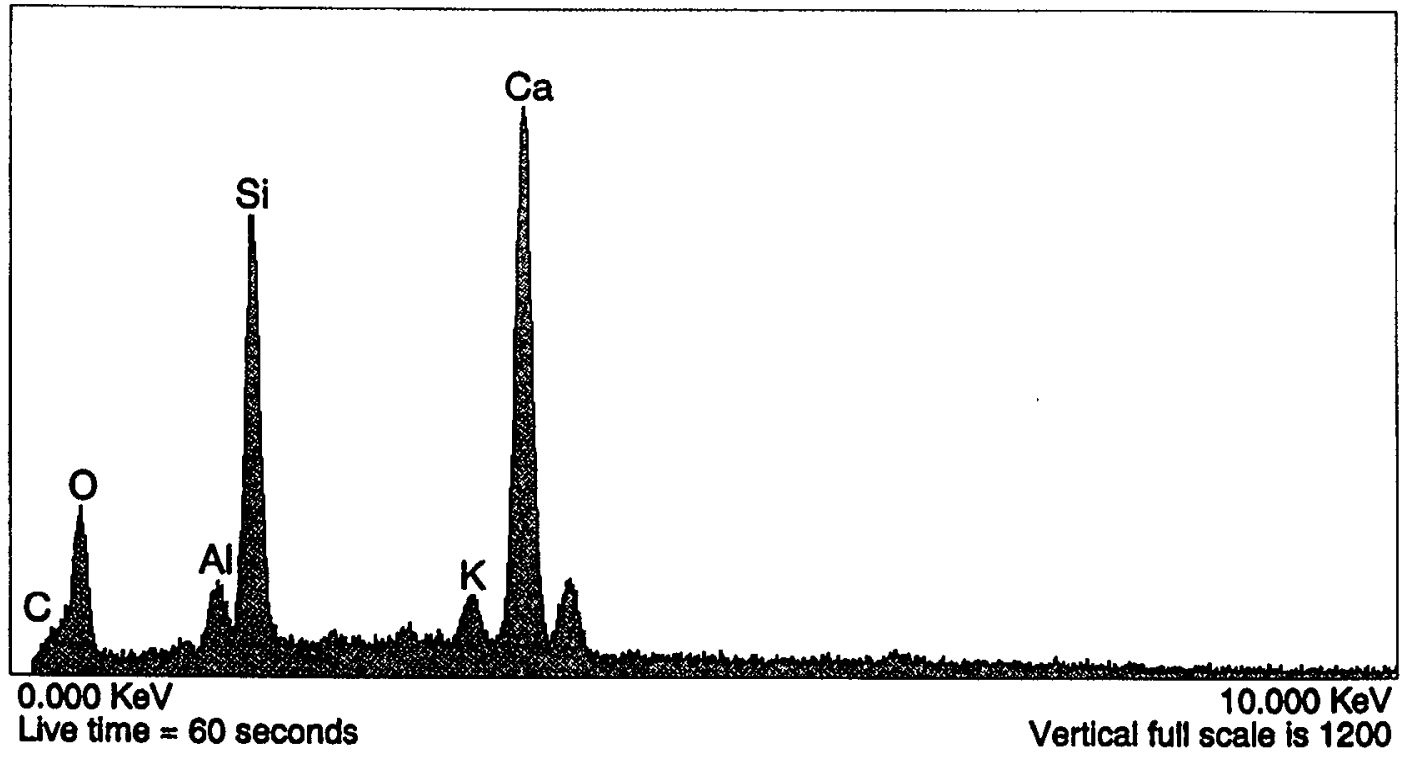

Figure 62. INV-23b (PV-18-23b). (a) SEM photomicrograph of grout showing white patches of crystals [identical to the crystals shown in Figure 64(b)], alternating with unreacted patches of grout substrate. This texture is common throughout the sample. (b) SEM photomicrograph of a patch of grout substrate at higher magnification. (c) EDS of the grout indicates a similar composition to the grout depicted in Figures 61(a) and (b), with $\mathrm{Ca}$, $\mathrm{Si}$, and $\mathrm{O}$ with minor amounts of $\mathrm{Al}, \mathrm{K}$, and $\mathrm{C}$. 


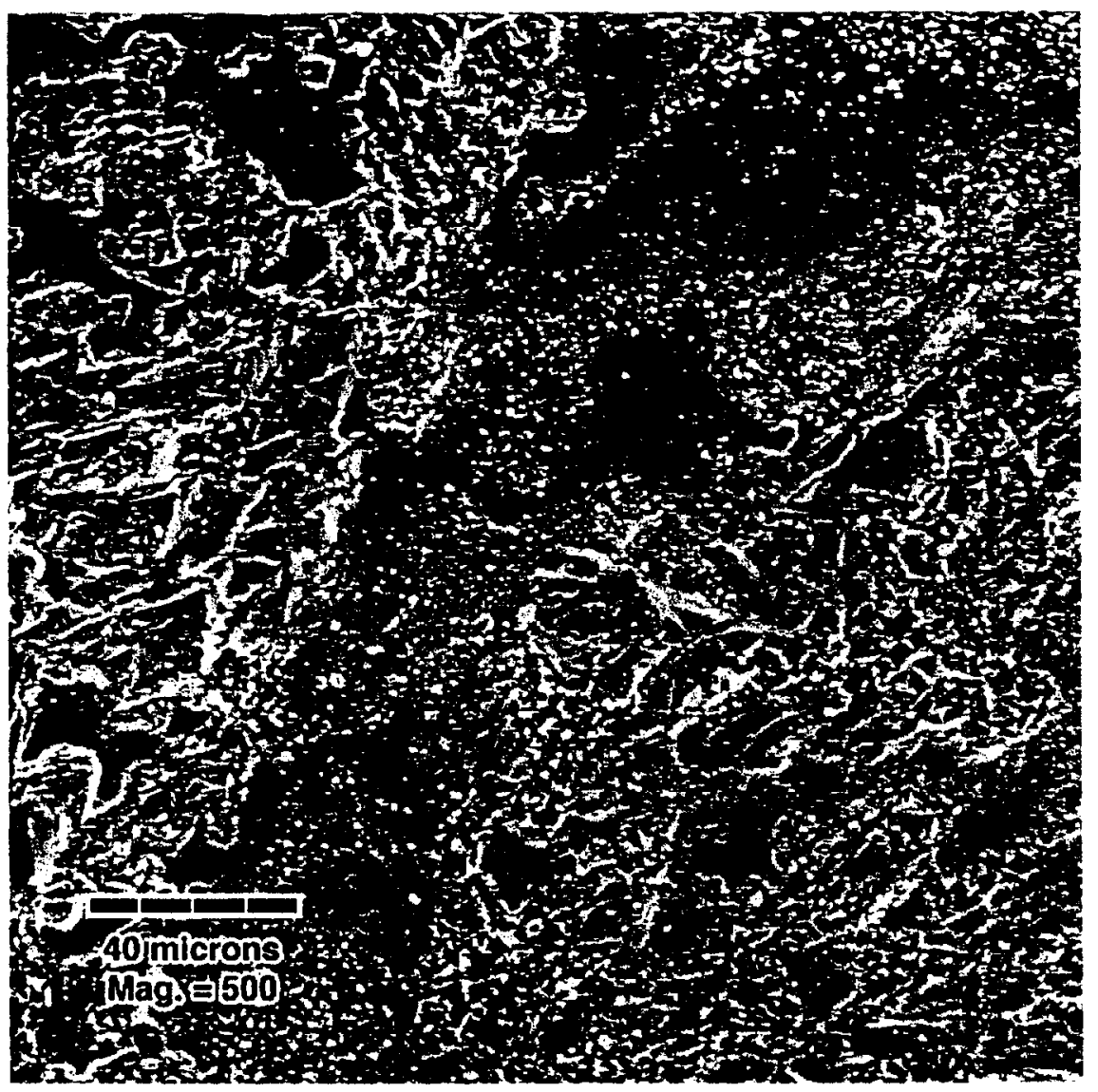

Figure 63. INV-23b (PV-18-23b). SEM photomicrograph of a strip of grout between two grains. The grout has low "topographic relief" compared to the grains. 


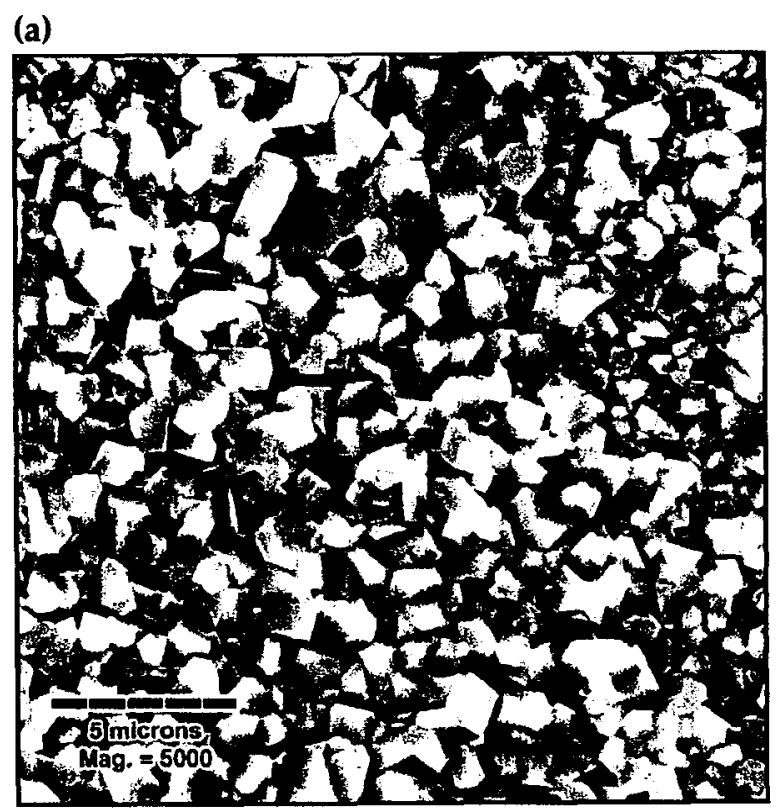

(b)

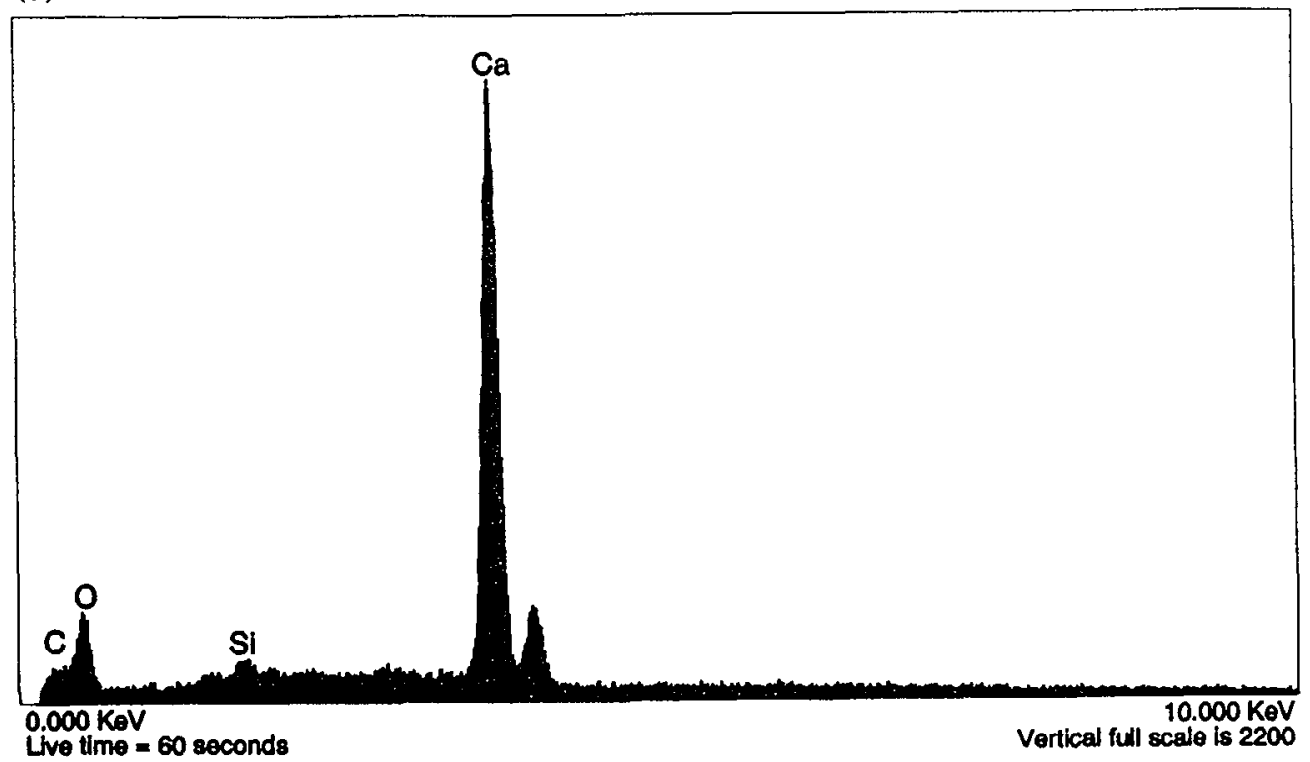

Figure 64. INV-23b (PV-18-23b). (a) SEM photomicrograph of tiny euhedral crystals on grout. These crystals are identical to those seen in Batch 1 Sample SH-2 Area 5. (b) EDS spectra indicates the presence of $\mathrm{Ca}, \mathrm{O}$, and $\mathrm{C}$ with possible minor amount of $\mathrm{Si}$. The tiny euhedral crystals are likely to be calcite. 
(a)

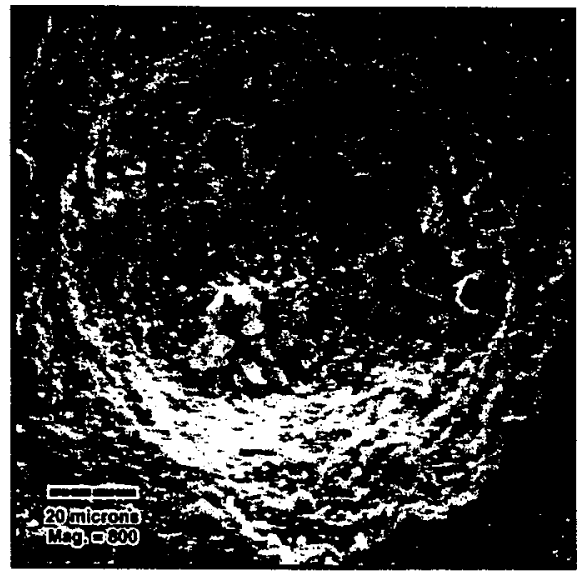

(c)

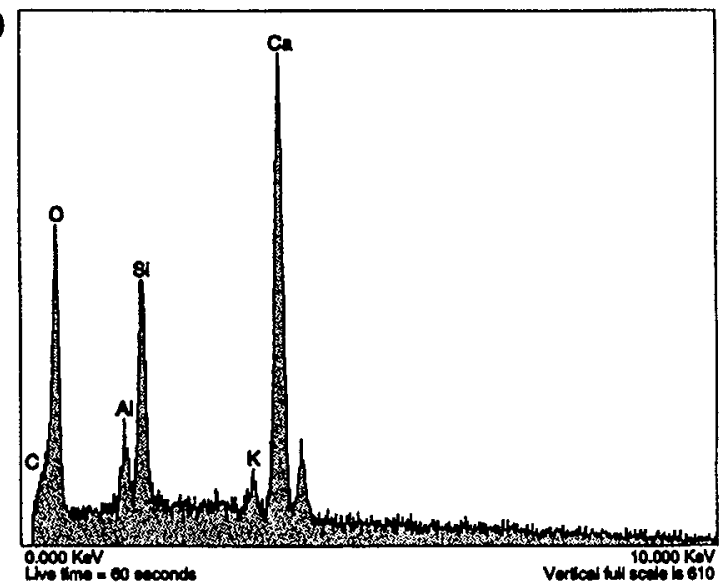

(b)

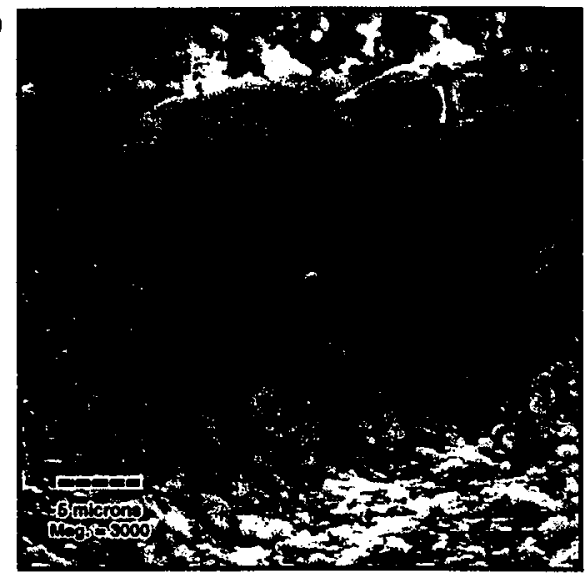

(d)

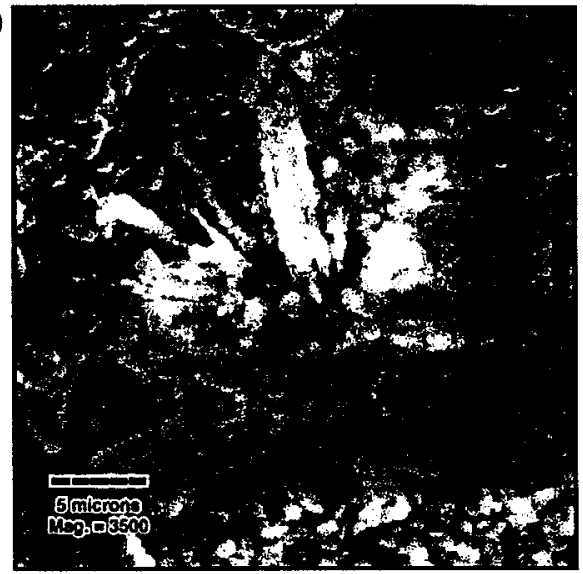

(e)

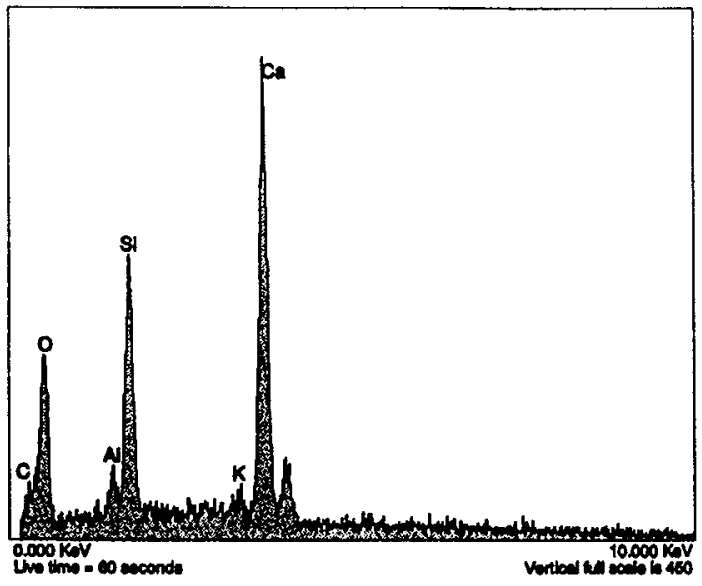

Figure 65. INV-23b (PV-18-23b). (a) SEM photomicrograph of a pit in grout. (b) SEM photomicrograph of one of the crystal clusters in the pit. (c) EDS of this cluster indicates the presence of $\mathrm{Ca}, \mathrm{Si}, \mathrm{O}, \mathrm{Al}, \mathrm{C}$, and $\mathrm{K}$. Because this phase is in a pit, all of the $x$-rays generated by the beam may not reach the detector (the pit walls may block some of the x-rays path to the detector). (d) SEM photomicrograph of another crystal cluster in the pit. (e) EDS of this cluster indicates the presence of $\mathrm{Ca}, \mathrm{Si}, \mathrm{O}, \mathrm{Al}, \mathrm{C}$, and $\mathrm{K}$. It differs from the other crystal cluster primarily in the $\mathrm{Si}: \mathrm{O}$ ratio. Because this phase is in a pit, all of the $\mathrm{x}$-rays generated by the beam may not reach the detector (the pit walls may block some of the $x$-ray path to the detector). 
(a)

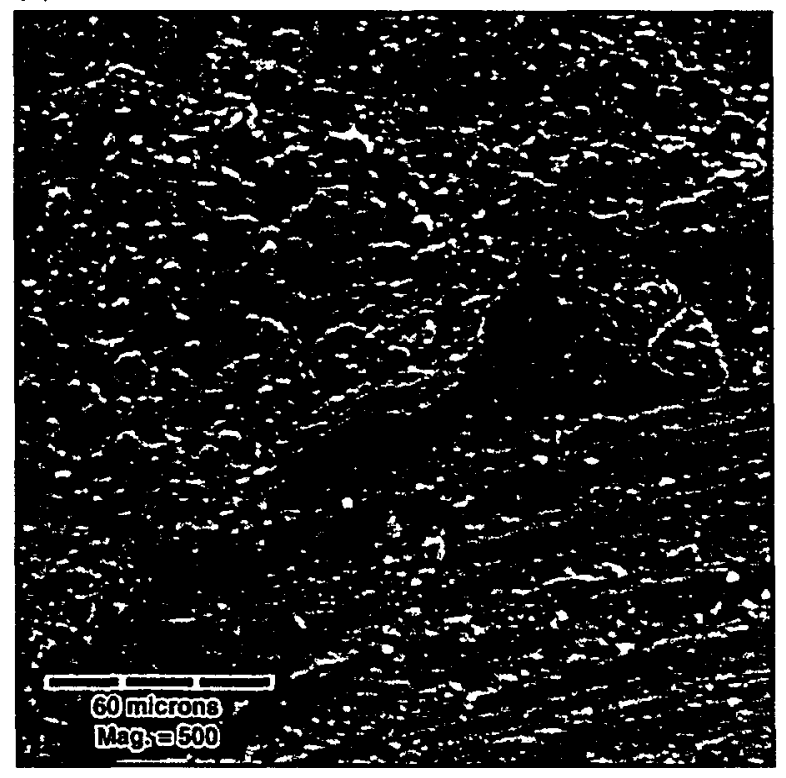

(b)

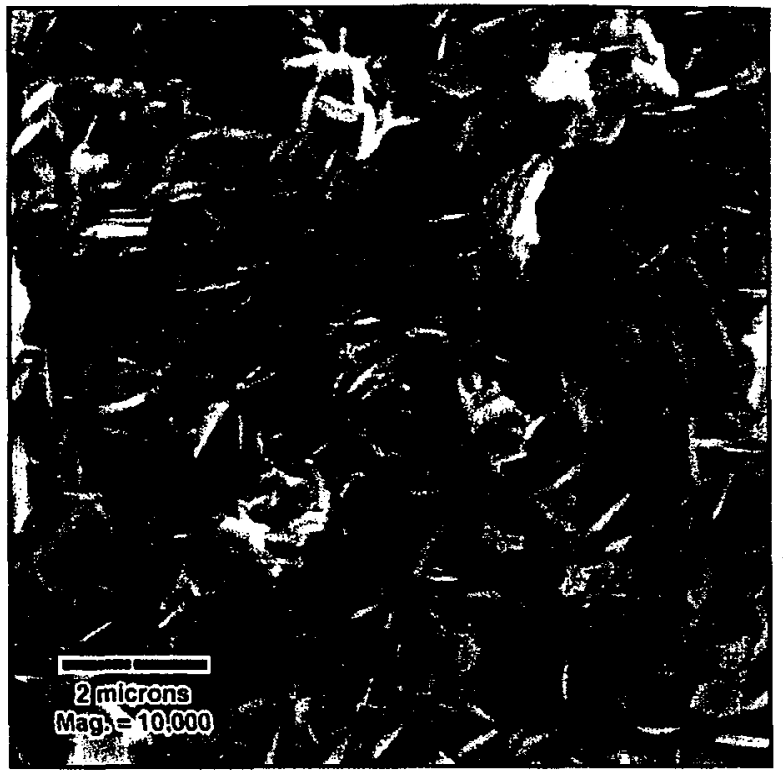

(c)

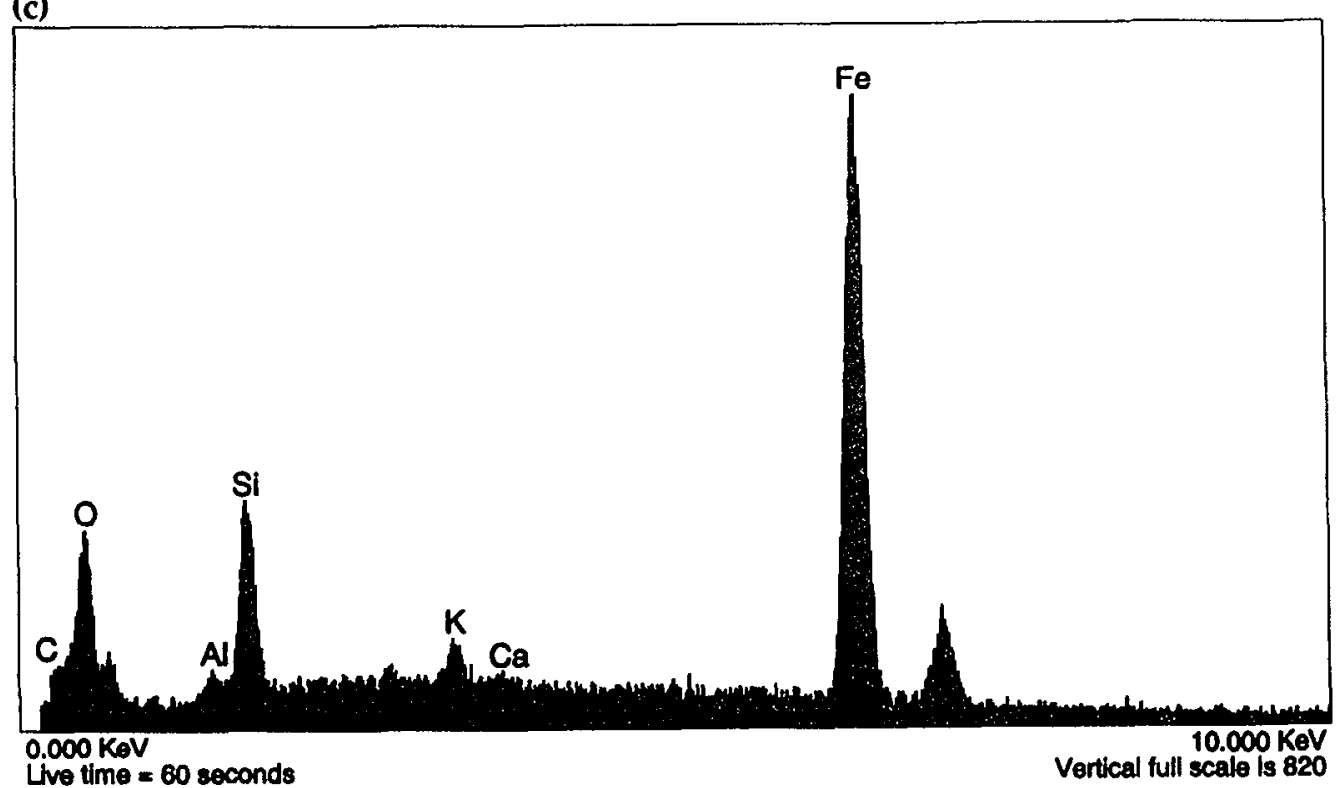

Figure 66. SH-10 (PV-18-10). (a) 500 $\times$ magnification of a steel fiber identified by light microscopy. (b) A more detailed view. SEM photomicrograph of the steel fiber surface covered with tiny platy crystals. The crystals are similar in morphology (not composition) to Batch 1 Sample SH-1 Area 4. (c) EDS indicates the presence of Fe, O, and $\mathrm{Si}$, with minor amounts of $\mathrm{K}, \mathrm{C}$, and $\mathrm{Al}$. The large $\mathrm{Fe}$ and some of the $\mathrm{O}$ peak is likely due to the underlying metal fiber, whereas the other peaks are probably derived from the platy phase. Ca is notably absent. 
(a)

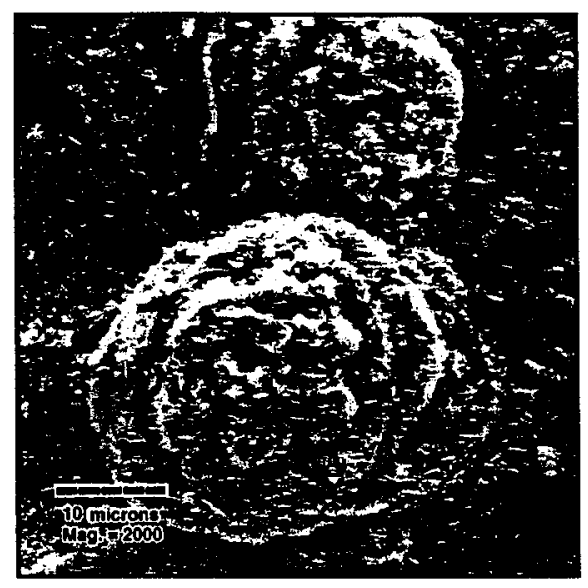

(c)

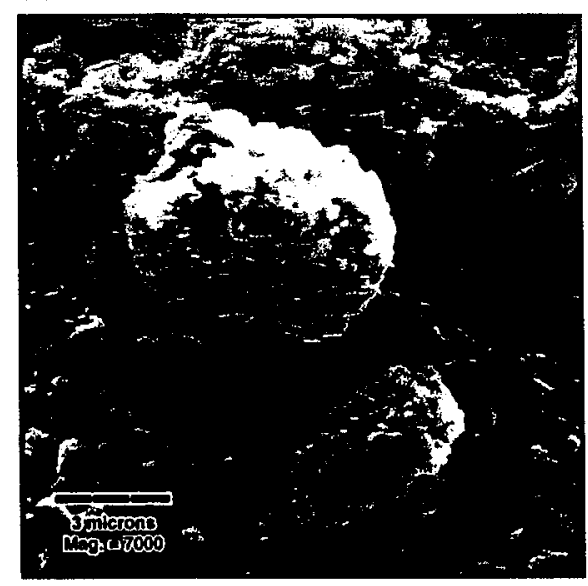

(b)

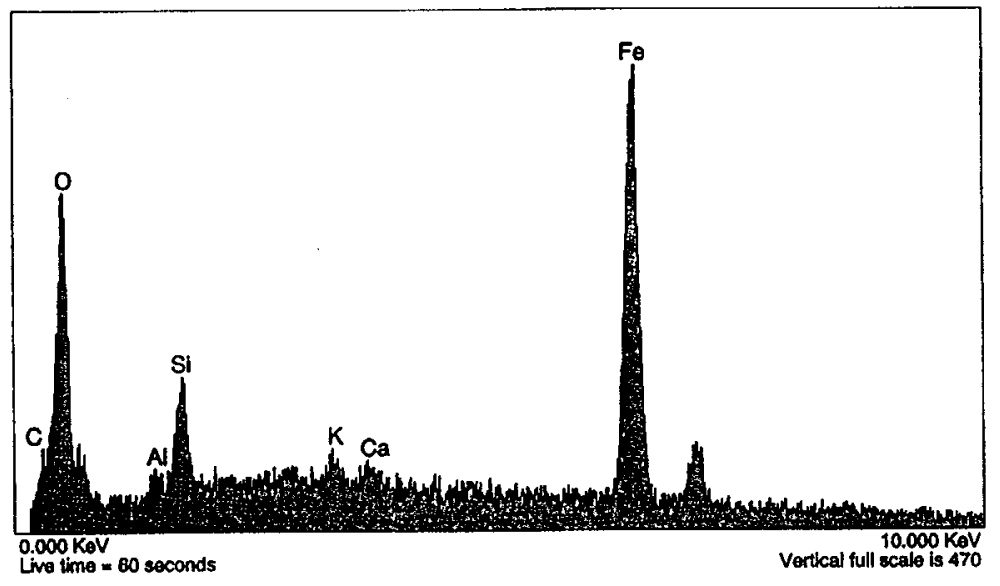

(d)

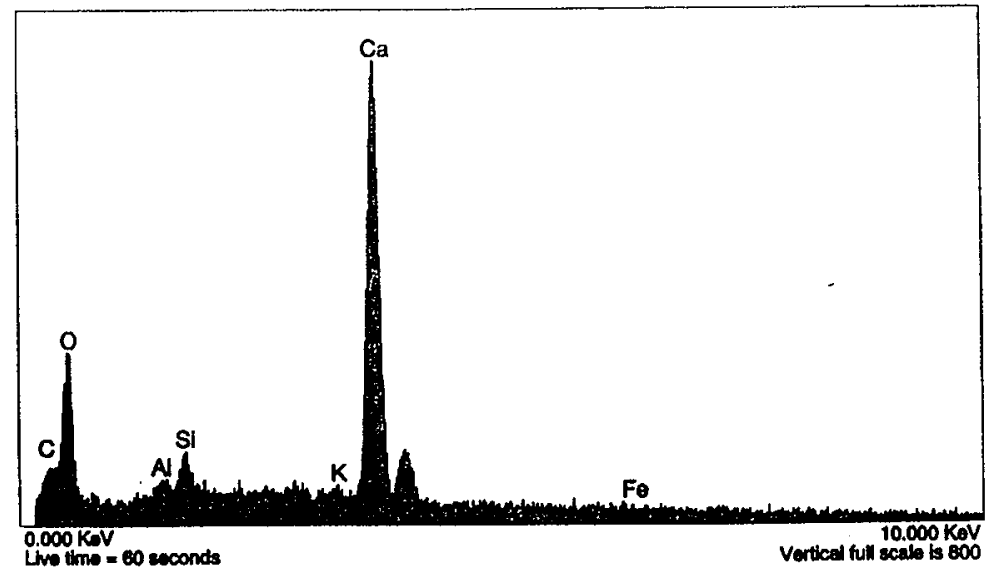

Figure 67. SH-10 (PV-18-10). (a) SEM photomicrograph of a rosette cluster of crystals on the metal fiber shown in Figure 66(a). At least five of these were found on and around the fiber. (b) EDS indicates the presence of $\mathrm{Fe}, \mathrm{O}$, and $\mathrm{Si}$ with minor amounts of $\mathrm{K}, \mathrm{Al}$, and $\mathrm{Ca}$. Fe and $\mathrm{O}$ might be contributed by the underlying fiber. (c) SEM photomicrograph of crystal clusters in the grout adjacent to the metal fiber. (d) EDS suggests a carbonate composition. 
(a)

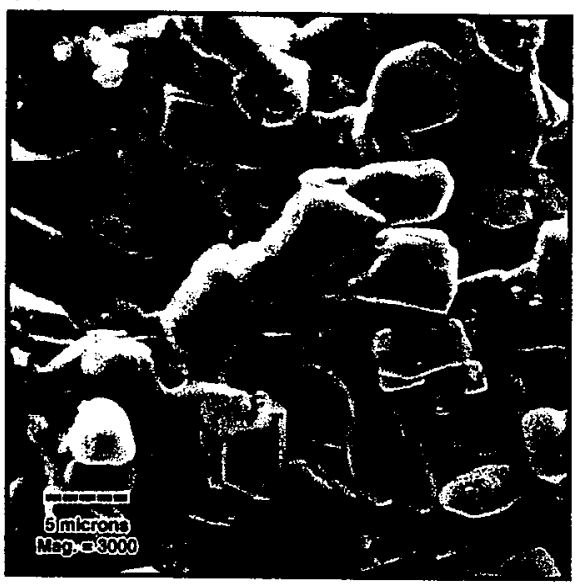

(c)

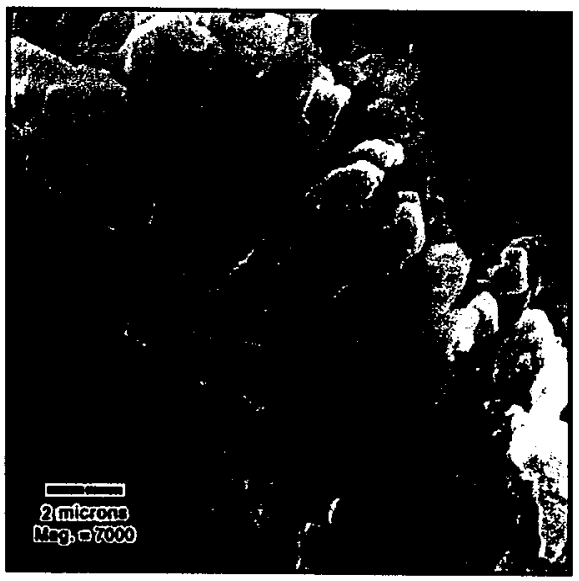

(b)

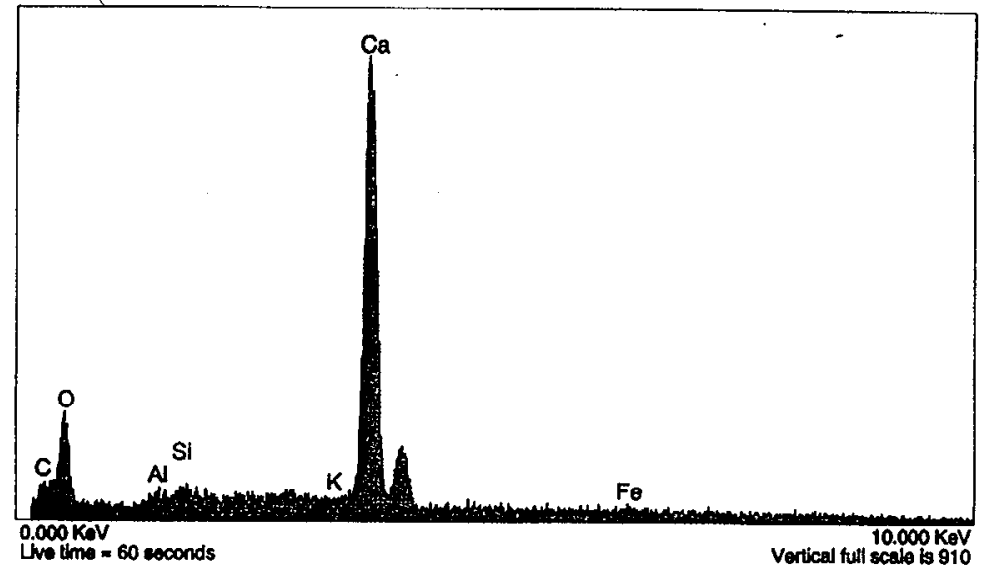

(d)

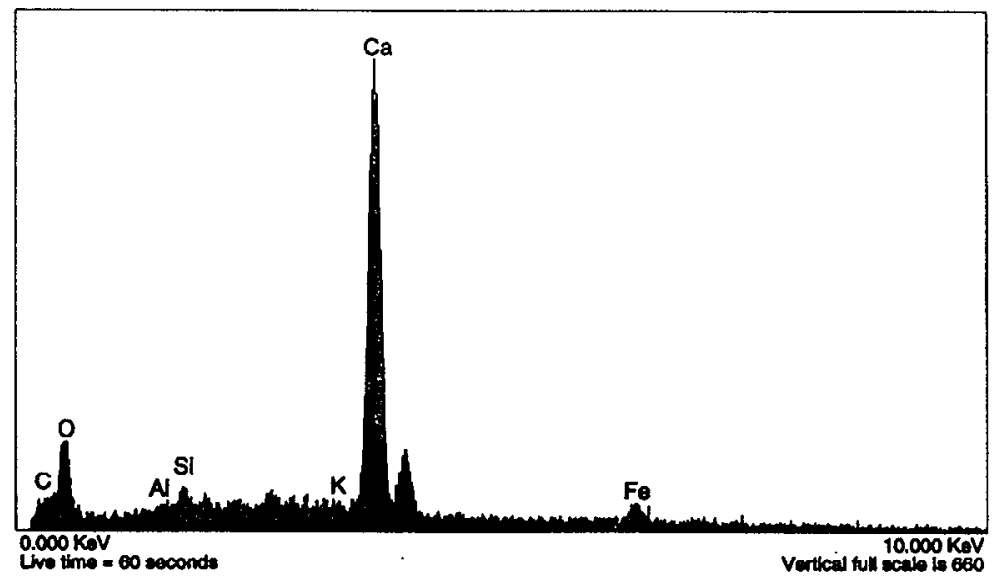

Figure 68. SH-10 (PV-18-10). (a) SEM photomicrograph elsewhere on the steel fiber shown in Figure 66(a), of one of the crystalline phases rimming the steel fiber. (b) EDS indicates the presence of $\mathrm{Ca}, \mathrm{O}$, and $\mathrm{C}$, probably carbonate. (c) SEM photomicrograph of another crystalline phase that rims the steel fiber. (d) EDS of this phase indicates the presence of $\mathrm{Ca}, \mathrm{O}$, and $\mathrm{C}$, with possible minor amounts of $\mathrm{Si}$ and $\mathrm{Fe}$. The phase is likely to be a carbonate. The small Fe and Si peaks are probably derived from nearby phases. 
(a)

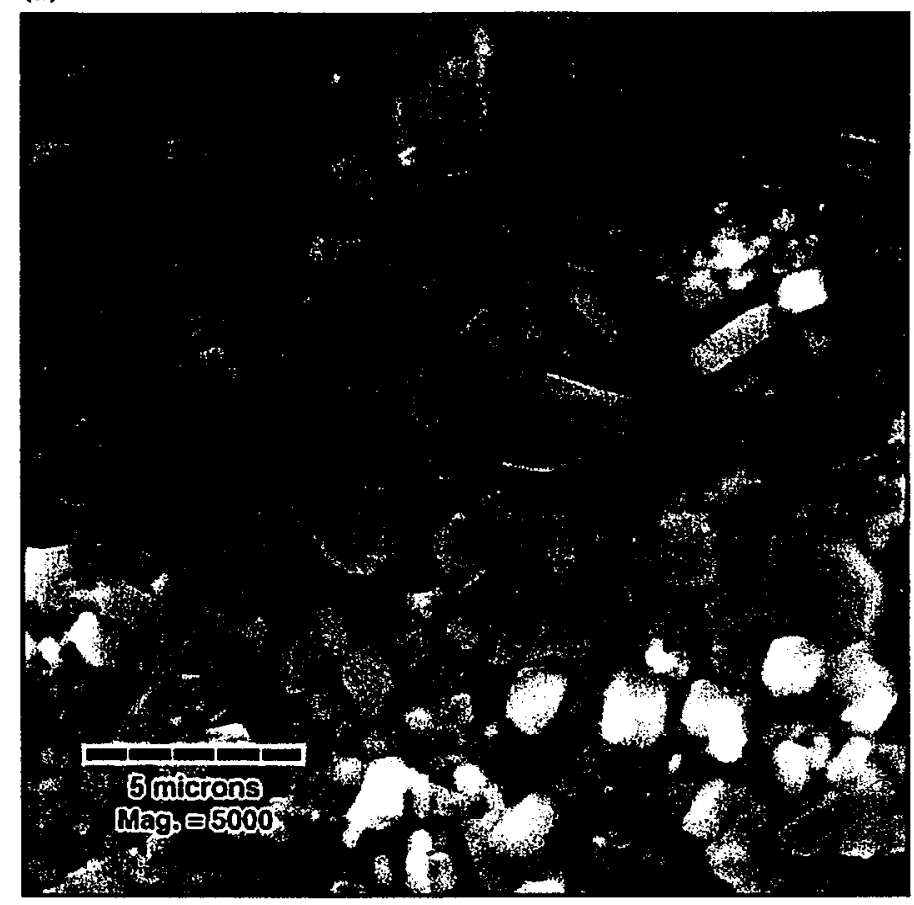

(b)

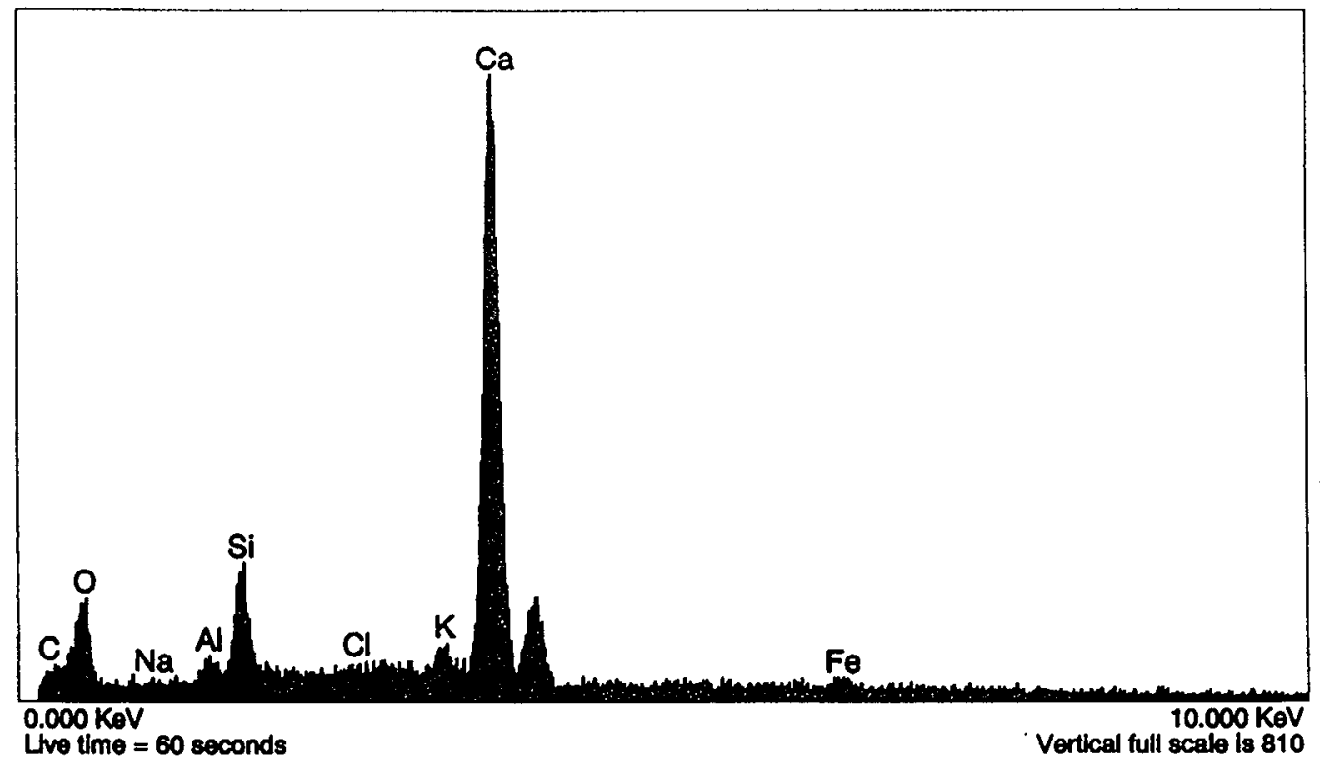

Figure 69. SH-10 (PV-18-10). (a) SEM photomicrograph of well-faceted tiny rhombs on grout. We found this phase to be widespread on the sample. (b) EDS suggests the presence of $\mathrm{Ca}, \mathrm{Si}, \mathrm{O}, \mathrm{C}, \mathrm{Al}$, and $\mathrm{K}$. We attribute $\mathrm{Si}, \mathrm{Al}, \mathrm{K}$, some $\mathrm{Ca}$, and $\mathrm{O}$ to the grout [see Figures 39(b), 41(b), 44(c), and 49(c)] and the remaining $\mathrm{Ca}, \mathrm{C}$, and $\mathrm{O}$ to the rhombic phase, probably calcite. 


\section{(a)}

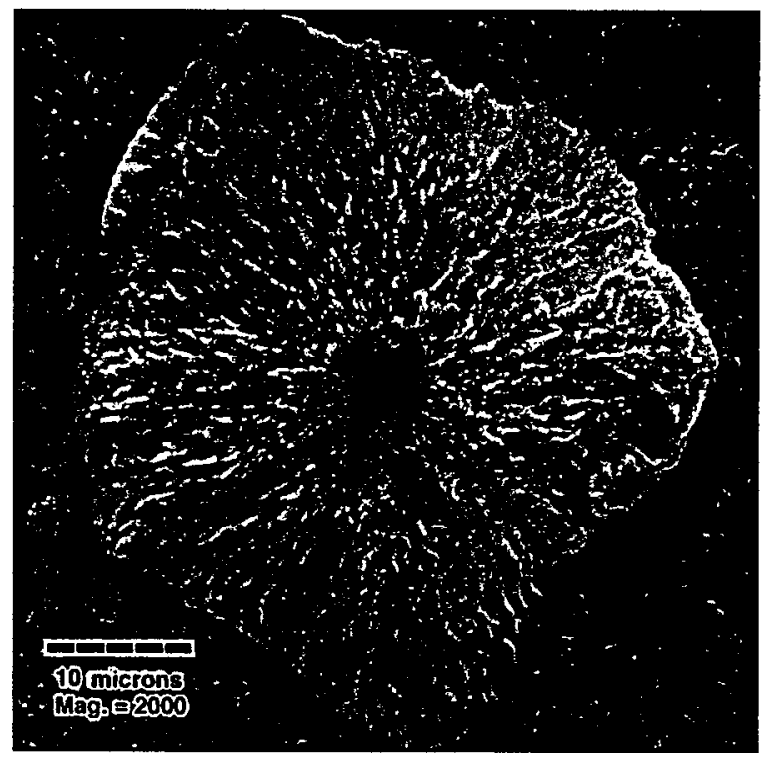

(b)

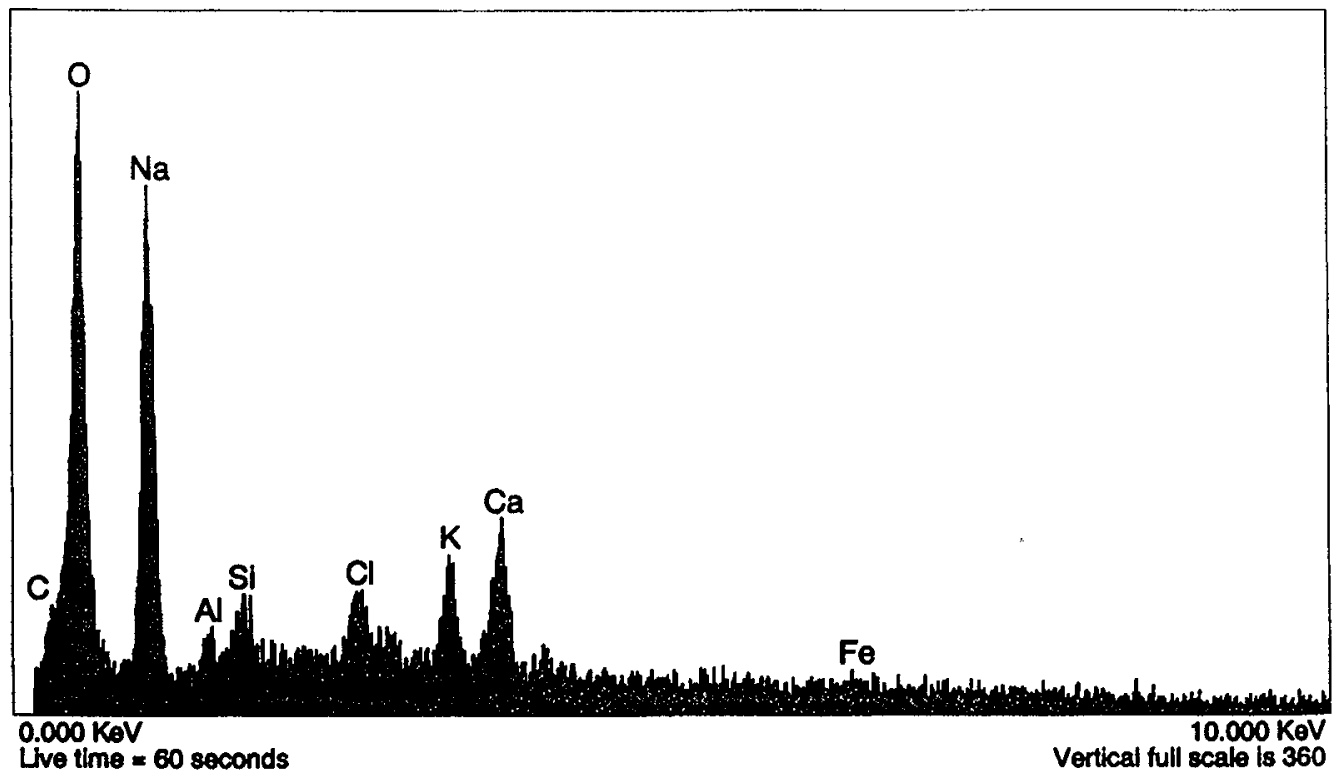

Figure 70. SH-10 (PV-18-10). (a) SEM photomicrograph of a honeycomb-like mineral on an unknown substrate adjacent to the metal fiber. At higher magnification, this phase is similar to Batch 1 Sample $\mathrm{SH}-2$ Area $1\left(\mathrm{NaHCO}_{3}\right.$ vapor treatment). (b) EDS suggests $\mathrm{O}, \mathrm{Na}, \mathrm{Ca}, \mathrm{K}, \mathrm{Cl}, \mathrm{Si}, \mathrm{Al}$, and $\mathrm{C}$. This composition is similar to Batch 1 Sample $\mathrm{SH}-2$ Area 1 which contains $\mathrm{Na}, \mathrm{O}, \mathrm{C}, \mathrm{S}, \mathrm{Cl}, \mathrm{Si}$, and $\mathrm{Ca}$. 
(a)

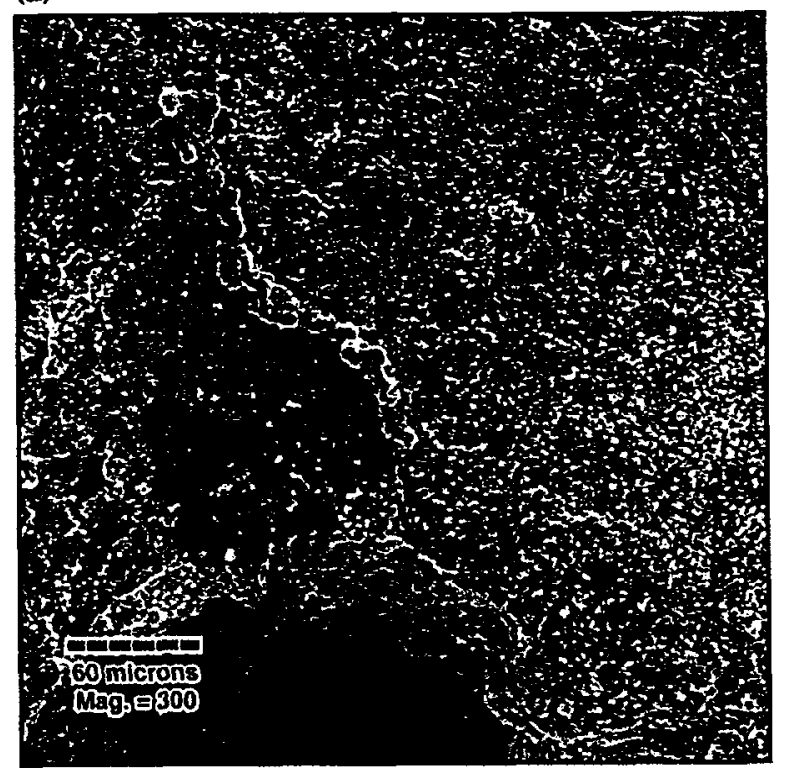

(b)

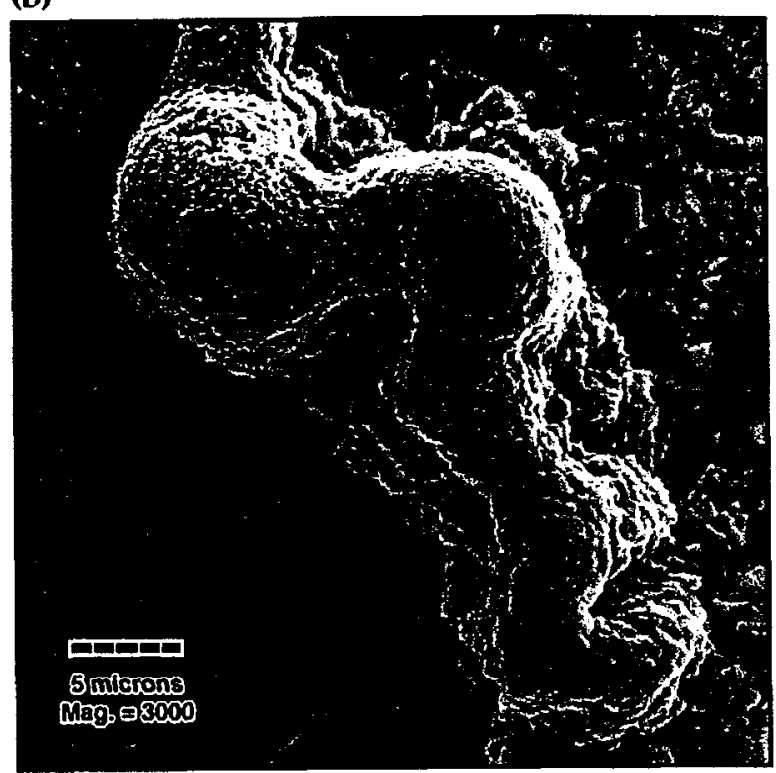

(c)

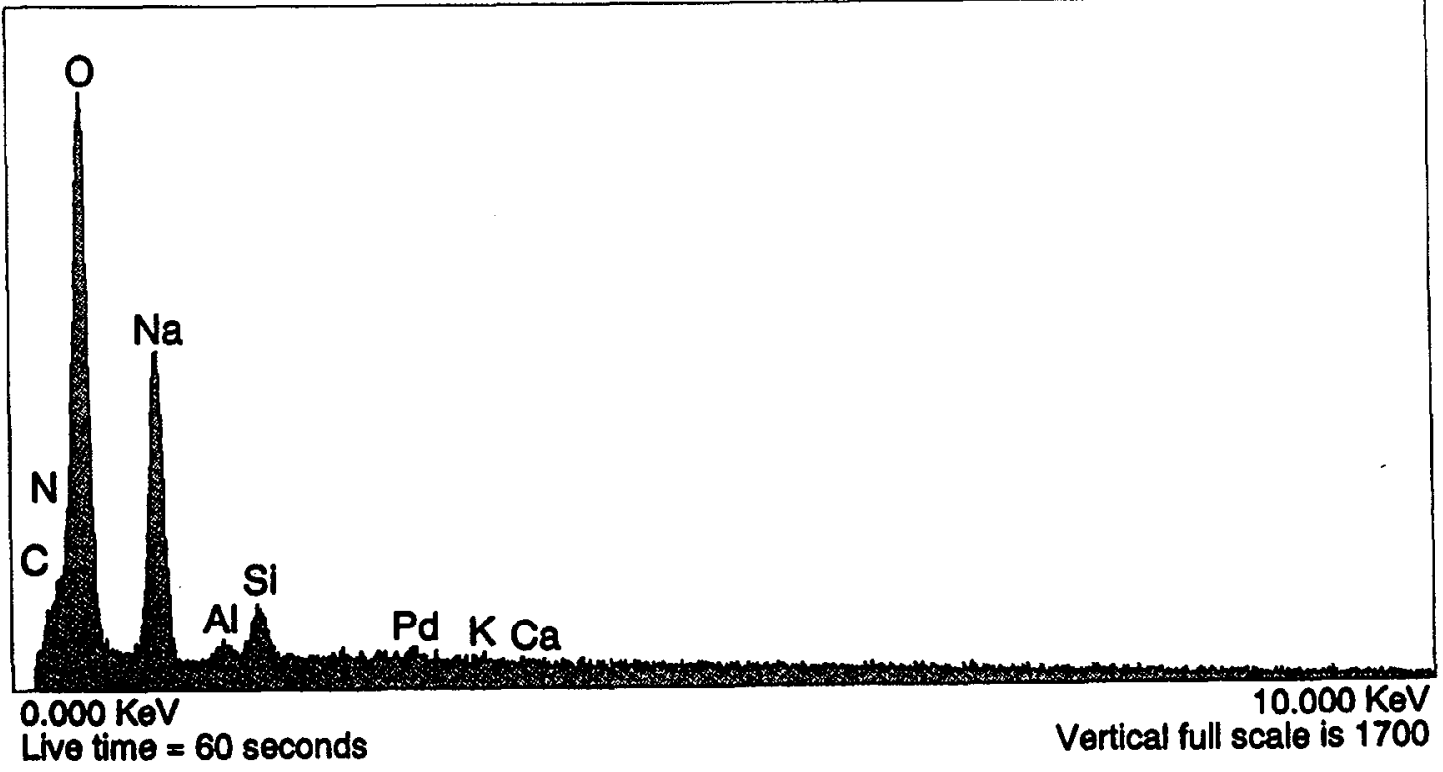

Figure 71. SH-10 (PV-18-10). (a) SEM photomicrograph of a band of secondary mineral. (b) SEM photomicrograph of the same band, at higher magnification. (c) EDS indicates the presence of $\mathrm{O}, \mathrm{Na}, \mathrm{C}$, and $\mathrm{Si}$, with possible $\mathrm{Al}$. 
(a)

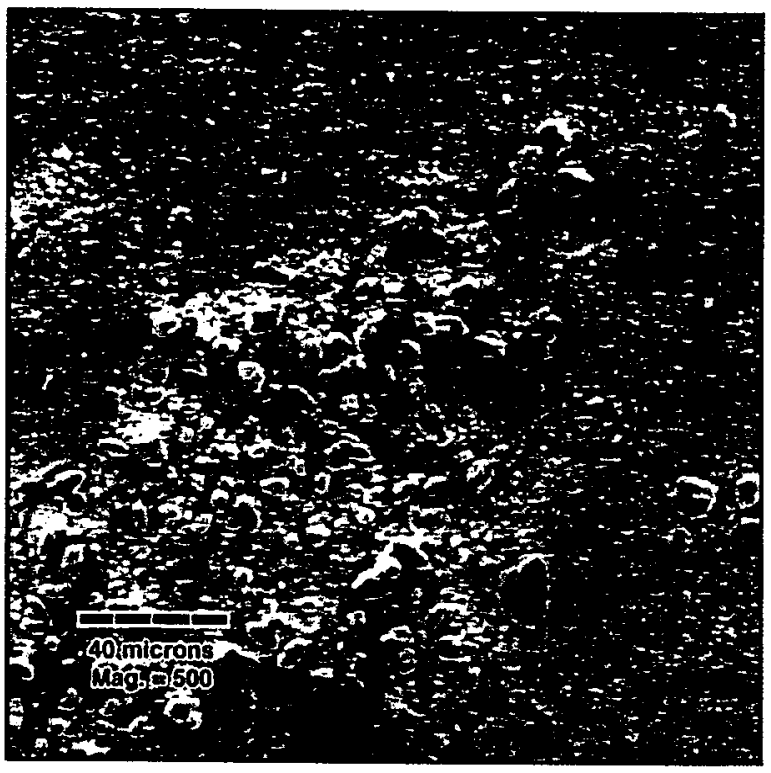

(b)

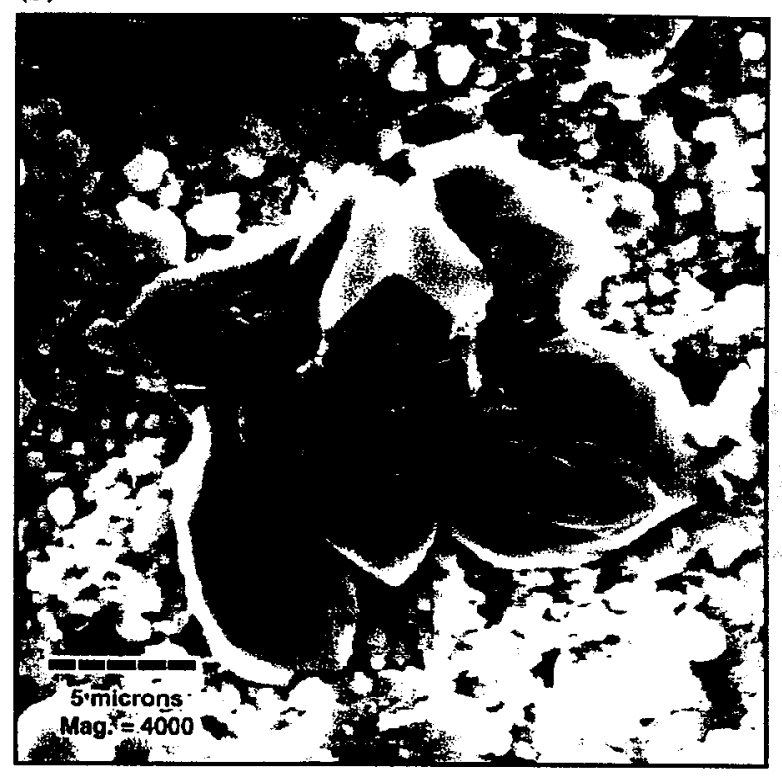

(c)

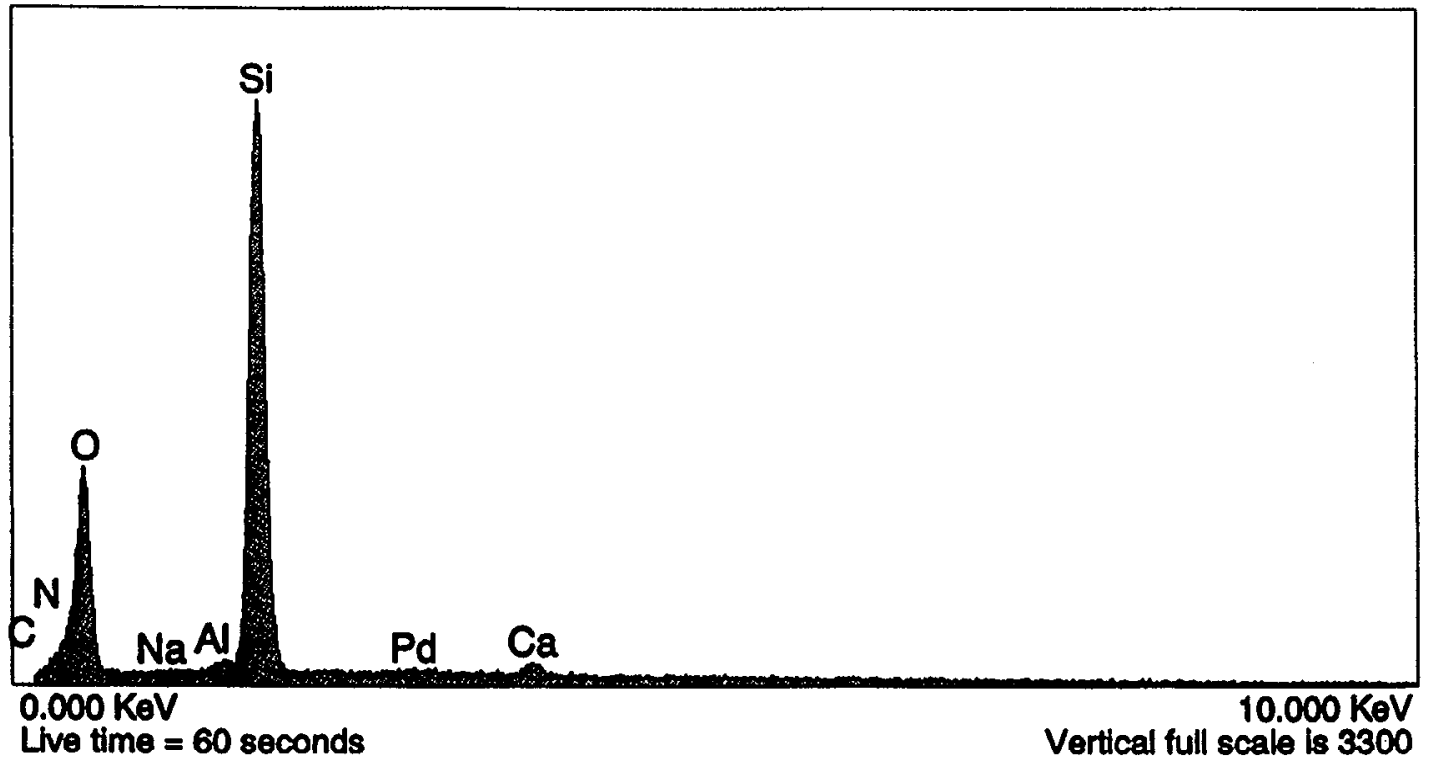

Figure 72. SH-10 (PV-18-10). (a) SEM photomicrograph of well-facetted, small crystals on grout. (b) SEM photomicrograph of same crystals at higher magnification. (c) EDS indicate that the crystals are quartz or another $\mathrm{SiO}_{2}$ phase. 
(a)

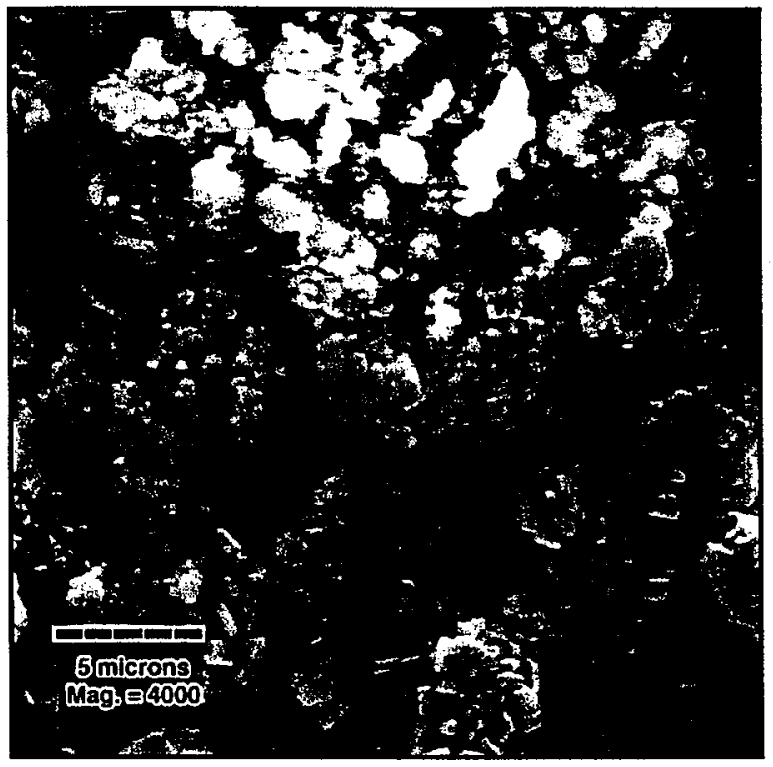

(b)

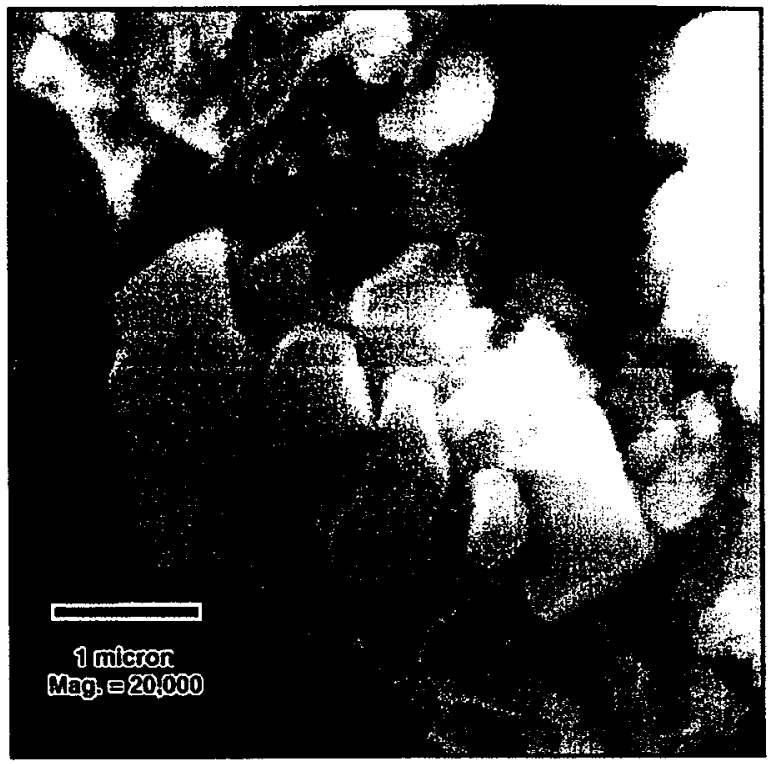

(c)

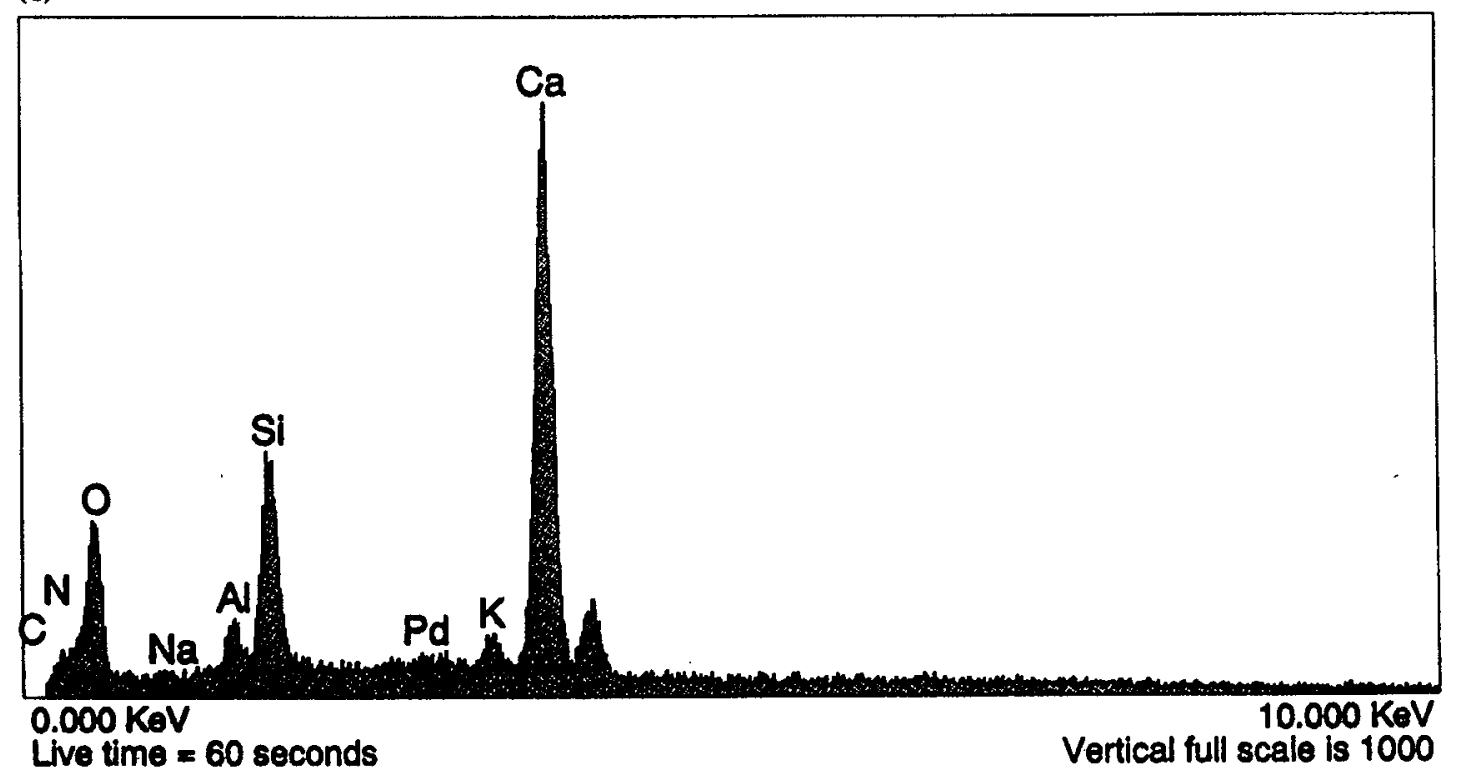

Figure 73. SH-10 (PV-18-10). (a) SEM photomicrograph of crystals on grout. (b) SEM photomicrograph of the same crystals at a higher magnification. These crystals have a morphology similar to those in Figure 68(c). (c) EDS indicate the presence of $\mathrm{Ca}, \mathrm{Si}$, and $\mathrm{O}$ with minor amounts of $\mathrm{Al}, \mathrm{C}$, and $\mathrm{K}$. The crystals in Figure 68(c) have a carbonate composition. 
(a)

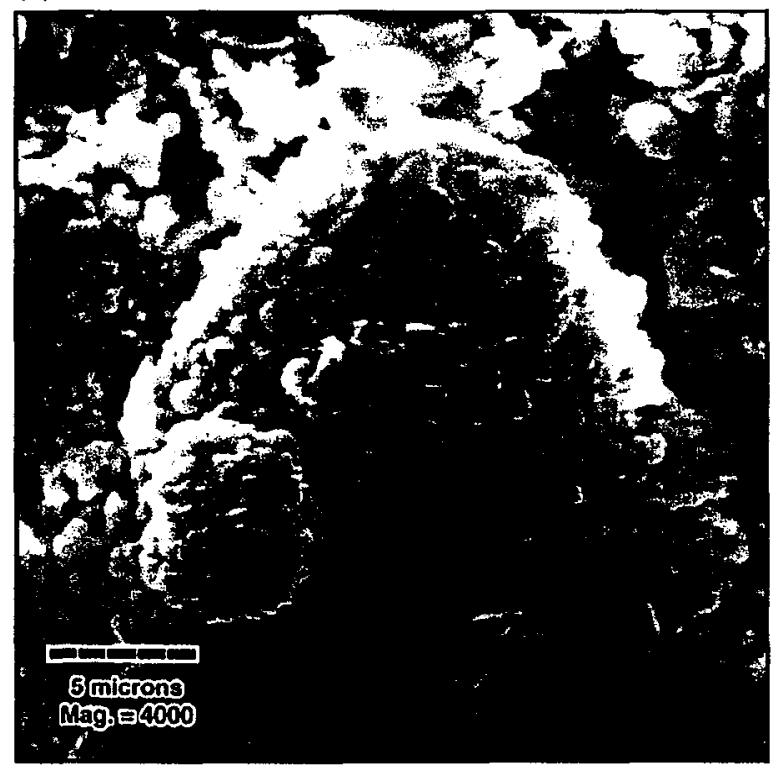

(b)

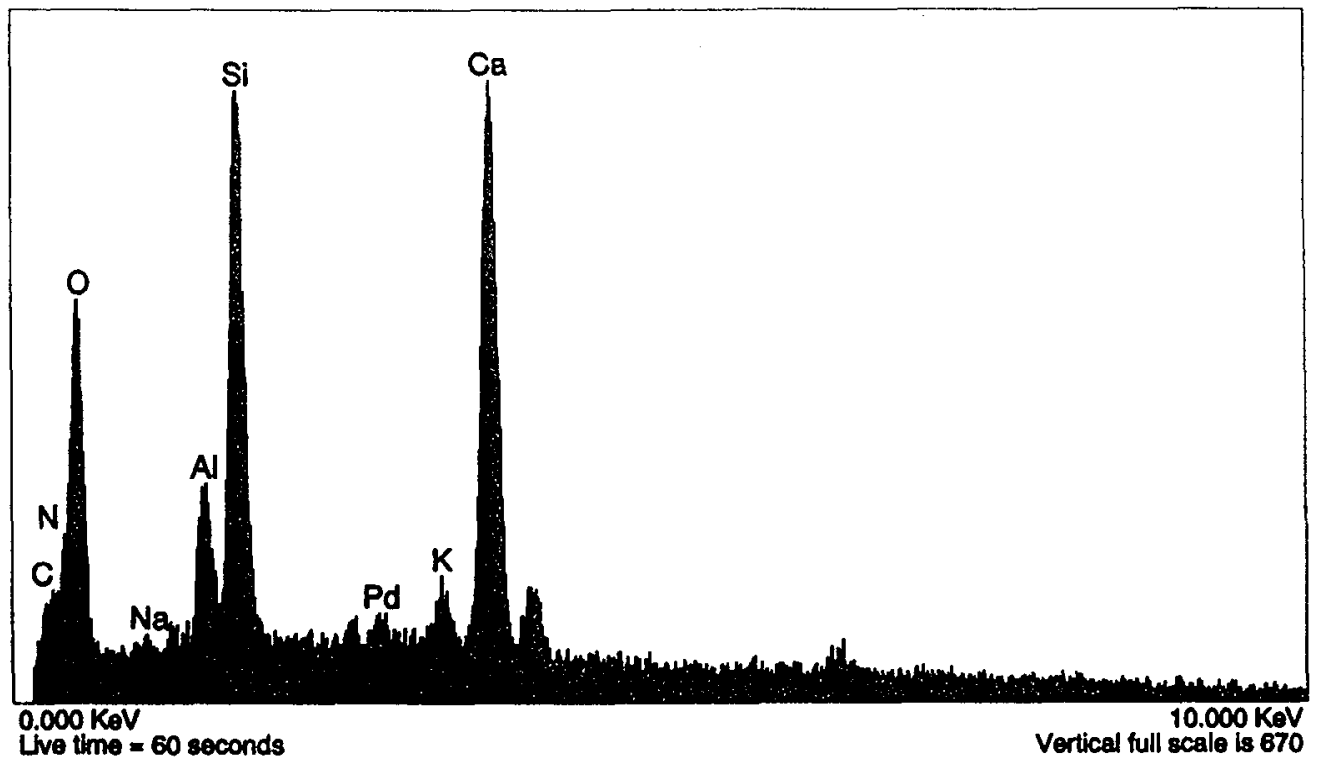

.Figure 74. SH-10 (PV-18-10). (a) SEM photomicrograph of crystals on grout. (b) EDS indicates the presence of Ca, $\mathrm{Si}, \mathrm{O}$, and $\mathrm{Al}$, with minor amounts of $\mathrm{C}$ and $\mathrm{K}$. Both this phase and the one depicted in Figure 73 are situated on grout. The variation in Ca:Si ratio, and Al:Si ratio are probably due to differences in the size of the crystal with respect to the cross section of the total analyzed area. 
(a)

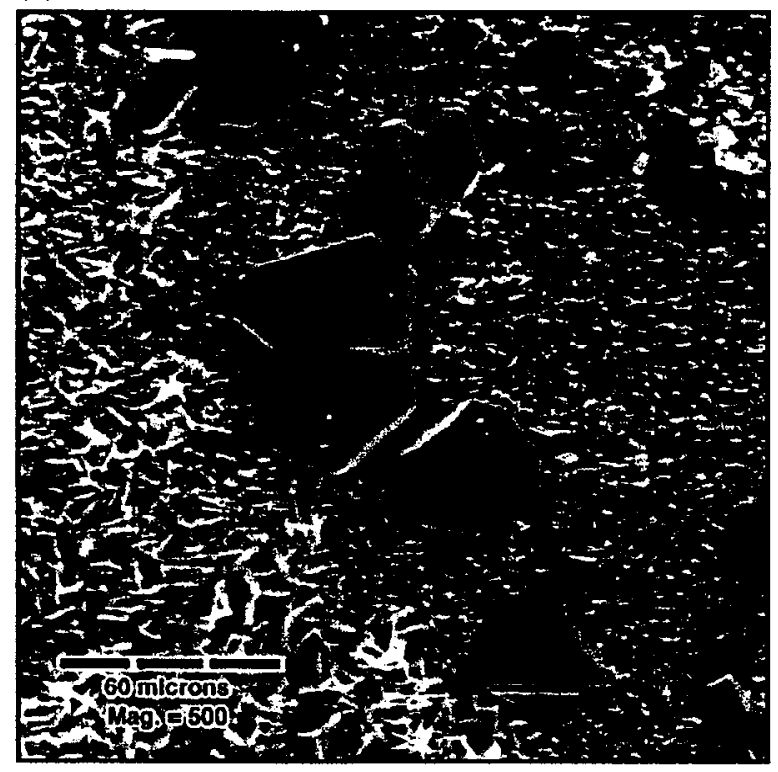

(b)

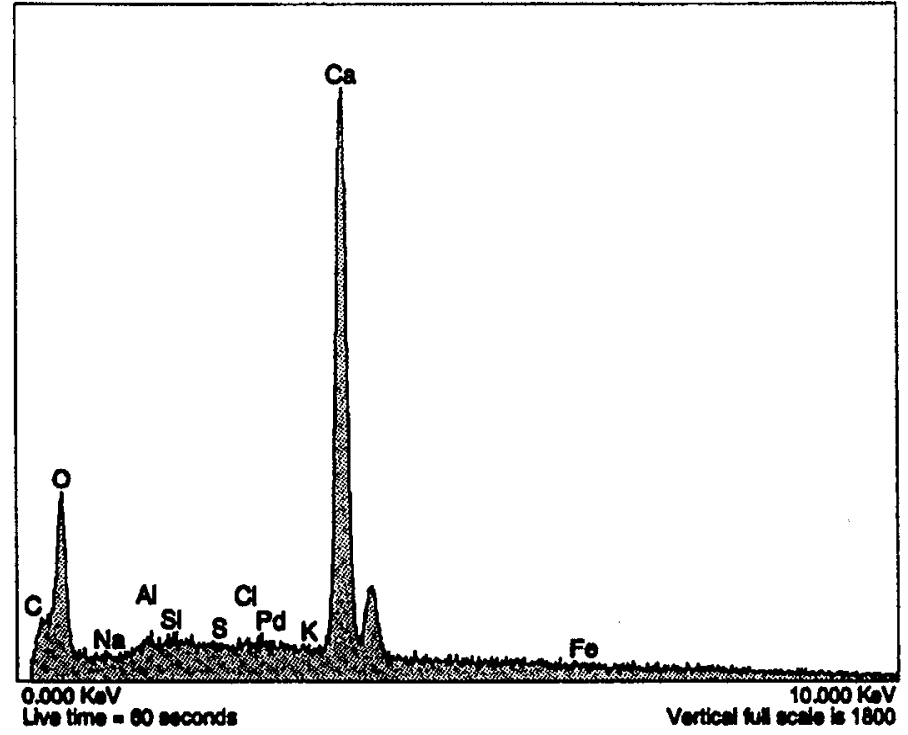

Figure 75. INV-21 (PV-7-21). (a) SEM photomicrograph of three crystalline phases: 1) a larger, faceted phase that appears on both grout and aggregate, 2) a smaller rhombohedral phase that occurs on the aggregate grain, and 3) a platy phase that occurs on grout. The rhombohedral and platy phases are shown at higher magnification in Figure 76. The faceted phase appears to occur more densely on aggregate. (b) EDS of the larger, faceted phase suggests $\mathrm{Ca}, \mathrm{O}$, and $\mathrm{C}$, probably calcite. 
(a)

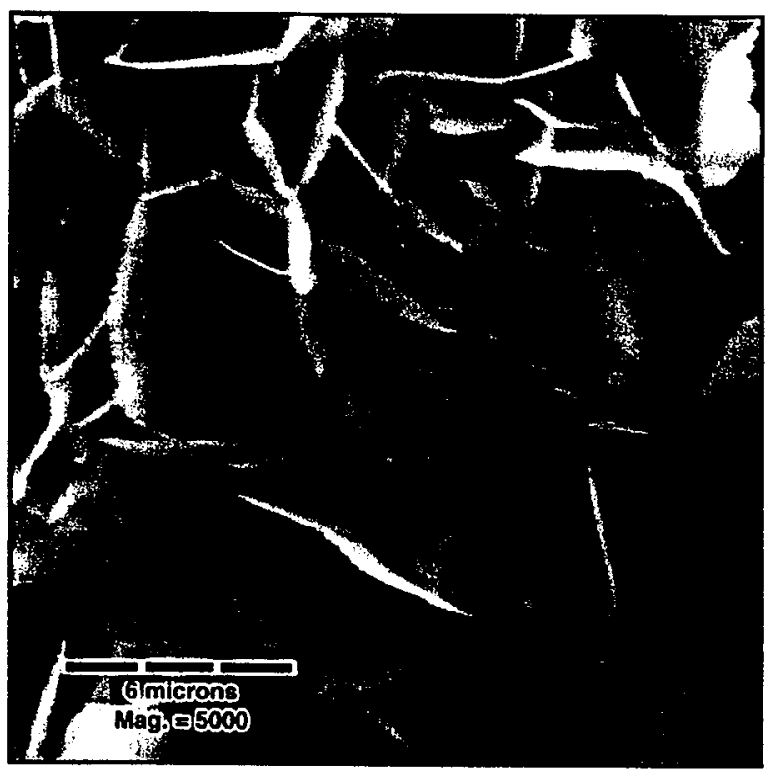

(c)

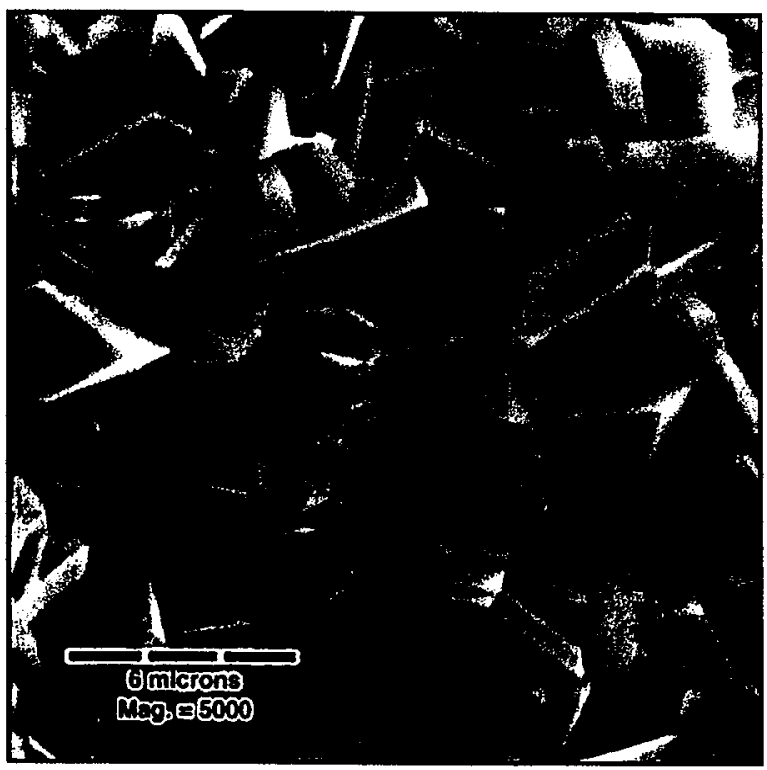

(b)

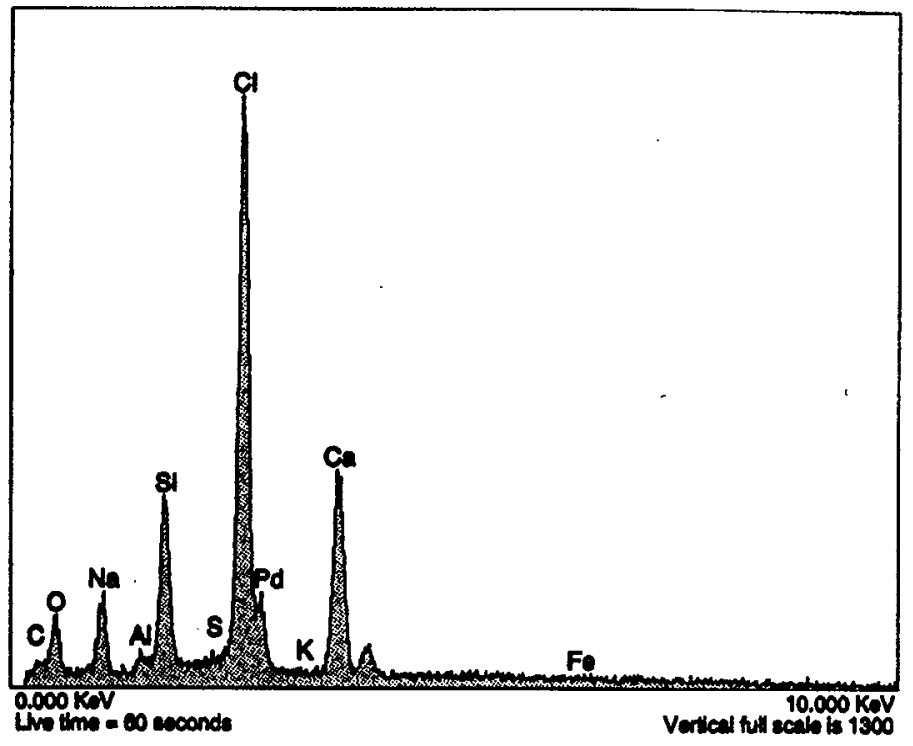

(d)

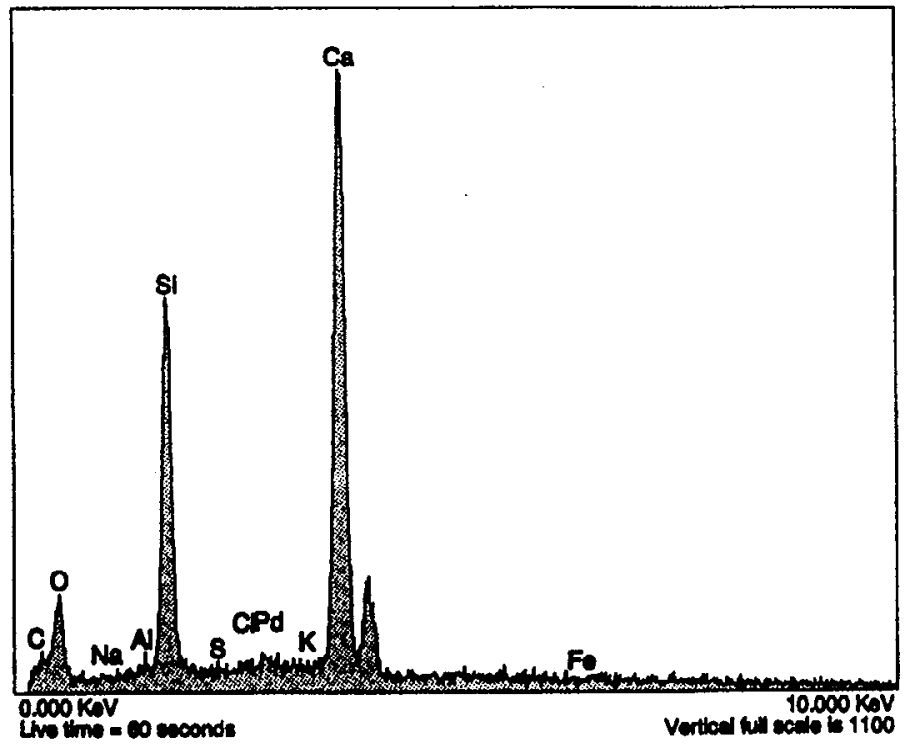

Figure 76. INV-21 (PV-7-21). (a) SEM photomicrograph of the small, platy phase that occurs on grout. Note the serrated edges on the plates. This phase occurs in random orientations, and sometimes is clustered into rosettes. (b) EDS of the platy phase indicates the presence of $\mathrm{Cl}, \mathrm{Ca}, \mathrm{Si}, \mathrm{Na}$, and $\mathrm{O}$. (c) SEM photomicrograph of the smaller, rhombohedral phase that occurs on aggregate. (d) EDS of the rhombohedral phase indicates the presence of $\mathrm{Ca}$, $\mathrm{Si}, \mathrm{O}$, and $\mathrm{C}$. 


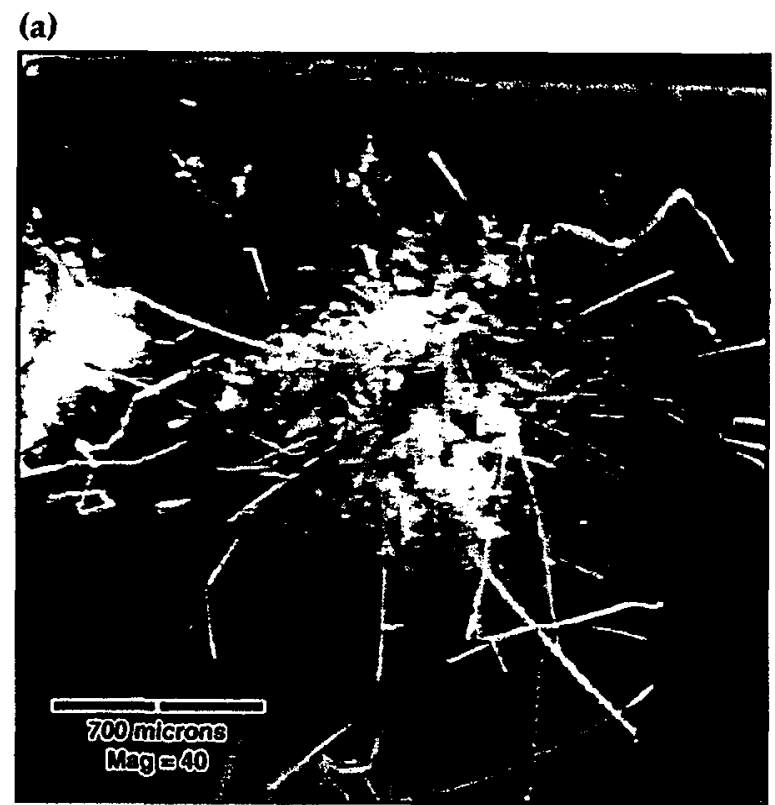

(b)

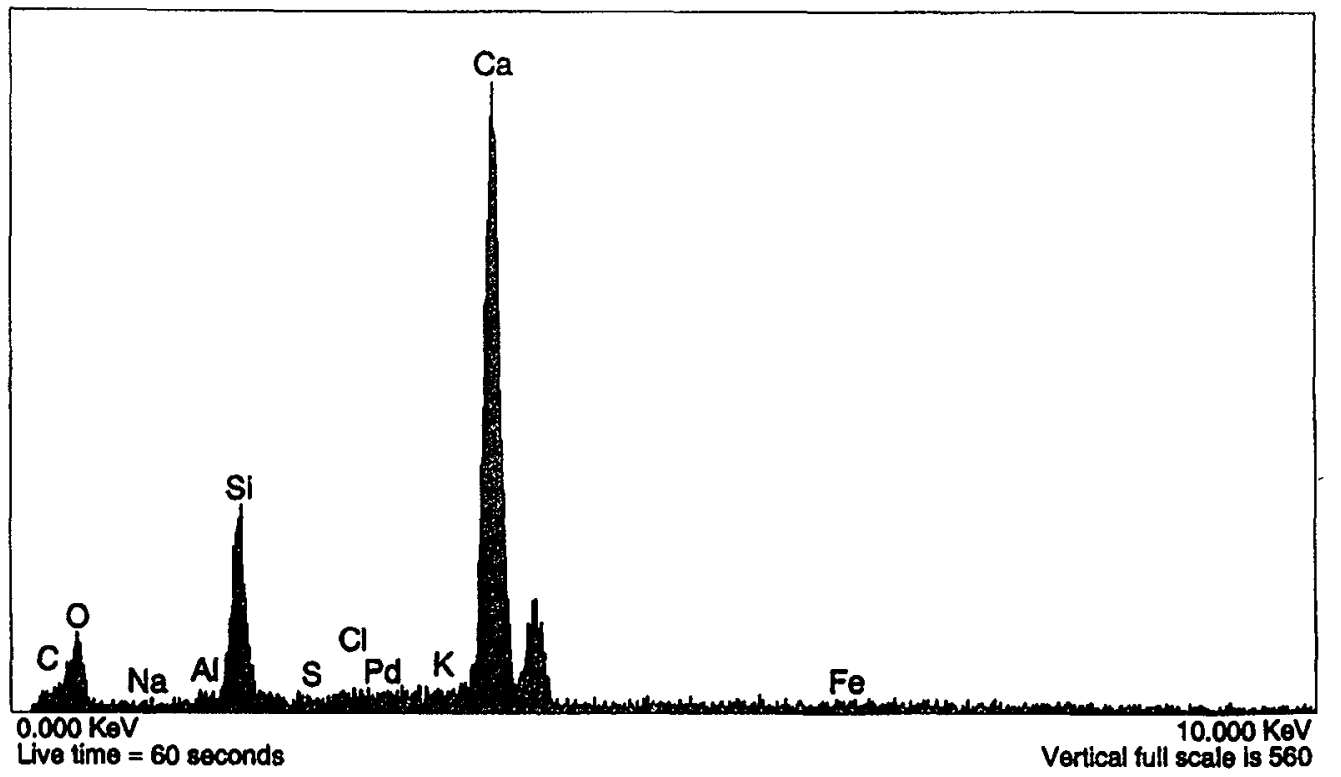

Figure 77. INV-21 (PV-7-21). (a) SEM photomicrograph of a crystal cluster on an aggregate grain. At higher magnification, cubic crystals are visible in the center of the cluster. (b) EDS of the cluster center suggests $\mathrm{Ca}$, $\mathrm{Si}$, and $\mathrm{O}$. 
(a)

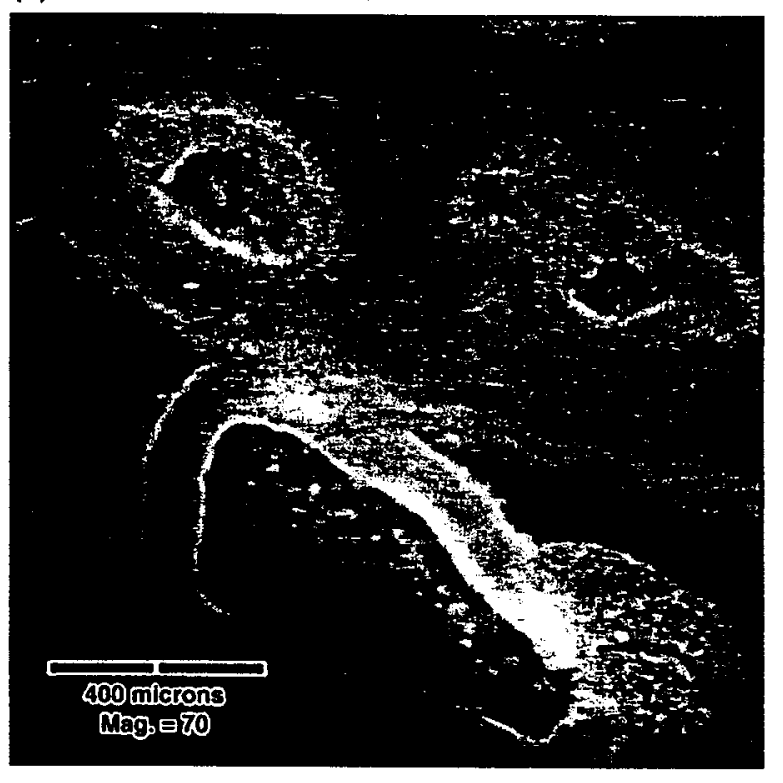

(c)

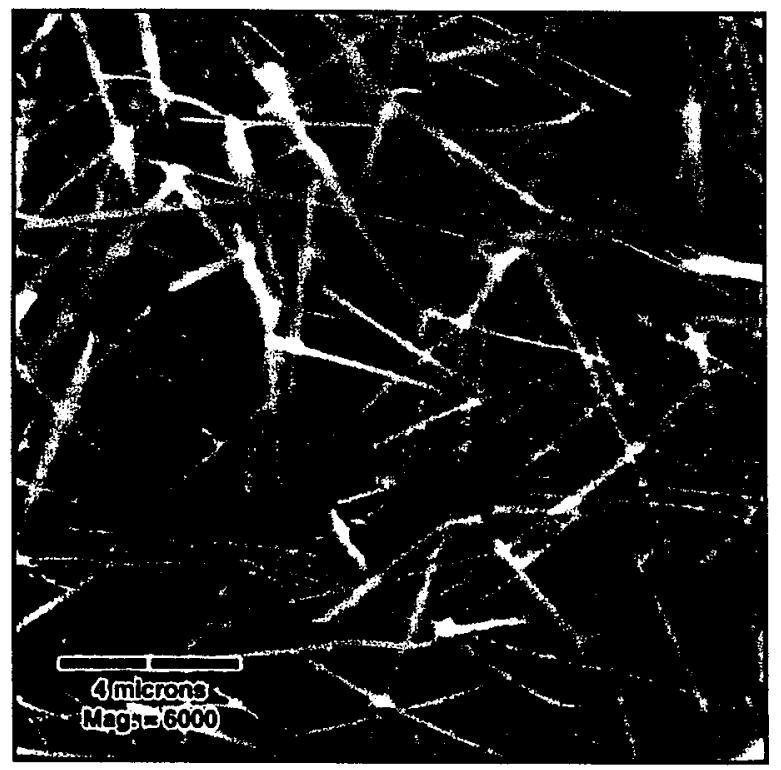

(b)

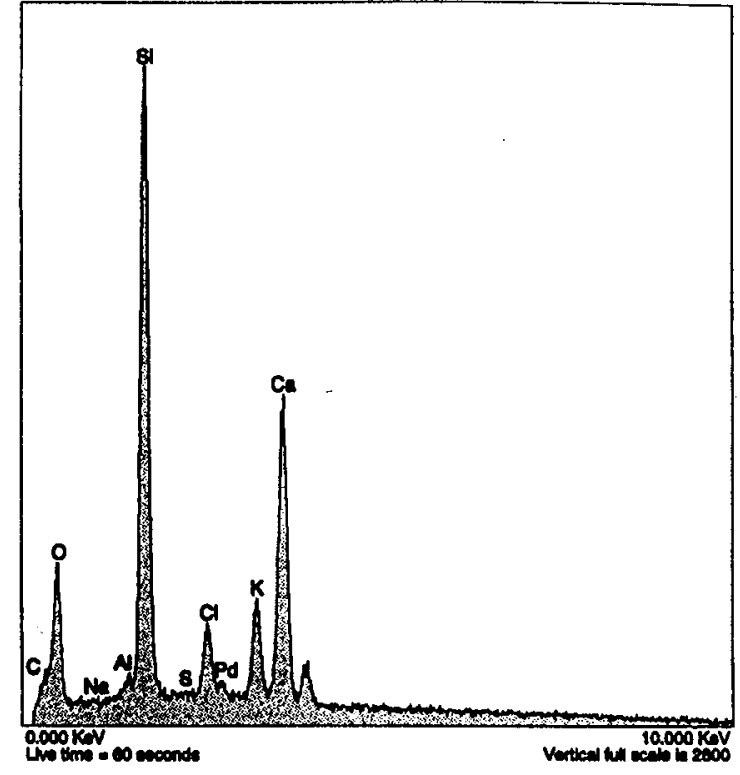

(d)

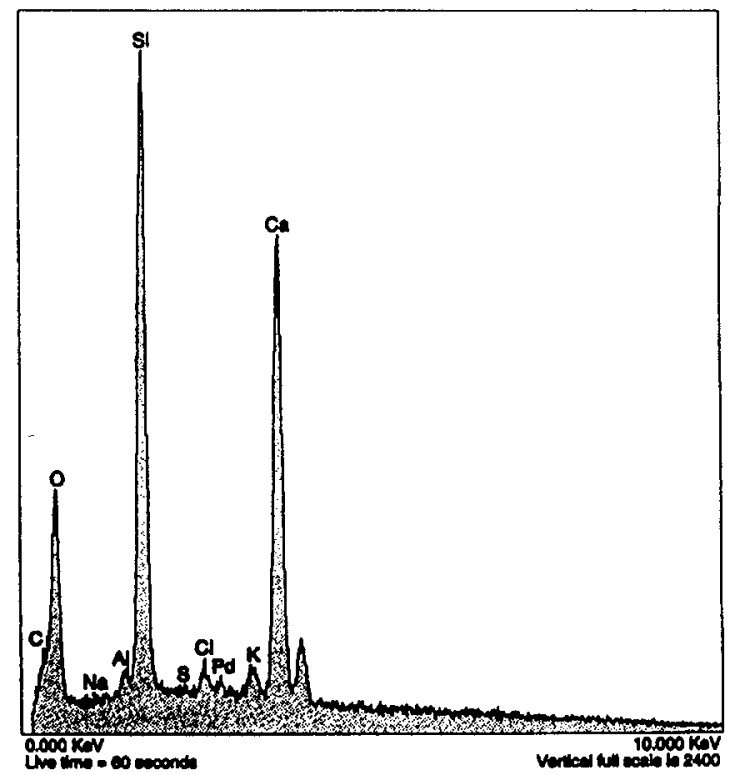

Figure 78. INV-36 (PV-7-36). (a) SEM photomicrograph of rims within and around an aggregate grain. The upper portion of the photo is a large aggregate grain with two faint rings within it, and a ring on the grain edge. The lower portion of the photo is grout, with a small aggregate grain surrounded by a thick ring. (b) EDS of the ring around the small aggregate grain suggests $\mathrm{Si}, \mathrm{Ca}, \mathrm{O}, \mathrm{K}$, and $\mathrm{Cl}$. EDS of the small grain center (not shown) suggests a quartz composition. (c) SEM photomicrograph of the ring at higher magnification. (d) EDS of one of the two faint rings within the large aggregate grain. 
(a)

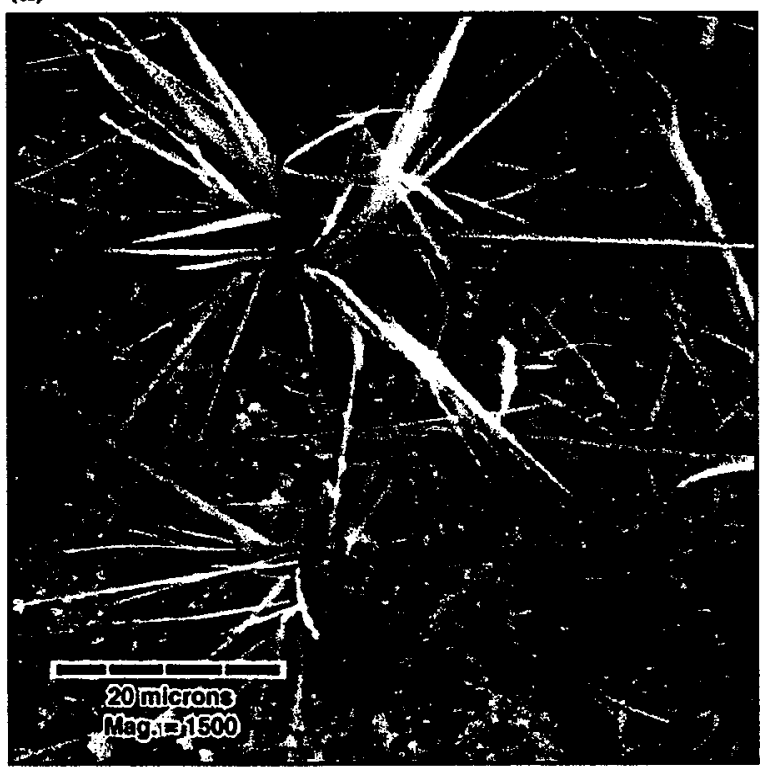

(b)

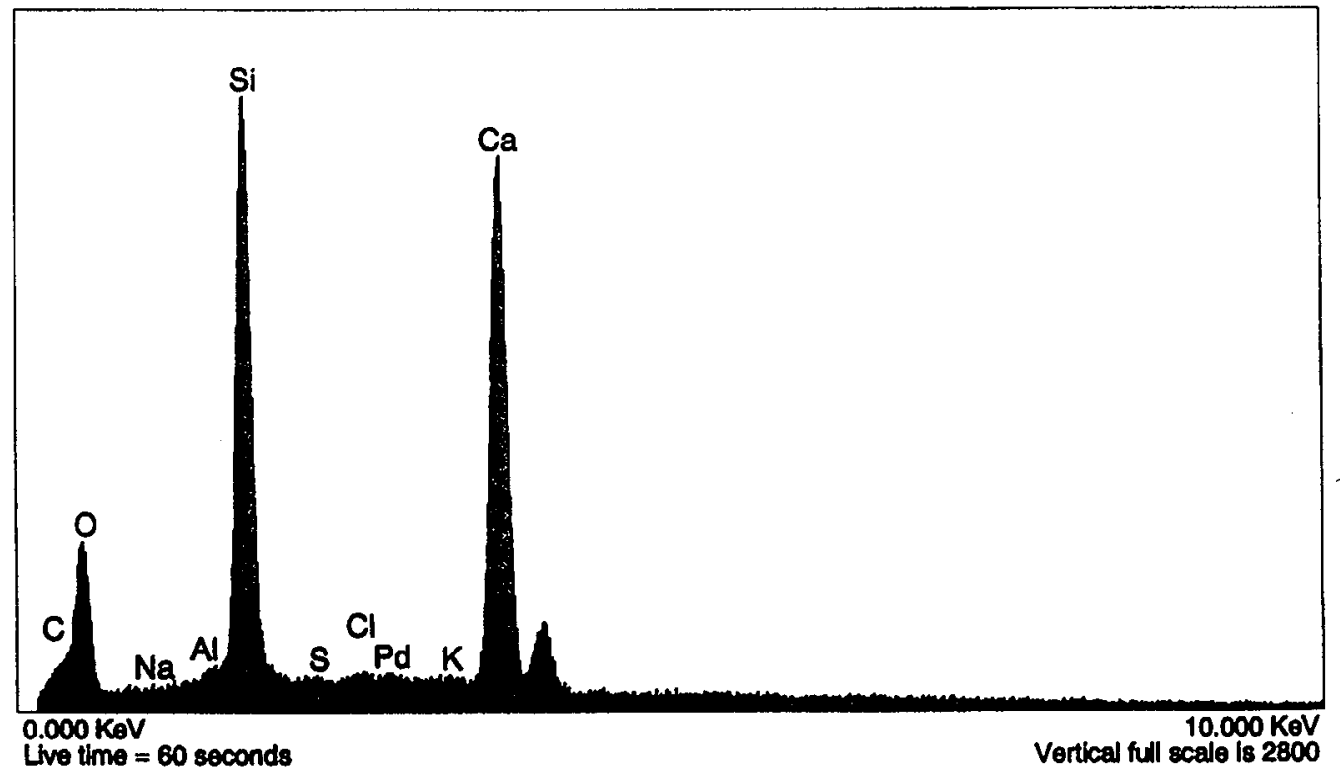

Figure 79. INV-36 (PV-7-36). (a) SEM photomicrograph of tiny crystal clusters with radiating spines that occur on aggregate. (b) EDS suggests $\mathrm{Si}, \mathrm{Ca}$, and $\mathrm{O}$. 
(c)

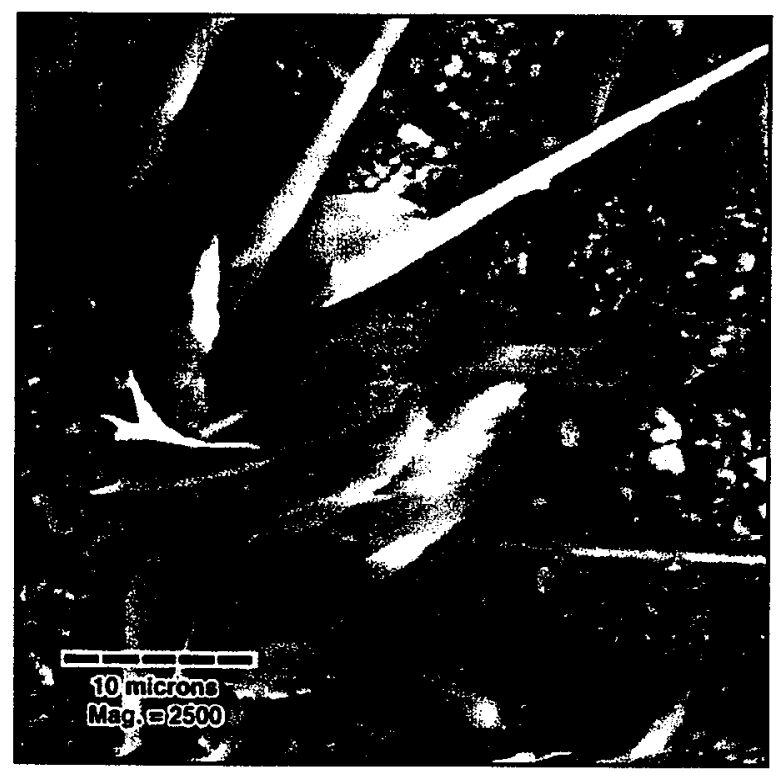

(d)

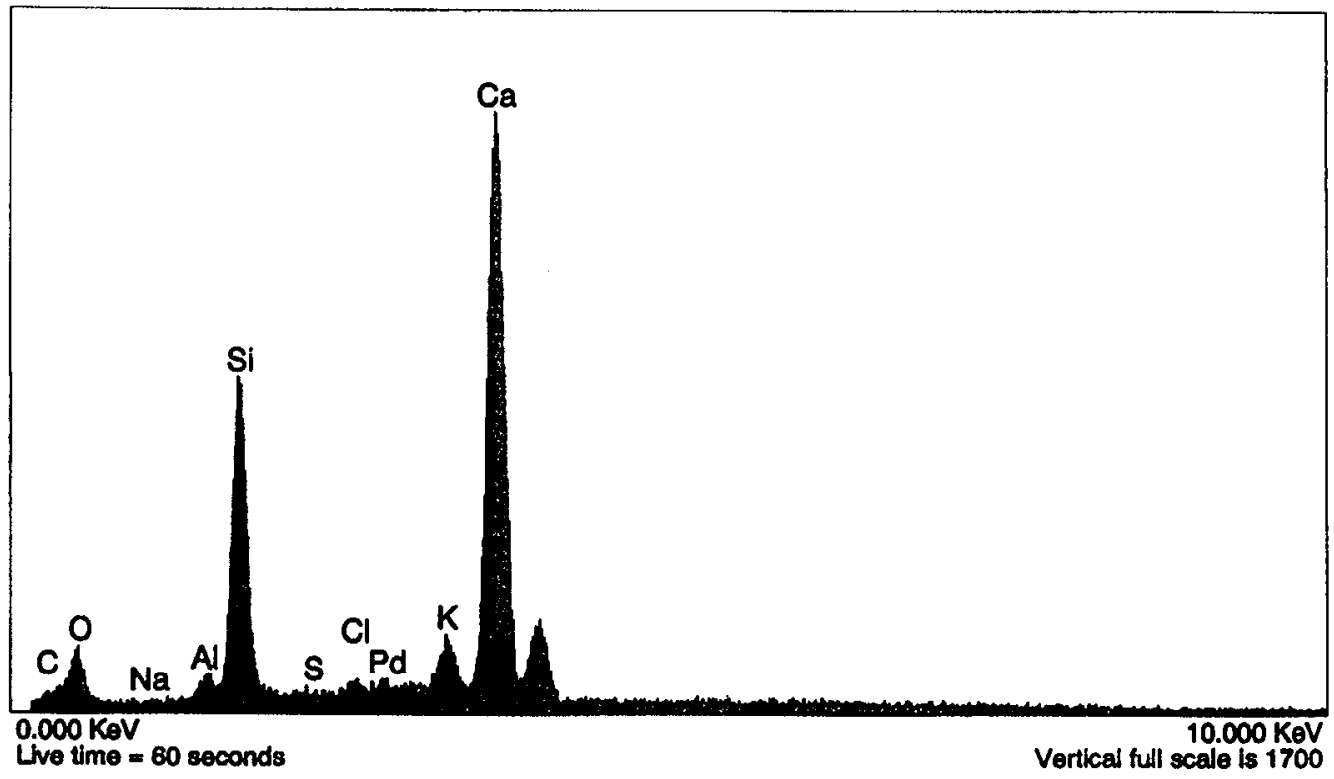

Figure 79 (continued). INV-36 (PV-7-36). (c) SEM photomicrograph of platy crystals that occur on a boundary between aggregate and grout. Note the serrated edges of the plates. (d) EDS suggests $\mathrm{Ca}, \mathrm{Si}, \mathrm{O}$, and K. EDS of the aggregate grain center (not shown) indicates a calcite composition. 
(a)

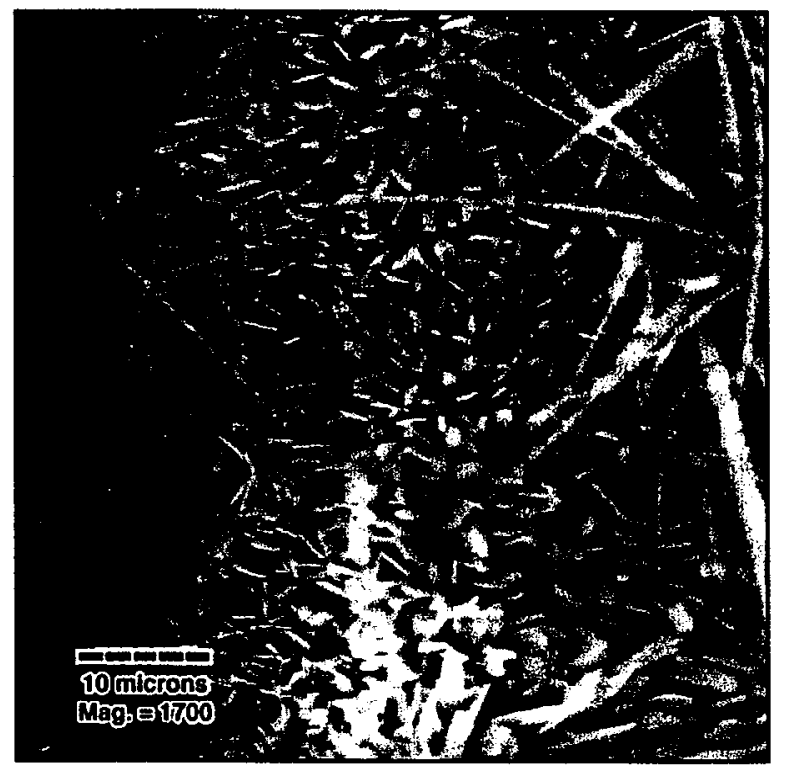

(b)

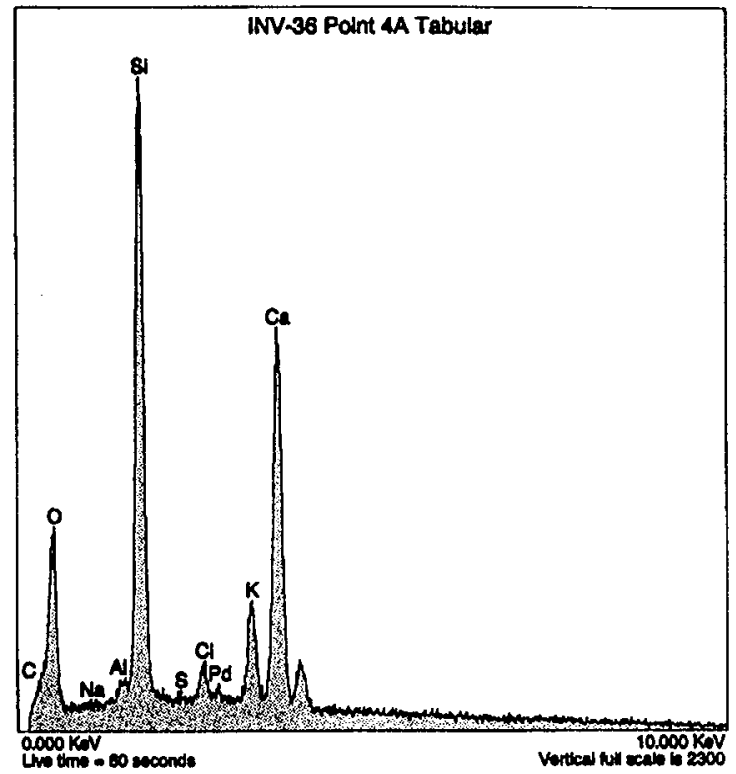

Figure 80. INV-36 (PV-7-36). (a) SEM photomicrograph of two phases that occur between an aggregate grain and grout. The outermost phase (with respect to the grain) is platy with serrated edges. Inboard of that is a mat of long, thin, straight crystals. (b) EDS of the platy crystals suggests $\mathrm{Si}, \mathrm{Ca}, \mathrm{O}, \mathrm{K}$, and $\mathrm{Cl}$. 


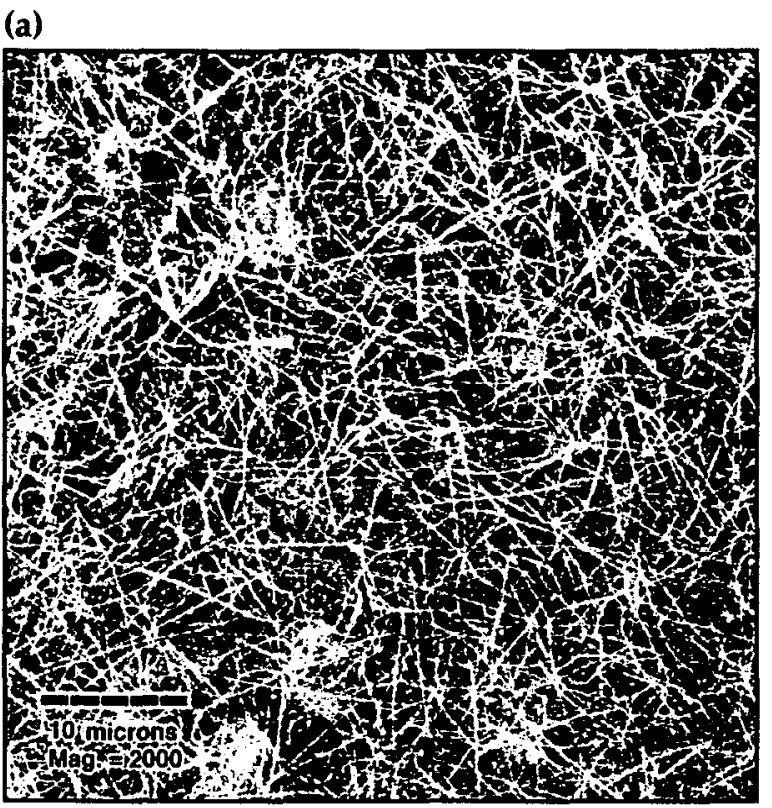

(b)

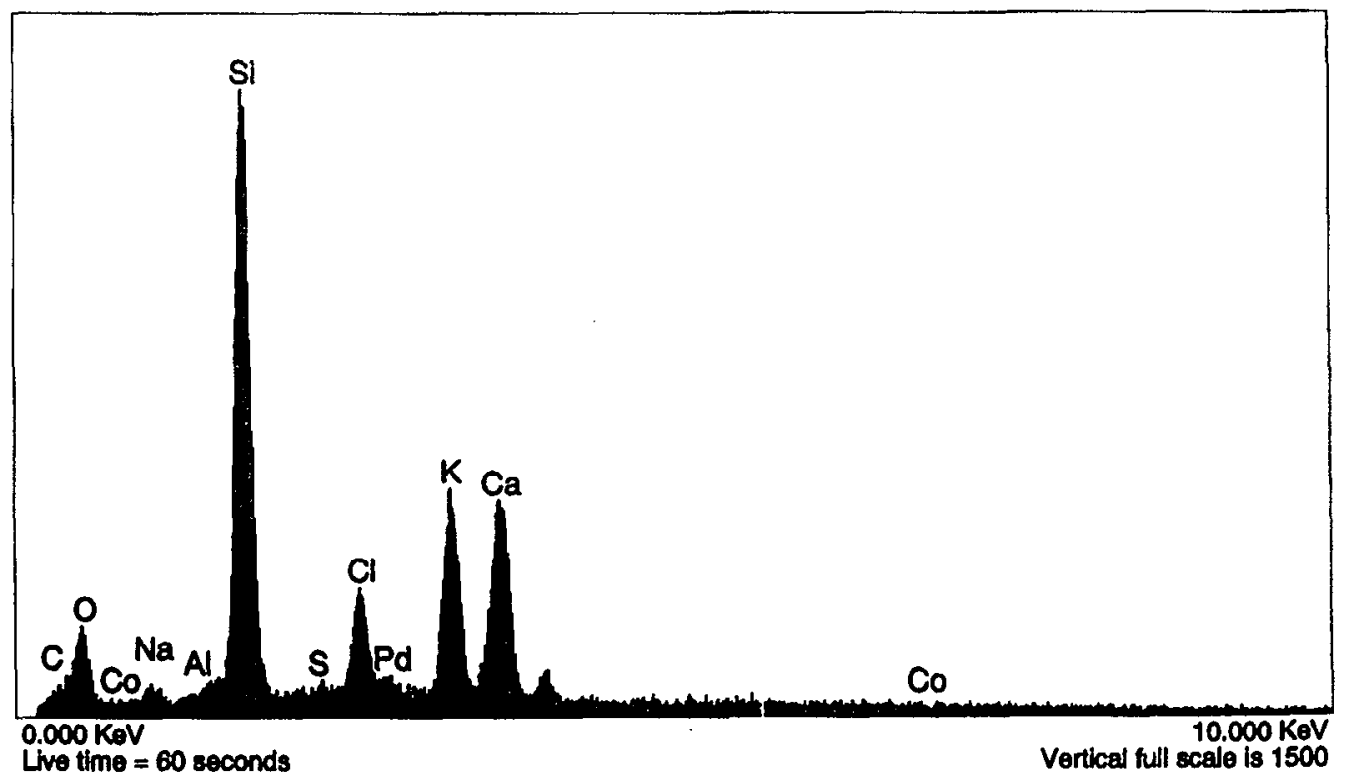

Figure 81. INV-36 (PV-7-36). (a) SEM photomicrograph of a mat of thin, curly fibrous crystals that coat the interior of the aggregate grain. (b) EDS of the mat of crystals suggests $\mathrm{Si}, \mathrm{K}, \mathrm{Ca}, \mathrm{Cl}$, and $\mathrm{O}$. 
(a)

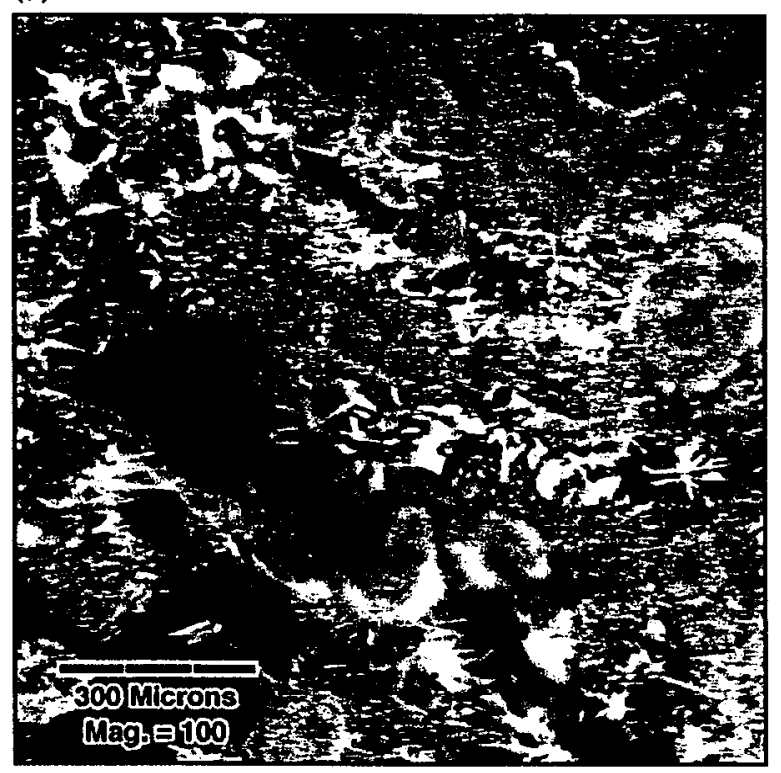

(b)

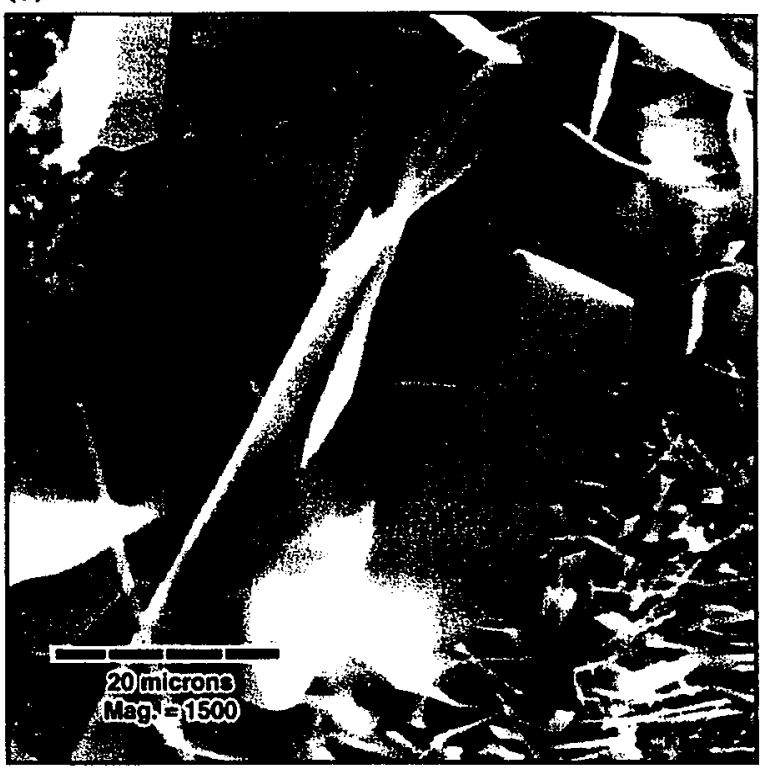

(c)

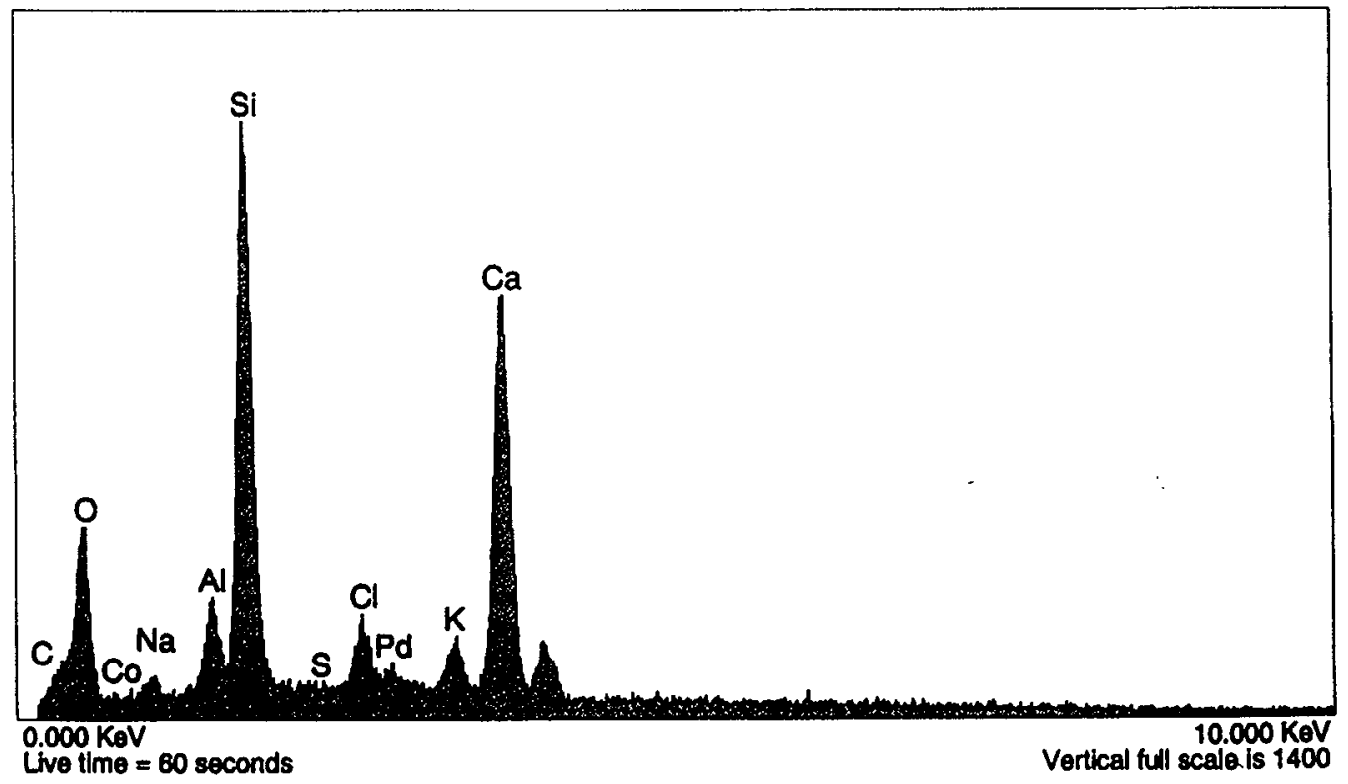

Figure 82. SH-13 (PV-7-13). (a) SEM photomicrograph of the surface of the sample at relatively low magnification. Several morphologies of crystals are visible, including ribbon-shaped, tabular, needle-shaped, and fibrous. (b) SEM photomicrograph of a ribbon-shaped phase on grout or very fine aggregate. (c) EDS of the ribbon-shaped phase suggests $\mathrm{Si}, \mathrm{Ca}, \mathrm{O}, \mathrm{Cl}$, and $\mathrm{Al}$. 
(a)

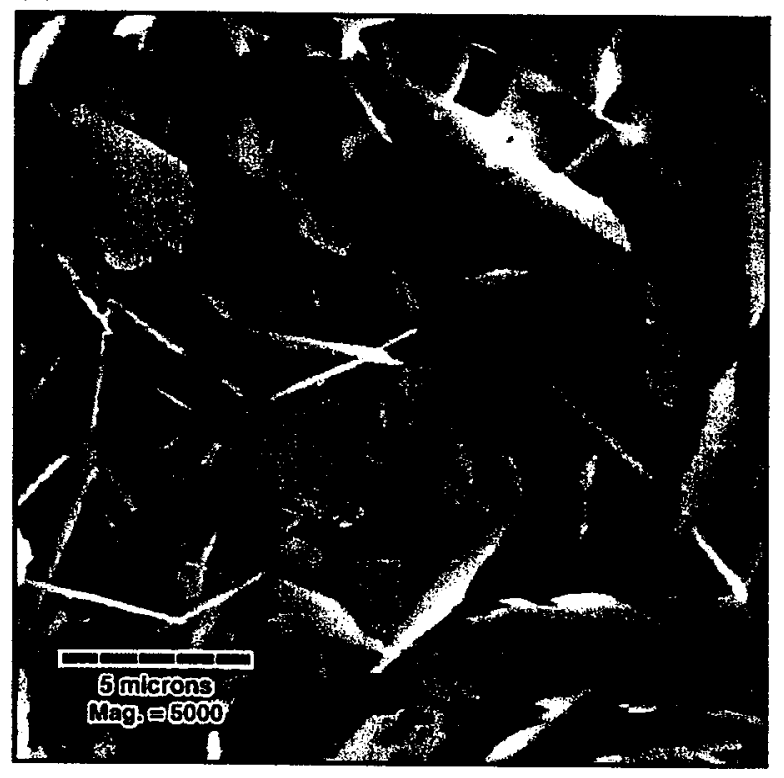

(c)

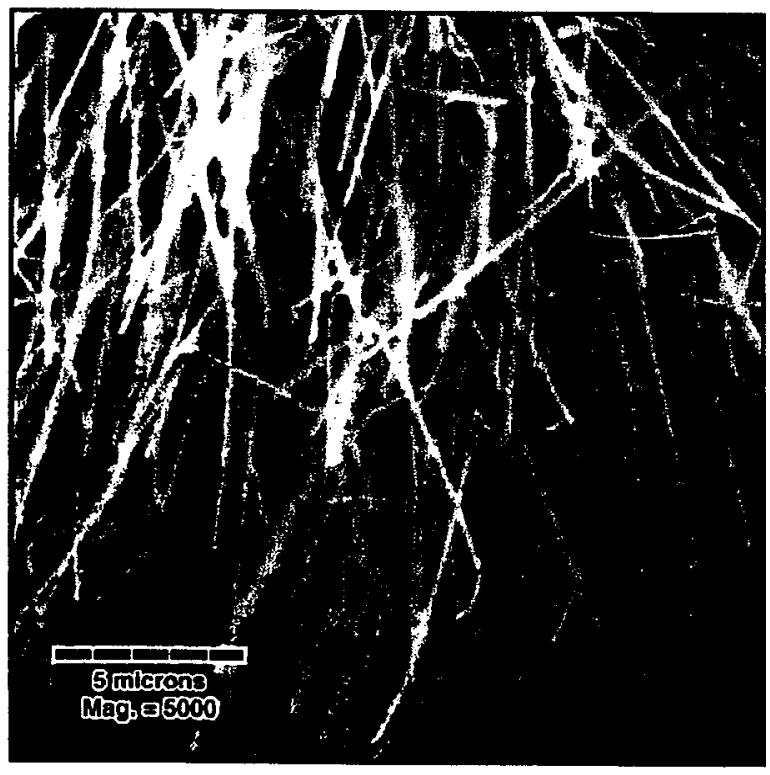

(b)

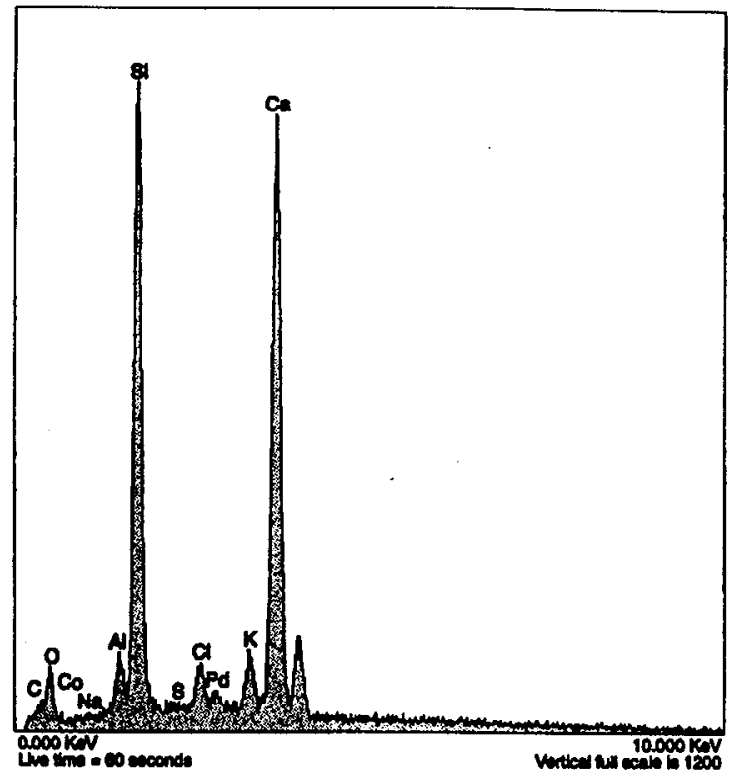

(d)

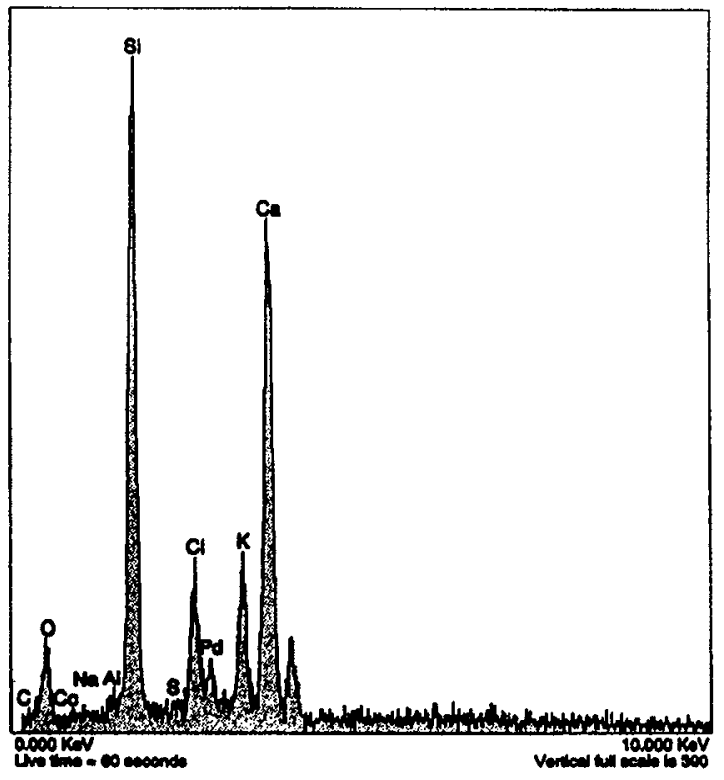

Figure 83. SH-13 (PV-7-13). (a) SEM photomicrograph of tabular crystals with serrated tips. These crystals are part of a larger cluster, not part of a distinctive ring around a grain. (b) EDS suggests $\mathrm{Si}, \mathrm{Ca}, \mathrm{Al}, \mathrm{Cl}, \mathrm{K}$, and $\mathrm{O}$. (c) SEM photomicrograph of a mat of thin, straight, long crystals that occur within the same cluster of crystals as those in (a). (d) EDS suggests $\mathrm{Si}, \mathrm{Ca}, \mathrm{K}, \mathrm{Cl}$, and $\mathrm{O}$. 


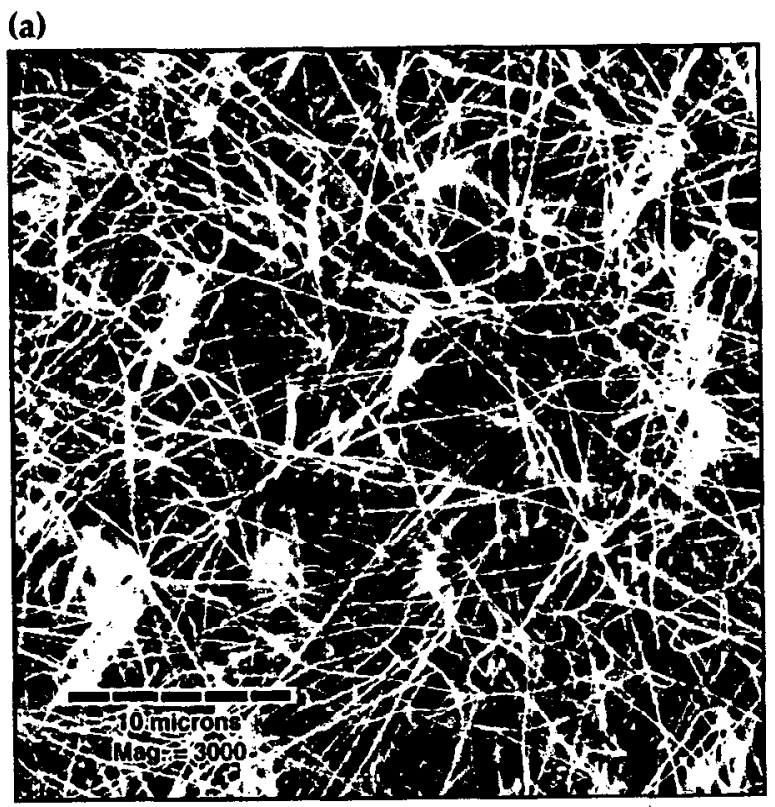

(b)

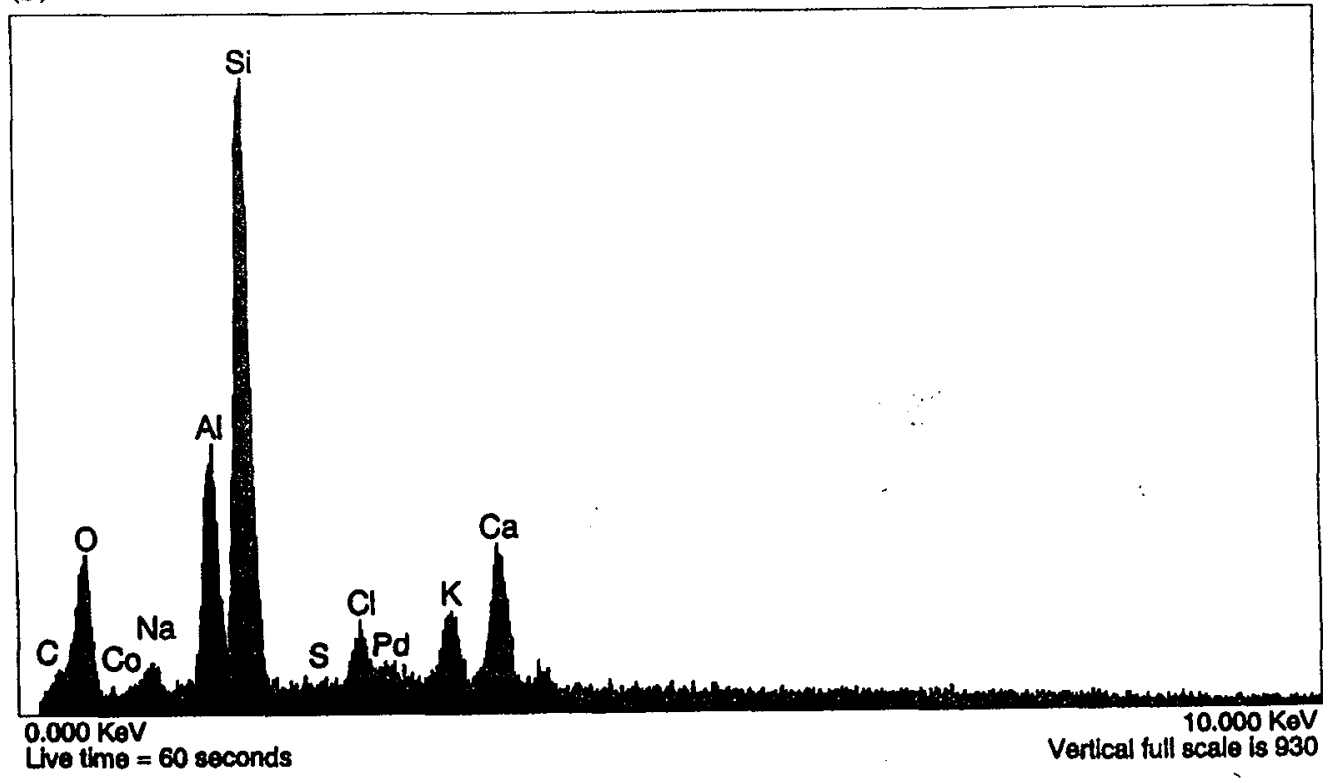

Figure 84. SH-13 (PV-7-13). (a) SEM photomicrograph of a fibrous mass of crystals that cover the interior of an aggregate grain. (b) EDS suggests $\mathrm{Si}, \mathrm{Al}, \mathrm{Ca}, \mathrm{O}, \mathrm{K}$, and $\mathrm{Cl}$. 
(c)

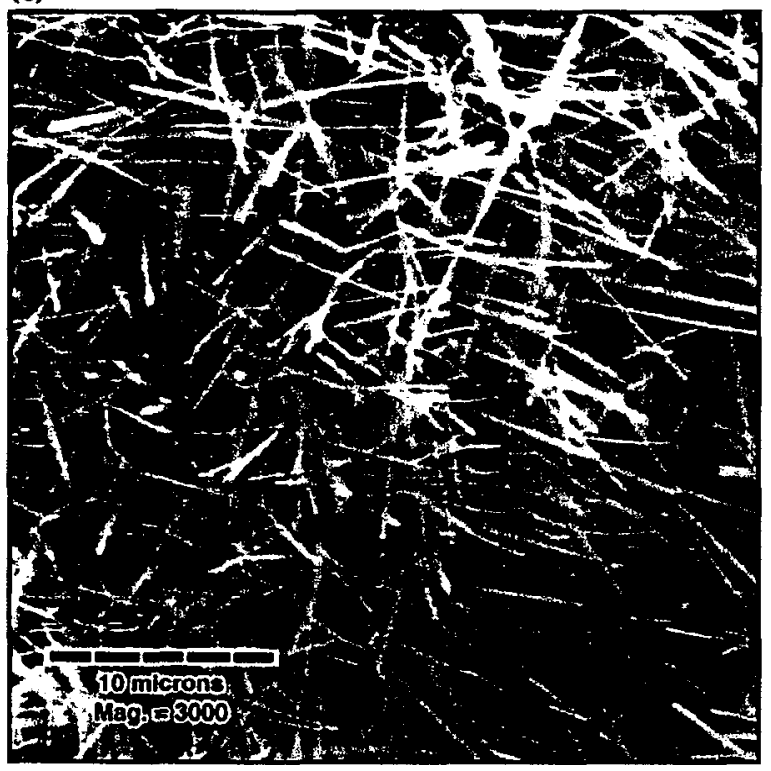

(d)

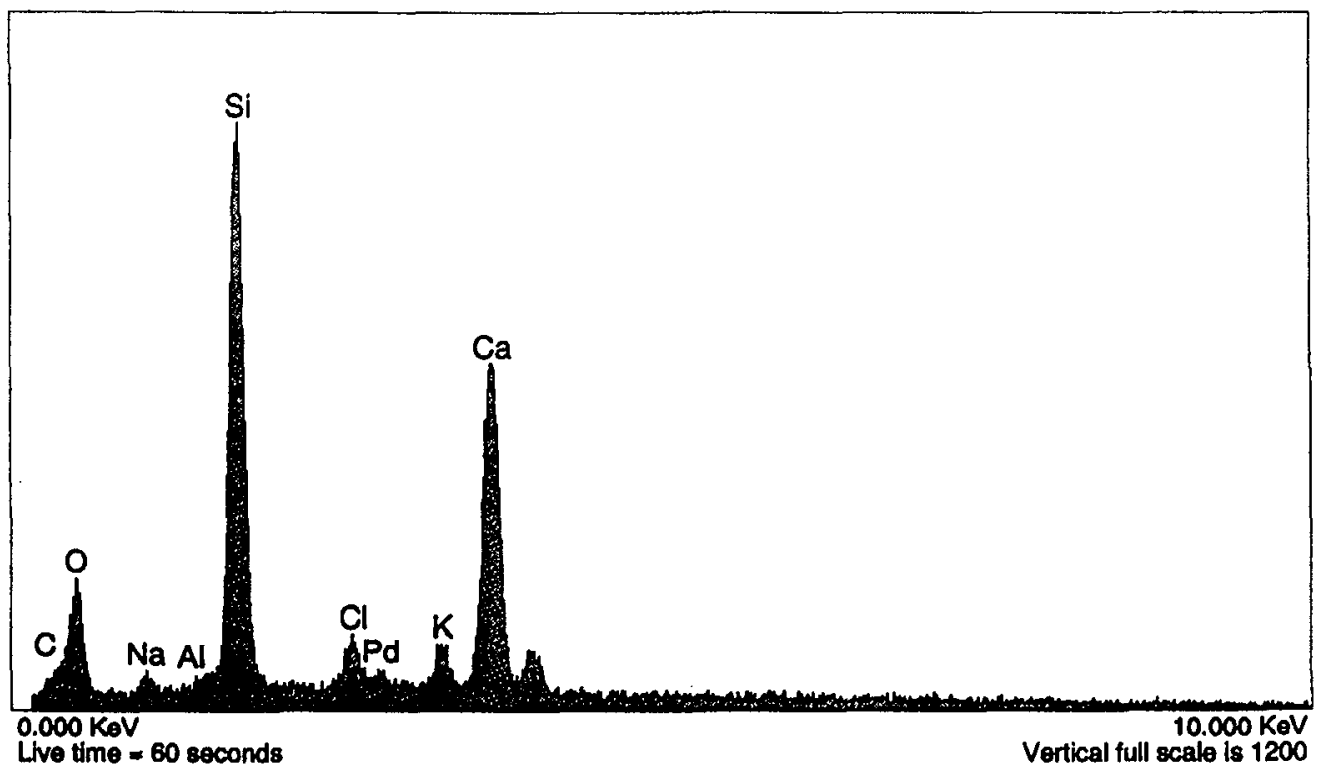

Figure 84 (continued). SH-13 (PV-7-13). (c) SEM photomicrograph of needle-shaped crystals that form a thick ring around an aggregate grain. This phase also forms mounds, with no aggregate grain visible (it could be small and obscured by the thick ring). (d) EDS of the needle-shaped crystals suggests $\mathrm{Si}, \mathrm{Ca}, \mathrm{O}, \mathrm{Cl}$, and $\mathrm{K}$. 
(a)

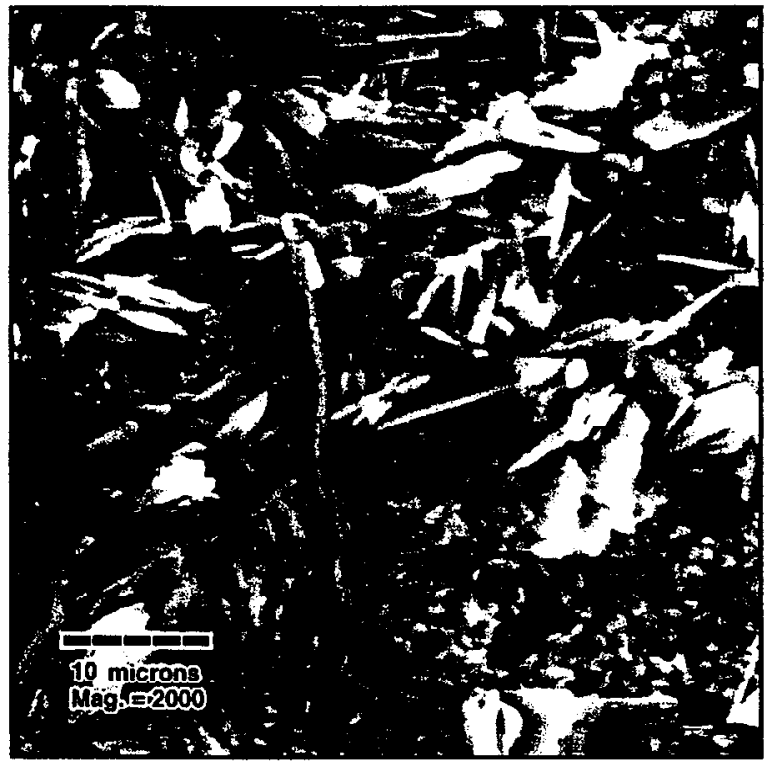

(b)

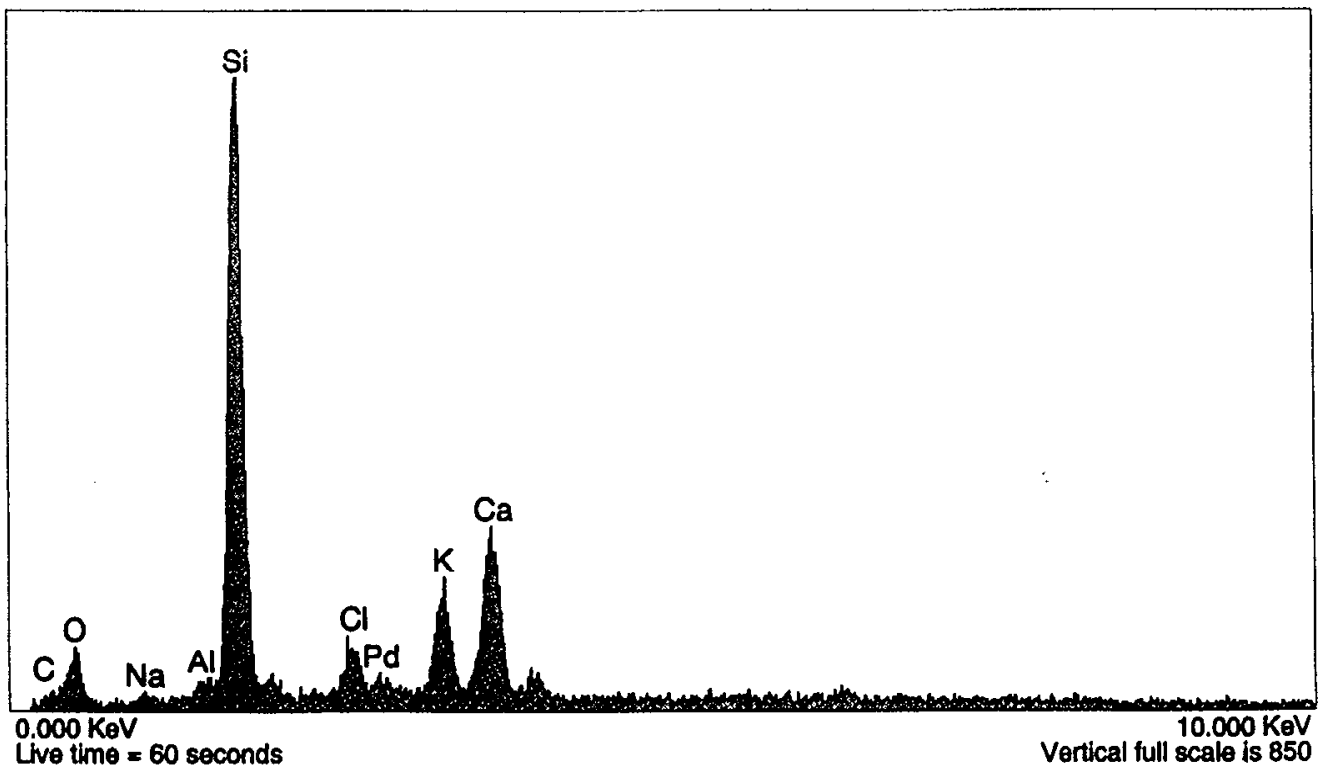

Figure 85. SH-13 (PV-7-13). (a) SEM photomicrograph of jagged, tabular crystals that occur on the surface of an aggregate grain. (b) EDS of the tabular phase suggests $\mathrm{Si}, \mathrm{Ca}, \mathrm{K}, \mathrm{Cl}$, and $\mathrm{O}$. EDS of the aggregate grain (not shown) indicates a quartz composition. 
(c)

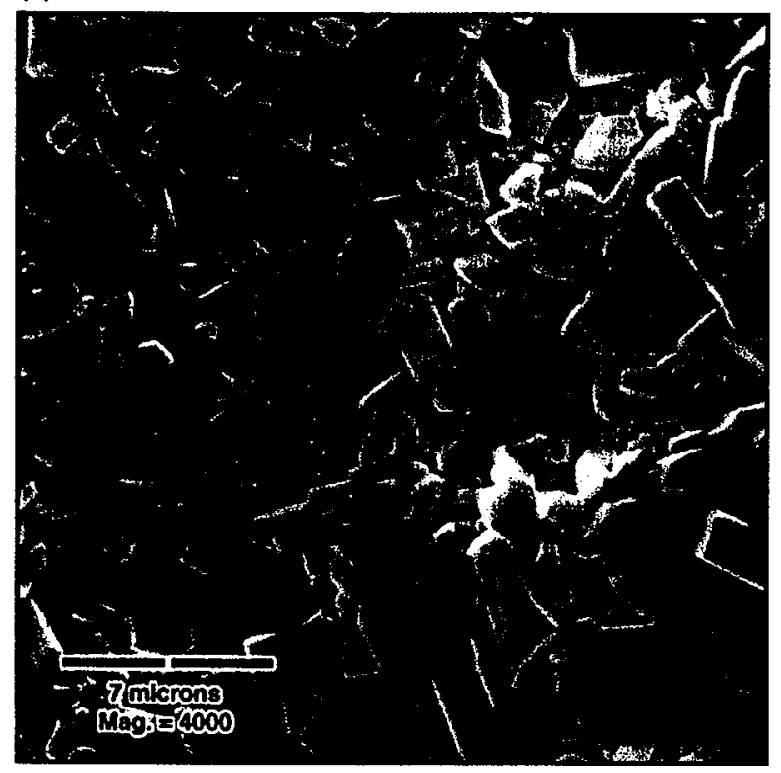

(d)

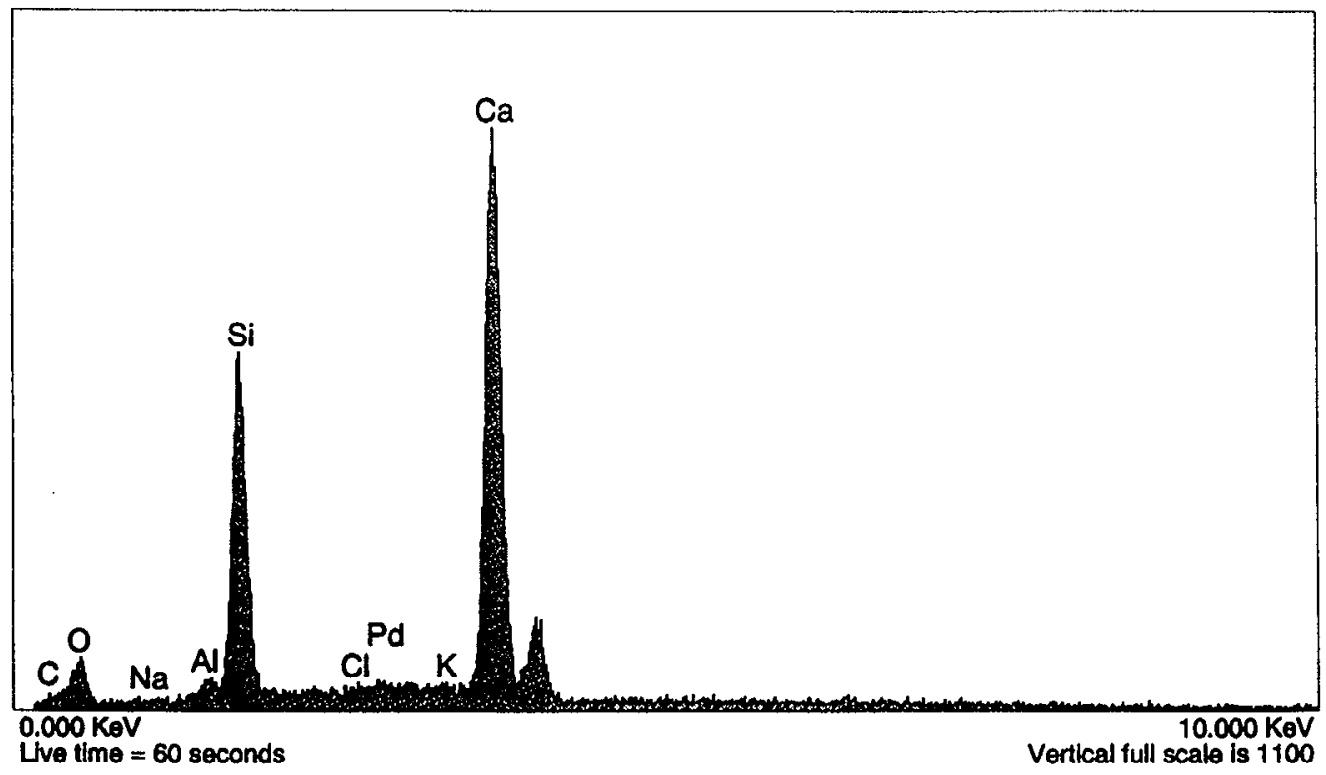

Figure 85 (continued). SH-13 (PV-7-13). (c) SEM photomicrograph of tiny rhombs on the surface of an aggregate grain. The grain is rimmed by a thick needle-shaped phase. (d) EDS suggests $\mathrm{Ca}$, $\mathrm{Si}$, and $\mathrm{O}$. It is possible that the thick phase on the rim absorbs the $\mathrm{C}$ and $\mathrm{O}$ signal. 
(a)

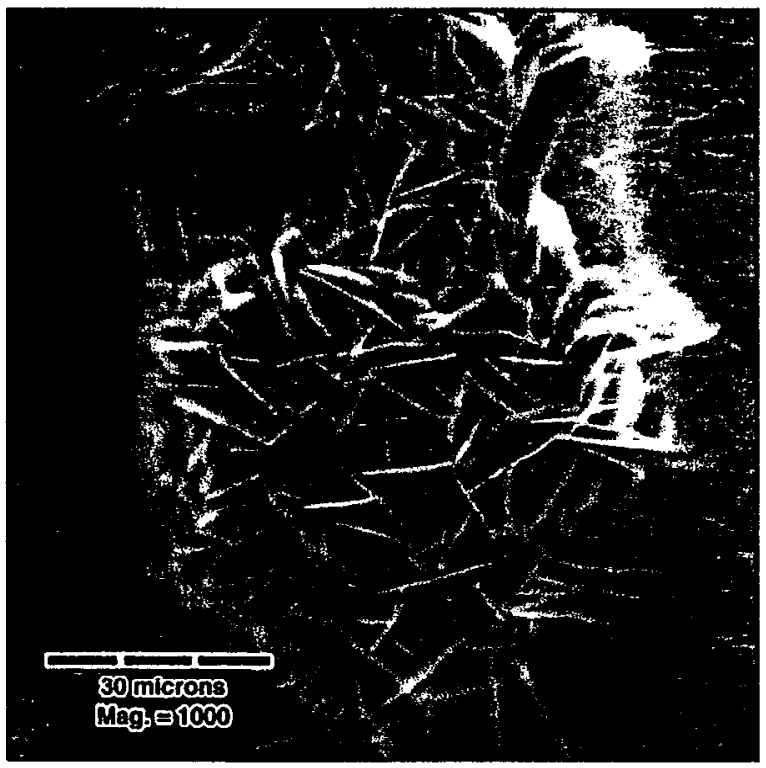

(b)

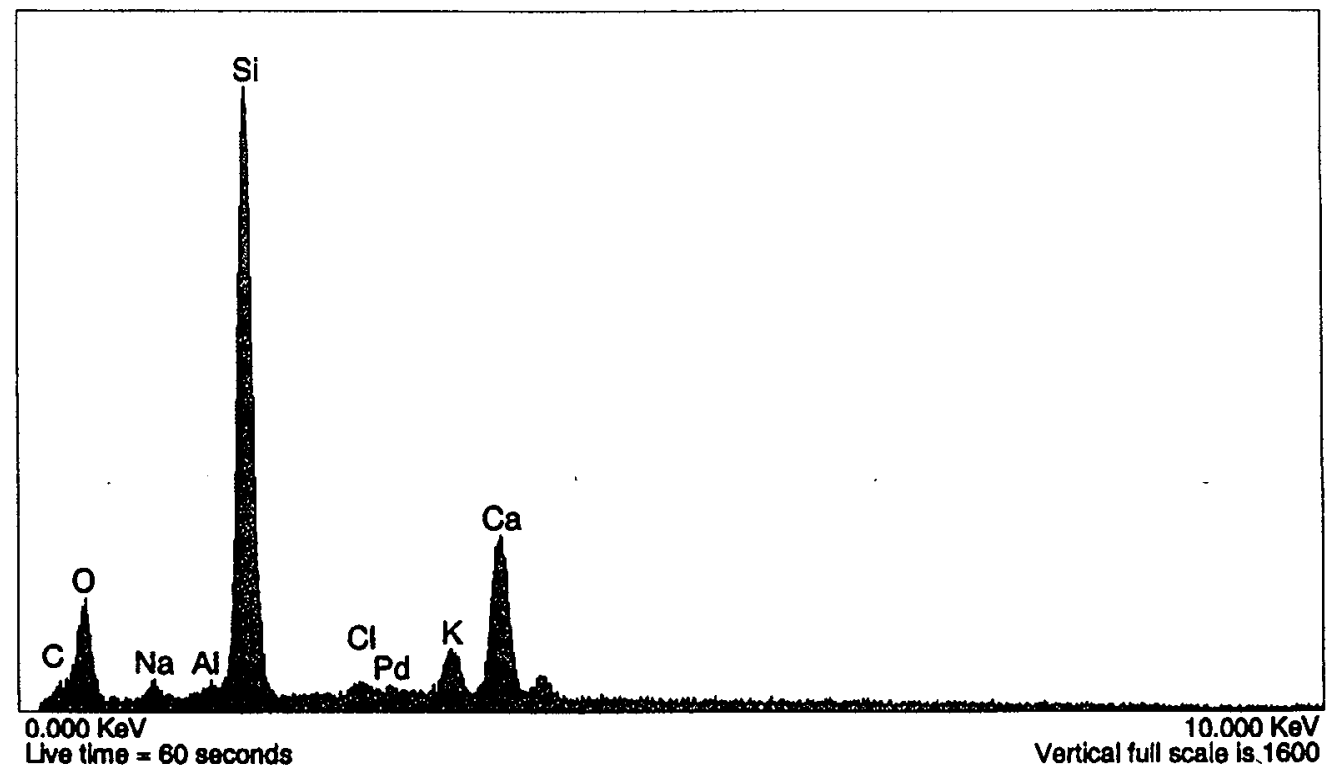

Figure 86. SH-13 (PV-7-13). (a) SEM photomicrograph of a rosette cluster of platy crystals. (b) EDS suggests $\mathrm{Si}$, $\mathrm{Ca}, \mathrm{O}$, and $\mathrm{K}$. 


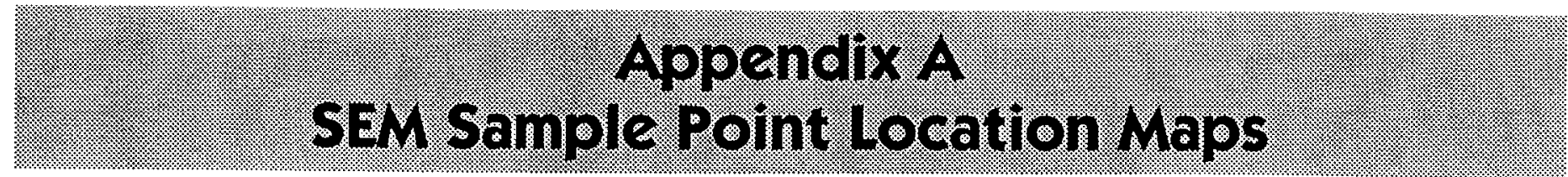

This appendix contains schematic drawings showing points analyzed with SEM and EDS. Each sample point identifies the corresponding figure referred to in the text and contained in Section 7 of this report. Drawings are provided in the following order:

- Sample INV-37

- Sample SH-9

- Sample INV-23a, side 1

- Sample INV-23a, side 2

- Sample INV-23b

- Sample SH-10

- Sample INV-21

- Sample INV-36

- Sample SH-13

No drawing is provided for sample INV-38. 
Hydrothermal Alteration of Cementitious Materials

SEM and EDS analysis points

Sample \# INV-37

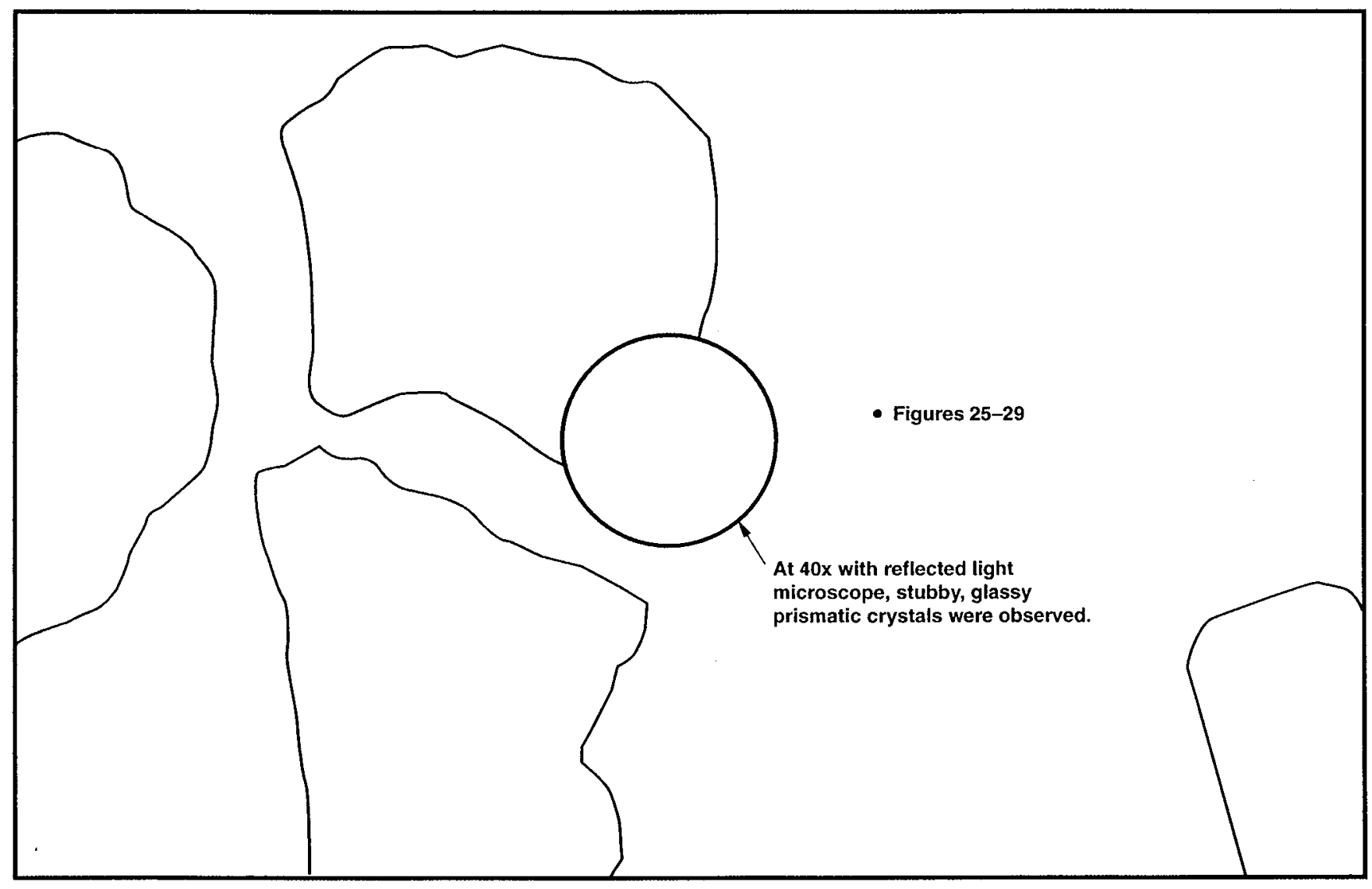


SEM and EDS analysis points Sample \# SH-9

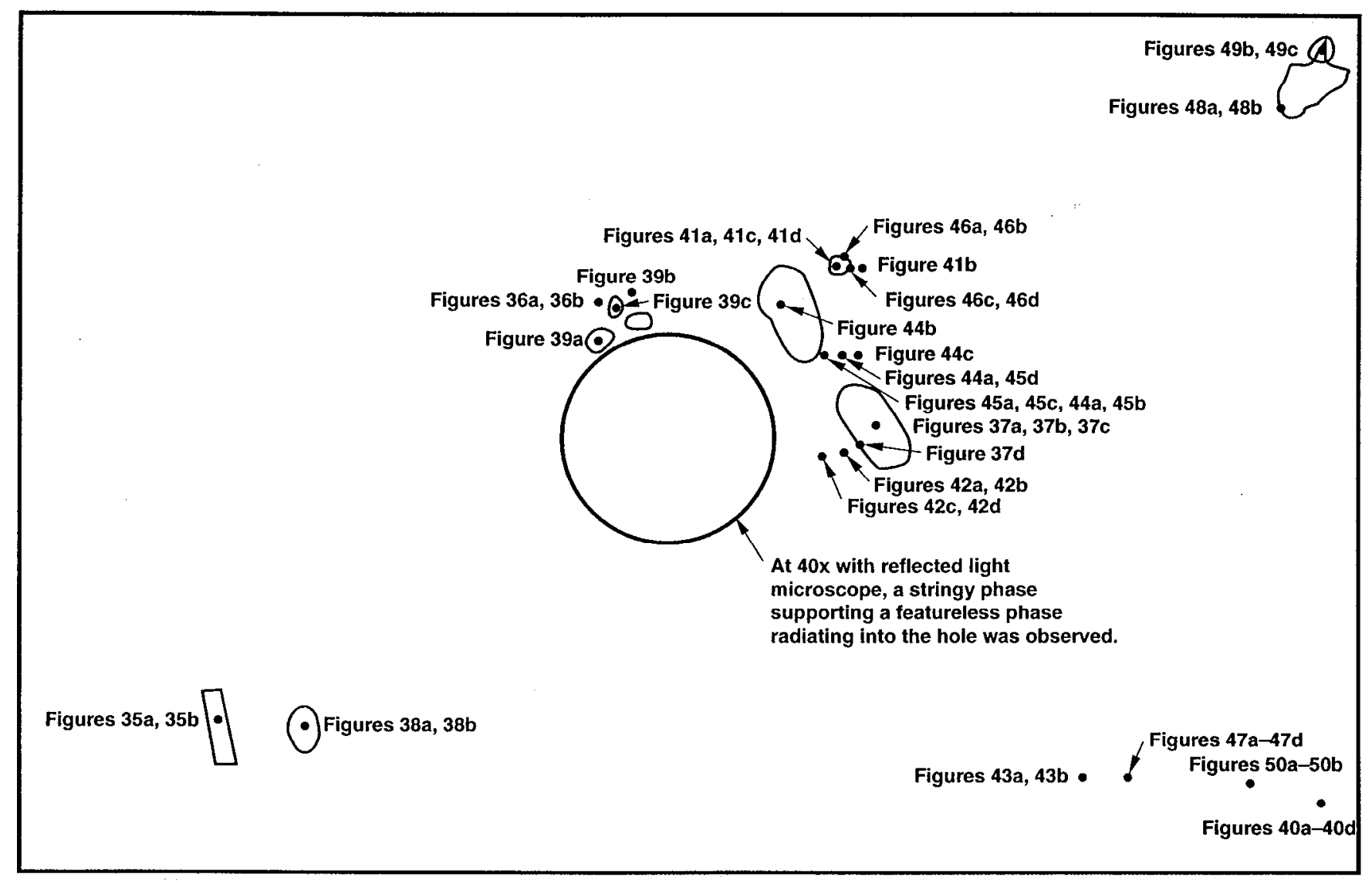


Hydrothermal Alteration of Cementitious materials

SEM and EDS analysis points

Sample \# INV-23a side 1

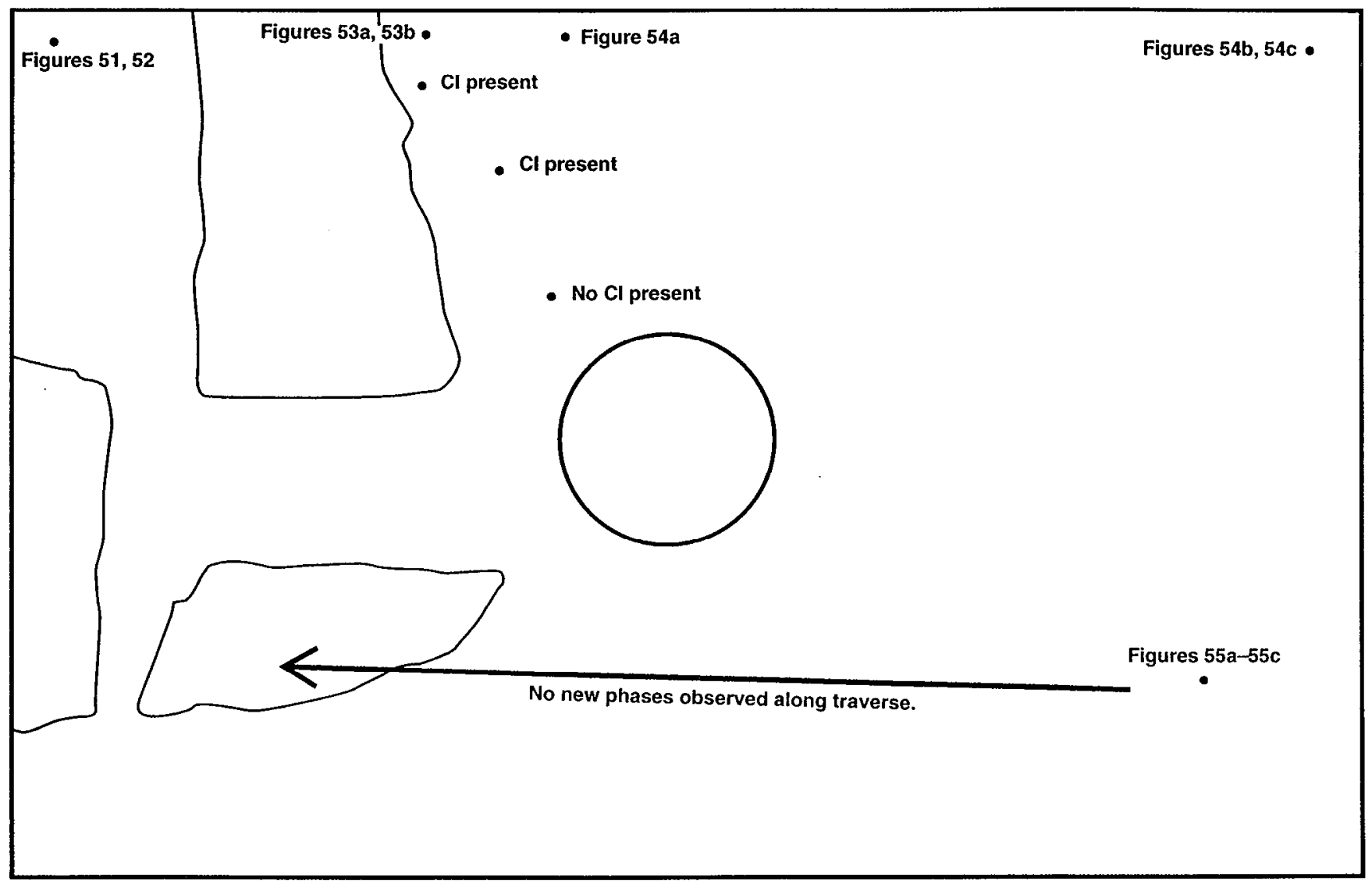

$\dot{A}-4$ 


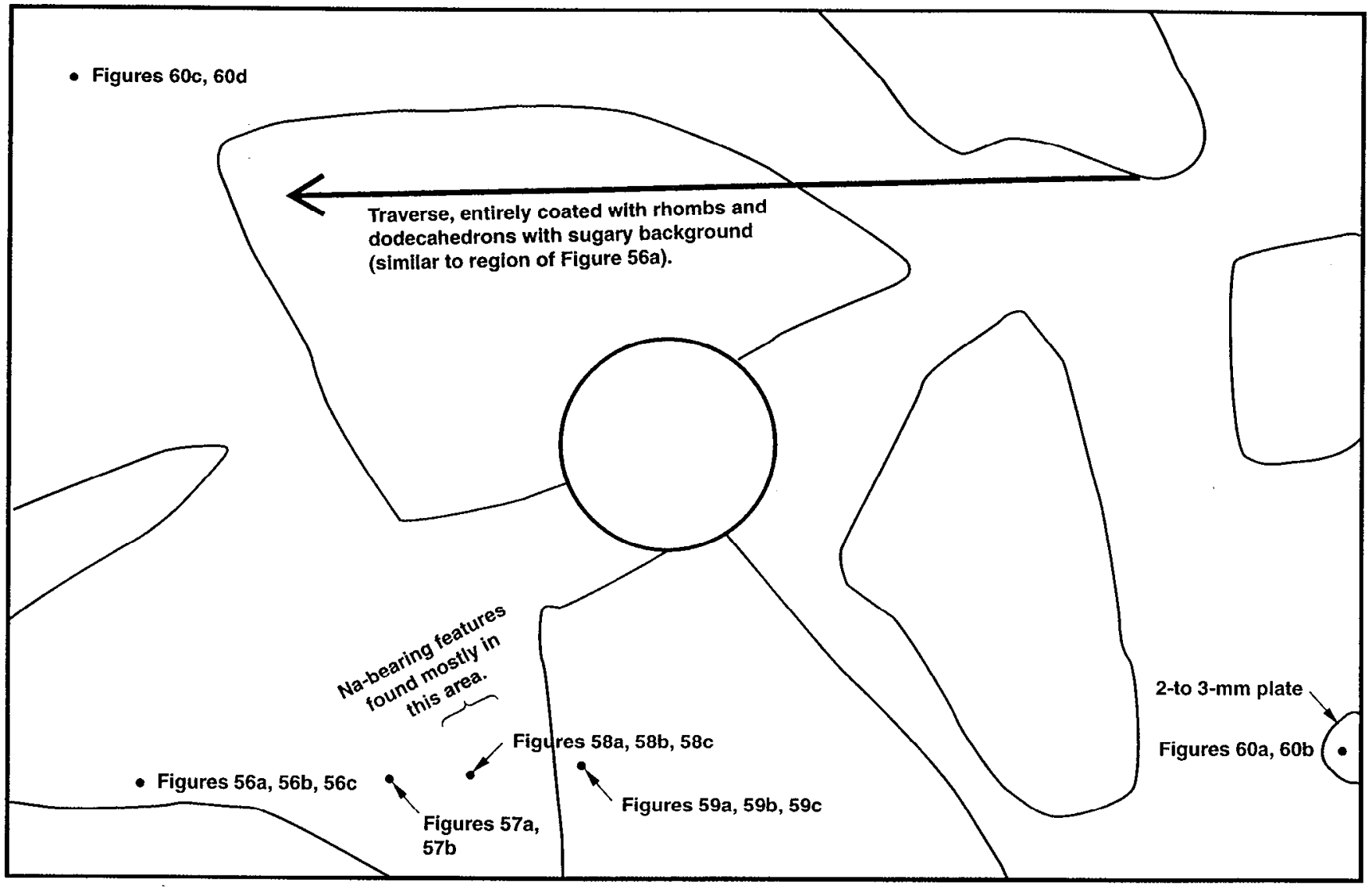




\section{SEM and EDS analysis points}

Sample \# INV-23b

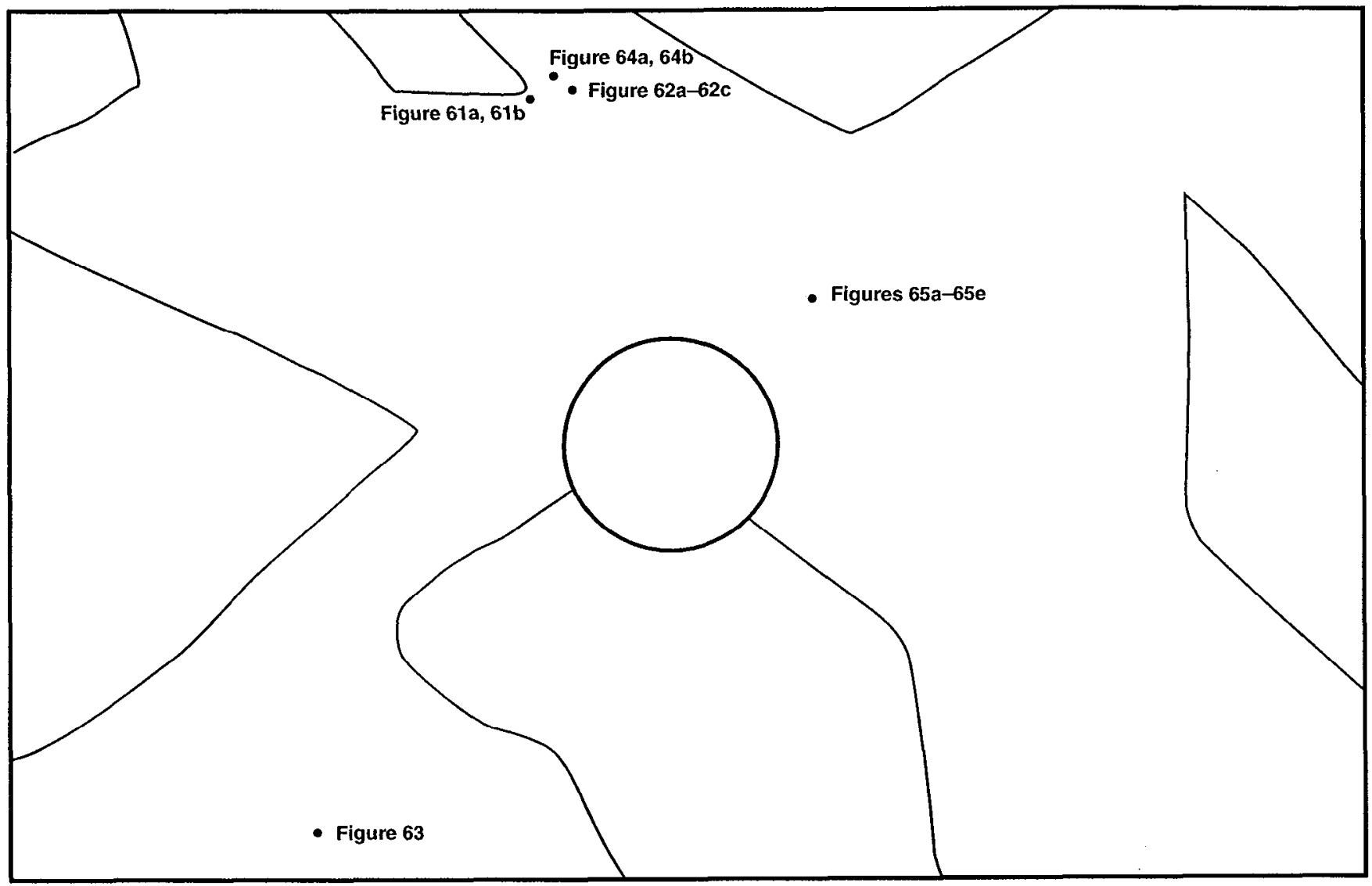


Part Il: SECONd and Third Batch of Samples

SEM and EDS analysis points

Sample \# SH-10

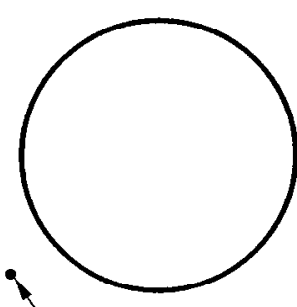

Figures 74a, 74b
Figures 69a, 69b

- Figures 73a, 73b, 73c

Figures 72a, 72b, 72c
- Figures 71a, 71b, 71c

Figures $68 \mathrm{a}, 68 \mathrm{~b}$

- Figures 67c, 67d

Figures 67a, 67b

Figures $66 a, 66 b, 66 c$

Figures $68 \mathrm{c}, 68 \mathrm{~d}$

Figures 70a, 70b 
Hydrothermal alteration of Cememtitious materials

SEM and EDS analysis points

Sample \# INV-21

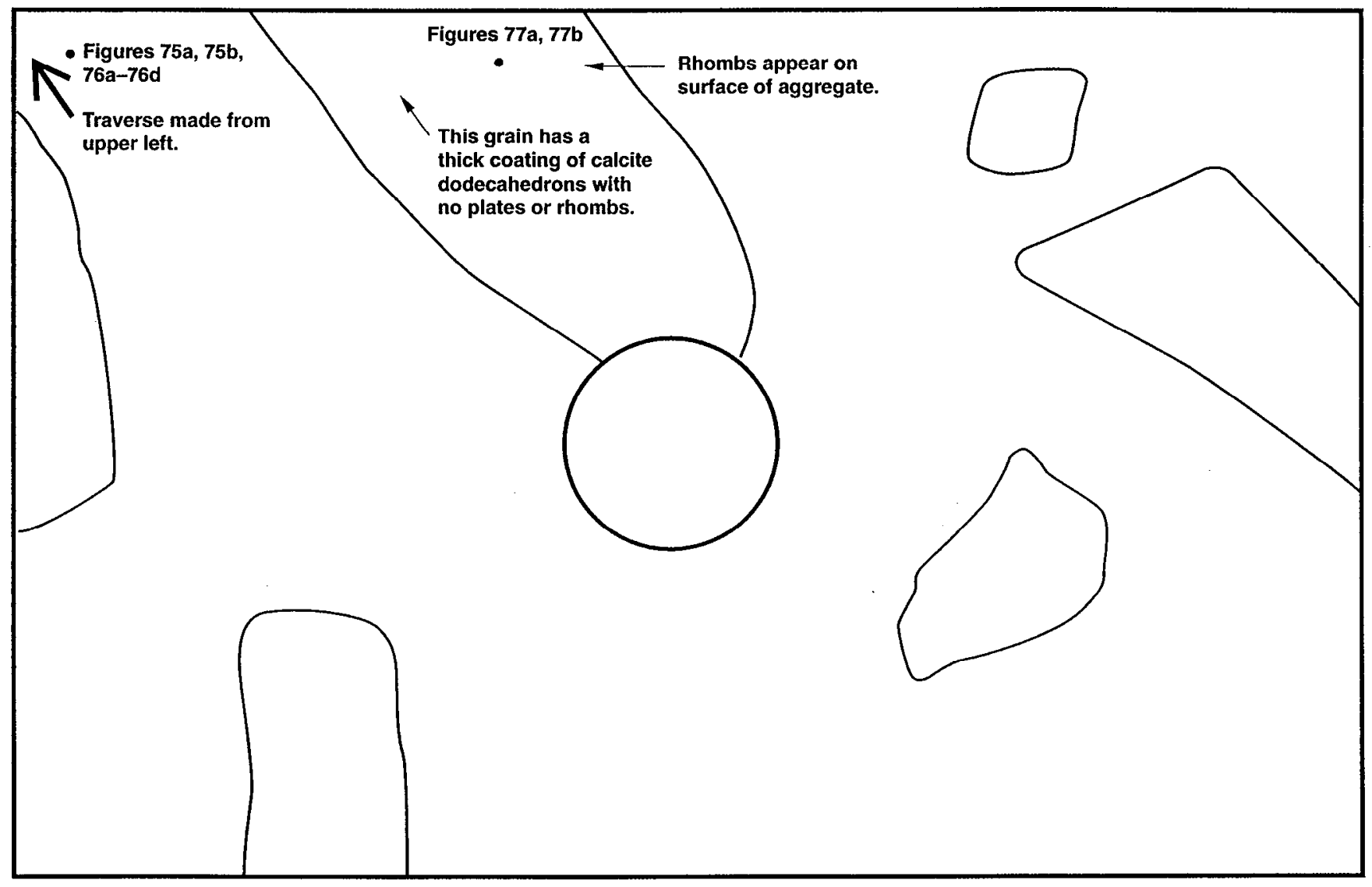


Part Il: Second and Third Batch of Samples

\section{SEM and EDS analysis points}

Sample \# INV-36

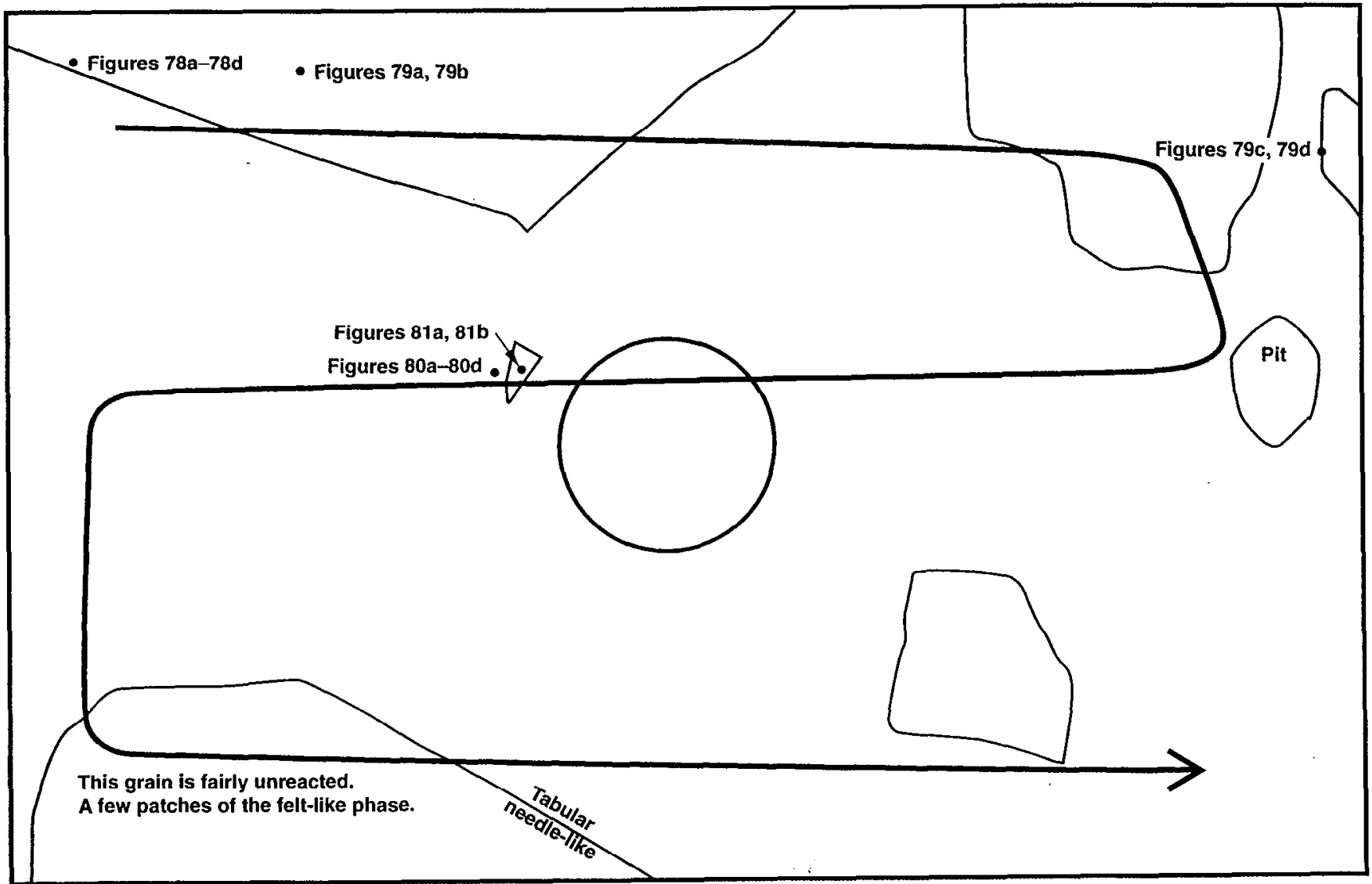




\section{SEM and EDS analysis points}

Sample \# SH-13

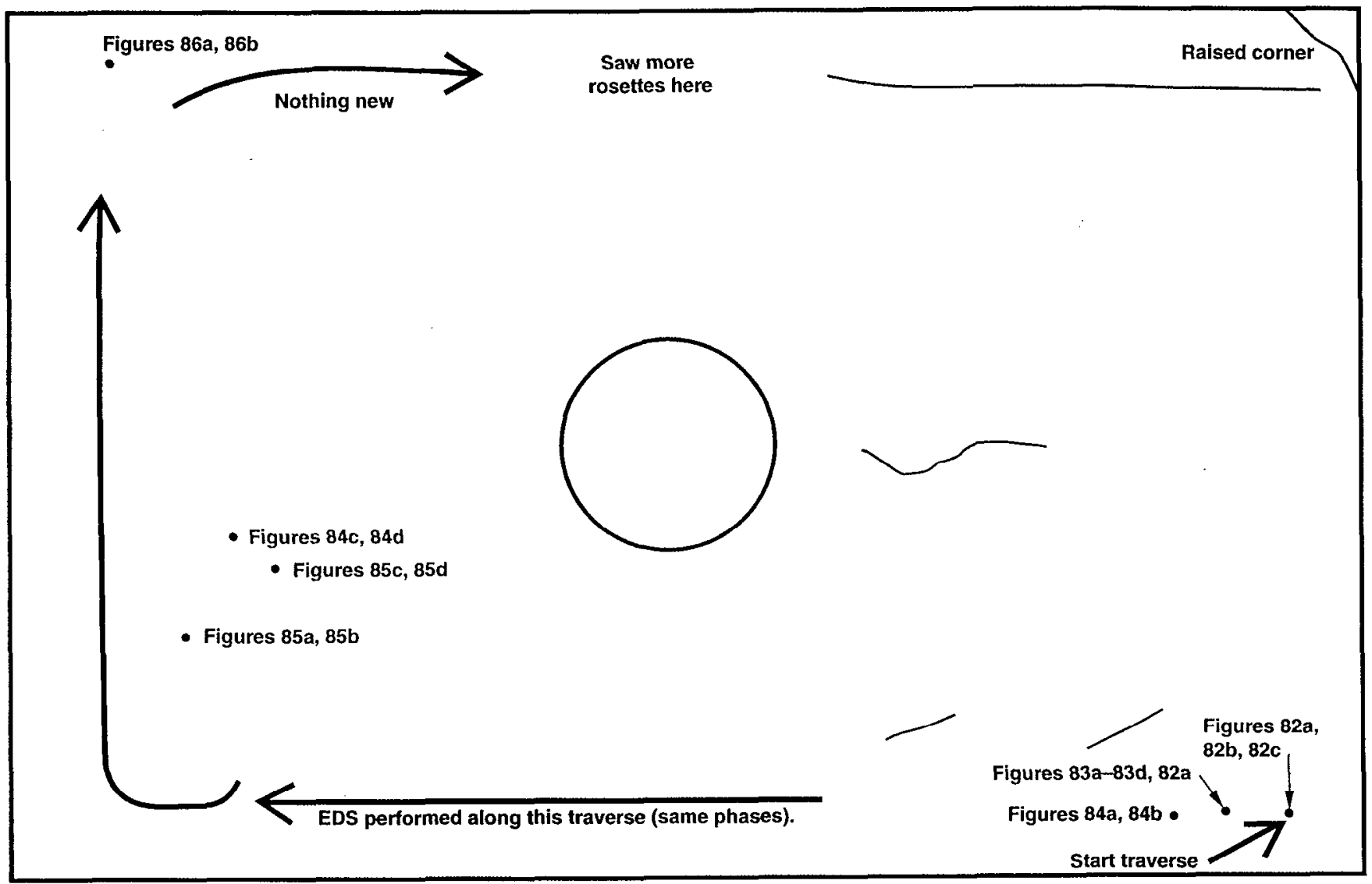




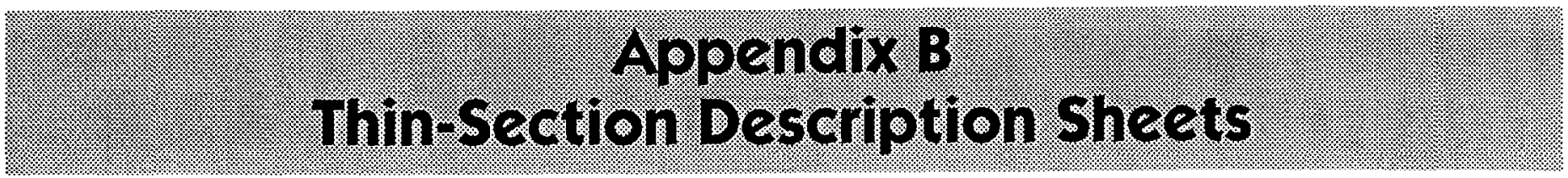




\section{Thin-Section Description Sheet Sample INV-17}

\section{TEXTURE}

Aggregate grain size (mm):

range

average
$>7 \quad 0.5$ to 4

too few to determine

\section{COMPOSITION}

$10 \%$ Coarse Aggregate

$100 \%$ Carbonate

$50 \%$ Fine Aggregate

$80 \%$ Carbonate (undifferentiated calcite, fossiliferous limestone (with Bryozoan), etc.)

8\% Quartz

$8 \%$ Chert (one grain is a composite of chert, calcite, and zeololite?)

$4 \% \quad$ Polycrystalline quartz

39\% Mortar

Brown, cloudy mottled with high birefringence, like SH-5

Under plain light, brown cloudy is more opaque

$1 \%$ Porosity

\section{General Observations}

Under plain light, there appears to be a dark rind around the edge of the coupon. Under polarized light however, there are high-birefringent crystals that penetrate the outer rind.

Most quartz grains have high-birefringence rims. Under plain light, most aggregate grains appear to have dark rims. Most aggregate has dark rim. 


\section{Thin-Section Description Sheet Sample INV-18}

\section{TEXTURE}
Aggregate grain size (mm):
range
8 to 10
0.5 to 4

\section{COMPOSITION}

30\% Coarse Aggregate

100\% Carbonate (undifferentiated calcite, limestone with clay, limestone with quartz grains, fossiliferous limestone)

35\% Fine Aggregate

More zeolite enclosed within a carbonate grain? See sketch.

This thin section has radiating crystals in the epoxy at edge of sample.

$\begin{array}{ll}90 \% & \text { Carbonate } \\ 5 \% & \text { Quartz } \\ 5 \% & \text { Chert } \\ 41 \% & \text { Opaque }\end{array}$

$33 \%$ Mortar

High-birefringent phase dominates brown cloud

\section{$1 \%$ Porosity}

Fxcluding big bubble

\section{General Observations}

There is no rind around the outer edge of the coupon.

Most, but not all, quartz grains have high-birefringence rims. The rinds are not as evident on chert. Rinds on carbonate grains are much less common than on quartz, and have a different appearance. The carbonate rinds are broader, and have the appearance of carbonate overgrowths.

There are several pits in the grout with an inner rind of high-birefringence minerals. 


\section{Thin-Section Description Sheet Sample INV-20}

TEXTURE

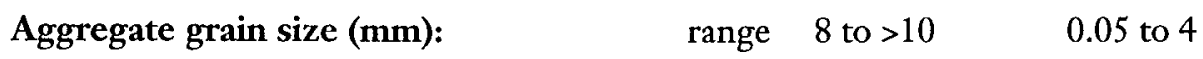

\section{COMPOSITION}

40\% Coarse Aggregate

$100 \%$ Carbonate (undifferentiated fossiliferous limestone, limestone, calcite, cherty limestone)

40\% Fine Aggregate

$90 \%$ Carbonate

$<1 \% \quad$ Hematite: reddish, semi opaque

$10 \%\left\{\begin{array}{l}\text { Quartz } \\ \text { Polycrystalline quartz } \\ \text { Chert } \\ \text { Dolomite? (reddish) }\end{array}\right.$

$20 \%$ Mortar

Brown, cloudy

$<1 \%$ Porosity

\section{General Observations}

There is no rind around the outer edge of the coupon.

Most, but not all, quartz grains have high-birefringence rims. The rinds are not as evident on chert. Rinds on carbonate grains are much less common than on quartz, and have a different appearance. They occur on straight grain edges, and could be primary features such as veins of mineralization along a cleavage plane.

There are several pits in the grout with an inner rind of high-birefringence minerals. The drilled-out center hole in the coupon has a similar inner rind. 


\section{Thin-Section Description Sheet Sample INV-24}

\section{TEXTURE}

$\begin{array}{llll}\text { Aggregate grain size }(\mathrm{mm}): & \text { range } & <4 \text { one grain, no huge ones } & \begin{array}{l}0.05 \text { to } 2 \\ \text { average }\end{array}\end{array}$

\section{COMPOSITION}

5\% Coarse Aggregate

$100 \%$ Fossilferous limestone

$50 \%$ Fine Aggregate

$90 \%$ Carbonate (undifferentiated limestone, calcite, fossiliferous limestone)

$10 \%\left\{\begin{array}{l}\text { Polycrystalline quartz } \\ \text { Chert } \\ \text { Quartz }\end{array}\right.$

$<1 \%\left\{\begin{array}{l}\text { Zeolite? epoxy? ( } 3 \text { to } 4 \text { grains) } \\ \text { Clastic lithic (with hematite stain) }\end{array}\right.$

45\% Mortar

Brown, cloudy, dominates, but difficult to tell because it looks like the thin section is thinner on one side

$<1 \%$ Porosity

\section{General Observations}

There is no rind around the outer edge of the coupon.

Approximately half of all quartz grains have high-birefringence rims. Rinds on carbonate grains are much less common than on quartz. 


\section{Thin-Section Description Sheet Sample INV-25}

\section{TEXTURE}

$\begin{array}{lll}\text { Aggregate grain size (mm): } & \text { range } & \sim 3 \text {, but no big hunks } \\ & \text { a few grains } 0.5 \text { to } 2\end{array}$

\section{COMPOSITION}

0\% Coarse Aggregate

(as compared with other invert samples)

Slide has thin side and is quite thin overall

$50 \%$ Fine Aggregate

95\% Carbonate (undifferentiated; limestone, calcite, fossiliferous limestone)

$5 \%\left\{\begin{array}{l}\text { Quartz } \\ \text { Chert (some hematite staining) } \\ \text { Polycrystalline quartz }\end{array}\right.$

$50 \%$ Mortar

Quite different, possibly due to slide thickness? Almost isotropic.

$\sim 1 \%$ Porosity

\section{General Observations}

There is no rind around the outer edge of the coupon.

High-birefringence rims of the same character engulf both pits in grout and several aggregate grains. 


\section{Thin-Section Description Sheet Sample INV-26}

\section{TEXTURE}

Aggregate grain size (mm):

range 0.05 to 3 , no huge grains

\section{COMPOSITION}

\section{0\% Coarse Aggregate}

Slide has thin side.

49\% Fine Aggregate

85\% Carbonate (undifferentiated; calcite, limestone, fossiliferous limestone)

$15 \%\left\{\begin{array}{l}\text { Lithics (A few grains are almost completely isotropic, med. relief) } \\ \text { Quartz } \\ \text { Chert } \\ \text { Polycrystalline quartz }\end{array}\right.$

$<1 \%\left\{\begin{array}{l}\text { Hematite? } \\ \text { Opaques }\end{array}\right.$

49\% Mortar

Viewed with the naked eye, buff coloration, very distinct brown cloudy mortar, mottled with high birefringence.

2\% Porosity

\section{General Observations}

There is no rind around the outer edge of the coupon.

High-birefringence rims of the same character engulf both pits in grout and several aggregate grains. The drilled-out center hole in the coupon has a similar inner rim. 


\section{Thin-Section Description Sheet Sample INV-27}

\section{TEXTURE}
Aggregate grain size (mm):
range 5 to 12
0.05 to 3

\section{COMPOSITION}

$20 \%$ Coarse Aggregate

$100 \%$ limestone and fossilferous limestone (fossils include: Foram, Bryozoan, coral

40\% Fine Aggregate

$85 \% \quad$ Carbonate (undifferentiated)

$15 \%\left\{\begin{array}{l}\text { Quartz } \\ \text { Chert (A few grains are almost completely isotropic, med. relief) }\end{array}\right.$

$<1 \% \quad$ Opaques

$40 \%$ Mortar

Viewed with naked eye, see buff coloration, birefringence dominates brown cloud

$1 \%$ Porosity

\section{General Observations}

There is no rind around the outer edge of the coupon.

Some quartz grains have high-birefringence rims. The rinds are not as evident on chert. The chert appears rather coarse in this sample, and some grains may possibly be zeolite. Rinds on carbonate grains are much less common than on quartz, and have a different appearance. The carbonate rinds are broader, and have the appearance of carbonate overgrowths. 


\section{Thin-Section Description Sheet Sample SH-1}

\section{TEXTURE}

Aggregate grain size (mm):

range 0.5 to 2

average 1

0.1 to 0.05

0.1

\section{COMPOSITION}

25\% Coarse Aggregate

$\begin{array}{ll}35 \% & \text { Quartz, angular, fractured } \\ 25 \% & \text { K-Feldspar } \\ 10 \% & \text { Quartz sandstone, hematite stained, carbonate cement } \\ 10 \% & \text { Plagioclase } \\ 5 \% & \text { Limestone, fine grained } \\ 5 \% & \text { Calcite with rhombs } \\ 5 \% & \text { Fossiliferous limestone with brachiopod plus quartz grains } \\ 1 \% & \text { Metamorphic lithic fragment (Schist with muscovite or sericite) } \\ 1 \% & \text { Biotite } \\ 1 \% & \text { Igneous lithic with Biotite, Hornblende, Quartz }\end{array}$

25\% Fine Aggregate

$\begin{array}{llll}72 \% & \text { Quartz/glass } & 1 \% & \text { Clinopyroxene } \\ 10 \% & \text { Calcite } & 1 \% & \text { Hematite? Reddish brown } \\ 5 \% & \text { Biotite } & 1 \% & \text { Hornblende } \\ 5 \% & \text { K-Feldspar } & 1 \% & \text { Angular opaque } \\ 5 \% & \text { Plagioclase } & & \end{array}$

$48 \%$ Mortar

Brown, cloudy

2\% Porosity

\section{General Observations}

There is no rind around the outer edge of the coupon.

High-birefringence rims occur on some quartz, plagioclase, and K-feldspar grains, but not all grains. 


\section{Thin-Section Description Sheet Sample SH-2}

\begin{tabular}{lll}
\hline & TEXTURE \\
\hline Aggregate grain size (mm): & $\begin{array}{l}\text { range } 0.5 \text { to } 2 \\
\text { average } 1.5\end{array}$ & 0.1 to 0.2 \\
& \\
\hline & COMPOSITION \\
\hline
\end{tabular}

Recent cement related alteration?

25\% Coarse Aggregate

$\begin{array}{ll}35 \% & \text { Quartz } \\ 20 \% & \text { K-Feldspar } \\ 15 \% & \text { Igneous intrusive lithic } \\ 15 \% & \text { Calcite } \\ 10 \% & \text { Quartzite lithic } \\ 5 \% & \text { Quartz sandstone w/carbonate cement } \\ 1 \% & \text { Siltstone } \\ 1 \% & \text { Plagioclase } \\ 1 \% & \text { Biotite } \\ 1 \% & \text { Volcanic lithic }\end{array}$

$20 \%$ Fine Aggregate

$\begin{array}{llll}30 \% & \text { K-Feldspar } & 1 \% & \text { Calcite (twins) } \\ 50 \% & \text { Quartz } & 1 \% & \text { Opaques } \\ 10 \% & \text { Plagioclase } & 1 \% & \text { Epidote } \\ 5 \% & \text { Biotite } & 1 \% & \text { Orthopyroxene } \\ 5 \% & \text { Calcite } & 1 \% & \text { Clinopyroxene }\end{array}$

$1 \%$ Hematite? Rusted metal

$53 \%$ Mortar

$2 \%$ Porosity

\section{General Observations}

There is a slight rind around the outer edge of the coupon.

High-birefringence rims occur on some quartz, plagioclase, and K-feldspar grains, but not all grains. The mortar is lighter in color. 


\section{Thin-Section Description Sheet Sample SH-5}

\begin{tabular}{lll}
\hline & TEXTURE \\
\hline Aggregate grain size (mm): & $\begin{array}{l}\text { range } 0.5 \text { to } 2.25 \\
\text { average } 1\end{array}$ & 0.05 to 0.1 \\
& & 0.1 \\
& COMPOSITION \\
\hline
\end{tabular}

25\% Coarse Aggregate Feldspar very altered, white mica

$\begin{array}{ll}30 \% & \text { Quartz } \\ 25 \% & \text { Plagioclase } \\ 25 \% & \text { K-Feldspar } \\ 5 \% & \text { Biotite } \\ 5 \% & \text { Carbonate } \\ 5 \% & \text { Quartz sandstone, or quartzite grain with high-relief, low-birefringent grains } \\ 1 \% & \text { Volcanic lithic } \\ 1 \% & \text { Plutonic lithic }\end{array}$

20\% Fine Aggregate

$\begin{array}{llll}50 \% & \text { Quartz } & 2 \% & \text { Chlorite } \\ 8 \% & \text { Carbonate } & 2 \% & \text { Muscovite } \\ 8 \% & \text { Biotite } & <1 \% & \text { Zircon } \\ 15 \% & \text { K-Feldspar } & 2 \% & \text { Clinopyroxene } \\ 10 \% & \text { Plagioclase } & 2 \% & \text { Hornblende } \\ 2 \% & \text { Opaques } & & \end{array}$

$52 \%$ Mortar

Two cement phases? (1) brown cloud (2) high-birefringent, calcite-like fine grain

\section{$2 \%$ Porosity}

\section{General Observations}

There is a patchy, discontinuous rind around the outer edge of the coupon.

High-birefringence rims occur on some quartz, plagioclase, and K-feldspar grains-more so than on SH-1 and SH-2.

There are also dark, somewhat opaque, 0.05 -mm-thick rims on some grains that almost appear to cement grains together.

The mortar is mottled, with patches of a brown, cloudy, somewhat opaque phase alternating with a high-birefringence phase. 


\section{Thin-Section Description Sheet Sample SH-12}

\section{TEXTURE}

Aggregate grain size (mm):

range 0.5 to 2.25

average 1.25

0.1 to 0.2

0.1

\section{COMPOSITION}

25\% Coarse Aggregate

$\begin{array}{llll}30 \% & \text { Quartz } & 3 \% & \text { Lithic: plutonic } \\ 20 \% & \text { K-Feldspar } & 3 \% & \text { Lithic: volcanic } \\ 20 \% & \text { Plagioclase } & 1 \% & \text { Chlorite } \\ 10 \% & \text { Lithic: quartz sandstone, quartzite } & 3 \% & \text { Biotite } \\ 10 \% & \text { Calcite/carbonate } & & \end{array}$

15\% Fine Aggregate

$\begin{array}{ll}50 \% & \text { Quartz } \\ 10 \% & \text { K-Feldspar } \\ 10 \% & \text { Plagioclase } \\ 10 \% & \text { Biotite } \\ 10 \% & \text { Carbonate } \\ 1 \% & \text { Opaques }\end{array}$

$<1 \% \quad$ Clinozoisite

$<1 \%$ Clinopyroxene

$1 \%$ Hornblende

$<1 \%$ Zircon

$1 \%$ Chlorite

$55 \%$ Mortar

5\% Porosity

\section{General Observations}

There is no rind around the outer edge of the coupon.

High-birefringence rims occur on some quartz, plagioclase, and K-feldspar grains, but not all grains. There are also dark, somewhat opaque, $0.05-\mathrm{mm}$-thick rims on some grains 


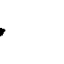

